Portland State University

PDXScholar

\title{
A Comparative Study of Perceptions of High School Department Chairs and High School Teachers on the Role of the High School Academic Department Chair: the Voice of the Teacher-department Chair
}

Rachel Mae Korach

Portland State University

Follow this and additional works at: https://pdxscholar.library.pdx.edu/open_access_etds Let us know how access to this document benefits you.

\section{Recommended Citation}

Korach, Rachel Mae, "A Comparative Study of Perceptions of High School Department Chairs and High School Teachers on the Role of the High School Academic Department Chair: the Voice of the Teacherdepartment Chair" (1996). Dissertations and Theses. Paper 1254.

https://doi.org/10.15760/etd.1253

This Dissertation is brought to you for free and open access. It has been accepted for inclusion in Dissertations and Theses by an authorized administrator of PDXScholar. Please contact us if we can make this document more accessible: pdxscholar@pdx.edu. 
A COMPARATIVE STUDY OF PERCEPTIONS OF HIGH SCHOOL DEPARTMENT CHAIRS AND HIGH SCHOOI TEACHERS

ON THE ROLE OF THE HIGH SCHOOL ACADEMIC DEPARTMENT CHAIR: THE VOICE OF THE TEACHER-DEPARTMENT CHAIR

by

Rachel Mae Korach

A dissertation submitted in partial fulfillment of the requirements for the degree of

\author{
DOCTOR OF EDUCATION \\ in \\ EDUCATIONAL LEADERSHIP: \\ ADMINISTRATION AND SUPERVISION
}

Portland State University 1996 


\section{DISSERTATION APPROVAL}

The abstract and dissertation of Rachel Mae Korach for the Doctor of Education in Educational Leadership:

Administration and Supervision were presented May 9, 1996, and accepted by the dissertation committee and the doctoral program.

\section{COMMITTEE APPROVALS:}
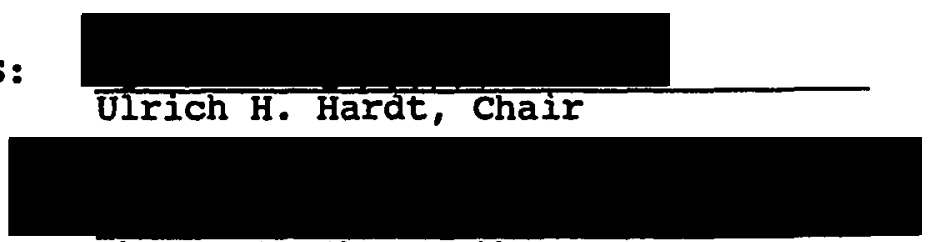

Thomas G. Chenoweth

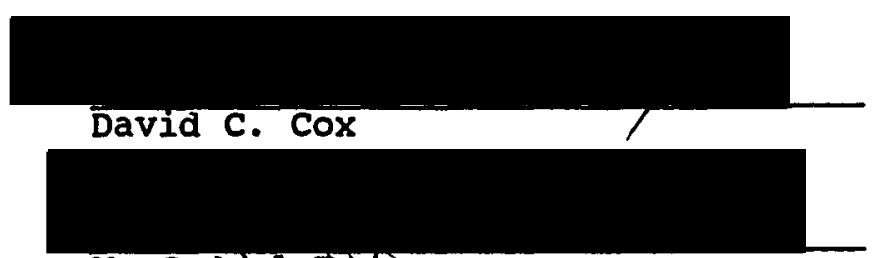

M. Cartol Täna

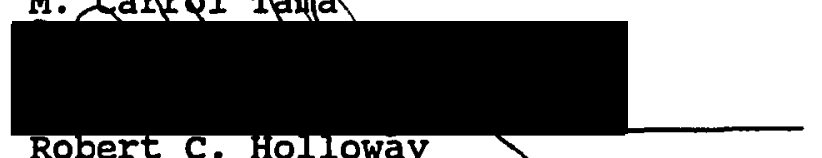

Robert C. Holloway

Representative of the office of Graduate studies

DOCTORAL PROGRAM APPROVAL:

$$
\begin{aligned}
& \text { Robert B. Everhart, Dean } \\
& \text { School of Education }
\end{aligned}
$$

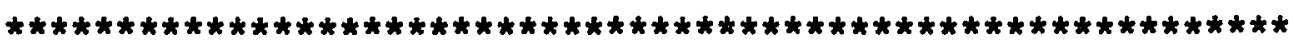

ACCEPTED FOR PORTLAND STATE UNIVERSITY BY THE LIBRARY

by on

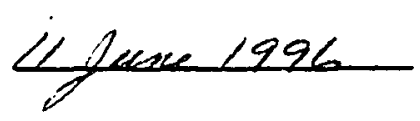


ABSTRACT

An abstract of the dissertation of Rachel Mae Korach for the Doctor of Education in Educational Leadership: Administration and Supervision presented May 9, 1996.

Title: A Comparative study of Perceptions of High School Department Chairs and High School Teachers on the Role of the High School Academic Department Chair: The Voice of the Teacher-Department chair

The purpose of this descriptive study was to examine and compare perceptions between high school department chairs and teachers regarding the role of the high school academic department chair in Oregon, a position which has been largely ignored in recent educational reform efforts. Schools selected for the study were limited to those sharing the same qualities of size and structure as those of the high schools in the researcher's own district.

A researcher-constructed questionnaire defining 44 activities comprising five categories of department chair responsibility provided data from 118 high school department chairs and 114 teachers from 34 Oregon high schools. 
Respondents addressed three issues: (a) definition-perceptions of what the role of the high school department chair looks like in practice; (b) clarification-perceptions of which activities are most important to the role; and (c) extension-perceptions of which activities are most important for the department chair to continue to improve in carrying out the role. Results of this study show teachers' expectations for the role of the department chair to be substantially different from those of the chairs themselves. Chi-square testing revealed statistically significant $(\underline{p}<.05)$ incongruence of perceptions between department chairs and teachers for 21 of the 44 activities across all five of the categories of department chair responsibility. Department chairs consistently perceived themselves to devote more time to their role than teachers perceived chairs to spend. Teachers placed more importance than did chairs on protection of instructional time and support of teachers' professional needs and concerns.

statistically significant differences in perception between males and females in the study population were also found for 24 of the 44 activities. Females consistently valued more highly than did males those department chair activities that reflect a facilitative, collaborative approach to leadership. Greater percentages 
of males more highly valued management activities than did females.

These findings suggest both ambiguity in role definition and incongruence of role expectations to be obstacles to effective role performance for the high school department chair. Open, focused dialogue is suggested as a means for resolving these contradictions. 


\section{DEDICATION}

"And in his heart my heart is locked, And in his life my life."

- Christina Rossetti

for Bill 


\section{ACKNOWLEDGMENTS}

Because of the unique nature of the study design, I am especially indebted to many people who saw the potential value of the study and committed themselves to bringing the project to successful completion:

Dr. Ulrich Hardt for his graciousness in accepting the chairmanship of the committee, his guidance and support, and his willingness to share his scholarly expertise.

Dr. M. Carrol Tama for her support and insightful contributions to the design and development of the project.

Dr. Robert Holloway for his wisdom, understanding, advocacy, and unwavering support.

Dr. David cox for his encouragement, advice, careful critique of the data analysis, and especially for his personal investment in the project.

Dr. John Lind, retired, for his leadership and assistance in conceptualizing the initial project.

Dr. Tom Chenoweth for kindly agreeing to become a member of the committee while on sabbatical and for his strong contribution to the study.

Dr. Robert Everhart for his continued belief in and support of the project. 
My appreciation to the 118 high school department chairs and to the $114 \mathrm{high}$ school teachers who took valuable time from their busy schedules to complete the questionnaire.

A special thank you to Pati sluys for contributing her expertise in the final editing of the manuscript. 
TABLE OF CONTENTS

PAGE

ACKNOWLEDGMENTS . . . . . . . . . . . . . . . . . . . ii

LIST OF TABLES - • . . . . . . . . . . . . . . viii

CHAPTER

I INTRODUCTION . . . . . . . . . . . . 1

Problem Statement . . . . . . 3

Questions to Be Investigated . . . 10

Significance of the studies . . . 16

Theoretical Framework for the

studies . . . . . . . . . 19

Operational Definitions . . . . 23

Limitations of the studies . . . . 26

The Population

The Instrument

Assumptions . . . . . . . . 28

II

REVIEW OF RELATED LITERATURE . . . . . 31

Evolution of the Position of

High School Department Chair . . 32

Historical Background

Ambiguity in the Position

Considerations for Role

Effectiveness ....... . 39

Role Theory and Role Conflict

Gender Issues

Instructional Leadership . . . 50 
Interrelationship of Top-down,

Bottom-up Perspectives . . . . 57

Summary . . . . . . . . . 62

III RESEARCH METHODOLOGY AND PROCEDURES • • 66

Overview .......... 66

Statement of the Problem . . . . 67

Study Hypotheses . . . . . . 68

The Study Population . . . . . 70

Development of the Instrument . . 71

Field Test .......... 76

Procedures for Data Collection . . 77

Treatment of the Data . . . . 81

IV ANALYSIS OF THE DATA ........ . 83

Overview ........... 83

Demographic Characteristics . . . 86

Department Chairs and Teachers . . 87

Personal Information

Educational Background

Educational Experience

Characterization of Current Position

Demographic Profiles

The Voice of the classroom

Teacher-Department Chair . . . . 94

Data Analysis . . . . . . . 95

Responsibility for Human Relations

Responsibility for Management

Responsibility for the Organization

Responsibility for Program

Responsibility for

supervision 
Testing of Hypothesis 1 . . . . . 113

Responsibility for Human Relations

Responsibility for Management

Responsibility for the

Organization

Responsibility for Program

Responsibility for

Supervision

Summary

Testing of Hypothesis 2 . . . . 119

Responsibility for Human Relations

Responsibility for Management

Responsibility for the

Organization

Responsibility for Program

Responsibility for Supervision

Testing of Hypothesis 3 . . . . 129

Discussion of Hypothesis 4 . . . 132

V

SUMMARY, CONCLUSIONS, AND

RECOMMENDATIONS . . . . . . . . 139

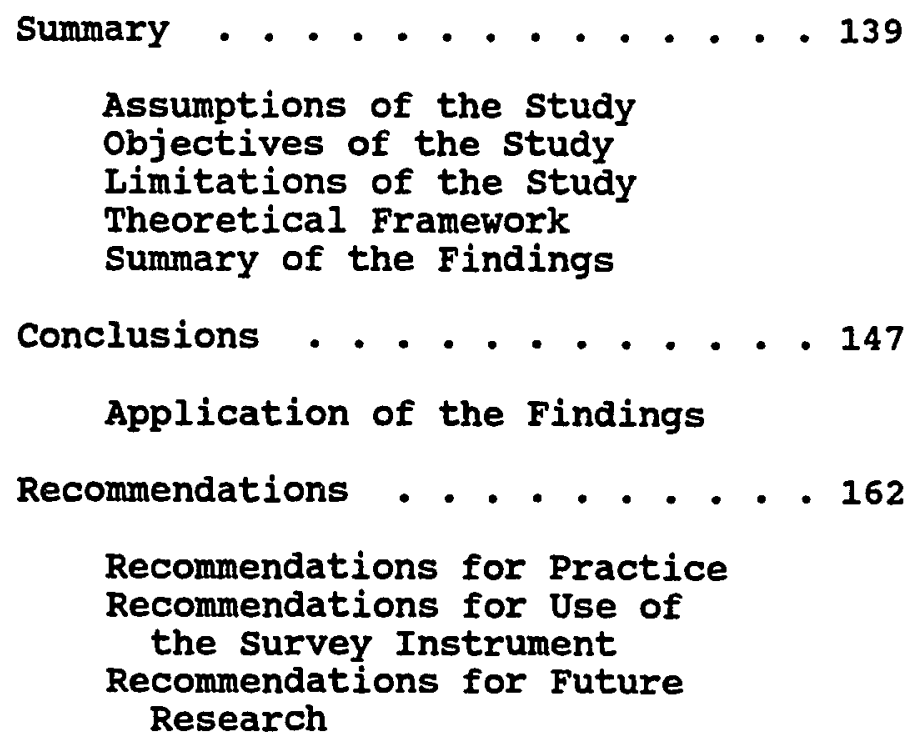


APPENDICES

A Survey Instrument . . . . . . 188

B Cover Letters . . . . . . . 193

C Frequency Distribution Charts: Department Chairs/Teachers; Mean and standard Deviation Charts: Department Chairs/Teachers . . . 198

D Frequency Distribution Charts: Males/Females; Mean and Standard Deviation Charts: Males/Females . 209

E Demographics Charts: Department Chairs Grouped by Discipline . . 220

F Frequency Distribution Charts: Department Chairs by Discipline . 223

G Mean and Standard Deviation Charts: Department Chairs Grouped . . . 234

H Summary of Chi-square values: Department Chairs Grouped by Discipline........... 240 
1. Questionnaire Returns by Educator Group . . . . . . . . . . 80

2. Questionnaire Returns by subject Matter Department Chairs and

Teachers ........ . . . . 81

3. Personal Data . . . . . . . . 87

4. Educational Background of Participants ......... . 88

5. Educational Experience of Participants . . . . . . . . 90

6. Demographic Information Regarding Department Chair Positions, Subjects: High School Department Chairs $(\underline{N}=118)$......... 91

7. Summary of Chi-square Values Indicating Significant Differences $(\underline{p}<.05)$ in Perception of Department Chair Activities in Five Categories of Responsibility, subjects: High School Department Chairs $(\underline{N}=118)$ and High School Teachers $(N=114) \cdot 114$

8. Summary of Chi-square values Indicating Significant Differences $(\mathrm{D}<.05)$ in Perceptions of Male and Female High School Department Chairs and Teachers Regarding Activities in Five Categories of Department Chair Responsibilities, subjects: Males $(\underline{N}=159)$, Females $\underline{N}=73)$. . 120 
9. Rank Ordering of Importance of Five Categories of Department Chair Responsibility as Perceived by Male High School Academic Department Chairs and High School Teachers and Female High School

Academic Department Chairs and High School Teachers [By Frequencies and Percentages of Respondents Giving

Each Ranking] Males $(N=159)$;

Females $(\underline{N}=73)$ 
CHAPTER I

INTRODUCTION

Reflecting a nationwide trend, the state of oregon has for the past 10 years been experiencing controversy centered upon a demand for educational reform. Publication of A Nation at Risk: The Imperative for Educational Reform (National Commission on Excellence in Education, 1983) focused national attention on the linkage between a perceived decline in the American educational system and America's increasing inability to compete in a rapidly changing global economy. The nation was at risk; the educational system, which was not producing a work force educated and trained to international standards, was at fault.

Developing a political agenda to stem what Nation at Risk (National Commission on Excellence in Education, 1983) had billed as "a rising tide of mediocrity," the Us Department of Education under the Reagan administration initiated the selection of Schools of Excellence-models to be held up as examples of what should be happening in America's schools. The effective schools research (clark, Lotto, \& Astuto, 1984; Edmonds 1979, 1982; Purkey \& Smith, 1982), which had provided the major thrust for the 
national movement for excellence in education during the early 1980s, offered criteria for selection of the schools to be so designated. On that basis, four oregon high schools (Crater High School, Crater; Lake Oswego High School, Lake Oswego; South Eugene High School, Eugene; and Sunset High School, Beaverton) were among those named Schools of Excellence in the first year of the program. Following their extensive examination of the effective schools research, Blum and McEady (1984) concluded that one of its most consistent findings had been the significant role of the principal as being the person best positioned to foster school improvement and higher levels of student achievement. Although most of the effective schools studies focused on the elementary principal, they have also been widely applied as a rationale for placing major significance on the high school principal's role as an instructional leader. Some sources question this practice however, pointing to fundamental ways in which high schools differ from elementary schools (Murphy, 1988; Siskin, 1991). Siskin (1991) identified "one key anatomical difference [as being] their departmentalized differentiation of specialized teachers" (p. 134). Murphy (1988) denoted "goal structure, administrative organization, student and faculty characteristics, and curricular organization and 
delivery" (p. 126) as other factors which are also significantly different in high schools.

other educational literature raises an additional objection. While acknowledging that leadership in curriculum and instruction "is essential to the success of our schools, principals are advantageously positioned to provide it, and change is unlikely to happen in schools without principals' support" (Patterson, Purkey, \& Parker, 1986, p. 103), many writers emphasize the impracticality, in terms of both time constraints and necessary expertise, of expecting the high school principal to bear the sole responsibility (Duke, 1987; Keefe \& Jenkins, 1984; Lucy, 1986; Pitner, 1986). One approach to addressing such concerns has been to look toward the high school department chair as having the potential "to fulfill just such a leadership role" (Lucy, 1986, p. 85). The expectation was that department chairs, possessing both subject matter knowledge and instructional expertise, should assume more responsibility in instructional leadership (DeRoche, Hunsaker, \& Kujawa, 1988; Greenfield, 1985, 1987; Hannay, 1994; Sergiovanni, 1984; Turner, 1983).

\section{Problem Statement}

Historically, the teacher serving as a high school academic department chair has occupied an ambiguous 
position between the teaching staff and the administration. In addition to a teaching assignment in the specific department, the chair's job functions, whether explicitly assigned or implicitly expected, have included leadership duties in supervision, curriculum and management-a combination of responsibilities which tends to blur the distinctions generally drawn between line and staff positions in the educational hierarchy, thereby potentially creating both confusion and conflict.

Most often, the literature indicates high school department chairs have had no clear, consistent description of exact functions, behaviors, or desirable skills and training which would define their instructional leadership role and assist them to carry it out (Costanza, Tracy, \& Holmes, 1987; Hall \& Guzman, 1984; Hord \& Murphy, 1985; Williams, 1979). Hall and Guzman (1984, p. 11) concluded "The definition of the job . . . is not well articulated and definitions are not available in the literature." Duke (1987) suggested that department chairs "would seem well able to exercise instructional leadership, since they possess subject matter expertise and interact regularly with the same group of teachers" (p. 47), but also noted that "few studies of how these persons spend their time are available" (p. 47). The literature indicates similar lack of clarity regarding the extent to which educators value the high 
school department chair as an instructional leader.

Wasley (1991) contended,

No teachers I have interviewed have seen these positions [department chairs] as ones that enable them to learn and to grow. Nor do they build any kind of shared vision for the school. (p. 5)

In contrast, among others (Gorton \& Thierbach-Schneider, 1991; Johnson, 1990; Pellicer, Anderson, Keefe, Kelley, \& Mccleary, 1990), Siskin (1991), makes a strong case for the importance of department chairs. siskin particularly argued that distinct differences exist from one department to another,

that effective English and math departments may have demonstrably and justifiably distinct goals, standards, and procedures and that they [teachers in individual departments] may well turn to chairs rather than to principals as appropriate instructional leaders. (p. 156)

Another possible source of differences is that the cultural construct of gender has seldom been addressed by educational research or by research on organizational dynamics to determine its impact on attitudes and behavior (Levine, 1989; Shakeshaft \& Hanson, 1986) or on successful supervision (Shakeshaft, Nowell, \& Perry, 1991). Consequently, lack of clarity exists regarding the possible impact of gender on the instructional leadership role of the high school department chair, either in the manner in which the role is performed or in the way the role is perceived. Some researchers have noted that women tend to lead in a more collaborative manner than do men, 
suggesting that this difference may be a significant factor in the way the role is defined and perceived by others in the organization (Gilligan, 1982; Helgesen, 1990; Shakeshaft, Nowell, \& Perry, 1991). And if Shakeshaft's (1993) unequivocal statement that "one's gender identification has a tremendous influence on behavior, perceptions, and effectiveness" (p. 95) has any validity, then one might expect gender to have an even stronger impact.

In Oregon, the already inherently imprecise character of the instructional leadership role of the high school department chair has become further mired in ambiguity as a result of a "second wave" of educational reform (Carnegie Forum on Education and the Economy, 1986; Conley \& Cooper, 1991; Conway \& Jacobson, 1991; Wasley, 1991). Emphasizing the restructuring of school governance to empower teachers, this second reform movement advocates giving teachers additional responsibilities in decision making, curriculum and management. It has not been determined how, or if, traditional hierarchical teacher leadership positions such as that of the high school department chair fit within this emerging framework. Glatthorn (1990) stressed that "Clarity about purpose and role is especially important especially . . as those issues relate to teacher development" (p. 283). Lack of clarity induces "tensions and ambiguities [caused by] 
overlapping and contradicting job . . definitions" (Goldring \& Rallis, 1993, p. 8). Studies of the influence of organizational culture on change suggest another caution for those advocating educational reform. Such studies reveal that the intended outcomes of any educational change process, no matter how well intentioned, will necessarily be dramatically influenced by the beliefs, values, and behavioral norms of the organizational culture into which the change is being introduced (Fullan, 1991; Sarason, 1971; Schein, 1985). As Oregon educational restructuring efforts go forward, there have been no recent attempts to investigate and to describe educators' perceptions of the nature of the role of the high school department chair as it is currently practiced in Oregon. Nor have explicit attempts been made to discover whether congruent perceptions exist among educators about what is valued in that role. Because of the negative impact, a lack of congruence in values and expectations has been found to have on the effectiveness of role performance (Katz \& Kahn, 1978), a clearer understanding of the perceptions of superintendents, high school principals, high school academic department chairs, and high school academic subject matter teachers is important to making informed decisions about the role of the high school department 
chair in the emerging instructional leadership structure in oregon high schools.

To serve as an initial step in bringing clarity to the existing role of the high school department chair in oregon, this study and its companion study proposed to identify, to describe, and to compare the perceptions of superintendents, high school principals, high school department chairs, and high school teachers concerning the nature and the value of the role of the high school department chair as it currently functions in oregon high schools. Specifically, these two studies attempt to add to the understandings of the current status of the role of the high school academic department chair by examining perceptions of these four groups of educators as they relate to five categories of responsibility comprising the role of the high school department chair:

1. responsibility for human relations,

2. responsibility for management,

3. responsibility for the organization,

4. responsibility for program, and

5. responsibility for supervision.

In addressing that purpose, this study speaks from the perspective of high school department chairs and the teachers in their departments-those who, in what have traditionally been described as staff positions, establish instructional priorities for an academic area in the high 
school and for their own classrooms. Its companion study, The Administrators' Voice, an unpublished doctoral dissertation by William Anthony Korach (1996), speaks from the perspective of superintendents and principals-those who, filling line positions in the traditional educational hierarchy, have the authority and responsibility for establishing instructional priorities at the district and individual building level.

This study and its companion study are based upon the belief that superintendents, high school principals, high school academic department chairs, and high school teachers all play significant and influential roles in the instructional improvement efforts of their school districts. As a beginning step in establishing the potential value of effective top-down, bottom-up collaborations to instructional improvement, these companion studies, taken together, offer conversations in two voices, that from the administrative perspective and that from the teacher/department chair perspective, on the role of the high school academic department chair as seen through the perceptions of superintendents, high school principals, high school academic department chairs, and high school teachers from those same departments in a defined group of school districts in oregon.

Mitchell (1990) contended that "educational leadership requires a leader to assume a being-with-others 
perspective of everything which occurs in the teachinglearning and leading-following experiences" (p. 211), and advocates a dialogical style of leadership which "asks the leader to put himself or herself in the place of the person who is being led." The dialogical approach between top-down and bottom-up perspectives around which these companion studies were designed corresponds to Mitchell's vision. By examining the instructional leadership role of the high school department chair from the perceptions of four different educator groups, these studies offer the district superintendent, the high school principal, the high school department chair, and the high school teacher each an opportunity to put himself or herself in the place of the others to develop a more comprehensive picture of the leadership-followership role of the high school department chair.

\section{Questions to Be Investigated}

These studies are based upon six underlying assumptions: (a) the role of the high school academic department chair is currently an important part of the instructional leadership structure in Oregon high schools; (b) the high school academic department chair will continue to play a valuable role in the developing context of school reform in the state of Oregon; (c) a lack of congruence in perceptions, values, and expectations anong 
key people who influence the role of the department chair could have a negative impact on the chair's role performance; (d) a lack of congruence between the perceptions, values, and expectations of the chairs themselves and those of others who influence the role of the department chair could have a negative impact on the chair's role performance; (e) a measure of the congruence of perceptions, values, and expectations could be determined by surveying superintendents, high school principals, high school academic department chairs, and high school academic subject matter teachers; and (f) for the role of the academic department chair to become most effective will require a combination of top-down, bottomup collaborations among individuals playing key organizational roles, including superintendents, high school principals, high school academic department chairs, and high school teachers.

In order to consider the possibilities of an instructional leadership role for the high school department chair which can be effectively performed within the emerging context, these studies undertake to discover the extent to which four different educator groups perceive department chairs as carrying out specific instructional leadership roles as well as to discover their perceptions about the value of that contribution. These studies take an important first step in identifying 
what is, i.e., what is perceived to be the way department chairs are spending their time, what are perceived to be the most valuable elements in the department chair role, and what are perceived to be the most important elements to improve in that role-in order to determine the degree of congruence among the perceptions of those four educator groups regarding the way the role of the high school department chair is viewed.

First, it was assumed that the role of the high school academic department chair currently is part of the instructional leadership structure in oregon high schools. From the combined educational experience of the researchers, four key referent groups whose actions influence the nature of instructional improvement in high schools had been identified. The intent was to investigate the perceptions of those four groups regarding the way the role of the high school academic department chair was currently being performed in oregon, i.e., what portion of department chair time was perceived to be spent in performing what activities. Although it was understood that, as Murphy (1988) warns, to equate the time devoted to performing a behavior either with its value or its impact on the leadership role would probably not be a valid measure, it was also assumed that incongruent perceptions about the amount of time spent in performing specific department chair activities would be a potential 
source of conflict in performance of the role. Thus, the first question to be addressed was:

What degree of congruence exists among the perceptions of superintendents, high school principals, high school department chairs in English, math, science, and social studies and high school teachers of English, math, science, and social studies about the amount of time spent by the department chair in fulfilling specific department chair activities in five categories of department chair responsibilities: human relations, management, the organization, program, and supervision?

Second, both one's own behaviors and the expectations held for others are influenced by one's values and beliefs. It was assumed that the chair's own perceptions about what was important in his/her role would be significant in determining his/her actions. However, what other people in key organizational roles perceived to be important about the department chair role would help define their expectations for the performance of the department chair, in turn impacting the chair's behavior. Incongruence in the two sets of expectations would potentially lead to conflict, resulting in loss of effectiveness. Thus, the second question to be addressed was: 
What degree of congruence exists among the perceptions of superintendents, high school principals, high school department chairs in English, math, science, and social studies and high school teachers of English, social studies, math, and science regarding the importance of specific department chair activities in five categories of department chair responsibilities: human relations, management, the organization, program, and supervision?

Third, it was assumed that the role of the high school academic department chair would continue to be developed as a significant part of the instructional leadership structure in oregon high schools. As districts consider the restructuring of roles and responsibilities, it is important to anticipate possible obstacles to role effectiveness. Determining what congruence there is among the perceptions of interrelated educator groups about what activities in which responsibilities of the role of the high school department chair are most important for the chair to continue to improve would be one significant step in that effort. Thus, the third question to be addressed was:

What degree of congruence exists among the perceptions of superintendents, high school principals, high school department chairs in English, 
math, science, and social studies and high school teachers of English, social studies, math, and science regarding the importance of the department chair's continuing to improve in performing specific department chair activities in five categories of department chair responsibilities: human relations, management, the organization, program, and supervision?

Additionally, these companion studies sought to construct a profile of the typical participant in each of the four educator groups in the defined high schools targeted for this study by identifying the following demographic characteristics of the respondents: age, gender, educational background (highest degree achieved and major subjects of study), and educational experience (current position held, number of years of teaching experience, and total number of years in education).

In summary, speaking from the voice of the high school teacher-department chair, this study investigates congruence of perceptions of high school department chairs and teachers in four academic disciplines (English, mathematics, science, and social studies) regarding the role of the high school department chair. Three different groupings are employed: first, responses of all department chairs are compared to those of all teachers; second, department chair responses from chairs of each of 
the four disciplines are compared against one another; and third, responses of all male department chairs and teachers are compared to responses of all female department chairs and teachers. In all three instances, issues addressed are: (a) perceptions of the amount of department chair time spent on each activity specified in each of the five defined categories of department chair responsibility; (b) perceptions of the importance of each activity in each of the five categories to the role of the department chair; and (c) perceptions of the importance of the department chair's continuing to improve in the performance of each activity in each of the five categories.

\section{Significance of the Studies}

These studies evolved from a strong belief in the need to take a "collective look backward, inward, and ahead" (Deal, 1987, p. 12) in clarifying the value of the instructional leadership role of the high school academic department chair within the evolving context of educational reform in oregon. As Siskin (1991) cautioned,

many of the current educational reform proposals call for "radical surgery" to rescue public schools from their apparent demise [without taking into account that] such radical surgery requires an accurate and intimate knowledge of the patient's anatomy . . (p. 136)

Because little information is available about the nature or the perceived value of the instructional leadership 
role of the high school department chair as it is now practiced in Oregon high schools, Oregon school districts lack important knowledge about the value of that role as they consider new governance roles and relationships under the "radical surgery" of the school reform effort. As Wasley (1991) stated, "The rhetoric of reform seems ignorant of the current conditions of practice" (p. 4). Fullan (1991) raised another concern. Because significant change involves a certain amount of ambiguity, ambivalence, and uncertainty for the individual about the meaning of the change, - . effective implementation is a process of clarification. (p. 106)

People who consistently accomplish what matters most to them are people who are continually "clarifying and deepening [their] personal vision" (Senge, 1990, p. 7). clarifying what has been perceived to be of value in the leadership structures under the current organizational system would assist districts in further defining and developing the instructional leadership role of the high school department chair by anticipating and resolving possible areas of conflict as the district vision of restructuring is carried forward.

The task faced by the oregon educational community, then, is to develop ways to examine and to reconcile the strengths of the current system with the potential benefits of the innovations being promoted by the 
reformers (Bacharach \& Conley, 1990). Deal (1987)

envisioned this undertaking as

a process of transformation akin to the one that produces a butterfly from a caterpillar-a cocoon of human experience in which past, present, and future are fused together in an organic process. (p. 12)

Through approaching the investigation of the instructional leadership role of the high school department chair from both the top-down perspective of the administrator and the bottom-up perspective of the teacher-department chair, this study and its companion study offer a unique contribution to the field of educational literature. By surveying four interconnected reference groups in the current educational system-superintendents, high school principals, high school academic department chairs, and high school teachers from a group of oregon school districts with defined characteristics in common-these companion studies seek to produce comparative analyses of the perceptions of those four educator groups and thus to determine the areas and degrees of congruence that exist in their perceptions of what has been most highly valued in the role of the high school department chair. This comprehensive examination of the current status of the role of the high school department chair from two different but interrelated perspectives should offer valuable additions to the knowledge base oregon school districts will need to 
consider in developing their instructional improvement agendas.

Having gained more understanding of what the nature of the role of the high school department chair is currently perceived to be and what in that role is most valued by differing groups of oregon educators, school districts charged with educational reform by oregon legislative mandate should be better able to make decisions about the definition and potential development of the instructional leadership role of the high school academic department chair within this evolving context. Thus, in an image suggested by Deal (1987), these studies offer what has been perceived to be most important in the "old" instructional leadership role of the high school department chair as threads to be woven into the "new" instructional leadership tapestry which is being designed through educational reform in Oregon.

Theoretical Framework for the studies

First, the role theory of leadership behavior affirms that "leadership behavior is shaped by the perceptions of how other people want the leader to behave" (Smith \& Andrews, 1987, p. 5). In applying role theory specifically to the instructional leadership role of the high school department chair, Sergiovanni (1984) concluded that 
One determiner of the chairperson's leadership effectiveness is the expectations for his or her performance as a leader held by important others, such as the principal and teachers. (p. 172)

Based upon the role theory of leadership behavior, then, the realities of a high school chairperson role are significantly influenced by the perceptions and expectations of superintendents, high school principals, and high school teachers. Sergiovanni (1984) went on to stress the necessity for congruence in such perceptions and expectations:

A further determiner is the extent to which these role expectations agree with each other and with how the leader feels he or she needs to behave. One need not have mirror agreement with superiors and subordinates in regard to role expectations, but reasonable agreement and mutual understanding of areas of agreement seem to be prerequisites for leadership effectiveness. (p. 172)

If conflicting expectations for the role of the high school academic department chair exist among superintendents, high school principals, high school department chairs, and high school teachers, the assumption is that the effectiveness of the department chair will be diminished. Although this study is not an attempt to determine effectiveness, per se, it does seek to determine possible obstacles to effectiveness by investigating the degree of congruence that exists in the perceptions of these four educator groups about the nature and the value of the role of the department chair as it is 
currently being practiced in a defined group of oregon high schools.

Second, Mitchell (1990) posited that educational leadership "is fundamentally a question of the educational values of the leader and the followers" (p. 65). Beare, Caldwell, and Millikan (1989) define values as "weights: the priorities we place on things" (p. 180). As such, values are perceptions of objects, ideas, or other people that guide behavior based upon personal belief systems (Hodgkinson, 1983; Mitchell, 1990). Sergiovanni (1987) believes the meaning of leadership behavior becomes more important than the behaviors themselves: "Leadership reality for all groups is the reality they create for themselves, and thus leadership cannot exist separate from what people find significant and meaningful" (p. 116). From this perspective, determining the importance of the instructional leadership role of the high school department chair requires consideration of the perceptions of both leaders and followers regarding the way that role is defined and what in that role is most valued.

Third, from a general systems theory perspective a system as defined by Kauffman (1980), is "a collection of parts which interact with each other to function as a whole" (p. 1). From a systems viewpoint, it is not the simple aggregate of the parts that is key, but the interaction of the parts-the essential nature, the 
"wholeness," of the organization depends upon its entire structure. In Wimpelberg's (1987) examination of school effectiveness, he concluded that it "clearly portrays instructional success as an integrated process [involving] each professional position, from teacher to superintendent" (p. 105). Wimpelberg further contended that "interactive decision making in a combination of 'top down' and 'bottom up' collaborations fosters instructional improvement" (p. 105).

Because of the dynamic and ever-changing nature of influence among the members of any organization, leadership and followership must be seen not as static but as evolving roles in which high school teacher, high school department chair, high school principal, and superintendent simultaneously function both as leaders and as followers. This study and its companion study, comprising conversations between two voices-that of the administrator and that of the teacher/department chair-offer a comprehensive "top-down," "bottom-up" perspective on these leadership/followership roles. Grounded in this theoretical framework, these studies offer the necessary first step in defining and clarifying the value of the role of the high school academic department chair in the instructional leadership context being developed by educational reform efforts in oregon. 
Operational Definitions

Because the researchers undertook these studies with the intent of broadening the knowledge base upon which instructional improvement decisions could be made in their own district, it was determined that a study population most comparable to that of their district would be defined. Thus, for purposes of these studies, the following operational definitions were employed.

1. The independent variable was defined as the current position held (superintendent, high school principal, high school academic department chair, high school teacher).

- Superintendent-the chief executive officer from a school district in the state of oregon with an Average Daily Membership of more than 3,000 but fewer than 12,000 students.

- Principal-the primary administrator of an AAAA high school (the oregon School Activities Association athletic competition designation for schools with populations of at least 650 students in grades 10-12) within one of the defined districts.

- Department chair-a faculty member from one of the defined high schools who, in addition to teaching responsibilities in one of four academic disciplines (English, mathematics, science, or 
social studies), has responsibility for leadership of that department. [For purposes of this study, the terms department head and department chairperson are synonymous with the term department chair.]

- Teacher-a classroom teacher from one of the defined high schools, the majority of whose teaching responsibilities fall within one of the four defined academic disciplines (English, mathematics, science, or social studies).

2. Dependent variables were defined as the five specific categories of leadership responsibility which had been delineated as comprising the role.

- Responsibility for Human Relations-the responsibility for fostering productive, positive, and rewarding working relationships among department members.

- Responsibility for Management-the responsibility for coordinating the activities of people and allocating resources to accomplish defined goals.

- Responsibility for the organization-the responsibility for contributing to the improvement of the organization at the department level, the school level, and the district level. 
- Responsibility for Program-the responsibility for the definition, delivery, and monitoring of what is taught by members of the department.

- Responsibility for supervision-the responsibility for overseeing the work of the individuals within the department, focusing on efforts to improve performance, promote professional growth, and accomplish expectations.

3. Line positions refer to those positions in the educational hierarchy which include supervisory responsibility with authority to recommend termination of an employee.

4. Staff positions refer to primarily advisory positions which are characterized by limited supervisory responsibility and no authority to recommend termination of another employee.

5. Educational experience refers to the number of years the respondent had served as a full-time educator in each defined position: high school teacher, high school department chair, high school principal, superintendent. Respondents were also asked to specify academic areas for any experience as a high school teacher and as a high school department chair.

6. Educational background refers to the credentials respondents had earned from institutions of higher learning: bachelor's degree, master's degree, doctorate, 
administrative certification. Respondents were also asked to specify major courses of study for each credential.

7. Value refers to "an enduring belief about the desirability of some means or end" (Raun \& Leithwood, 1993, p. 56).

8. Perception refers to the interpretation placed on an experience; recognition or identification, especially as a basis for or as verified by action (Reber, 1985). 9. Top-down refers to influence by superintendents and high school principals which is exerted on individuals with less formal power and authority in the educational hierarchy.

10. Bottom-up refers to influence by high school department chairs and teachers which is exerted on individuals with more formal power and authority in the educational hierarchy.

\section{Limitations of the studies}

The findings and conclusions of these studies were limited in scope, purpose, and methodology; thus the generalizations which can be drawn from the studies are also limited in several respects.

\section{The Population}

The studies were limited by the extent to which the defined population is similar to like groups in other areas. 
1. Participants were elicited only from within the state of oregon.

2. The studies sought data only from high schools. No junior high schools nor middle schools were included in the studies.

3. Only those high schools: (a) which were classified as AAAA (based upon populations of at least 650 students in grades 10-12) by the Oregon School Activities Association for purposes of athletic competition, and (b) which were located in school districts with Average Daily Memberships of at least 3,000 but not more than 12,000 students were asked to participate.

4. Superintendents, high school principals, high school academic department chairs, and high school teachers were the only school personnel contacted for participation in the studies. No assistant principals, curriculum coordinators, supervisors or persons holding other titles were contacted.

5. Including high school department chairs and teachers from only the disciplines of English, mathematics, science and social studies further restricted the studies by the extent to which chairs and teachers from these disciplines are representative of those in other departments in the high school organizational structure. 
6. These studies also did not address the extent to which the leadership functions delineated in the questionnaire ought to be performed by the department chair. (It is possible a particular activity could be considered important to be performed within the system, but considered to be the responsibility of someone other than the department chair.)

The Instrument

1. Only those five specific categories of activity identified in the questionnaire were offered in defining the perceived instructional leadership role of the department chair.

2. Only those questionnaire items about specifically defined activities were used in describing perceived importance of the instructional leadership role of the department chair. Perhaps there are other activities which respondents consider part of the department chair role and which they perceive to be more important than those identified on the questionnaire.

\section{Assumptions}

In addition to the six assumptions identified in the construction of the questions to be investigated, several other assumptions were considered to underlie the design and implementation of these studies. These assumptions were the following: 
1. That approaching the studies from both the topdown perspective of the administrator and the bottom-up perspective of the teacher/department chair would take advantage of the researchers' rich background of experience in the full range of educational roles being addressed in the studies: high school teacher, high school department chair, high school principal, and superintendent.

2. That much meaningful research is collaborative in nature and that each study would be enriched and informed by its companion study viewing the topic from a complementary perspective.

3. That the questionnaire was the appropriate method for gathering data.

4. That the survey instrument as it was constructed was sufficiently valid and reliable to generate adequate meaningful data.

5. That the anonymity of responses would assure that respondents would reply candidly to the survey instrument.

6. That the importance of the topic to high school teachers, high school department chairs, high school principals and superintendents would lead to a high rate of questionnaire returns.

7. That the teacher surveys were distributed as requested and that respondents were therefore 
representative of the total teacher population defined for the study. 
CHAPTER II

REVIEW OF RELATED LITERATURE

Based upon a belief in establishing the potential value for effective top-down, bottom-up collaborations toward instructional improvement, this study focused on the role of the high school academic department chair as it is perceived by high school academic department chairs and high school teachers from those same departments in a defined group of school districts in oregon. From the bottom-up perspective of the high school teacher/academic department chair, the literature related to the instructional leadership role of the high school department chair was reviewed in four parts.

First, the literature on the establishment and institutionalization of the high school department chair position was reviewed, demonstrating the wide disparity and resultant ambiguity in the nature of the position. Second, literature on issues related to role effectiveness was examined, substantiating the importance of role clarity, the impact of the perceptions and expectations of others on the role, and the need for congruence of expectations for effective role performance. Literature regarding the impact of gender on perceptions 
of role and behavior expectations was investigated, suggesting a potential relationship between gender and perceived effectiveness of role performance.

Third, the influence of instructional leadership as a strong characteristic of effective schools was reviewed, establishing a definition of instructional leadership for the purposes of this study and identifying instructional leadership with role expectations for the department chair.

Fourth, literature on the school district as a dynamic system was reviewed, establishing the importance of understanding instructional leadership role expectations from both the top-down administrative perspective of superintendents and high school principals and the bottom-up instructional perspective of high school teachers and high school department chairs.

\section{Evolution of the Position of High} School Department Chair

\section{Historical Background}

Blumberg (1974) contended that school systems, like other organizations, tend to develop structural patterns to deal with problems as they arise or to further organizational goals. This perspective offers a useful way by which to trace the evolution of the departmental organization of the American high school, a phenomenon which siskin (1991) indicated began to appear around the 
beginning of the twentieth century and was well

established as an organizational structure by the 1930s.

During this period, social changes were bringing more students into the high school system; at the same time, scientific discoveries and technological advances had produced a "knowledge explosion." with high schools becoming larger and more complex, school administrators were faced with problems that had not existed in the atmosphere of the "little red school house" or the selfcontained elementary classroom. As Callahan (1971) stated, "The department head position appears in the organizational charts and faculty rosters of school. districts in every state. The reason for this is simple: the chairman fills an administrative vacuum created by the rapid growth of public education in America during this century" (p. 21).

The practice of configuring high schools around departments had been noted as early as 1928 by Foster, who attributed this structural change to required teacher specialization resulting from a need for the high school curriculum to address subject matter that was itself increasingly specialized.

Due in the last analysis to the more advanced subjects taught, the departmental system prevails in secondary education, with the results that no one person is supposed to be familiar with all the subject matter taught. Hence, we have department heads and department teachers, each a specialist in one field. (p. 250) 
Expansion of knowledge created both new, specialized disciplines and an increase in the application of that knowledge. The need to expand the curriculum beyond the basic skills in reading, writing, and arithmetic increased the need for more attention to curriculum and more supervision of an increased number of teachers. McLaughlin, Talbert, and Bascia (1990) noted that "The position of department head has been the most uniform response to the problems of school size and curriculum complexity" (p. 215).

According to siskin (1991), greater numbers of students seeking higher education motivated the establishment of the departmental organization of the high school as a way to "fill the gap" between elementary schools and universities. Hipps (1965) also stressed that the high school departmental organization was originally somewhat patterned after colleges, and that until relatively recently, the main function of high schools had been to prepare students for college.

Faced with addressing these evolving expectations and desiring to further its educational goals, the school system, as siskin (1991) pointed out, has structured as a nearly universal feature of the 22,000 secondary schools across the United States . . highly standardized department labels [that] divide teachers and courses along department lines. ( $p$. 134) 
Numerous sources (Easterday, 1965; Gorton \& ThierbachSchneider, 1991; Manlove \& Buser, 1966; McLaughlin, Talbert \& Bascia, 1990; Siskin, 1991) indicated that within this structure, the use of the department chair has become a common method of organization which principals employ to provide supervision, enhance communication, and develop and improve the curriculum.

Ambiguity in the Position

McLaughlin, Talbert and Bascia (1990) contended that

Although it has not been studied in depth, the role of department head deserves attention both because it is one of the few formal opportunities for teacher leadership within schools and because it is a relatively uniform structural feature of American secondary schools. (p. 215)

One of the first systematic studies designed to gather information about the department chair position was conducted by Harlan Koch and reported in The School Review in 1930. From data collected from 171 schools in 114 cities spanning 31 states, Koch concluded that although nearly two thirds of the schools surveyed used department heads, there was wide disagreement among administrators about both the definition of the role and its importance. A survey conducted by the Association for Supervision and Curriculum Development (1948, pp. 11-12) among 124 department chairs in six states revealed that the chairs performed the following activities, listed in order from 
those most frequently performed to those least frequently performed:

1. Selecting textbooks

2. Selecting supplies and equipment

3. Initiating new teachers into the department

4. Surveying available instructional materials

5. Appraising and revising courses offered in the department

6. Requisitioning instructional supplies for the department

7. Planning for efficient use of supplies and equipment

8. Preparing instructional material

9. Planning some phase of remedial instruction

10. Requisitioning for repair and equipment

11. Developing and trying out new courses.

Sporadic studies over the next 30 years managed to do more to obscure than to clarify the position, apparently confirming Axley's (1947) colorful metaphor, "race horses with plow horse duties" (p. 274), for the discrepancy between the apparent potential offered by the department chair role and the seeming futility and impotence produced by the constraints under which the role was carried out in actual practice. Noting that the duties and responsibilities of the department chair had not changed significantly between 1940 and 1959, Kidd 
(1965), concluded that "little has been done to develop the potential of the department headship" (p. 72).

A number of studies (Durkee, 1947; Easterday, 1965; Johnson, 1990; Pellicer et al., 1990; Squire \& Applebee, 1968) praised the value of the department chair position, citing examples of department chairs fostering and/or effecting organization, efficiency, direction, purpose, unity and coherence, directed toward achieving department and school goals. However, a significant number of studies concluded either that the department chair position had been inadequately studied (Hipps 1965; Manlove \& Buser 1966) or that ambiguity or a lack of agreement and understanding of the role of the department chair prevailed (Berrier, 1974; Fish, 1976; Hord \& Murphy, 1985; Lieberman \& Miller, 1984; Roach, 1976; Wasley, 1991). McLaughlin, Talbert, and Bascia (1990) indicated that available studies of the role of the department chair are "revealing for the variations, inconsistencies and ambiguities they portray; that is, there appears to be no widely known and accepted role for the department head" (p. 215). In short, as Gorton and Thierbach-schneider (1991) summarized, "The roles and responsibilities of the department head are no more or less than the principal defines them to be" (p. 319).

Another element of ambiguity addressed in much of the literature was the issue of where the position of the 
department chair fits in the organizational hierarchy. Was it or should it be designated a line position or a staff position? Ciminillo (1967) concluded that most department heads perceived their functions to be both administrative and supervisory, but that their primary concern was the supervisory aspects of their jobs. Hipps (1965, p. 487), however, referred to the department head as the "weakest link" in the line and staff organization because of confusion between his/her administrative and supervisory functions. Oliva (1989) observed that as a supervisor the high school department chair was in a "precarious position . . often perceived as a member of the administrative team" (p. 70) but not having administrative authority to evaluate teachers because of also being a member of the teachers' union. Hoy and Forsyth (1986), noting the "inherent tension between supervisory and administrative positions" (p. 9), even insisted that the two functions are not compatible.

on the other hand, while acknowledging administrative tasks often associated with the role, a number of studies (Fish 1976; Gruman, 1955; High, 1965; Hipps, 1965; Man?ove \& Buser, 1966; Pellicer et al., 1990) also defended the value of a supervisory function for the department chair. Weber (1987) advised principals that the department chair might well be used "for goal-setting and the formative tasks of teacher supervision, but [that] summative tasks 
are the responsibility of the principal and school authorities above the principal" (p. 30). In other words, in Weber's apparent attempt to resolve the ambiguity by differentiating between line and staff responsibilities, the department chair would be charged with a supervisory role for instructional improvement but would not have the responsibility or authority to evaluate teachers.

Reacting to what he had apparently concluded were its unresolvable ambiguities, Metty (1969) commented that the role of the department chair is "by definition, schizophrenic" (p. 1). Although Metty's response may appear to have been overstated, the negative effects of role ambiguity-dissatisfaction, frustration, lack of effectiveness, low self-confidence-have been widely noted (Budner, 1962; Deal, 1987; Katz \& Kahn, 1978; Kirby \& Teddlie, 1989).

Considerations for Role Effectiveness

\section{Role Theory and Role Conflict}

The concept of role as a critical aspect of the social organization of human beings has been attributed to anthropologist Ralph Iinton (cited in Parsons, 1959). According to Iinton, (a) within the social structure individuals function in a variety of relationship positions, each characterized by marked status, rights, and duties which are instrumental in motivating particular 
behavior; and (b) problems evolve when individuals find themselves attempting to carry out conflicting roles at the same time. Using Linton's ideas, Parsons theorized that since an individual's behavior patterns were determined according to organizational goals or standards that were either stated or implied, one could study an individual's patterns of behavior as responses to the expectations of others within the organization. Schmuck and Runckel (1988) concurred that "insofar as an organization comprises persons interacting in roles, much organizational behavior can be understood by understanding role relationships" (p. 301).

Organizational theorists also commended the usefulness of role theory for analyzing interpersonal behavior in many kinds of organizations, including schools (Bennis, 1966; Owens, 1981; Yukl, 1981). Stressing that role refers to a psychological concept (as distinguished from job titles or job descriptions), Owens characterized it as emerging from a combination of (a) the expectations of behavior that both observers and the person in an organizational position attach to that particular position, and (b) the individual personality characteristics of the person occupying the position. In discussing role theory, Owens offered the following definitions of terms: fairly well established in the literature... 
Role description refers to the actual behavior of an individual performing a role or, more accurately, one's perception of that behavior.

Role prescription is the relatively abstract idea of what the general norm in the culture is for the role.

Role expectation is the expectation that one person has of the role behavior of another. Teachers expect certain behaviors from a principal; the principal has expectations of behaviors from teachers. As teacher and principal interact in their roles in the school, they have complementary role expectations.

Role perception is used to describe the perception that one has of the role expectation that another person holds for him or her.

Role conflict (commonly thought to be a source of less-than-satisfactory performance in organizations) occurs when different people make incompatible demands on the person. Confusion over role expectation and role perception is commonly observed. (p. 69)

Bennis (1966, p. 193) more explicitly detailed this phenomenon in his explanation of role set in hierarchical organizations. Bennis places the role player-the person holding a defined position in the organization-in the center of his model. Those to whom the role player reports, his/her superordinates, occupy higher positions in the model. The persons who report to the role player, his/her subordinates, are placed lower on the model. The role player thus occupies a complex pivotal role-the receiver of many differing, perhaps conflicting, role expectations being transmitted in a variety of ways by numerous individuals occupying diverse positions in the 
organizational hierarchy. Owens (1981, p. 71), in adapting the Bennis model, included the role player's colleagues (those occupying positions on the same hierarchical level) as an additional component in the role player's role set, or "referent group."

Some researchers (Katz \& Kahn, 1978) have found role set to be a beneficial operational concept in examining role conflict and role ambiguity while attempting to explain leadership behavior. For purposes of the current study, casting the high school department chair as the role player, then, would designate the superintendent and the high school principal as his/her superordinates, other teachers in his/her department as subordinates, and chairs of other subject matter departments as his/her colleagues. Thus, the expectation would be that the behavior of the department chair would be influenced by the chair's perceptions of how the superintendent, the high school principal, the teachers within his/her department, and department chairs in other academic areas want him/her to behave in carrying out the role of department chair (Kahn, Wolfe, Quinn, \& Snoek, 1964). Brann and Emmet (1972) pointed out that

Even in the most tranquil of times, the [department] chairman finds his loyalties and responsibilities divided among . . groups with immense differences in goals, attitudes, needs, and yardsticks of approval. (p. 5) 
Kahn et al. (1964) indicated a role player attempting to resolve such role conflicts will more likely respond to the expectations of his/her superordinates, because they have more power over the role player than do subordinates or colleagues. In looking at high school principals as role players, vann (1978) did find that the amount of time which principals allocated to particular tasks was most strongly related to the principals' perceptions of what their superiors wanted done. However, in investigating behaviors of high school department chairs, cognetta (1967) found the chairs seemed to be more influenced by their perceptions of what teachers in their own departments expected them to do than by their perceptions of what the administration appeared to want.

Getzels and Guba (1957) provided additional insight into role conflict. Their model of the organization as a social system depicts social behavior as the interaction of two dimensions: the nomothetic (the organizational), defined as the role and behavior expectations established by the organization and designed to contribute to meeting the goals of the organization; and the idiographic (the individual), defined as the personalities and needs of the persons occupying those organizational roles. For the department chair, nomothetic factors impacting his/her role perceptions would include written job descriptions and regulations applicable to the role as well as direct 
requests from superordinates. Although role expectations from subordinates (for the department chair, the teachers in the department) are often communicated in a more subtle manner, the leader finds him/herself both under pressure from superordinates to attain the goals of the organization and under pressure from subordinates to meet their personal needs. Gorton and Thierbach-Schneider (1991), after cataloging an extensive list of difficulties intrinsic to the role of the department chair, specifically pinpointed role conflict as a major difficulty. "They have expectations placed on them in regard to their behavior by both the principal and the teachers in the departments. These expectations may be-and frequently are-incompatible, thereby creating role conflict for the department heads" (p. 136).

Getzels and Guba (1957) concluded that role conflict varies directly with the incompatibility of multiple role expectations; the greater the role conflict the greater the corresponding loss of effectiveness of the individual in the leadership role. In the case of high school department chairs, the potential for loss of role effectiveness is compounded by their own conflicted identity as Fish (1976) noted:

Because they teach some classes and because of close social relationships with other faculty, they [chairpersons] regard themselves as teachers. Yet their responsibilities to direct 
the work of department members in curriculum development and their responsibilities to influence their colleagues toward improved classroom performance give the role a distinctly administrative flavor. (p. 107)

An American Federation of Teachers study reported in Conley and cooper (1991) also confirmed that many teachers in leadership roles felt their greatest conflict resulted from the general ambiguity of their roles and their discomfort with "having a foot in two worlds (teacher and administrator)" (p. 230).

In the Getzels and Guba model (1957), effectiveness is the observed behavior of the leader relative to some expectation for that behavior held by the person making the judgment. That is, effectiveness is the function of the congruence of behavior with expectations. People generally feel they should carry out their role effectively, even if conflicting demands make it seemingly impossible to do so. When the department chair experiences a lack of congruency in perceptions of and expectations for his/her leadership role, the chair might reasonably be expected to experience role conflict, role ambiguity, and feelings of inadequacy and powerlessness (Kottkamp \& Mansfield, 1985). Palmer (1981) stated, "The fact that the role is inherently conflicted does not necessarily act as a mitigating factor" (p. 66) for such responses. Sarbin and Farberow (1952) offered additional insight: 
Variations in the perceptions and enactments of roles are in part . . a function of the contribution of the self . . Motivation is defined as the degree to which a role is congruent with the subject's self-perceptions. Where there is a high degree of congruency, motivation is said to be favorable. Where there is a low degree or absence of congruency, the motivation is not favorable. (pp. 117-118)

Congruence of perceptions, expectations, and behavior has been established as vital to one's effective role performance, motivation, and sense of well being. Such consistently negative impact in such a variety of conditions having been attributed to a lack of congruence in perceptions of one's role and expectations for one's role underscores the importance of identifying possible sources of incongruent perceptions and expectations for the role of the high school department chair as new leadership structures are developed for oregon high schools.

\section{Gender Issues}

Few organizational or educational studies that have addressed gender issues are available in the literature. This lack has been attributed to a bias toward androcentrism in the educational system (Capper, 1993; Levine, 1989; Robertson, 1992; Shakeshaft, 1993) and its resultant valuing of characteristics and behaviors that are stereotypically masculine. Differences between men and women are typically not explored in educational research, and as Robertson (1992) pointed out "gender 
issues and teacher development are almost always dealt with as mutually exclusive spheres of enquiry" (p. 43). Belenky, Clinchy, Goldberger, and Tarule (1986) presented an academic feminist perspective that perceives generally accepted world views and attitudes to be male constructs. Their contention is that

Drawing on their own perspectives and visions, men have constructed the prevailing theories, written history, and set values that have become the guiding principles for men and women alike. (p. 5)

Thus, as Robertson (1992) pointed out, the male experience is accepted as universal experience, and "whether we are born male or female, the masculine paradigm dominates our cultural interpretation of reality" (p. 44).

Although there were few organizational studies that addressed gender issues, studies in human development offered additional perspective. Kohlberg's (1981) sixstage model of moral development, characterized as a ruleoriented morality of justice, has been accepted to represent stages of human moral development. However, Gilligan's (1982) research investigating women's development suggested women experience differing patterns of moral development from those delineated in Kohlberg's studies. Oja (1991, p. 45) referred to Gilligan's having discovered a different "voice" of morality-an ethic of care. Men tend to focus on justice; therefore, Kohlberg's model seems accurate when applied to men. In contrast, 
women tend to focus on care (Lyons, 1983). As Gilligan

explained,

The failure to see the different reality of women's lives and to hear the differences in their voices stems in part from the assumption that there is a single mode of social experience and interpretation. (p. 173)

Gilligan, Ward, Taylor and Bardige (1988) challenged this assumption, describing the two moral voices of justice and care as two different frameworks for problem solving.

From the perspective of someone seeking or loving justice, relationships are organized in terms of equality, symbolized by the balancing of scales. Moral concerns focus on problems of oppressions, problems stemming from inequality, and the moral ideal is one of reciprocity or equal respect. From the perspective of someone seeking or valuing care, [emphasis added] relationship connotes responsiveness or engagement, a focus on problems of detachment, on disconnection or abandonment, or indifference, and the moral ideal is one of attention and response. (p. xvii)

Oja (1991) asserted that "By adopting one or the other moral voice, [men and women] focus attention on different types of concerns" (p. 45).

Even the evidence upon which men and women make judgments about the same kinds of concerns may be different. For instance, Shakeshaft, Nowell, and Perry (1991) contended that men and women define trust differently and therefore look for differing indicators as evidence of betrayal of trust. They assert that men consider divulging information or discussing conversations or actions with others to be betrayals of trust, whereas 
women expect individuals to discuss such topics with other people. For women, untrustworthiness is manifested in people who do not follow through with what they have said they would do at the time they have said they would do it, behaviors which men would see as simply issues of incompetence or lack of time management. Gilligan (1982), through her use of opposing imagery, also suggested differences between what men and women value:

The images of hierarchy and web, drawn from the texts of men's and women's fantasies and thoughts, convey different ways of structuring relationships, and are associated with different views of morality and self. (p. 62)

Studies have shown women lead differently from men, not through asserting hierarchical control but in a more collaborative style, through creating web-like circles of relationships (Belenky et al., 1986; Helgeson, 1990; Robertston, 1992; Shakeshaft Hanson, 1986). Irwin (1995) characterized this feminine image of the circle as being expansive and flexible in contrast to the images of rigidity and control associated with traditional masculine top-down hierarchical models of leadership. Shakeshaft, Nowell, and Perry (1991) extended this characterization, citing research suggesting "the sex of participants in supervisory situations affects what is communicated and how. Men and women communicate differently and listen for different information" (p. 134). Irwin (1995) referred to 
the work of several other researchers in pointing out that women's communicative style is most often directed toward "specific tasks or persons," whereas men's orientation is more often toward "image development and autonomy" (p. 21). Shakeshaft and Hanson (1986) additionally noted that women tend to view the major role responsibility of principals and superintendents to be master teachers and educational leaders, while men tend to view the same positions from a managerial and industrial perspective. Calabrese and Anderson (1986) concluded in their study of the public school system that male orientation of curriculum, administration, and the school environment creates for women feelings of powerlessness, isolation, and meaninglessness. Thus, women teachers experience more stress than male teachers.

Robertson (1992) had charged that androcentrism's "mandated gender neutrality requires us to see the world from the male point of view [and] to assume and to assert that this is not selective or limited perception" (p. 43). Shakeshaft (1993) adamantly argued that in reality "One's gender identification . . has a tremendous influence on behavior, perceptions, and effectiveness" (p. 95).

Instructional Leadership

In contrast to the dearth of studies dealing with gender, the fascination with which twentieth century 
Western society has pursued the study of leadership has produced a rich and diverse range of perspectives from which to view leaders. However, scholarly agreement about the essential elements of a definition of leadership is limited. Hoy and Forsyth (1986) summarized the complexity of the definitional task:

The concept of leadership remains elusive because it depends not only on position, behavior, and personality of the leader but also on the nature of the situation as well as the interaction of the situation with the personality and behavior of the leader. Moreover, leadership occurs in a cultural context in which symbols and meanings are important. (p. 199)

Similarly, as Duke (1982) pointed out, there is a "lack of conceptual clarity concerning the notion of instructional [italics added] leadership" (p. 1) which the effective schools research base has clearly concluded to be a critical element in school effectiveness.

Citing several studies, Pellicer et al. (1990) noted that the effective schools research identifies "certain essential behaviors which must be exercised" (p. 27) in redirecting the focus of the principal's job toward instructional leadership. These include: (a) identification and expression of a set of values and expectations that place a high priority on instruction in the total school program; (b) a clear instructional goal focus with systematic plans for accomplishment; (c) the ability of principals to share instructional leadership 
functions with others; and (d) maintenance of a safe and orderly school environment that promotes learning and protects students' instructional time. Despite this listing, however, Pellicer et al. concluded that instructional leadership is not just a set of discrete activities and behaviors. The effective schools research and strategies were criticized as being too narrow and simplistic by others as well (Burlingame, 1987; McLaughlin, Talbert, \& Bascia, 1990). Peterson's (1989) synthesis of research on instructional leadership clearly delineated significant obstacles to implementing such behaviors for principals who work in large, differentiated, complex high school settings.

In Greenfield's (1987) report of studies of instructional leadership by the principal, he acknowledged that "The idea [instructional leadership] connotes multiple and ambiguous meanings" (p. 57). However, he chose to define it as specifically referring to "actions undertaken with the intention of developing a productive and satisfying working environment for teachers and desirable learning conditions and outcomes for children" (p. 60). He thus implied a focus on improvement in both areas. While conceding that the entire picture of instructional leadership is a much broader one, Bird and Little (1987) also maintained that "the test of instructional leadership is its influence on teaching at 
the level of the classroom" (p. 119). For Gorton and Thierbach-Schneider (1991), "the ultimate goal of instructional leadership should be to improve student learning, but its more immediate objective is to improve the instructional program" (p. 330). The study done by Bird and Little also found observation and supervision to be most important factors in the improvement of instruction.

In applying Leithwood's profile of effective instructional leaders specifically to instructional supervisors, Beach and Reinhartz (1989) characterized supervision as "leadership that serves to link the administrative and managerial functions with the curriculum and teaching functions through the focus on instruction" (p. 69). Weber (1987) noted that research suggests observation and feedback to be potentially one of the most effective methods of practicing instructional leadership, "for influencing higher expectations in instruction and, by extension, motivated outcomes in students" (p. 27), but questioned whether the complexities and constraints of managing a high school might not preclude the principal's directly carrying out such activities. In arguing for a shared model of instructional leadership, Weber (p. 30) declared that the high school department chair's greater familiarity with "effective teaching techniques or appropriate content area 
goals" may make him/her better qualified than the

principal to exercise this form of leadership. The point of view that as instructional leaders practicing supervision department chairs have the advantage of being subject matter specialists in their field as well as having an understanding of curriculum in their department was found in much of the literature (Bird \& Little, 1987; Gorton \& Thierbach-Schneider, 1991; Mitchell, 1990; Pellicer et al., 1990).

Organizational theory offered additional insight on the concept of leadership. Schools have been described as loosely coupled systems (Weick, 1989) with relatively low levels of interdependence among the various levels within the hierarchy, thus providing groups and individuals within them with a good deal of autonomy. This perspective has been used as a rationale for shared leadership (Glatthorn, 1990; Glatthorn \& Newberg, 1984), in which principals can delegate responsibility for instructional leadership functions to trusted subordinates, including department chairs. McLaughlin, Talbert, and Bascia (1990) added that

By broadening the structure of leadership to include teachers, secondary schools address - problems of scale while also concentrating both symbolic force and material resources in leaders who are close to the action, that is, directly knowledgeable about the subject area, the specific curriculum constraints and possibilities, the student population, and the faculty. (p. 241) 
Interviews and observations conducted at eight high school sites by Pellicer et al. (1990) led to the definition of instructional leadership as "the initiation and implementation of planned changes in a school's instructional program, through the influence and direction of the various constituencies in the school" (p. 31). Their studies concurred with Peterson's (1989) conclusions that instructional leadership is not a function solely of principals, but is a shared responsibility.

In contrast to Gorton and Thierbach-Schneider's (1991) contention that

in practice the department chair has frequently been grounded in the quicksand of administrative trivia and handicapped by inadequate released time to carry out instructional improvement activities, (pp. 134-135)

Pellicer et al. (1990) pointed to department chairs as most often being identified as major sources of instructional leadership. In their study of eight South Carolina schools (p. 31) they found the "most common pattern [to be] shared instructional leadership, with the administrative team (principals and assistants) providing support to department chairpersons who exercised functional leadership by working with faculty members in various departments."

Glatthorn and Newberg (1982) used interviews, observations, and a survey (the sources of Instructional Leadership, or SOIL, which identified 31 instructional 
leadership functions) in concluding after a 17-week study that sustained efforts in instructional leadership were often provided by a department chairperson. In questioning externally imposed teacher-leadership positions advocated by proponents of teacher empowerment, Johnson (1990) indicated:

many schools already have differentiated roles for teachers that have endured over time with the strong support of teachers . . . such as department heads in junior and senior high schools. (p. 131)

Noting the simultaneous teaching and administrative responsibilities of individuals in these positions, Johnson contended "they have credibility with teachers as few other administrators do" (p. 132). Other literature pointed to department chairs, given the opportunity to exercise leadership as an integral part of the school's administrative team, having the potential to shape curriculum and instruction by applying their subject matter and methodological expertise (DeRoche, Hunsaker, \& Kujawa, 1987; Gorton \& Thierbach-Schneider, 1991). Sergiovanni and starratt (1971) declared that The basic issue in regard to instructional leadership is simple: How do we reconcile the gap which frequently exists between the authority for leadership (by virtue of position) which supervisors have and the ability for leadership (by virtue of professional expertness) which subordinates have? (p. 97) 
Interrelationship of Top-down,

Bottom-up Perspectives

Wimpelberg (1987) generalized that "Linkages among roles and units based on the supremacy of hierarchy and leading to a predominance of 'top-down' decisions appears to be dysfunctional" (p. 105) as a means of bringing about instructional improvement. McLaughlin, Talbert and Bascia (1990) also criticized the effective schools reform model of examining site-level, top-down, principal-directed influences on student performance outcomes for being too limited in its focus. They supported productive teacher roles and dispositions, such as collegiality, teachers' involvement in decision making, increased instructional support, and resources for professional development as called for in several other research studies (Bacharach, Bauer, \& Shedd, 1986; Little, 1981; Rosenholtz, 1985; Rosenholtz, 1989). McLaughlin, Talbert, and Bascia referred to this perspective as "bottom-up" in that it "means looking at the important contexts of secondary school teaching through the eyes of teachers . . ." (p. 6). However, just as criticism has been directed at leadership approaches which are solely top-down, approaches which are primarily bottom-up have also been criticized as being largely dysfunctional in bringing about school improvement (Fullan, 1991; Wimpelberg, 1987). A major theme in Fullan's (1991) work on educational 
change was that "neither centralization nor

decentralization really works" (p. 211). Instead, there

is necessity for balance between the influence of upper

administration and the influence of members of the school

community. Both Fullan and Wimpelberg advocated a

combination of top-down and bottom-up collaborations as

the most effective means of fostering instructional

improvement.

Rather than the traditional hierarchical view of leadership which has been prevalent in school districts, Mitchell (1990) suggested a "re-visioning" of leadership as dialogical. "Dialogue assumes that an educational leader is looking at both sides of the total state of affairs in the educational process. Thus, the leader sees things from the viewpoint of the followers, as well as from his or her own viewpoint" (p. 239). Offering a perspective on shared leadership, sergiovanni and starratt

(1971) proposed that

The focus of instructional leadership [should be] to see that the process (instructional leadership) indeed does emerge, regardless of who the leader is, and that leadership efforts are consistent with the school's purpose... . Instructional leadership then occurs in a dynamic system of interchanging roles, with teachers, students, supervisors, administrators, and others assuming one role (client) or the other role (consultant) depending upon the uniqueness of circumstances. (p. 98)

Given the sheer magnitude of the structure and organization of secondary schools and the nature of 
competing constituencies and goals, Bird and Little (1987) suggested skilled teacher leaders spending substantial time supporting teachers in the classroom setting are necessary to the development of a collaborative culture in the secondary schools. The Mentor (Ohio) model, based on extensive research on instructional leadership and school culture, was suggested by Costanza, Tracy and Holmes (1987), who maintained that

Coordinators can function at the essence of the instructional improvement process: people, helping people, and when such cooperative efforts exist, the culture of the school becomes one of expectation of cooperative problem solving and instructional excellence. (p. 82)

This vision of leadership, which was further developed by case studies on the teacher workplace, depicts leader effectiveness as being largely influenced by the culture of the school, including the faculty, their beliefs and their behaviors (Bird \& Little, 1987; Lightfoot, 1983; Rosenholtz, 1985). In this bottom-up view of leadership, the informal leadership of the teachers within the cultural context of the school plays a key role. Peterson (1989) characterized school culture as "the implicit set of understandings that shapes teachers' views of reality, of teaching; and of the purposes of schooling" (p. 15).

Patterson, Purkey and Parker (1986, p. 48) defined the first dimension of organizational culture as beliefs-foundation norms and values which ideally provide 
people with the basis for all major decisions. The second dimension of organizational culture is the actual behavior of employees-the rites, rituals and routines of people within the organization. When taken together, the beliefs of the people within the organization and the daily behavior of the employees form tangible manifestations of school culture. Deal $(1987$, p. 7) maintained that "Culture imbues life with meaning and through symbols creates a sense of efficacy and control."

Mitchell (1990) contended that educational leaders should be concerned about "how and why people attach meanings to things, how and why these meanings change, and how and why people's meanings and people's actions are interconnected" (p. 209). Sergiovanni (1984) proposed that "The development of a culture of purpose, meaning, and commitment is the secret to quality leadership" (p. 502). Meaning is also a significant factor in Duke's (1987) discussion of what being a school leader means. Duke saw leadership in schools as "linked inextricably to helping others find meaning in their school experience," and further suggests that the close connection of the department chair to the instructional program may result in the chair's being "more apt to be aligned with what is meaningful to teachers than is the principal" (p. 290). Leithwood's (1992) case study of 12 "improving" schools indicated a primary factor in developing a 
collaborative, professional school culture was that

"school leaders actively communicated the school's cultural norms, values, and beliefs in their day-to-day interpersonal contacts" (p. 10). Stressing the significance of school culture in any successful improvement effort, Fullan (1991) said one should, "Assume that changing the culture of institutions is the real agenda, not implementing single innovations" (p. 107). Sergiovanni (1987) advised seeing leadership as "power to accomplish," focused on helping "people become more successful, to accomplish the things that they think are important, to experience a greater sense of efficacy" (p. 122) as distinguished from power over-controlling through dominance. Leithwood (1992) also argued for this kind of "transformational leadership," indicating it is "based on a form of power that is 'consensual' and 'facilitative' in nature-a form of power manifested through other people, not over them" (p. 18). Badaracco and Ellsworth (1989) pointed to two types of leadership which depend upon bottom-up influence. For the politically minded leader, it is important for "people at lower levels to have a sense of autonomy, control, and initiative" (p. 127). From the point of view of valuesdriven leadership, the leader relies "heavily on bottom-up decision making, with the knowledge that shared norms and values will help shape the decisions" (p. 128). 
"Top-Down, Bottom-Up: Not Either-Or, But Both" (Lieberman \& Miller, 1984) summarized the perspective on instructional leadership from which this study evolved. "Both policy from the top and engagement from the bottom deal with the process of improvement. One without the other leaves out a significant part of the [instructiona] improvement] process" (p. 92). As Mitchell (1990) contended,

Educational leaders are those who can take the fragments of the educational process and form a meaningful whole, an educational process where students and other constituents learn how to live a meaningful and worthwhile life. (p. 112)

Summary

Mirroring the national trend, the oregon reform agenda of the 1990 s clamors for teacher leadership stirred by compelling images of teacher empowerment, shared decision making, and site-based management. This study seeks to provide a foundation from which decisions about the teacher-department chair's future roles in instructional leadership can be made. Informed decisions require sound perspective; thus, this study seeks to discover the perceptions and expectations of high school academic department chairs in four disciplines (English, mathematics, science, and social studies) and those of the teachers with whom they work in those same disciplines-all 
of whose decisions and actions influence the role of the high school academic department chair.

To develop a sound basis for understanding the multidimensional nature of the leadership role of the high school academic department chair requires an understanding of the literature from several perspectives. First, the literature on the establishment and institutionalization of the department chair position was reviewed. Established to fill an important managerial role in the large, complex, departmentalized structure of the American high school, the department chair position is one of the few formal opportunities for teacher leadership. Although the position appears to be universal, the expectations for it have been poorly defined.

Next, in examining considerations for role effectiveness, a discussion of role theory has contributed to understanding that the ambiguity of the department chair position suggests different referent groups will hold different perceptions and different behavior expectations for the role, thus creating potential role conflict. An examination of research on gender differences has identified another potential source of role conflict in that male and female perceptions of and expectations for the role may differ from one another. The third section provides perspective on the construct of instructional leadership and its impact on 
instructional effectiveness. Effective schools research has identified strong principal leadership as a significant factor. However, the broad nature of the high school program with its specialized content areas requires a subject matter specific leadership. Much of the literature holds that the principal cannot be an instructional leader in all the specialized disciplines. One often-mentioned solution to the problem is to identify department chairs as appropriately providing instructional leadership at the classroom level. Some more recent research has been critical of the department chair role as perpetuating a hierarchical system of control in an era of collaboration and shared leadership.

The last section characterizes the school district as a dynamic system in which individuals at all levels of the organizational hierarchy perform interactive roles within the cultural context. From the perspective of the culture of the school system being loosely coupled, a combination of top-down, bottom-up collaboration is suggested to be most effective in bringing about instructional improvement, with leadership functions being distributed among several persons in the organization. This study, in conjunction with its companion study, The Voice of the Administrator (Korach, 1996), examines the nature of the instructional leadership role of the department chair as it is currently perceived-both from the top-down 
administrative perspective and from the bottom-up teacher perspective of the classroom teacher who is also an academic area department chair. The literature review thus provides a framework from which to investigate the perceptions of these referent groups in determining what has been most valued in the role of the high school academic department chair in the state of oregon and what is considered most important for the department chair to continue to improve, critical information from which to make decisions about the future of that role within the context of the current restructuring efforts. 
CHAPTER III

RESEARCH METHODOLOGY AND PROCEDURES

Overview

This study, in concert with its companion study, sought to offer a beginning step in establishing possibilities for the instructional leadership role of the high school academic department chair as a viable component of a restructured system of governance envisioned under school reform in oregon. Consistent with that purpose, this study investigated from the bottom-up contextual perspective of a high school English teacherEnglish department chair the perceptions of high school academic department chairs in four subject matter areas (English, math, science and social studies) and of high school teachers from those same subject matter areas. The intent of the study was twofold:

1. to develop a demographic profile of the respondents based upon the characteristics of age, gender, educational background, and educational experience; and

2. to determine the congruence of perceptions (a) between these two educator groups, and (b) between the male and the female study participants regarding: 
- the amount of department chair time spent on each activity specified in each category of department chair responsibility;

- the importance of each activity in each category to the role of the department chair;

- the importance of the department chair's continuing to improve in each activity in each category .

The narrative of this chapter, divided into six sections, provides a description of the methodology of the study. The first section identifies the general study hypotheses which the study investigated. The second section provides an overview of the study population. The third section details the development of the survey instrument that was utilized in the study. The fourth section describes the procedures followed for field testing the survey instrument. The fifth section explains the procedures followed in distributing, collecting, and monitoring returns of the survey instrument. The sixth section outlines the processes followed in the analysis, interpretation, and descriptive reporting of the data as detailed in chapter IV.

\section{Statement of the Problem}

This study investigates the degree of congruence in the perceptions of high school academic department chairs 
and high school teachers regarding five responsibilities defined for this study as comprising the role of the high school department chair:

1. responsibility for human relations,

2. responsibility for management,

3. responsibility for the organization,

4. responsibility for program, and

5. responsibility for supervision.

In examining these department chair responsibilities, this study focuses on three issues:

1. the amount of time spent by chairs in carrying out the responsibilities,

2. the importance of the responsibilities to the role of the department chair, and

3. the importance of the department chair's continuing to improve the performance of the responsibilities.

Study Hypotheses

General hypotheses developed to guide the statistical analysis portion of this study and stated in the null form for test purposes were as follows:

Hypothesis 1. Perceptions of department chair responsibilities in five categories (human relations, management, the organization, program, and supervision) will not differ significantly between high school academic 
department chairs and high school academic area teachers, grouped by role, on the issues of the amount of time the department chair devotes to each activity, the importance of each activity to the overall department chair role, and the importance of the department chair's continuing to improve in the performance of each activity.

Hypothesis 2. Perceptions of department chair responsibilities in five categories (human relations, management, the organization, program, and supervision) on the issues of time spent, importance to the role, and importance for the department chair to continue to improve will not differ significantly between high school department chairs and high school teachers as grouped by gender.

Hypothesis 3 . There will be no significant differences between male department chairs and teachers and female department chairs and teachers in their rank ordering of the importance of the five categories of department chair responsibility delineated for this study.

Hypothesis 4. Perceptions of department chair responsibilities in five categories (human relations, management, the organization, program, and supervision) will not differ significantly among high school department chairs grouped by the subject matter areas of English, math, science, and social studies on three issues: time 
spent, importance to the role, and importance for the department chair to continue to improve.

The Study Population

For purposes of this study and its companion study, Oregon school districts with total student populations of more than 3,000 but fewer than 12,000 students and with high schools designated as AAA (at least 650 students in grades 10-12) by the oregon School Activities Association were targeted. There were 31 school districts, which included 38 high schools, that were found to meet the defined criteria. Because the identified study population consisted of relatively few school districts, it was determined that all districts should be included.

After the researchers had received permission from the superintendents of each of the targeted districts for their districts to participate in the study, surveys were mailed to the superintendents of all 31 districts and to the principals and department chairs in the academic areas of English, math, science and social studies of the 38 high schools within those same districts. These four departments were selected because of the consistency with which they make up the academic core in the current high school organizational structure in oregon and because they comprise the majority of the high school teaching staff. 
Stratified random sampling was used to identify a $10 \%$ sample to be surveyed from the total population of 1446 teachers with the majority of their teaching assignments in these four academic departments in the 38 high schools. Questionnaires were then sent to 145 teachers, who proportionally represented the total defined teaching population.

When one principal returned the questionnaire indicating that department chairs were not part of the organizational structure in his building, all personnel from that school and its corresponding district were dropped, reducing the population for these companion studies to its final level: superintendents $(\underline{N}=30)$; high school principals $(\underline{N}=37)$; high school department chairs $(\underline{N}=148)$; and high school teachers $(\underline{N}=141)$, a $10 \%$ stratified random sample from the study population $(\underline{\mathrm{N}}=1407)$.

Development of the Instrument

To facilitate the descriptive purposes of these studies, the questionnaire was chosen as the method for gathering pertinent data for testing the hypotheses. The decision to use the survey format was prompted by several considerations, primarily those delineated by Ary, Jacobs, and Razavieh (1985, p. 344). 
1. It is a less time-consuming and less expensive method for obtaining desired information than the personto-person interview would be.

2. The confidentiality of responses offered by the questionnaire format may encourage more truthful responses than the interview would elicit.

3. Each respondent receives the same questions in the same format without the possibly intrusive presence of the interviewer's appearance, attitude, or behaviors.

4. The conscribed format of the questionnaire makes it easily adapted to computerized scoring, thus reducing the task of summarizing and comparing responses.

Construction of the survey instrument to be used in these companion studies was accomplished in several steps. First, a literature search utilizing the Educational Resources Information Center yielded more than 650 resources to be examined for relevance, most of which were journal articles and books located either in the Portland State University library or in the researchers' personal libraries. A search of Dissertation Abstracts was also conducted, with a total of six pertinent dissertations then being ordered from University Microfilms.

This extensive review of the literature and studies related to the role of the high school department chair established that no existing instrument would suffice to gather the required information to accomplish the purposes 
of these companion studies. While some similarities in topic and design were noted in previous studies (Price, 1969; Kirkland, 1978; Ritter, 1979; Orfinger, 1980), their differences in focus made those questionnaires unusable for purposes of these studies. Thus, as the second step in developing an effective and relevant questionnaire, a careful examination of several existing questionnaires and self-inventories categorizing and defining functions of the role of the high school academic department chair preceded the construction of tentative items (Anderson, 1987; Costanza et al., 1987; DeRoche et al., 1987; Duke, 1987; Glatthorn, 1990; Hatfield, Blackman, Claypool, \& Master, 1986; Sergiovanni, 1984; Weaver \& Gordon, 1979; Weber, 1987; Williams, 1979). Third, informed by this information base as well as by the two researchers' combined 55 years of experience in education (as high school English teachers, English department chairs and high school principal and superintendent), five categories of responsibility for the role of the high school academic department chair were identified and tentative descriptors for activities which would comprise each category were constructed.

Fourth, more exact and careful definition of the specific activities was accomplished through discussions with other administrators, high school department chairs, 
and high school teachers, none of whom would be part of the population to be studied.

The fifth step was to structure the questionnaire into five different sections.

Part I requested demographic information: gender, age, educational background (highest degree earned, major areas of study) and educational experience (teaching experience, teaching area, experience as an administrator-principal and/or superintendent).

Part II categorized 44 department chair activities under the five areas of department chair responsibility identified earlier (responsibilities for human relations, for management, for the organization, for program, and for supervision). Participants were asked to respond to each item on a five-point Likert-type scale from three different perspectives: the amount of time they perceived the department chair to spend in performing each activity; their perception of the importance of each specified activity to the role of the department chair; and their perception of the importance of the department chair's continuing to improve in each area.

Part III requested respondents to place the five categories of department chair responsibilities listed in Part II into rank order from 1 (most important) to 5 (least important) according to the respondents' perceptions of the importance of each area of 
responsibility to the role of high school academic department chair.

Part IV consisted of 12 statements of opinion regarding expectations for the instructional leadership role of the high school department chair. Respondents were asked to indicate on a five-point Likert-type scale the extent to which they agreed or disagreed with each statement: 1 (strongly disagree); 2 (disagree); 3 (neutral); 4 (agree); or 5 (strongly agree).

Part $\mathrm{V}$ was an open-ended question inviting participants to provide additional information, to make comments, and/or to clarify or expand upon any of their previous responses.

To help establish content validity and to solicit suggestions for improvement, the researchers submitted the instrument to a panel of four individuals knowledgeable in the field: two current high school academic department chairs, an English teacher, and a central office instructional supervisor, none of whom were to be included in the ensuing study. They were each asked to consider whether items were clearly understandable, whether each item was clearly related to the category of department chair activity into which it had been placed, and whether or not each item would elicit valid information. They were also asked to suggest any modifications and/or 
deletions as well as to indicate the amount of time required to complete the questionnaire.

Items which were considered vague or difficult for the respondent to answer were then modified for greater clarity. One activity in the second section was moved from the Responsibilities for the organization category to the Responsibilities for Human Relations category and one activity was added to the Responsibilities for Supervision category. One set of directions was also clarified and two opinion statements were more exactly worded.

\section{Field Test}

In order to continue to establish the reliability and validity of the instrument, a field test was conducted. Survey questionnaires were distributed to high school teachers, high school academic department chairs, high school principals, and central office administrators in a neighboring school district (again, none of whom were members of the targeted study group). Each was asked to provide feedback on the clarity of the instructions for completion and the clarity, adequacy and appropriateness of the selected role responsibilities in defining the department chair position. The 32 responses indicated that the directions were clear and that respondents agreed the defined responsibilities were appropriate in 
describing the position. The printed questionnaire required 20-25 minutes to complete.

Thus, content validity of the survey instrument was addressed through (a) careful examination of survey instrument items for direct relation to the categories of instructional leadership behaviors being defined, (b) alteration or modification of word choice to eliminate ambiguity, and (c) refinement of syntax to improve clarity. In view of these steps taken to improve the survey instrument, and affirmation received from the consulting practitioners and from the field test that it measured what it purported to measure, it was considered reasonable to assume that conditions for content validity and reliability of the survey instrument were met. The completed survey instrument, a copy of which may be found in Appendix A, was then forwarded to the Human subjects Research Review Committee at Portland State University for review.

Procedures for Data Collection

Names of superintendents and high school principals and addresses for individual districts and high schools were taken from the oregon school Directory (Oregon Department of Education, 1990). After permission to conduct the study had been obtained from the Central office of each targeted school district, questionnaire 
packets were mailed to each of the superintendents $(\underline{N}=30)$ and to the principals and the four academic area department chairs of each of the high schools ( $\underline{\mathbb{N}}=37$ ). Individual cover letters explained the importance and significance of the study, solicited the cooperation of the recipients in completing the questionnaire and offered to share the results of the study if requested. The letters also assured the anonymity of the responses. stamped, self-addressed envelopes were enclosed to encourage participants to respond quickly and to facilitate a greater number of responses. Copies of the cover letters are included in Appendix B. Stratified sampling was used to select teachers in each of the four academic departments from the individual high schools whose participation in the study would be requested. Telephone calls to each of the high schools ascertained the total population of teachers with the majority of their assigned classroom responsibilities in the targeted departments: English ( $\underline{N}=431)$; mathematics $(\underline{N}=323) ;$ science $(\underline{N}=286) ;$ social studies $(\underline{N}=367)$. All teachers were assigned numbers in sequence by specific departments by first listing the schools in alphabetical order and then noting the total number of teachers in each of the targeted departments in each school. A random number table was used to select the $10 \%$ sample from the total number of teachers in each of the targeted 
departments from all 37 schools. Packets were sent to the head secretary in each high school with the request that, using an alphabetical listing of teachers in each department, the secretary distribute the packets to the designated teachers who had been randomly selected (e.g., math teacher $\# 3$ on the alphabetical listing).

In order to facilitate the sending of follow-up letters as necessary, each return envelope was coded to the list of participants. Returned responses were checked off on the master list and the envelopes were then discarded, the identity of the respondents and their responses to the questionnaire remaining confidential.

Three weeks after the initial mailing, a follow-up letter was mailed to targeted participants who had not yet responded. Each letter included a second copy of the questionnaire, another request for participation, and a stamped, addressed return envelope.

The anticipated rate of return of the survey instrument was set at $70 \%$ so as to give credibility to the study. Of the 352 survey instruments distributed, 304 responses were received, an overall response rate of $86 \%$. Department chairs from four high schools responded that the disciplines of science and math were combined into one department in their buildings. Because each chair had filled out two separate questionnaires, the total population was reduced by two $(\underline{N}=35)$ for both 
mathematics and science department chairs, thereby reducing the overall study population of department chairs by four $(\underline{N}=144)$. Each chair's responses were counted in the discipline in which the survey instrument indicated the majority of the chair's classes were taught. out of the total of 304 survey instruments returned, seven were determined to contain insufficient information for them to be usable for purposes of this study. These adjustments reduced to 293 the usable responses from the 352 survey instruments originally distributed, for an overall usable response rate of $83 \%$. Rates and percentages of returns as well as usable responses are reported by educator group in Table 1.

Table 1

Questionnaire Returns by Educator Group

\begin{tabular}{lcccc}
\hline \multicolumn{1}{c}{ Educator Group } & $\begin{array}{c}\text { Number } \\
\text { Surveyed }\end{array}$ & $\begin{array}{c}\text { Number } \\
\text { Responding }\end{array}$ & $\begin{array}{c}\% \\
\text { Responding }\end{array}$ & $\begin{array}{c}\text { Number of } \\
\text { Usable } \\
\text { Responses }\end{array}$ \\
\hline Superintendents & 30 & 27 & 90 & 27 \\
Principals & 37 & 34 & 92 & 34 \\
Department Chairs & 144 & 122 & 85 & 118 \\
Teachers & 141 & 121 & 86 & 114 \\
\hline TOTALS & 352 & 304 & 86 & 293 \\
\hline
\end{tabular}

For the four separately identified high school academic department chair and four high school academic subject matter teacher populations, rates and percentages of returns as well as usable responses are reported by subject matter department chairs and teachers in Table 2. 
Table 2

Questionnaire Returns by Subject Matter Department Chairs and Teachers

\begin{tabular}{lcccc}
\hline Referent Group & $\begin{array}{c}\text { Number } \\
\text { Surveyed }\end{array}$ & $\begin{array}{c}\text { Number } \\
\text { Responding }\end{array}$ & $\begin{array}{c}\text { \% } \\
\text { Responding }\end{array}$ & $\begin{array}{c}\text { Number of } \\
\text { Usable } \\
\text { Responses }\end{array}$ \\
\hline Department Chairs & 144 & 122 & 85 & 118 \\
English & 37 & 33 & 89 & 31 \\
Mathematics & 35 & 29 & 83 & 29 \\
Science & 35 & 28 & 80 & 27 \\
Social Science & 37 & 32 & 86 & 31 \\
Teachers & 141 & 121 & 86 & 114 \\
English & 43 & 37 & 86 & 34 \\
Mathematics & 32 & 30 & 94 & 30 \\
Science & 29 & 25 & 86 & 24 \\
Social Science & 37 & 29 & 78 & 26 \\
\hline
\end{tabular}

\section{Treatment of the Data}

After questionnaires had been returned, data were entered into the SYSTAT (Wilkinson, Hill, \& Vang, 1992) for the Macintosh, Version 5.2 computer program for analysis, with findings being reported in primarily descriptive form. A narrative profile of the study population was constructed from demographic data also reported in tabular form. To facilitate analysis and comparisons of the descriptive questionnaire data among groups, frequency distributions were computed for all responses. Percentages, means, and standard deviations were reported and used to describe the total population as well as to describe groups differentiated by demographic characteristics. 
To develop a global perspective on possibilities for significant difference, a Pearson's matrix of probabilities was run for all responses. Chi-square values of frequencies of responses of high school department chairs and teachers and those of department chairs and high school principals for all items on the survey instrument were generated by computer analysis. Frequencies of responses of department chairs and teachers grouped according to gender were also compared by chisquare analysis. These computed chi-square values were used to test the null hypotheses. Results of the data analysis are reported in Chapter IV. 
CHAPTER IV

ANALYSIS OF THE DATA

Overview

Using an exploratory descriptive design, this study and its companion study (Korach, 1996) offer a first step in clarifying the instructional leadership potential of the role of the high school academic department chair in oregon, a position which has been largely ignored in recent educational reform efforts. In addressing that goal, this study speaks from the voice of the high school classroom teacher-department chair. To ascertain the qualities of that voice, this chapter presents, analyzes, and interprets the data obtained from responses to a researcher-constructed survey instrument designed to investigate the congruence of perceptions of high school academic department chairs and high school teachers about the role of the chair.

Specifically, the study focused on: (a) defining the role of the department chair (What does it look like in practice? How much time does it take?); (b) clarifying what is most valued in the role (What activities are most important?); and (c) extending the role (What is most 
important for the chair to continue to improve?) as part of an emerging educational reform effort in oregon.

From the broad array of data generated by the survey instrument, the major findings reported in the data analysis may be characterized as follows:

- Perceptions of time commitments for carrying out department chair responsibilities vary widely between high school department chairs and high school teachers.

- Perceptions of the manner in which the department chair role should be carried out vary less between department chairs and teachers than they do between males and females in the study.

- Perceptions of what is most highly valued in developing an improvement agenda for the department chair vary widely between males and females in the study.

The first section of the data analysis describes the demographic information from Part I of the survey, delineating the demographic characteristics of the high school department chairs and the high school teachers who participated in the study.

The second section presents data pertinent to Hypothesis 1. For each of 44 activities comprising five categories of department chair responsibility defined for this study-human relations, management, the organization, 
program, and supervision-respondents offered their

perceptions regarding three issues: the amount of time the department chair spends on the activity, the importance of the activity to the role of the department chair, and the importance for the chair to continue to improve in the performance of the activity. The distributions of responses of high school department chairs and high school teachers to the items in Part II of the survey instrument are described by percentages. Results of the chi-square test of the null hypothesis to determine differences in perceptions between the two groups considered significant at the $p=<.05$ level of confidence follow the description.

The third section of this chapter analyzes the data applicable to Hypothesis 2 . It examines differences determined to be significant at the $\underline{p}<.05$ level of confidence in perceptions between male high school department chairs and teachers and female high school department chairs and teachers regarding the five role responsibilities of the department chair.

The fourth section analyzes the data applicable to Hypthosis 3. It examines differences determined to be significant at the $\underline{\underline{1}}<.05$ level of confidence between the rank orderings assigned to the five categories of department chair responsibility by male department chairs 
and teachers and those assigned by female department chairs and teachers.

Section five presents some contextual data relative to a third hypothesis originally planned to be included in the study. As the computations were being carried out, it became clear that samples would be too small to provide conclusive results. However, some interesting trends did emerge that, while not conclusive, were useful in providing additional context for looking at the results of testing of Hypotheses 1, 2, and 3 .

\section{Demographic Characteristics}

One facet of this study was to investigate demographic factors in order to develop a profile of the typical high school academic department chair and the typical high school academic subject matter teacher who comprised the study population in oregon high schools. Respondents were requested to answer questions that provided demographic information in the following areas: gender, age, educational background (highest degree earned, major areas of study), and educational experience (teaching experience, teaching area, number of years in the current position, total years of experience in education).

This section reports demographic characteristics of the study participants in two parts. Tabular displays and 
descriptive highlights of the demographic characteristics of all respondents are followed by a narrative profile of the typical department chair and typical teacher respondent.

Department chairs and Teachers

\section{Personal Information}

Department chair and teacher respondents provided personal information (gender and age) as reported in Table 3.

Table 3

Personal Data

\begin{tabular}{|c|c|c|c|c|}
\hline \multirow[b]{2}{*}{ Characteristic } & \multicolumn{2}{|c|}{$\frac{\text { Department Chairs }}{(\underline{N}=118)}$} & \multicolumn{2}{|c|}{$\frac{\text { Teachers }}{(N=114)}$} \\
\hline & $\underline{n}$ & 8 & $\underline{\mathbf{n}}$ & $q$ \\
\hline \multicolumn{5}{|l|}{ Gender: } \\
\hline $\begin{array}{l}\text { Male } \\
\text { Female }\end{array}$ & $\begin{array}{l}91 \\
27\end{array}$ & $\begin{array}{l}77.12 \\
22.88\end{array}$ & $\begin{array}{l}68 \\
46\end{array}$ & $\begin{array}{l}59.65 \\
40.35\end{array}$ \\
\hline \multicolumn{5}{|l|}{ Age: } \\
\hline $\begin{array}{l}29 \text { or under } \\
30-39 \\
40-49 \\
50 \text { or over }\end{array}$ & $\begin{array}{r}1 \\
18 \\
65 \\
34\end{array}$ & $\begin{array}{r}0.85 \\
15.25 \\
55.08 \\
28.82\end{array}$ & $\begin{array}{l}5 \\
39 \\
51 \\
19\end{array}$ & $\begin{array}{r}4.39 \\
34.21 \\
44.74 \\
16.67\end{array}$ \\
\hline
\end{tabular}

Consistent with the traditional, historical pattern in education, males in this study occupy the majority of leadership positions even at this entry level of the organizational hierarchy. Ages of the highest number of 
both department chair and teacher participants were in the 40-49-year-old age range. Only five teachers (4.398) and one department chair $(0.85 \%)$ were under 30 years old.

\section{Educational Background}

Responses of study participants to questionnaire items regarding subject matter background and educational degrees earned are reported in Table 4.

Table 4

Educational Background of Participants

\begin{tabular}{|c|c|c|c|c|}
\hline Characteristic & \multicolumn{2}{|c|}{ Department Chairs } & & $\frac{\text { hers }}{114)}$ \\
\hline \multicolumn{5}{|c|}{ Highest Degree Earned: } \\
\hline $\begin{array}{l}\text { Bachelor's } \\
\text { Master's } \\
\text { Doctorate }\end{array}$ & $\begin{array}{r}19 \\
96 \\
3\end{array}$ & $\begin{array}{r}16.10 \\
81.36 \\
2.54\end{array}$ & $\begin{array}{r}24 \\
90 \\
0\end{array}$ & $\begin{array}{c}21.05 \\
78.95 \\
0\end{array}$ \\
\hline \multicolumn{5}{|c|}{ Major Area of study: } \\
\hline $\begin{array}{l}\text { English } \\
\text { Math } \\
\text { Science } \\
\text { Social Studies } \\
\text { Other }\end{array}$ & $\begin{array}{r}32 \\
29 \\
27 \\
30 \\
0\end{array}$ & $\begin{array}{c}27.12 \\
24.58 \\
22.88 \\
25.42 \\
0\end{array}$ & $\begin{array}{r}34 \\
33 \\
21 \\
26 \\
0\end{array}$ & $\begin{array}{l}29.82 \\
28.95 \\
18.42 \\
22.81 \\
0\end{array}$ \\
\hline
\end{tabular}

Study participants were found to have an extensive educational background. A substantial majority (about $80 \%$ ) of both department chairs and teachers had earned a master's degree. Three department chairs out of 118 had also earned a doctorate. All respondents had majored in 
one of the four academic disciplines defined for this study: English, mathematics, science, or social studies. Demographic data from each of the two aggregate categories (high school department chair and high school teacher) were further divided into these same four subject matter groupings (English, math, science, and social studies) according to current positions held by the respondents. These data are reported in tabular form in Appendix E.

\section{Educational Experience}

Table 5 reports the distribution of responses from high school teachers and department chairs regarding their educational experience.

Participants in this study were found to be experienced educators. Over 54\% reported 10-19 years of teaching experience, and the largest number (over 45\%) had been teaching in their present roles for 10 years or more. Teachers generally had held their current positions for longer periods of time than had department chairs. However, nearly $70 \%$ of department chairs reported more than 20 years of total educational experience. In contrast, only slightly over $30 \%$ of teachers had been in education for more than 20 years. 
Table 5

Educational Experience of Participants

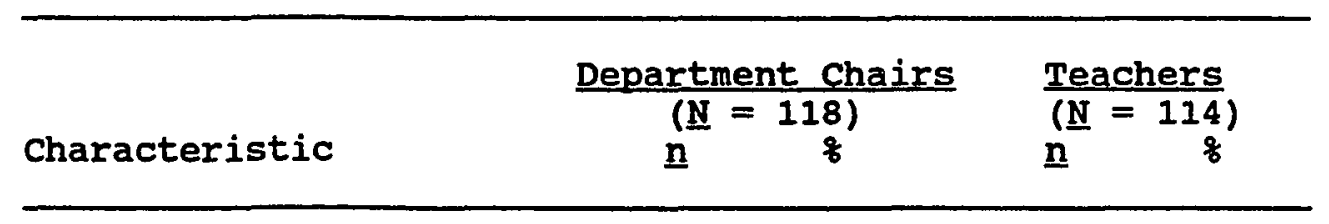

Total Years of Teaching Experience:

$\begin{array}{lrrrr}\text { fewer than } 5 & 8 & 6.78 & 4 & 3.51 \\ 5-9 \text { years } & 15 & 12.71 & 24 & 21.05 \\ 10-19 \text { years } & 64 & 54.24 & 62 & 54.39 \\ 20-29 \text { years } & 29 & 24.58 & 23 & 20.18 \\ 30 \text { years or more } & 2 & 1.69 & 1 & 0.88\end{array}$

Total Years in Current Position:

$\begin{array}{lllrr}\text { first year } & 22 & 18.64 & 6 & 5.26 \\ 2-4 \text { years } & 24 & 20.34 & 18 & 15.79 \\ 5-9 \text { years } & 33 & 27.97 & 37 & 32.46 \\ 10 \text { or more years } & 39 & 33.05 & 53 & 46.49\end{array}$

Total Years in Education:

\begin{tabular}{|c|c|c|c|c|}
\hline $\begin{array}{l}\text { fewer than } 10 \\
10-19 \\
20-29 \\
30 \text { or more years }\end{array}$ & $\begin{array}{r}6 \\
34 \\
57 \\
21\end{array}$ & $\begin{array}{r}5.09 \\
28.81 \\
48.31\end{array}$ & $\begin{array}{l}24 \\
55 \\
30\end{array}$ & $\begin{array}{l}21.05 \\
48.25 \\
26.32\end{array}$ \\
\hline
\end{tabular}

\section{Characterization of current}

Position

Department chairs were also asked to provide information to help characterize their current position. A complete display of department chair responses to these additional demographic questions is provided in Table 6 . 
Table 6

Demographic Information Regarding Department Chair Positions, Subjects: High School

Department Chairs $(\underline{N}=118)$

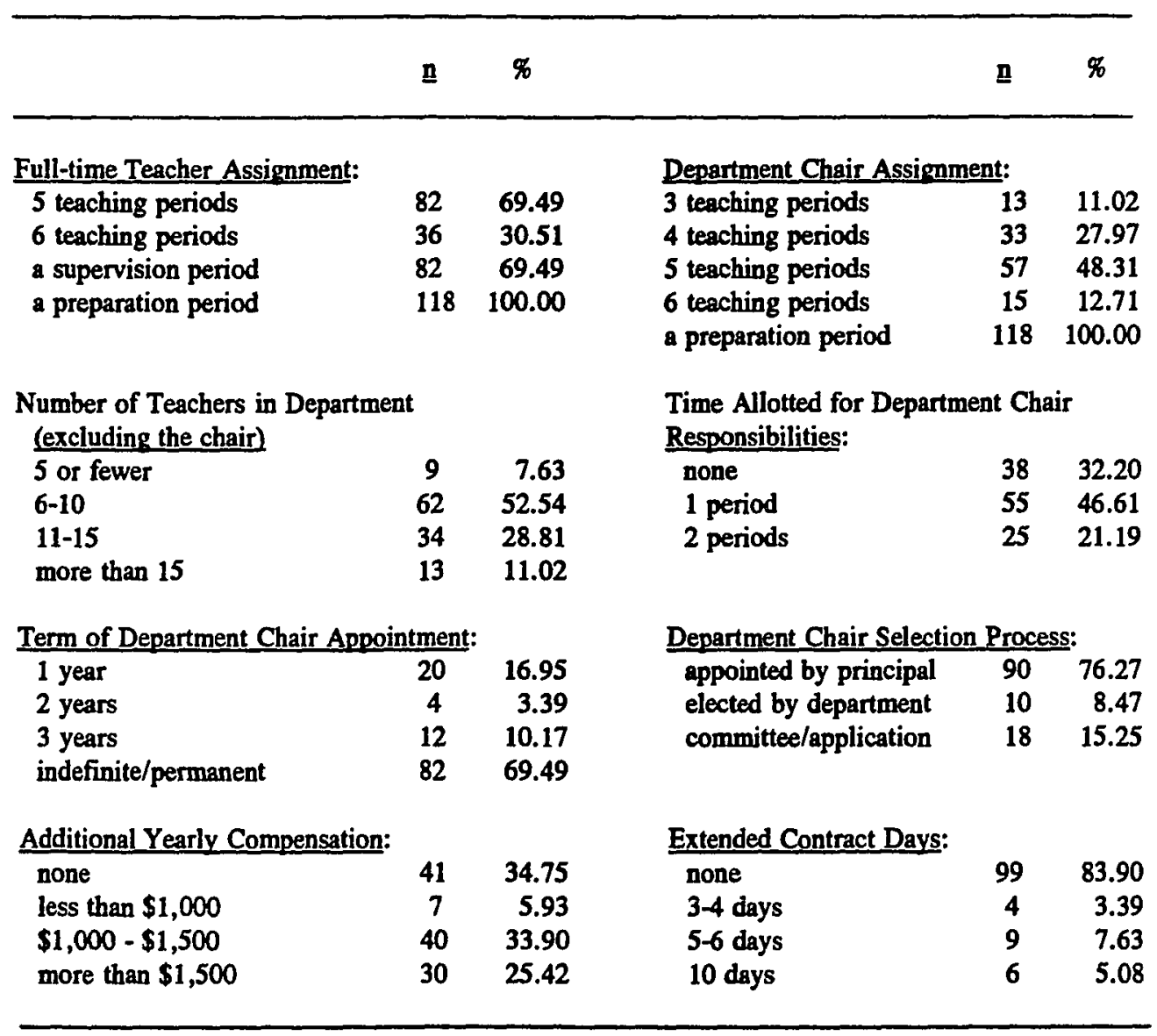

A seven-period instructional day was universal in the oregon high schools participating in this study. The majority of the department chairs (698) indicated that a full-time assignment for teachers in their department was five classes. The greatest number of chairs (53\%) were responsible for a department of 6-10 teachers. 
Department chairs were typically appointed by the principal (76\%) on a permanent basis or for an indefinite time period (698).

\section{Demographic Profiles}

One purpose of this study was to develop a profile of the respondents-the typical high school academic department chair and the typical high school academic area teacher. The most noticeable detail in the demographic data was that in the high school population defined for this study, both teaching and department chair positions in all subject matter areas were dominated by males. Of additional note was that very few department chairs were under the age of 40 , perhaps a result of the majority of the chairs having been appointed for an indefinite period of time. From the information reported by study participants, the following profiles were constructed.

1. The typical high school department chair was a male between the ages of 40 and 50 who had taught between 10 and 20 years in the academic area which had been his major area of study. Having earned a master's degree, he had been appointed by his principal to his department chair position, which he had held for at least 10 years. Responsible for between 6 and 10 teachers in his department, he receives $\$ 1,000$ in additional compensation and is given one instructional period per day to devote to his department chair role. 
2. Of the 118 high school department chairs who responded to the survey instrument

- 27 were female; 91 were male

- 31 were English department chairs; 29 were math chairs; 27 were science chairs; 31 were social studies chairs

- 99 were 40 years of age or older; 19 were under 40

- the largest number of chairs over $50(\underline{n}=12)$ were English department chairs

- 96 had earned a master's degree; 3 held doctorates; 19 had a bachelor's degree.

3. The profile of the typical high school teacher participant was almost identical to that of his department chair. He was a male, between 40 and 50 years old, who reported between 10 and 20 years of teaching experience in his major area of study. He had been in his current position for at least 10 years and had earned a master's degree.

4. Of the 114 high school academic area teachers who participated in the study,

- 46 were female; 68 were male

- 34 were English teachers; 30 were math teachers; 24 were science teachers; 26 were social studies teachers

- 70 were 40 years of age or older; 39 were 30-39 years old; 5 were under 30 
- the 19 teachers 50 years of age or older were distributed fairly evenly across the four departments

- 90 had earned a master's degree; 24 held a bachelor's degree; none had earned a doctorate.

\section{The Voice of the Classroom Teacher- Department Chair}

As a beginning step in establishing the potential value of effective top-down, bottom-up collaborations to instructional improvement within the emerging context of educational reform in Oregon, this study provides a teacher-department chair voice on the role of the high school academic department chair as that role is perceived by high school department chairs and teachers in a selected group of oregon high schools.

The voice of the teacher-department chair is spoken from the perspective of those who are responsible for the delivery of the instructional program, those who actually perform in the context of the teaching-learning process. While the principal has general overall knowledge of what constitutes good instruction as well as some idea of what should be going on in the academic departments, the administrative voice is, in general, one that is removed from practice. Department chairs have more highly specific and specialized knowledge-a theoretical understanding of a discipline and what instruction should 
be in the discipline-that is also shaped and informed by firsthand knowledge gained through the continuing experience of practice in the classroom. Department chairs are not only experts in the subject matter area, but are the ones experiencing firsthand what that theoretical program (the program in concept) actually looks like when it is taught-applied in practice. Thus, the teacher-department chair voice is a perspective that combines theory with practice in carrying out the responsibilities comprising the role of the high school academic department chair as defined for the purposes of this study.

Data Analysis

SYSTAT (Wilkinson, Hill, \& Vang, 1992) for the Macintosh, Version 5.2, was used on a Power Macintosh 6100 for the statistical analysis of the data. Frequency distributions were compiled and percentages of responses were computed for high school department chair and teacher responses classified by time, importance, and importance to improve for each of the activities in five categories of department chair responsibility. These data can be found in Appendix C, Charts Cl through C5. Means and standard deviations, reported in Appendix $C$, Charts $C 6$ through C10, were calculated for all responses from each group according to current role. To determine if significant differences $(p<.05)$ existed among the 
differences $(\underline{Q}<.05)$ existed among the distribution of responses, chi-square values were then computer generated.

Data analysis in this section is organized according to the five categories of department chair responsibility delineated for this study: Human Relations, Management, the Organization, Program, and Supervision. Findings address two areas: (a) the perceptions of department chairs and teachers as separate groups regarding activities in the five categories of responsibility comprising the role of the high school academic department chair, and (b) the degree of congruence between the perceptions of the two groups on each of three issues -time spent, importance to the role, and importance for the chair to continue to improve-in regard to each of those activities.

Preliminary chi-square analysis of frequency distributions revealed several expected cell sizes smaller than the five responses required to conduct a valid chisquare test. Examination of the patterns of those responses further established that frequency distributions for levels 1 (no time, no importance) and 2 (little time, little importance) offered no meaningful discrimination for purposes of this study. Consequently, these two sets of responses were collapsed for descriptive and testing purposes. Because frequency distributions for levels 4 (a good deal of time, very important) and 5 (a great deal of 
time, extremely important) did provide useful distinctions in addressing the intent of this study to offer suggestions for the development of an improvement agenda for the department chair, responses at the upper end of the scale were not collapsed.

\section{Responsibility for Human}

\section{Relations}

For this study, the department chair Responsibility for Human Relations category encompasses the following nine activities:

HR-1. Build and maintain a supportive department team

HR-2. Encourage open communication among department members

HR-3. Facilitate effective conflict resolution

HR-4. Foster cooperative problem solving

HR-5. Encourage trust, caring, and respect among department members

HR-6. Maintain regular, open communication with department members

HR-7. Practice collaborative, participative decision-making processes

$\underline{\mathrm{HR}-8}$. Promote an atmosphere that encourages continuous improvement

HR-9. Encourage department members to share in leadership roles. 
Study participants were asked to address three separate issues in relation to each of these eight activities:

- Time - amount of department chair time spent on the activity

- Role - importance of the activity to the role of the department chair

- Improve - importance for the chair to continue to improve in the activity.

Responses of department chairs. In the category of Responsibility for Human Relations, department chairs most highly valued communication with the members of their department. The greatest numbers of department chairs saw maintaining regular, open communication with department members (HR6) as the most time-consuming activity; $72 \%$ of the chairs rated it as requiring either a good deal or a great deal of time. That activity also received the highest ratings from $92 \%$ of department chairs on the issue of its importance to the department chair role. Department chairs ( $86 \%$ ) rated encouraging open communication among department members (HR2) as most important to their own improvement efforts; promoting an atmosphere that encourages continuous improvement (HR8) was identified by $84 \%$ of the chairs as also important to their own improvement. 
Facilitating effective conflict resolution (HR3) received the greatest percentages of low ratings from department chairs from all three perspectives. In relation to time spent, $37 \%$ perceived themselves to spend little or no time; $10 \%$ rated it as having little or no importance to the role; and 98 perceived it to be of little or no importance for the chair to continue to improve.

Responses of high school teachers. High school teachers similarly valued communication, concurring with chairs that communication with department members (HR6) was the activity which consumed the greatest amount of department chair time in this category. However, $75 \%$ of the chairs indicated they spend at least a good deal of time maintaining communication with their department members, whereas just $53 \%$ of the teachers perceived their chairs to devote that much department chair time to maintaining communication. Teachers' responses (40\%) that their chairs spend little or no time facilitating effective conflict resolution (HR3) paralleled those reported by department chairs.

Most teachers (93\%) saw encouraging open communication among department members (HR2) as very important to the role of the department chair. Teachers (92\%) also pointed to maintaining regular, open communication with department members (HR6) as being very 
important. These perceptions of the importance of communication to the role of chair were congruent with those of the department chairs.

The activity teachers rated least important was encouraging department members to share in leadership roles (HR9). It received the least (54\%) very or extremely important ratings for any activity in the category; it also received the most ratings of moderate or below (35\%).

For the issue of the importance for the chair to continue to improve, teachers continued to focus on communication. Maintaining regular, open communication with department members (HR6) had the highest percentage of extremely important ratings (49\%), followed closely (48\%) by encouraging open communication among department members (HR2). For the teachers in this study, the activity least important for the chair to continue to improve in the human relations category was again encourage department members to share in leadership roles (HR9). It was considered of moderate importance or less by $32 \%$, while fewer teachers indicated it was very important (38\%) or extremely important (25\%) than was true for any other activity in this category.

Summary. Seven of the nine activities in the Responsibility for Human Relations category were considered to be either very important or extremely 
important by more than $75 \%$ of both the department chairs and the teachers (see Appendix C), both for their importance to the role of the department chair and for their importance for the chair to continue to improve. These responses attest to the high value both groups place upon the chair's Responsibility for Human Relations. Department chairs, however, perceived themselves to spend considerably more time than teachers perceived them to spend in encouraging trust and sharing. (HR5), maintaining regular, open communication (HR6), practicing collaborative decision-making processes (HR7), and promoting an atmosphere of continuous improvement (HR8). The majority of department chairs indicated they spend a good deal or a great deal of time on all four activities; the most teachers perceived chairs to spend only a moderate amount of time. A much higher percentage of teachers than department chairs also perceived department chairs to spend little or no time on every activity in the Responsibility for Human Relations category.

\section{Responsibility for Management}

As defined for this study, eight specific activities comprise the Responsibility for Management category, traditionally an expectation for the role of the department chair.

MG-1. Develop department teaching schedule and assignments 
MG-2. Participate in the selection of department instructional personnel

MG-3. Develop and administer the department budget

MG-4. Disseminate information to department staff

MG-5. Allocate and maintain equipment, instructional materials, and facilities

MG-6. Interpret and apply district policy and building standards

MG-7: Plan and organize relevant department meetings MG-8. Serve as liaison between department members and the administration.

Study participants were asked to address three separate issues in relation to each of these eight activities:

Time - amount of department chair time spent on the activity

- Role - importance of the activity to the role of the department chair

- Improve - importance for the chair to continue to improve in the activity.

Responses of department chairs. The highest percentage of department chairs (70\%) rated serving as liaison between department members and the administration (MG8) as occupying the most time as well as being most important for the chairs to continue to improve (41\%) in the management category. The greatest percentages of 
department chairs (47\%) rated both disseminating information to department staff (MG4), and serving as liaison between department members and the administration (MG8) as extremely important to the role of the chair. Participating in the selection of department personnel (MG2) was also considered to be extremely important by $45 \%$ of the department chairs.

Responses of teachers. In contrast to the department chairs, teachers $(70 \%)$ saw the most time-consuming management activity to be developing and administering the department budget (MG3). More than $80 \%$ of the teachers also saw budgeting to be highly important to the role of the chair. However, the greatest percentage of teachers (86\%) rated serving as liaison between department members and the administration (MG8) as most important to the role of the chair. Developing the department teaching schedule and assignments (MG2) was highly valued by $75 \%$. As perceived by the teachers, the most important management activities for the department chair to continue to improve were serving as liaison between department members and the administration (46\%) and developing department teaching schedule and assignments (42\%).

Summary. The patterns of response seemed to indicate that, despite some differences, there is a high degree of congruence in the value high school department chairs and teachers place on the management role of the department 
chair as well as in perceptions of the amount of department chair time devoted to management activities.

Responsibility for the organization

Eight activities were identified for this study in the category of department chair Responsibility for the Organization:

OR-1. Engage department members in an organized department growth and improvement effort

OR-2. Represent the department in developing and implementing the school's organized improvement effort

OR-3. Serve as department spokesperson at community and board meetings

OR-4. Prepare requested information on department topics for administration

OR-5. Act as advocate for the protection of classroom instructional time

OR-6. Support teachers' professional needs and concerns

OR-7. Work with other department chairs to develop an integrated school instructional program

OR-8. Participate in curricular planning and decision making at the district level.

Responses of department chairs. In the category of Responsibility for the organization, the greatest numbers 
of department chairs (51\%) saw themselves devoting the greatest amounts of department chair time to representing the department in developing and implementing the school's organized improvement effort (OR2).

Department chairs indicated they valued the importance of working with other department chairs to develop an integrated school instructional program (OR7), and participating in curricular planning and decision making at the district level (OR8) with their highest percentage of extremely and very important ratings (69\%). Acting as an advocate for protection of classroom time (OR5) was nearly as highly valued by $64 \%$ of the chairs. For the issue of most importance for department chairs to continue to improve in carrying out their Responsibility for the organization, the highest percentage of chairs (67\%) rated working with other department chairs to develop an integrated school instructional program (OR7) most highly.

Responses of teachers. Teachers' perceptions of the distribution of department chair time varied more than they did on other issues in this category. The highest percentage (18\%) felt that supporting teachers'. professional needs and concerns (OR6) took a great deal of time. The two activities the most teachers valued most highly in the role of the chair were supporting teachers' professional needs and concerns (OR6), which $76 \%$ 
considered to be very or extremely important, and acting as an advocate for protection of classroom time (OR5), rated as very or extremely important by $75 \%$. Even greater percentages of teachers (77q) valued supporting teachers' professional needs and concerns (OR6) as being most important for department chairs to continue to improve in the category of Responsibility for the Organization; $74 \%$ also rated acting as an advocate for protection of classroom time (OR) highly for the improvement agenda.

Summary. For the issue of importance to the role of the department chair and the issue of importance for the department chair to continue to improve, high school teachers rated protecting classroom instructional time and supporting teachers' professional needs and concerns as most important. Both activities are ones that would be considered to have the most immediate impact upon the personal, day-to-day activities of teachers. In contrast, department chairs seemed to reflect a stronger valuing of organizational concerns. Their highest ratings of importance were for working with other department chairs to develop an integrated school instructional program and participating in curricular planning and decision making at the district level. 
Responsibility for Program

The category of department chair Responsibility for Program is made up of eight activities for purposes of this study:

PG-1. Facilitate development of curriculum (philosophy, goals, objectives)

PG-2. Supervise the implementation of curriculum PG-3. Monitor the continued maintenance of curriculum

PG-4. Devise and implement process for program evaluation

PG-5. Provide leadership in selection/development of instructional materials

PG-6. Coordinate departmental selection of textbooks and supplemental materials

PG-7. Assess learning outcomes to identify program strengths and weaknesses

PG-8. Establish goals for program improvement. Responses of department chairs. The two program activities rated by more than one half the department chairs (56\%) as most time-consuming were coordinate selection of textbooks and supplemental materials (PG6), and facilitate development of curriculum (PG2). Activities the most department chairs (31\%) perceived to be extremely important to their department chair role were facilitating development of curriculum (PGI) and 
supervising the implementation of curriculum (PG2). These same activities were marked as very important by an additional $47 \%$ and $42 \%$. Establish goals for program improvement (PG8) also received high ratings for its importance to the role. One fourth (25\%) of the chairs rated it as extremely important, while another 498 saw it as very important.

Identifying activities most important for department chairs to continue to improve in their Responsibility for Program, the most chairs (74\%) marked facilitating development of curriculum (PGI), followed by establishing goals for program improvement (PG8), $72 \%$.

Responses of teachers. In regard to program, the highest percentage of teachers $(618)$ perceived that providing leadership in the selection and development of instructional materials (PG5) consumed at least a good deal of department chair time. Rating program activities for their importance to the role of the department chair, teachers valued facilitate development of curriculum (PG1) as very or extremely important (71\%). Assess learning outcomes to identify program strengths and weaknesses (PG7) was rated as very or extremely important for the department chair to continue to improve by 69\%; facilitate development of curriculum (PG1) and establish goals for program improvement (PG8) were similarly valued by $68 \%$. 
Summary. In the category of Responsibility for Program, several contrasts were apparent in department chairs' and teachers' valuing of activities. The greatest difference between department chair responses and teacher responses in this category was that chairs perceived monitoring the continued maintenance of curriculum (PG3) to be more important to the role and more important for the chair to continue to improve than the teachers perceived it to be. Interestingly enough, it was the teachers who perceived assessing learning outcomes to identify program strengths and weaknesses (PG7) to be more important, both to the role of the chair and for the chair to continue to improve, than did the chairs themselves.

\section{Responsibility for Supervision}

Even though supervision was one of the role functions originally identified as part of the department chair position, expectations are not well defined. Based upon the review of the literature as well as the experience of the researchers, eleven different activities were delineated as comprising the category of department chair Responsibility for supervision for purposes of this study. SP-1. Model a variety of instructional strategies SP-2. Assist teachers in developing professional growth plans

SP-3. Encourage experimentation and innovation among teachers 
SP-4. Coordinate instruction among department members

SP-5. Observe teachers in their classrooms and provide feedback

SP-6. Monitor teacher lesson plans

SP-7. Practice clinical supervision (pre-conference, observation, post-conference)

SP-8. Communicate high expectations for teacher performance

SP-9. Assist teachers with the improvement of their instruction

SP-10. Organize plan for teacher sharing, peer coaching (e.g., videotaping)

SP-11. Evaluate teacher performance. For each activity in the Responsibility for Supervision category, study participants were asked to respond from the perspectives of the three issues defined for the questionnaire: the amount of department chair time spent, importance to the role of the department chair, and importance for the chair to continue to improve.

Responses of department chairs. Many of the activities under the Responsibility for supervision category were marked by department chairs as accounting for little of their time. Notably, most department chairs indicated that they spend little or no time to monitor teacher lesson plans (SP6), 91\%, practice clinical 
supervision (SP7), $82 \%$, or evaluate teacher performance (SP11), 82\%. Only two activities were perceived by more than $25 \%$ of the chairs to consume either a good deal or a great deal of time: encourage experimentation and innovation among teachers (SP3), 298, and coordinate instruction among department members (SP4), 318.

The highest percentages of department chairs agreed on the importance to the role of the department chair of assisting teachers in developing professional growth plans (SP2) and encouraging experimentation and innovation among teachers (SP3), both of which were extremely important to 25\%, very important to $41 \%$.

From the perspective of importance for the department chair to continue to improve, 698 of the chairs perceived encouraging experimentation and innovation among teachers (SP3) as very or extremely important. coordinating instruction among department members (SP4) was perceived to be very or extremely important by $64 \%$.

Responses of teachers. The teachers in this study concurred with the department chairs that a good many of the activities in the Responsibility for supervision category were on the low end of the scale relative to the amount of department chair time they consumed, with $86 \%$ indicating that department chairs spent little or no time monitoring teacher lesson plans (SP6), $81 \%$ marking practicing clinical supervision (SP7) as taking little or 
no time, and $73 \%$ stating chairs spent little or no time in evaluating teacher performance (SPI1).

From the point of view of the high school teachers, the supervision activity most important to the department chair role was encouraging experimentation and innovation among teachers (SP3), which 648 of the teachers perceived to be very or extremely important. It was also the activity which the highest percentage of teachers (66\%) rated as very or extremely important for the department chair to continue to improve.

Summary. The lower percentages of 4 and 5 ratings given by department chairs in the Responsibility for Supervision category in comparison to those in the other four suggest that department chairs place less value on supervision than they place on their responsibilities in other role categories. Somewhat paradoxically, department chairs perceived coordinating instruction among department members to be the activity on which they spend the most supervisory time as well as having the most importance to the role and being the most important for chairs to improve, whereas teachers perceived chairs to spend the most time encouraging experimentation and innovation among teachers-a supervision behavior most highly valued by teachers both for its importance to the role of the chair and for its importance for the chair to continue to improve. 
Testing of Hypothesis 1

Hypothesis 1 was stated in the null form for test purposes: Perceptions of department chair activities in five categories of responsibility (human relations, management, the organization, program, and supervision) will not differ significantly between high school academic department chairs and high school academic area teachers, grouped by role, on three issues: the amount of time the department chair devotes to each activity, the importance of each activity to the overall department chair role, and the importance of the department chair's continuing to improve in the performance of each activity.

Null Hypothesis 1 was tested by chi-square analysis for each activity in Part II of the survey instrument. Three issues were examined: the amount of time the department chair devotes to each activity, the importance of each activity to the overall department chair role, and the importance of the department chair's continuing to improve in the performance of each activity. It was determined that differences considered significant at the $\underline{p}<.05$ level of confidence would allow for the rejection of the null hypothesis.

As depicted in Table 7, responses from high school department chairs and high school teachers to 44 activities in five categories of department chair responsibilities yielded significant chi-square values at 
a $\underline{p}<.05$ level of confidence on a total of 21 activities. The null hypothesis was, therefore, rejected.

\section{Table 7}

Summary of Chi-square Values Indicating Significant Differences $(\mathrm{p}<.05)$ in Perception of Department Chair Activities in Five Categories of Responsibility, Subjects: High School Department Chairs $(\underline{\mathrm{N}}=118)$ and High School Teachers

$$
(\underline{\mathrm{N}}=114)
$$

\begin{tabular}{llrrrr}
\hline Activity & Issue & $\underline{\mathbf{N}}$ & $\chi^{2}$ & $\underline{\text { df }}$ & $\mathbf{p}^{*}$ \\
\hline HR1 & Time & 232 & 9.861 & 3 & 0.020 \\
HR2 & Time & 232 & 16.581 & 3 & 0.001 \\
HR3 & Importance & 232 & 7.916 & 3 & 0.048 \\
HR3 & Improvement & 232 & 9.518 & 3 & 0.023 \\
HR5 & Time & 232 & 21.412 & 3 & 0.000 \\
HR6 & Time & 232 & 27.149 & 3 & 0.000 \\
HR8 & Time & 232 & 11.712 & 3 & 0.008 \\
MG8 & Time & 232 & 15.703 & 3 & 0.001 \\
OR2 & Time & 232 & 8.058 & 3 & 0.045 \\
OR3 & Time & 232 & 12.245 & 3 & 0.007 \\
OR3 & Importance & 232 & 8.786 & 3 & 0.032 \\
OR5 & Improvement & 232 & 14.178 & 3 & 0.003 \\
OR6 & Improvement & 232 & 11.228 & 3 & 0.011 \\
PG2 & Importance & 232 & 8.118 & 3 & 0.044 \\
PG3 & Time & 232 & 8.371 & 3 & 0.039 \\
PG5 & Time & 232 & 15.022 & 3 & 0.002 \\
PG7 & Time & 232 & 10.529 & 3 & 0.015 \\
PG8 & Time & 232 & 8.876 & 3 & 0.031 \\
SP4 & Time & 232 & 11.022 & 3 & 0.012 \\
SP5 & Time & 232 & 9.315 & 3 & 0.025 \\
SP11 & Importance & 232 & 11.470 & 3 & 0.009 \\
& & & & & \\
\hline
\end{tabular}

*Level of Significance

Responsibility for Human Relations

In the category of Responsibility for Human Relations, a major finding was that department chairs 
perceived themselves to devote substantially higher amounts of time to five of the nine activities than the teachers perceived their chairs to spend on those activities: build a department team (HRI); encourage communication among departmetn members (HR2); encourage trust, caring, and respect among department members (HR5); maintain communication with department members (HR6; and promote an atmosphere that encourages continuous improvement (HR8).

From the perspective of the teachers, facilitate effective conflict resolution (HR3) was considered to be higher in its importance to the role of the department chair than it was rated by the chairs themselves. Teachers also perceived that facilitating effective conflict resolution was more important for the department chairs to continue to improve than the chairs perceived it to be.

\section{Responsibility for Management}

There was virtual agreement between department chairs and teachers in their perceptions regarding department chair Responsibility for Management, indicating their congruent valuing of management activities to the role of the chair and for the chair to continue to improve. The only statistically significant difference was found in the perception of time chairs spent in serving as a liaison between department members and the administration (MG8). 
Chairs indicated a higher amount of time spent than did teachers.

Responsibility for the

organization

Department chairs perceived themselves to be spending more time representing the department in developing and implementing the school's organized improvement effort (OR2) than teachers felt chairs were spending. On the other hand, the perception of teachers was that serving as a department spokesperson at community and board meetings (OR3) both required more department chair time and was more important to the role of the department chair than the chairs perceived it to be. Teachers also rated higher than did the department chairs the importance for the department chair to continue to improve in acting as an advocate for the protection of classroom instructional time (OR5) and supporting teachers' professional needs and concerns.

\section{Responsibility for Program}

Time issues were again a source of statistically significant differences between department chairs and teachers in the category of Responsibility for Program. Department chairs perceived themselves to spend higher amounts of time than teachers perceived them to spend on four activities: monitor the continued maintenance of curriculum (PG3); provide leadership in the selection and 
development of instructional materials (PG5); assess learning outcomes to identify program strengths and weaknesses (PG7; and establish goals for program improvement (PG8).

Responsibility for Supervision

Only three statistically significant differences were found between the perceptions of department chairs and teachers in the category of department chair Responsibility for supervision. Department chairs perceived themselves to spend more time coordinating instruction among department members (SP4) than teachers perceived chairs to spend, whereas teachers saw chairs as spending more time in teacher observation (SP5) than the chairs perceived themselves to spend. Teachers' perceptions of the importance to the department chair role of evaluating teacher performance (SP11) were higher than those of the department chairs.

\section{Summary}

Null Hypothesis 1 was rejected. Statistical examination revealed that significant differences at the $\underline{p}<.05$ level of confidence did exist between the perceptions of high school teachers and high school department chairs with regard to activities in five role responsibilities. Of the 21 activities for which statistically significant differences were found between 
the perceptions of department chairs and the teachers in their departments regarding the instructional leadership role of the department chair, 14 reflected differences in perceptions of the amount of time devoted to the activity.

In regard to the importance of specific activities to the role of the department chair, perceptions of high school department chairs and high school teachers were not congruent on four of the 44 activities across the five categories of role responsibility. However, congruence of perceptions on 40 of the 44 activities also suggested that both groups held fairly clearly defined and similar expectations for what that role should encompass.

The issue of importance for the department chair to continue to improve generated the remaining three significant incongruent perceptions, with teachers more highly valuing all three activities for department chairs to improve than did the chairs themselves: facilitate effective conflict resolution (HR3); act as an advocate for the protection of classroom instruction (OR5); and support teachers' professional needs and concerns (OR6). Perceptions of teachers and department chairs regarding the issue of importance for the department chair to continue to improve were congruent for each of the other 41 activities. 
Testing of Hypothesis 2

Hypothesis 2 was stated in the null form for test purposes: Perceptions of department chair activities in five categories of responsibility (human relations, management, the organization, program, and supervision) will not differ significantly between male high school academic department chairs and teachers and female academic department chairs and teachers on three issues-the amount of time the department chair devotes to each activity, the importance of each activity to the overall department chair role, and the importance of the department chair's continuing to improve in the performance of each activity. Frequency distributions can be found in Appendix D, Charts D1 through D5. For a differing view, means and standard deviations can be found in Appendix D, Charts D6 through D10.

As summarized in Table 8 , chi-square analysis of differences in frequencies of responses by male and female high school department chairs and teachers to activities in all categories of department chair responsibilities yielded significant chi-square values at $a \underline{p}<.05$ level of confidence on a total of 24 items, nearly half of which reflected differences in perceptions regarding activities in Responsibility for Human Relations. 
Table 8

Summary of Chi-square Values Indicating Significant

Differences $(\mathrm{p}<.05)$ in Perceptions of Male and Female High School Department Chairs and

Teachers Regarding Activities in Five

Categories of Department Chair

Responsibilities, Subjects:

Males $(\underline{N}=159)$, Females

$(\underline{N}=73)$

\begin{tabular}{llcccc}
\hline Activity & Issue & $\mathbf{N}$ & $\boldsymbol{X}^{2}$ & df & $\mathbf{p}^{*}$ \\
& & & & & \\
\hline HR1 & Time & 232 & 10.632 & 3 & 0.014 \\
HR3 & Improvement & 232 & 9.625 & 3 & 0.022 \\
HR4 & Improvement & 232 & 13.773 & 3 & 0.003 \\
HR5 & Importance & 232 & 11.903 & 3 & 0.008 \\
HR5 & Improvement & 232 & 16.730 & 3 & 0.002 \\
HR6 & Improvement & 232 & 11.638 & 3 & 0.009 \\
HR7 & Importance & 232 & 15.324 & 3 & 0.002 \\
HR7 & Improvement & 232 & 17.175 & 3 & 0.001 \\
HR8 & Importance & 232 & 15.695 & 3 & 0.001 \\
HR8 & Improvement & 232 & 14.297 & 3 & 0.003 \\
MG1 & Time & 232 & 13.462 & 3 & 0.009 \\
MG2 & Time & 232 & 11.283 & 3 & 0.010 \\
MG2 & Importance & 232 & 10.908 & 3 & 0.012 \\
MG8 & Improvement & 232 & 11.586 & 3 & 0.009 \\
OR1 & Importance & 232 & 10.068 & 3 & 0.018 \\
OR1 & Improvement & 232 & 10.081 & 3 & 0.018 \\
OR2 & Improvement & 232 & 10.516 & 3 & 0.015 \\
OR6 & Improvement & 232 & 10.868 & 3 & 0.012 \\
OR7 & Importance & 232 & 8.006 & 3 & 0.046 \\
OR7 & Improvement & 232 & 10.132 & 3 & 0.017 \\
PG8 & Importance & 232 & 9.091 & 3 & 0.028 \\
PG8 & Improvement & 232 & 8.600 & 3 & 0.035 \\
SP1 & Importance & 232 & 12.459 & 3 & 0.006 \\
SP3 & Importance & 232 & 8.014 & 3 & 0.046 \\
& & & & & \\
\hline
\end{tabular}

*Level of Significance

The issue of time was the source of differences for

only three activities. For 21 activities, however, males

and females revealed differing perceptions of what they

valued either in the role of the department chair or in 
what was most important for the chairs to continue to improve. Wherever significant differences were found-for all activities in all categories of department chair responsibility from all three perspectives-responses of female study participants were higher than were those of male participants. Therefore, Null Hypothesis 2 was rejected.

\section{Responsibility for Human}

Relations

Chart DI (see Appendix D) reports frequency distributions of male and female department chair and teacher responses for activities in the category of Responsibility for Human Relations.

Males perceived chairs to spend greater amounts of time in building a supportive department team (HRI), encouraging open communication among department members (HR2), encouraging trust, caring and respect (HR5), and maintaining regular, open communication with department members (HR6) than females perceived the chairs to spend. However, each of those activities was considered more highly valued by females than by males, both for its importance to the role and its importance to improve. with respect to only two activities, both addressing the need for communication (HR2 and HR 6), did more than $90 \%$ of the male department chairs and teachers as well as $90 \%$ of the females indicate the activities were very 
important or extremely important to the role of department chair. In contrast, however, more than $90 \%$ of the female department chairs also gave such high ratings to four other activities: building a supportive department team (HR1); encouraging trust, caring, respect among department members (HR5); practicing collaborative, participative decision making (HR7); and promoting an atmosphere that encourages continuous improvement (HR8). More than $90 \%$ of the female respondents also perceived those same six activities to be very or extremely important to the improvement agenda for department chairs. No activity in this category was rated that highly by the same percentage of male respondents, just over $84 \%$ of whom again gave (HR2) the highest rating for the issue of improvement. All other activities in the Responsibility for Human Relations category received higher ratings from greater percentages of females than from males in response to all three issues, suggesting that regardless of the position held, females tend to value human relations activities more highly overall than do males.

\section{Responsibility for Management}

Chart D2 (see Appendix D) reports frequencies of male and female responses for the management category of department chair responsibility.

In the Responsibility for Management category, both male and female department chairs and teachers perceived 
the most time-consuming activity to be developing and administering the department budget (MG3). With the exception of allocating and maintaining equipment and supplies (MG5), all other activities in this category were considered by females to consume more time than males felt they required.

In addressing the management activities considered most important to the role of the department chair, more than $90 \%$ of the females in this study pointed to participating in the selection of department instructional personnel (MG2) and serving as liaison between department members and the administration (MG8). The highest percentage of males concurred that the department chair liaison role was most important.

More than 908 of female respondents felt disseminating information to department staff (MG4) was the most important activity for department chairs to continue to improve. Both males and females saw interpreting and applying district policy and building standards (MG6) as the least important activity for chairs to improve.

With only two exceptions, for all activities in the Responsibility for Management category, greater numbers of females gave higher ratings for all three issues. As compared to the females in the study, males perceived developing and administering the department budget (MG3) 
to be slightly more important to the role of the department chair, and allocating and maintaining equipment, instructional materials, and facilities (MG5) to require slightly more time.

Responsibility for the organization

Frequency distributions of responses offered by male department chairs and teachers and by female chairs and teachers in the category of Responsibility for the organization are delineated for comparison in Chart D3 (see Appendix D).

For the category of Responsibility for the Organization, the highest percentages of female respondents again gave the highest ratings to the majority of the activities. Only two activities received higher percentages of 4 or 5 ratings, both in regard to the issue of time, from males: representing the department in developing and implementing the school's organized improvement effort (OR1) and supporting teachers' professional needs and concerns (OR6).

The greatest percentage of female respondents (81\%) identified working with other department chairs to develop an integrated school instructional program (OR7) to be either very important or extremely important to the role of the department chair as well as to be most important for the department chairs to continue to improve. 
Engaging department members in an organized department growth and improvement effort (OR1) was also considered by females to be an important activity for chairs to continue to improve.

\section{Responsibility for Program}

The frequency distribution of all responses from male department chairs and teachers and from female department chairs and teachers in the category of department chair Responsibility for Program is presented in Chart D4 (see Appendix D) .

Examination of the ratings assigned by males and females to the activities in the Responsibility for Program category identified a similar pattern to that already established for the preceding categories. The percentages of females giving 4 and 5 ratings are higher in nearly every instance.

Males did perceive providing leadership in the selection and development of instructional materials (PG5) and assessing learning outcomes to identify program strengths and weaknesses (PG7) to require slightly more time than did females. In addition, for all three issues-time spent, importance to the department chair role, and importance for the chair to improve-males gave coordinating departmental selection of textbooks and supplemental materials (PG6) higher ratings. 
Both groups rated all activities in the Responsibility for the organization category as being very important both to the role and for the chair to continue to improve; however, no activity in this category was valued by either group as extremely important in regard to either issue.

Responsibility for supervision

Chart D5 (see Appendix D) gives frequencies of responses from all male department chairs and teachers and from all female department chairs and teachers to all three issues with respect to activities in the category of department chair Responsibility for supervision.

In the Responsibility for supervision category, the differences in strength of responses between males and females are even more pronounced than they were found to be for the previous categories. Only for the issue of time in regard to three activities did males offer higher ratings than did females. Coordinating instruction among department members (SP4), monitoring teacher lesson plans (SP6), and evaluating teacher performance (SP11) were all perceived by males to require slightly more time than females perceived them to require. Mean scores of responses from females were higher for 30 of the 33 items specified under Responsibility for Supervision (see Appendix D, Chart D15). 
Responsibility for human relations. As indicated in Table 8 , significant differences in perceptions between males and females were found on ten items in this category of responsibility. Females perceived department chairs to spend more time building and maintaining a supportive department team (HRI) than did males. On the issue of importance to the role of the department chair, females considered three human relations activities to be more important than did males: encouraging trust, caring, and respect among department members (HR5); practicing collaborative, participative decision-making processes (HR7) $;$ and promoting an atmosphere that encourages continuous improvement, (HR8).

For six human relations activities, female responses were higher than were those of males on the issue of the department chair's continued improvement: facilitate effective conflict resolution (HR3); foster cooperative problem solving (HR4); encourage trust, caring, and respect among department members, (HR5); maintain regular, open communication with department members (HR6); practice collaborative, decision-making processes (HR7); and promote an atmosphere that encourages continuous improvement (HR8).

Responsibility for management. Females perceived chairs to spend more time than males perceived them to spend on developing department teaching schedules and 
assignments (MG1) and participating in the selection of department personnel (MG2). Females also rated participating in the selection of department personnel higher in its importance to the role of the department chair than males rated it. The one activity which females rated higher than males in its importance for the department chair to continue to improve was serving as liaison between department members and the administration (MG8) •

Responsibility for the organization. Engaging department members in an organized department growth and improvement effort (OR1) was rated higher by females than by males both for its importance to the role of the department chair and for its importance for the department chair to continue to improve.

Females perceived representing the department in the school's organized improvement effort (OR2), supporting teachers' professional concerns (OR6), and working with other department chairs to develop an integrated school instructional program (OR7) all to be more important for the department chair to continue to improve than males perceived them to be.

Responsibility for program. There was virtual agreement between males and females in their perceptions regarding department chair Responsibility for Program. Significant chi-square statistics were produced for only two items. Females perceived establishing goals for 
program improvement (PG8) to be more important to the role of the chair than males perceived it to be and to be more important for the department chair to continue to improve. Responsibility for supervision. Again, male and female perceptions in this category were nearly congruent. The only noticeable differences were in females' perception that modeling a variety of instructional strategies (SP1) and encouraging experimentation and innovation among teachers (SP3) were of higher value in their importance to the role of the department chair than males perceived them to be.

\section{Testing of Hypothesis 3}

This pattern of differences between responses of male department chairs and teachers and female department chairs and teachers was further strengthened by the rankings of importance assigned to the five categories of department chair responsibilities by each gender group. Hypothesis 3 was stated in the null form for test purposes: There will be no significant differences between male department chairs and teachers and female department chairs and teachers in their rank ordering of the importance of the five categories of department chair responsibility delineated for this study. Table 9 gives the frequencies and percentages of respondents assigning each of the five rankings to each category of department chair responsibility. 
Table 9

**Rank Ordering of Importance of Five Categories of Department Chair Responsibility

as Perceived by Male High School Academic Department Chairs and High School

Teachers and Female High School Academic Department Chairs and High

School Teachers [BY Frequencies and Percentages of Respondents

Giving Each Ranking] Males ( $\underline{N}=159)$; Females $(\underline{N}=73)$

\begin{tabular}{|c|c|c|c|c|c|c|c|c|c|c|c|}
\hline \multirow{2}{*}{$\begin{array}{l}\text { Category of } \\
\text { Responsibility }\end{array}$} & \multirow[b]{2}{*}{ Gender } & \multicolumn{2}{|r|}{1} & \multicolumn{2}{|r|}{2} & \multicolumn{2}{|c|}{$\begin{array}{c}\text { Rankings } \\
3\end{array}$} & \multicolumn{2}{|r|}{4} & \multicolumn{2}{|r|}{5} \\
\hline & & $\underline{n}$ & $q$ & $\underline{n}$ & 8 & $\underline{n}$ & $\%$ & $\underline{n}$ & 8 & $\underline{n}$ & $\frac{9}{8}$ \\
\hline Human Relations & $\begin{array}{l}\text { Male } \\
\text { Female }\end{array}$ & $\underline{66}$ & $\begin{array}{l}43.22 \\
43.84\end{array}$ & $\frac{27}{\underline{24}}$ & $\begin{array}{l}22.03 \\
32.88\end{array}$ & $\frac{21}{10}$ & $\begin{array}{l}10 \cdot 17 \\
13 \cdot 70\end{array}$ & $\underline{34}$ & $\begin{array}{r}17.80 \\
6.85\end{array}$ & $\frac{11}{2}$ & $\begin{array}{l}6.78 \\
2 \cdot 74\end{array}$ \\
\hline Management & $\begin{array}{l}\text { Male } \\
\text { Female }\end{array}$ & $\underline{\frac{33}{20}}$ & $\begin{array}{l}22.03 \\
27.40\end{array}$ & $\frac{35}{15}$ & $\begin{array}{l}21 \cdot 19 \\
20.55\end{array}$ & $\frac{33}{14}$ & $\begin{array}{l}21 \cdot 19 \\
19.18\end{array}$ & $\frac{47}{17}$ & $\begin{array}{l}33 \cdot 35 \\
23 \cdot 29\end{array}$ & $\frac{11}{7}$ & $\begin{array}{l}4.24 \\
9.59\end{array}$ \\
\hline The Organization & $\begin{array}{l}\text { Male } \\
\text { Female }\end{array}$ & $\frac{19}{7}$ & $\begin{array}{r}11.02 \\
9.59\end{array}$ & $\frac{47}{15}$ & $\begin{array}{l}22.84 \\
20.55\end{array}$ & $\frac{47}{22}$ & $\begin{array}{l}29.66 \\
30.14\end{array}$ & $\frac{36}{24}$ & $\begin{array}{l}28.81 \\
32.88\end{array}$ & $\frac{10}{5}$ & $\begin{array}{l}7.63 \\
6.85\end{array}$ \\
\hline Program & $\begin{array}{l}\text { Male } \\
\text { Female }\end{array}$ & $\underline{31}$ & $\begin{array}{l}18.64 \\
17.81\end{array}$ & $\frac{43}{12}$ & $\begin{array}{l}28.81 \\
16.44\end{array}$ & $\underline{45}$ & $\begin{array}{l}32.36 \\
28.77\end{array}$ & $\frac{29}{22}$ & $\begin{array}{l}16.95 \\
30.14\end{array}$ & $\frac{11}{\underline{5}}$ & $\begin{array}{l}4.24 \\
6.85\end{array}$ \\
\hline Supervision & $\begin{array}{l}\text { Male } \\
\text { Female }\end{array}$ & $\frac{8}{1}$ & $\begin{array}{l}3.39 \\
1.37\end{array}$ & $\frac{6}{7}$ & $\begin{array}{l}4.24 \\
9.59\end{array}$ & $\frac{13}{6}$ & $\begin{array}{l}4.24 \\
8.22\end{array}$ & $\frac{13}{5}$ & $\begin{array}{l}5.08 \\
6.85\end{array}$ & $\frac{119}{\underline{54}}$ & $\begin{array}{l}79.66 \\
73.97\end{array}$ \\
\hline
\end{tabular}

* Scale was $1=$ of most importance through $5=$ of least importance 
Application of the chi-square test to frequencies of these responses yielded a significant chi-square value for Responsibility for Human Relations, $\chi^{2}(4, \underline{N}=232)=$ $13.670, \mathrm{p}<.05$. Female high school department chairs and teachers were found to place higher value on the department chair's Responsibility for Human Relations than did male high school department chairs and teachers. Therefore, Null Hypothesis 3 was rejected.

Rankings assigned by male high school department chair and high school teacher respondents seemed to differ greatly from those of female high school department chairs and teachers for two categories of department chair responsibility. As shown in Table 9, 66\% $(\underline{n}=104)$ of the male chairs and high school teachers ranked the Responsibility for Human Relations as either the first or the second most important category of department chair responsibility. However, more than three fourths $(77 \%$, $\underline{n}$ $=56$ ) of the female high school department chair and high school teacher respondents valued Responsibility for Human Relations as either the most important or second most important category of responsibility. At the opposite end of the continuum, $25 \%(\underline{n}=39)$ of the male respondents rated human relations as either fourth or fifth in importance of the five categories of department chair responsibility, whereas only $10 \%(\underline{n}=7)$ of the female 
respondents saw human relations as fourth or fifth in importance.

A reverse trend emerged in the rankings given to Responsibility for Program. This category was perceived to be either first or second in importance by $47 q(\underline{n}=75)$ of the male department chairs and teachers, with just over one third $(34 \%, \underline{n}=25)$ of the female respondents ranking program as either first or second in importance. Conversely, $37 q(\underline{n}=27)$ of the female high school department chairs and teachers ranked program activities as either fourth or fifth in importance, whereas only $21 \%$ $(\underline{n}=15)$ of the male respondents perceived program responsibilities to be valued as fourth or fifth in importance of the five categories of department chair responsibilities.

Clearly, the data show that statistically significant differences do exist between the perceptions of male high school department chairs and teachers and female department chairs and teachers in regard to the value placed upon the five categories of department chair responsibility.

\section{Discussion of Hypothesis 4}

In the Owens (1981) model of role conflict, in addition to differing perceptions of subordinates (teachers) and superordinates (administrators), differing 
perceptions of the role of the department chair held by the department chair's colleagues (academic chairs in other departments) were considered to constitute a source of potential role conflict. The fourth hypothesis originally intended for this study addressed the issue of the impact of dissension among one's peers on one's role performance:

Perceptions of department chair responsibilities in five categories (human relations, management, the organization, program, and supervision) will not differ significantly among high school department chairs grouped by the subject matter areas of English, math, science, and social studies on three issues: time spent, importance to the role, and importance for the department chair to continue to improve.

The relatively small sample size caused numbers of expected responses to be insufficient to draw valid statistical conclusions. However, the number of department chairs who responded to the survey represented from $80 \%$ (science) to $89 \%$ (English) of the total population targeted for this study in each discipline. The data are strong, suggesting patterns of differences that would bear further investigation in exploring potential sources of role conflict among colleagues as educational reform efforts continue to evolve in the 
oregon high schools delineated for this study. Hypothesis 4 was therefore converted from a working hypothesis to a contextual data hypothesis. The purpose of this discussion is to compare responses among the four groups of high school department chairs, considering additional background perspective and insight such comparisons may offer regarding conclusions reached for Hypothesis 1 , Hypothesis 2, and Hypothesis 3.

Appendices E, F, $G$ and $H$ provide the data base for this discussion. Demographic data supplied by department chairs are grouped in Appendix E according to the four subject matter areas delineated for this study: English, math, science, and social studies.

Appendix $F$ reports frequency distributions of department chair responses by academic discipline. Responses are paired in tabular form by the traditionally complementary humanities-oriented academic disciplines of English with social studies and the traditionally complementary technically oriented academic disciplines of math with science. Appendix $\mathrm{G}$ gives means and standard deviations for those same responses. Appendix $\mathrm{H}$ reports preliminary chi-square testing, which small sample sizes prevented from yielding statistical conclusions. However, results did suggest support for a pattern of differences in perception among chairs from different departments which had been noted in the frequency distributions. 
Responses by department chairs from the four disciplines demonstrated evident differences in perception regarding how department chair time was allocated, what activities were considered most important to the role of the department chair, and what activities were most important to include on the improvement agenda for department chairs.

A pattern of valuing communications activities was consistent across the disciplines.

- For all activities in the category of Human Relations Responsibility, the highest number of English department chairs gave higher ratings than those given by any other group of chairs.

- Mean scores of English chairs were consistently the highest on all three issues for all nine activities in the Human Relations category. In contrast, mean scores of math chairs were lowest among the four groups for two thirds (18 out of 27) of the items (see Appendix G, Chart G1).

- Few appreciable differences in perception, and only on issues of time, were demonstrated between English and social studies chairs or between math and science chairs.

- Social studies and math chairs appeared to differ in their perceptions of the importance of Human Relations and Program activities, with social 
studies chairs valuing those activities more highly than did math chairs.

- Perceptions of English chairs and science chairs seemed to differ more widely than those of social studies and science chairs.

- Perceptions of English chairs and math chairs appeared to differ much more greatly than those of any other paired group of department chairs.

- For the majority of activities, the greatest numbers of English department chairs consistently gave higher ratings than those given by any of the other chairs.

- Conversely, for the majority of activities, the greatest numbers of math chairs almost as consistently gave the lowest ratings of any of the chairs.

The data are strong, and it appears reasonable to speculate that significant differences in perceptions may exist among high school academic department chairs who represent different academic disciplines. These data suggest that high school English department chairs and social studies department chairs are more closely aligned to one another in their perceptions than they are to either science or math department chairs. At the same time, the data suggest that math and science department chairs are more closely aligned to one another in their 
perceptions than they are either to social studies or English department chairs.

The two departments with the greatest number of significant differences in perception were English and math. A continuum depicting the degree of congruence among the perceptions of the department chairs from the four academic disciplines would then extend from English department chairs on one extreme to math department chairs on the other extreme, with social studies department chairs more closely aligned to English chairs and science department chairs more closely aligned to math department chairs.

The value of these data to interpreting the conclusions derived for Hypothesis 1 Hypothesis 2, and Hypothesis 3 is to offer a caution about the application of those conclusions to any specific subject matter area, even within the study population. The data used in testing Hypotheses 1, 2, and 3 were not differentiated by subject matter respondents. The foregoing discussion of that same data suggests that substantial differences may exist among the chairs of the four different academic disciplines represented in this study. Therefore, the generalizations drawn from grouping the data may not apply to a particular discipline.

In testing Hypothesis 2 , statistically significant differences $(\underline{p}<.05)$ were found between perceptions of 
males and females regarding more than one half of the activities comprising the five categories of department chair responsibility. These results were further strengthened by the statistically significant difference in male and female rankings of the importance of the five categories of responsibility found in testing Hypothesis 3. Demographic data grouped by academic discipline (see Appendix E) indicate that very few of the chairs in three of those disciplines are female. Only in English were a majority of the chairs found to be female. Since female department chairs are the exception rather than the rule among the study population, much greater role conflict may be experienced by individual female department chairs than the results of this study would indicate. These contextual considerations for interpreting results of the study suggest the need for additional studies of perceptions of department chairs, perhaps including a wider geographical area, in order to provide a large enough study population to investigate the generalizability of these results. 


\section{CHAPTER V}

SUMMARY, CONCLUSIONS, AND RECOMMENDATIONS

Summary

Motivated by the researchers' belief in the value of top-down, bottom-up collaborations for effective instructional improvement decision making, this study and its companion study, The Voice of the Administrator, an unpublished doctoral dissertation by william Anthony Korach (1996), were designed to investigate the traditionally ambiguous role of the high school academic department chair from two voices: that of the top-down administrative perspective and that of the bottom-up high school academic department chair-teacher perspective. The purpose of these companion studies was to offer an initial step in clarifying what has been perceived to be of most value under the existing high school organizational structure. Specifically, these studies sought to identify and to construct comparative analyses of the perceptions of four different groups of educators regarding the nature and the value of the role of the high school department chair as it is currently practiced in a narrowly defined group of oregon high schools. The intention was to be 
able to offer perspective to guide the possible reshaping of that role within the context of evolving educational reform efforts in oregon.

Assumptions of the study

This study originated from several assumptions regarding the importance of the role of the high school academic department chair to the structure and operation of the Oregon high school. These assumptions were the following:

1. The role of the high school academic department chair is currently an important part of the instructional leadership structure in oregon high schools.

2. The high school academic department chair will continue to play a valuable role in the organizational structure of public high schools.

3. The lack of congruence in values and expectations among referent groups who influence the role of the department chair can have a negative impact on the chair's role performance.

4. Lack of congruence in values and expectations between the chairs themselves and their superordinates (superintendents/principals), their subordinates (teachers), and/or their colleagues (chairs in other academic departments) can have a negative impact on department chairs' role performance. 
5. A measure of the congruence of these values and expectations could be determined by surveying the perceptions of superintendents, high school principals, high school academic department chairs, and high school academic subject matter teachers on specific department chair activities comprising five categories of department chair role responsibility in relation to time spent, importance to the role, and importance for the department chair to continue to improve.

6. One means of increasing the probability of high school department chairs becoming more effective in their role would be to focus on a combination of top-down, bottom-up collaborations among individuals in key organizational roles, including superintendents, high school principals, high school academic department chairs, and high school teachers.

\section{objectives of the study}

From the perspective of the high school academic department chair as a role player (Bennis, 1966) in an organizational hierarchy whose role performance is being impacted by superordinates (administrators), subordinates (teachers), and colleagues (chairs in other departments), this study addressed three major objectives:

1. To determine if perceptions of high school academic department chairs and high school academic subject matter teachers were congruent on each of three 
issues (time, importance to the role, and importance to continue to improve) with respect to activities defined by the researchers as comprising five areas of responsibility for the role of the high school department chair:

- responsibility for human relations

- responsibility for management

- responsibility for the organization

- responsibility for program, and

- responsibility for supervision.

2. To determine if perceptions of males and females in the study population were congruent on the issues of time, importance to the role, and importance to improve regarding activities in the five areas of role responsibility of the high school department chair as they had been defined for this study.

3. To determine if perceptions of department chairs among the four academic disciplines targeted for this study (English, mathematics, science, and social studies) were congruent on the issues of time, importance to the role, and importance to improve regarding activities in the five areas of their role responsibility as they had been defined for this study.

\section{Limitations of the study}

1. The findings reported in this study are specific to the state of Oregon in AAA high schools in school districts with a total district population of under 12,000 
students. These findings could be generalized to other high schools with similar conditions but should not be generalized with complete confidence outside the state of oregon.

2. This study addresses the role of the high school academic department chair only in relation to 44 activities defined by the researchers as comprising five areas of department chair responsibility: human relations, management, the organization, program, and supervision. Department chairs undoubtedly engage in many activities which were not addressed by the survey instrument. Therefore the general trends identified in this study are confined to the perceptions of the respondents regarding a limited number of department chair activities.

3. The study population was restricted to only those department chairs in the academic disciplines of English, mathematics, science, and social studies. Conclusions may not be generalizable to chairs in other subject matter areas.

4. Although a very high percentage of high school department chairs targeted for participation in this study responded to the survey instrument (English 89\%; math 83\%; science $80 \% ;$ social studies $86 \%$ ) the limited size of the study population restricted the conclusions which could be 
reached by comparing the responses among the four groups of department chairs.

\section{Theoretical Framework}

The theoretical framework which guided this study was derived from a review of the literature. First, literature on the establishment and institutionalization of the high school department chair position characterized the nature of the department chair position to be one of wide disparity and resultant ambiguity. Second, the importance of role clarity, the impact of the perceptions and expectations of others on the role, and the need for congruence of expectations for effective role performance were substantiated by a review of role theory and studies on role effectiveness. Additionally, literature on gender studies suggested a relationship between one's gender and one's perceptions of role and behavior expectations as well as perceived effectiveness of role performance. Third, a review of effective schools literature provided a definition of instructional leadership that was applied to role expectations for the department chair for the purposes of this study. Finally, literature on the school district as a dynamic system was reviewed, establishing the importance of understanding instructional leadership role expectations from both the top-down administrative perspective of superintendents and high school principals and the bottom-up instructional 
perspective of high school department chairs and high school teachers.

Informed by these theoretical perspectives, this study and its companion study (Korach, 1996) comprise conversations between two voices-the voice of the administrator and the voice of the teacher-department chair-to offer a comprehensive "top-down," "bottom-up" perspective on the instructional leadership role of the department chair. As such, these studies provide a basis for dialogue about the possible reshaping of that role in the evolving context of educational reform in oregon.

\section{Summary of the Findings}

1. Findings in this study support the conclusions of earlier researchers (Fish, 1976; Gorton \& ThierbachSchneider, 1991; Hord \& Murphy, 1985; Lieberman \& Miller, 1984; Wasley, 1991) that the role of the high school academic department chair continues to be ambiguous. Perceptions of department chairs and teachers were congruent for many of the activities in the five categories of responsibility comprising the department chair role. At the same time, however, significant differences were found regarding at least one issue for an activity in each category, a total of 21 of the 44 activities in the five categories, most of them on the issue of the amount of time spent. 
2. Significant differences in perception regarding the role were found to exist between high school teachers and high school department chairs. From these differences it was concluded that the department chair will likely experience role conflict generated by attempts to meet expectations from subordinates (teachers) for his/her role performance which are different from his/her own perceptions of what that performance should be, potentially leading to subsequent lack of effectiveness in role performance as well as discontent within the department.

3. Significant differences in perception by gender were also found to exist, implying an even greater potential for role conflict for the department chair. Demographic data generated by this study establish that a majority of chairs of high school academic departments and even a majority of high school teachers in the study population are male. As W. A. Korach (1996) found, 24 of the 27 high school principals and all 34 superintendents in the study population were also male. Role conflict therefore may be particularly high for female high school department chairs. Not only are they potentially faced with conflicting expectations for their behavior from their superordinates (superintendents and high school principals), their subordinates (high school teachers), and their colleagues (department chairs in other subject 
matter areas), but they also work in a primarily male environment.

\section{Conclusions}

The conclusions of this study were derived from the descriptive and statistical analyses of responses from high school department chairs and high school teachers to a researcher-constructed survey instrument. Computation of frequency distribution data, computation of means and standard deviations, and chi-square tests on the frequencies of group responses to individual activities comprising five categories of high school department chair responsibility led to the conclusions discussed in this chapter.

Results of this study clearly identify potential obstacles to the effective role performance of the high school academic department chair in oregon. Differences in perception of what is most important in the role as it is currently defined and in what is most important for the department chair to continue to improve in the role were found between department chairs and teachers, among chairs of the four different academic areas, and between males and females in the study population. Thus, the study indicates that ambiguity continues to characterize the definition of the role of the academic department chair in 
the oregon high schools which made up the study population.

Examination of the data also revealed that the voice of the teacher-department chair in this study is not a single voice, but that of a chorus a range of disparate, sometimes harmonious, but often competing voices. The ambiguity which was found to exist in the role itself would therefore appear to be compounded by the dissonance in the voices of those who occupy the role.

one could further conclude that such a multiplicity of voices would likely communicate multiple expectations for role performance, thus contributing to role conflict for the department chair. In that the intensity of role conflict experienced by the chair would presumably vary in relation to the incompatibility of these multiple expectations, the negative impact of any resulting conflict on role performance would also be expected to vary. The comparison of responses from the chairs of the four different academic departments remained incomplete in that the small sample sizes precluded the drawing of definitive statistical conclusions. However, the pattern of the data is strong in suggesting substantial differences in perception exist among chairs from differing subject matter areas. While responses of English and social studies chairs were mostly congruent, as were those of math and science chairs, substantial 
incongruence was noted in subsequent pairings of department chairs. English department chairs and math department chairs, in particular, diverged widely in their valuing of activities which comprise the various role responsibilities of the chair as well as in their valuing of the activities that they considered important for the chair to continue to improve. Results of this study definitely invite additional research targeting a larger population of high school department chairs in order to investigate the influence of subject matter orientation on perceptions of the value of activities comprising the different categories of responsibility defining the leadership role of the department chair.

Because what is valued about the role of the department chair would determine the expectations for role performance by the chair, differing values held among the referent groups would also be expected to contribute to role conflict for the chair. Huston (1988) reminded us that "Values lie at the heart of all decisions about curriculum, school organization, and teaching" (p. 120). This study sought to determine what participants valued by asking them what they considered most important to the role of the department chair and what they considered most important for the department chair to continue to improve. In examining the responses, the researchers looked for 
patterns of what seemed to be most valued by the different groups of respondents.

Analysis of the responses generated by this study suggests high potential for role conflict. One distinct pattern of differences in activities that were valued by department chairs and those that were valued by teachers was noted in the category of Responsibility for the organization. For both the issue of importance to the role of the department chair and the issue of importance for the department chair to continue to improve, high school teachers rated protecting of classroom instructional time and supporting teachers' professional needs and concerns as most important. These activities are ones that would be considered to have the most immediate impact upon the day-to-day activities of teachers.

In contrast, department chairs focused on those activities connected with their broader organizational role-organizing a department improvement plan, working with other chairs to develop an integrated school improvement effort, and participating in district-level curriculum development. In other words, the emphasis of the department chairs seems to be more on the needs of the organization than on the needs of the individual, whereas the teachers seem to value the needs of the individual more highly than the needs of the organization. 
Incongruent perceptions between teachers and department chairs with respect to what is of most value would presumably cause the role player (the department chair) to experience conflicting pressures between his/her own commitment to attaining the goals of the organization and the expectations of his/her subordinates (the teachers) that he/she support their personal needs. Role conflict produced by this incongruity between the idiographic (personal) and nomothetic (organizational) dimensions of the Getzels and Guba (1957) model of the organization as a social system would, in turn, be expected to have a detrimental impact on the chair's effectiveness.

The department chairs' voicing a stronger valuing of organizational concerns perhaps indicates that department chairs, even though they are also teachers, have developed more of an organizational perspective than have the teachers. One might hypothesize that their leadership role has given chairs an understanding that teachers may lack-the understanding that by improving organizational conditions in a planned and organized manner such that teachers are able to focus most of their energies on their classroom concerns, one is in effect addressing the needs of the individual.

A second pattern of responses which suggested potential for role conflict emerged in the category of Responsibility for Human Relations. Department chairs and 
teachers consistently agreed on the high value of eight human relations activities to the role of the chair and for the department chair to continue to improve, but just as consistently disagreed on the amount of time the department chairs were devoting to fulfilling their human relations responsibilities. The chairs perceived themselves to be spending more time than the teachers perceived them to be allocating to human relations activities that both groups indicated they valued highly, thus increasing the likelihood of role conflict for department chairs.

Somewhat ironically, in a category of responsibility which seems to have such potential for role conflict, the one activity which chairs valued significantly less than did the teachers was facilitating effective conflict resolution. For both its importance to the role and importance for the department chair to continue to improve, higher ratings were recorded by greater percentages of teachers than department chairs. Department chairs would seem to be placing less value than teachers on the human relations activity which might turn out to be the most important for the chairs to be able to perform well.

The implications of the findings derived from comparing responses of male high school department chairs and teachers with those of female high school department 
chairs and teachers point to even more possibilities for role conflict. In contrast to the differences in perception found between teachers and department chairs, two-thirds of which were related to the issue of time, the areas of disagreement between males and females in the study population focused more on the manner in which the role of the chair was characterized as well as what was important for the chair to continue to improve.

In rank ordering the five categories of department chair responsibility according to their perceived importance to the role of the chair, females valued human relations activities significantly more than did males. Females also valued three human relations activities to be significantly more important to the role of the chair than did males, and valued six human relations activities to be significantly more important for the chair to continue to improve than did males. While the differences were not found to be statistically significant, greater percentages of males on the other hand valued management more highly than did females.

The essentially masculine orientation of the hierarchical structure of education also has perceived supervision from a largely managerial perspective, and consequently often has defined role behaviors for the department chair from that same perspective. In fact, much of the literature on restructuring and certainly the 
educational reform efforts in oregon have for the most part dismissed the role of the department chair as primarily clerical or at the most managerial in its practice. As a result, the department chair has largely been ignored in the pursuit of sources of instructional leadership for educational change. The reform efforts have focused instead upon the empowerment of teachers outside of the hierarchical leadership structure which includes the role of the department chair.

In the light of Oregon's "second wave" of educational reform influences (Carnegie Forum on Education and the Economy, 1986; Conley \& Cooper, 1991; Conway \& Jacobson, 1991; Wasley, 1991) calling for the restructuring of school governance to empower teachers by giving them leadership responsibilities in decision making, curriculum, and management, it is important to note, however, that the high school teachers in this study valued department chairs' encouraging department members to share in leadership roles (HR9) the least in this category of department chair responsibilities, both for its importance to the department chair role and for its importance for the department chair to continue to improve. While one cannot conclude therefore that teachers have no wish to assume these responsibilities, the reasons for their placing less value on being encouraged to assume leadership roles than they place on 
other activities in the human relations category need to be explored.

At the same time, the findings of this study suggest a need to reexamine the instructional leadership possibilities inherent in the role of the chair. The dismissal of this position which has been ignored in most of the reform effort in oregon should be rethought. Within the context of ongoing restructuring efforts, as Conley (1993) suggested, "The reshaping of the role of department chair holds great potential for creating new leadership opportunities" (p. 250). Paradoxically, even though the results of this study support as well as extend the assertion that the department chair is caught between conflicting expectations that could produce role conflict, it is also that position at the confluence of these competing forces- the center or the eye of the storm-which may place the chair in the best position to reconcile those conflicts to effect a positive, synergistic force for school improvement (Deal \& Peterson, 1994).

For instance, Irwin (1995) presented an argument for a reconsideration and reconstruction of the idea of leadership toward a facilitative rather than a controlling orientation. Those who call for such a facilitative leadership approach describe it as a type of leadership that is feminine in nature (Conley \& Goldman, 1994; Hargreaves, 1992; Lashway, 1995). Perhaps it is not 
surprising then that so many of the images that are used to characterize this form of leadership are closely connected to those described by the literature on gender difference. Huston (1988) contends that "A web of interlocking responsibilities for devising and implementing school policy must be established . . a network of interdependent people" (p. 125). Lashway referred to Dunlap and Goldman (1990) in describing facilitative power as "based on mutuality and synergy, and [flowing] in multiple directions" (p. 1). Sergiovanni (1994) emphasized the development of a community of learners.

The findings in this study lend support to observations by Lyons (1983) and Gilligan et al. (1988) that women tend to focus on care, relationships based on responsiveness or engagement, and a more collaborative style of leadership than men employ. While it is understood that masculine and feminine perspectives do not necessarily coincide with male and female orientations to the world, the findings of this study reflect that female department chairs and teachers value more highly than do males the kinds of department chair leadership activities which support such a facilitative approach to leadership. Sergiovanni's (1994) concept of community, for example, sees relationships as the key to developing a collaborative culture. In this view of leadership, the 
department chair as an instructional supervisor would be expected to act in what Irwin (1995) characterizes as "a dialectical relationship between teachers and administrators" (p. 163). The structural frameworks would not be altered, but the emphasis for the role of the chair would shift from that of the maintaining of organizational stability which Cuban (1988) defines as "the managerial imperative" to that of leaders using their power to facilitate collaborative dialogue among professionals. Such a revisioning of the role of the department chair would require embracing the paradox identified by Deal and Peterson (1994). Not unlike the imaginative power of the poetic imagination described by coleridge (cited in Witherspoon, 1951) in Biographica Literaria as reconcilement of opposite or discordant qualities: of sameness, with difference, the creative tension generated by the interplay of the opposing forces would be seen as the source of the creative power.

The majority of female department chairs and teachers in the study population were found to be in the English department. Perhaps it is not coincidental then that so many of the metaphors used to characterize facilitative leadership are derived from the humanities, particularly in arguing for the power of the narrative voice. Goodson (1992) quoted folk-song collector, Robin Morton, that "it was in the singer that the song becomes relevant" (p. 
101). Hargreaves (1992) pointed to the importance of listening to the voices of teachers telling their stories in order to discover their values, needs, and concerns as educational change efforts are designed. Polkinghorne (1988) credits stories and narrative with the capacity to define and create community. Irwin (1995) drew on conclusions reported from studies by Lincoln (1989) in also arguing for the power of narrative: (a) in communicating meaning, (b) in providing for discussions of moral values, (c) in offering not only the voice of the story teller, but the voices of those whose stories are being told, (d) in making known the experiential perspectives of those who will be impacted by proposed changes, and (e) in providing an avenue through which to examine future possibilities.

As the data presented in this study and its companion study, The Voice of the Administrator (Korach, 1996), have demonstrated, in telling their stories people tend to concentrate on their own role and to perceive what is most important through the perspective of that role. Superintendents want to see things from a whole-district perspective; principals focus on the whole building. Department chairs see the English, math, science, or social studies department; teachers see their own classroom. Because people's perceptions are filtered through their own perspective, if there is no dialogue 
there is less chance that they will understand the ramifications of other perspectives. There must be acknowledgment that all these perspectives are interrelated, that the melody and the counterpoint are equally important in creating the harmony, that each voice is both valid and valuable to consider in educational reform efforts.

\section{Application of the Findings}

The findings of this study, supported by the literature and informed by some related findings from a companion study by W. A. Korach (1996), have made available considerable data to help clarify the role of the high school department chair as it is currently practiced in a selected group of oregon high schools. Several key distinctions can now be identified among the perceptions of administrators, high school department chairs, and high school teachers regarding activities comprising the leadership role of the high school academic department chair as it was defined for this study. Thus the findings have significant possibilities for their application in designing the goals, strategies, processes, and practices to bring about the improvement of education in the oregon high schools selected to participate in this study.

1. The conclusions of the study confirm, as had been suggested by the literature, that significant differences 
in perception exist among the referent groups. The resultant potential for role conflict and subsequent loss of role effectiveness point up the need for top-down, bottom-up collaboration. It is important to create processes and avenues for dialogue to make individuals aware of and to develop a clear understanding of differing points of view about what is most important in the role of the department chair in order to work toward reaching common ground in reconciling the differences.

2. Differing perceptions among administrators, high school department chairs, and high school teachers regarding department chair Responsibility for Management should be addressed. Department chairs see their management responsibilities as more important to the role and as more important for them to continue to improve than do the administrators. To lessen the potential for role conflict and increase the potential for role effectiveness for department chairs, it is important to involve them in decisions about management practices.

3. In order for administrators and teachers to be able to develop a collaborative, collegial, shared commitment to accomplishing a common improvement agenda, effective channels of communication (processes) must be developed between administrators and high school department chairs and between department chairs and high school teachers. 
4. Because the top of the educational hierarchy is dominated by male administrators who, as concluded by $\mathrm{W}$. A. Korach (1996), speak in a singular voice, male high school department chairs, who are also in the majority, presumably experience less role conflict than do females. Male administrators need to consider that for women in these roles the need for dialogue to reach understanding is perhaps even greater than it is for males.

5. Administrators' expectations for the supervisory role of the department chair were substantially higher than were those of the department chairs themselves. To lessen the potential for role conflict and to increase the potential for role effectiveness, it is important that department chairs voicing the needs, values, and concerns of teachers be involved in shaping the assumptions and the criteria that guide administrative decisions about supervisory practices.

6. Comparing the results of chi-square testing of the responses of high school department chairs and high school teachers in this study with the results of chisquare testing between responses of high school department chairs and administrators in the study by $\mathrm{W}$. A. Korach (1996) provides further insight. On the issue of the amount of time spent, perceptions of department chairs are shown to align more closely with perceptions of administrators, but perceptions of department chairs align 
more closely with perceptions of teachers on the issues of importance to the role of the department chair and importance for the department chair to continue to improve.

These findings suggest that administrators perhaps have more realistic, experience-based perceptions of the amount of time necessary to perform the activities comprising the role of the chair than do teachers. At the same time, the results lend support to Duke's (1987) assertion that department chairs are more likely than are principals to be aligned with what is meaningful to teachers. Both factors are important to consider in efforts to define the instructional leadership role of the high school department chair.

\section{Recommendations}

Leithwood (1992), in defining what he referred to as transformational leadership, identified three goals for administrators :

(1) helping staff members develop and maintain a collaborative, professional school culture, (2) fostering teacher development, and (3) helping them solve problems together more effectively. (pp. 9-10)

Fundamental to this study is the belief that effecting instructional improvement at the high school level also requires such collaborative leadership practices between administrators and high school department chairs, a 
combination of top-down administrative influence and bottom-up teacher influence integrated in a collegial, systematic effort.

Practicing collaboration, as Schrage (1990) asserted, means that individuals both realize they "need insights, comments, questions, and ideas from others . . . [and] accept and respect the fact that other perspectives can add value to their own" (p. 40). Within a collaborative leadership framework such as Lieberman (1990) described, department chairs can contribute their specialized, practical knowledge of content and the classroom to extend and inform the organizational perspective of administrators in the effort to improve instruction. As Arredondo, Brody, Zimmerman, and Moffett (1995) pointed out in referring to Hargreaves and Dawe, "unless the supervisor can function as an equal and establish trust and collegiality, neither the supervisor nor the teacher will grow from classroom experiences" (p. 76). Open, trusting dialogue is essential to system-wide top-down, bottom-up collaborations between administrators and teacher leaders-a willingness to risk, to suspend judgment, and to think together. This study provides one means of generating such a dialogue by offering a discussion guide for stimulating thinking about the role of the high school department chair in ongoing school reform efforts. 
Recommendations for practice

According to Sergiovanni (1984), "Reasonable agreement and mutual understanding of areas of agreement seem to be prerequisite for leadership effectiveness" (p. 172). Results of this study suggest that to minimize role conflict for the chair and potentially increase effectiveness, clear and consistent expectations for role performance need to be defined and clarified. Without meaningful dialogue among administrators, department chairs, and teachers, it is unlikely that consistency of definition of the role or expectations for performance in the role will evolve.

As Chenoweth (1993) pointed out, a significant guiding principle for making such decisions is the development of "unity of purpose," (p. 7) which he defines as the forging of personal visions into "a shared vision of what the school is all about." All structures and individual efforts would then be focused toward accomplishment of that shared vision. As a guide for developing such a shared vision for the role of the high school academic department chair, it is recommended that department chairs, the teachers in their departments, and their administrators address a series of statements in an open, focused dialogue, applying to each statement the following three specific questions: 
- To what extent does the statement characterize your vision of what the educational leadership role of the department chair should be? (What is the desired state? Is this a clear statement of what should be?) If the statement is not an accurate characterization, develop consensus about what the statement should be and rewrite the statement to express that collective vision.

- once agreement is reached about the statement, what is the difference between the expectations for the role as it currently exists and the vision being characterized in the discussion statement? (What is the state of current practice in regard to this statement?)

- What changes need to be made in the definition of the role in order to accomplish the vision being characterized in the discussion statement? (What are the human as well as the structural needs?)

At the heart of effective educational change must be shared beliefs about best practice. Guided by the results of this study, and informed from the companion study by $w$. A. Korach (1996) as well as more than thirty years of experience as a high school English teacher and department chair, the researcher proposes the following series of belief statements as a basis for dialogue. From the voice of the teacher-department chair, perspectives for 
discussion are organized in three categories: definition of the role of the chair, credibility in the role of the chair, and the collegial nature of the role of the chair. These belief statements, when combined with those from the voice of the administrator offered in the study by $W$. A. Korach (1996), offer a comprehensive series of concepts to address through dialogue in defining and clarifying the role of the high school department chair in a district's integrated vision for instructional improvement.

Definition of the role of the academic department chair.

1. An effective department chair inspires and engages teachers in a focused, cooperative, and collegial effort toward instructional and program improvement.

2. The job description for department chairs should place strong emphasis on instructional leadership while also acknowledging the department chair position to be multi-faceted. Specifically, four major interrelated role responsibilities should be included in the department chair job description:

- program management, including planning, coordinating, organizing, budgeting, scheduling, and problem solving

- teacher support, including communications, human relations, change facilitation, and decision making 
- program development, including the designing, implementing, and ongoing assessment of the instructional program

- teacher supervision, including professional development, collegial inquiry, teacher observation, peer sharing.

3. The chair should model the belief that the student and teacher share the responsibility to design and to shape knowledge. This concept of the teaching role closely parallels a vision of the role of the department chair as instructional leader, one in which department chairs and teachers assume shared responsibility to construct and to shape their knowledge and practice.

credibility of the role of the academic department chair.

1. The authority of the department chair role, combined with the credibility of subject matter knowledge and instructional expertise, provides a unique position from which the department chair may address instructional improvement as well as the professional development of teachers.

2. For teacher leaders in the role of high school department chair to influence instructional and program improvement without their role including the organizational authority and power of the administrator 
requires them to base their leadership efforts upon their credibility as expert practitioners.

3. The department chair must have a thorough and comprehensive vision of instruction, understanding that there are many effective skills, strategies and models for good teaching, but that the dynamic, ever-changing nature of the classroom precludes the development and/or utilization of a single template.

4. A department chair must (a) be able to recognize and to model a repertoire of instructional approaches appropriate to a variety of specific learning outcomes, (b) be able to select approaches which consistently increase the probability of learning in specific situations, and (c) be able to implement those instructional approaches in an effective manner.

5. Having his or her own subject matter expertise and a history of successful teaching experience enhances the chair's credibility as an instructional leader as does demonstrating an understanding of instructional theory and both knowledge and skill in the technical aspects of teaching.

6. As an instructional leader, a department chair should also understand the reciprocal relationship between teaching and learning, realizing that in an ideal learning environment the department chair is both teacher and 
learner, and teachers within the department are both

learners and teachers.

Collegial nature of the role of the academic

department chair.

1. Department chairs should work with teachers in ways which encourage meaningful personal and professional growth, including assisting teachers in developing their own growth plans and providing them with information, resources, and support that will better enable them to carry out those plans.

2. Meaning is derived from one's ability to have influence on the system and on one's own personal and professional development within that system. Members of the department experience meaningful participation when they are engaged in a shared, collegial effort to shape instructional improvement plans within the department as well as to devise processes and materials to assure their implementation in the classroom.

3. Department-wide instructional improvement requires teacher collegiality, defined as professionals working together to improve teaching and learning, specifically sharing approaches to practice and supporting one another's improvement efforts.

4. An atmosphere of colleagues engaged in mutual inquiry can be further developed within the department through establishing a framework and processes for peer 
sharing, an organized means for teachers to share ideas, to be exposed to an expanding repertoire of instructional strategies, to meet and discuss what they have observed, and to plan jointly.

5. Creating and participating in collegial sharing processes can be invaluable to the department chair in establishing and monitoring coherence within the total program, in assessing the need for and/or the impact of curriculum innovations, and in creating a sense of mutual support, enthusiasm, and meaningful growth within the department.

6. A central concern for department chairs must be ways teachers will be able to renew themselves and continue to grow professionally while meeting the responsibilities of full-time teaching.

Recommendations for Use of the Survey Instrument

The survey instrument seems to be an effective means of determining the perceptions of superintendents, high school principals, high school academic department chairs, and high school teachers concerning the amount of time department chairs spend on activities specific to their role, the relative importance of those activities, and the importance of the chair's continuing to improve in the activities. The survey instrument can be recommended for further use: (a) in its current form, (b) in a modified 
form to include different activities, and (c) in a modified form to create additional areas of focus. For example, activities could be made specific to additional distinctions, such as the importance of providing specific feedback to teachers on skill instruction versus the importance of providing specific feedback to teachers on concept development instruction. The instrument could also be easily redesigned to focus the inquiry on additional questions. For example, it would be simple to ask how difficult or costly bringing about improvement would be in a particular area rather than how important the area was to improve.

The survey instrument was an effective tool for gathering perceptual data from a large number of respondents from throughout the state of oregon. Additionally, the data from the survey instrument allowed the researcher to draw conclusions about the perceptions of the amount of time spent on and the value placed on specific department chair activities. It should also be noted that the format of the information from the survey allowed for an effective transfer of data into the structure used in the data analysis for the study. Finally, it is important to stress that the single survey was versatile enough to work for all study participants regardless of role differences, eliminating problems associated with multiple forms of a survey. 
One area that should be considered for expansion or revision would be the demographic section of the survey. Because the intention of this study was to describe the participants, not to determine if relationships existed between demographic variables and the respondents' perceptions of the role of the chair, this section was not extensive, nor was it designed to reveal meaningful distinctions among study respondents. Those considering future research may wish to make such distinctions.

\section{Recommendations for Future}

Research

The following recommendations for future research are based on the literature and the findings, conclusions, and implications of this study.

1. A major limitation of this study was its focus on only oregon high schools which most closely matched the characteristics of those in the researchers' own district. To the extent which other high schools differ, research is needed on those contexts to determine if the results of this study are generalizable to other defined populations.

2. Since this study involved only high schools, future research should target teachers and teacher leaders at other educational levels, i.e., elementary, middle level, to see if the significant differences in perceptions found in this study according to subject matter affiliation and gender hold true. 
3. This study focused on what activities in five categories of role responsibility were most valued in the role of the department chair. Further studies should address how effectively department chairs are currently performing responsibilities in each of the five categories as defined for the study and what the department chair could do to improve his/her effectiveness in performance of each of the activities, both issues which were not addressed in this study.

4. Further research should be done to determine whether effectiveness in carrying out the role responsibilities of the department chair is dependent on congruent perceptions existing among referent groups, thereby eliminating, or at least reducing, role conflict for the department chair.

5. This study addressed only what was considered to be most important to the role of the department chair. It did not address the reasons why some activities are considered to be more important than others. Further studies should investigate the criteria different groups of educators consider in making such judgments.

6. Further research should be done with larger sample sizes to investigate whether the pattern of incongruent perceptions among department chairs from different academic disciplines holds true. 
7. Further studies could target a population with more equal numbers of department chairs by gender in each discipline in order to more clearly establish whether the wide disparities between perceptions of department chairs in math and department chairs in English exist because of differences in subject matter orientation or because of differences in gender.

8. Additional studies should be done with larger populations of teachers from those same academic disciplines to discover if a similar pattern of disparities by subject matter orientation as that found for department chairs in this study also exists among teachers.

9. Additional studies could be done to determine if there are defining characteristics of the different academic disciplines that could potentially lead to incongruent perceptions among the high school department chairs and teachers from differing disciplines.

10. As more females enter the administrative ranks, additional research should address the question of whether the pattern of differences in perception between administrators and department chairs remains consistent or alters as a result of gender influences. 


\section{REFERENCES}

Anderson, C. J. (1987, December/January). Instructional leadership behaviors of high school principals, assistant principals, and department chairpersons: $A$ comparison. The High School Journal, 70, 115-123.

Arredondo, D. E., Brody, J. L., Zimmerman, D. P., \& Moffett, C. A. (1995, November). Pushing the envelope in supervision. Educational Leadership, 53, 74-78.

Ary, D., Jacobs, L. C., \& Razavieh, A. (1985). Introduction to research in education (3rd ed.). New York: Holt, Rinehart and winston.

Association for Supervision and Curriculum Development. (1948). The department head and instructional improvement. Washington, DC: Author.

Axley, L. (1947, January). Head of department: A racehorse with plowhorse duties. clearing House, 21, 174-276.

Bacharach, S. B., Bauer, S. B., \& Shedd, J. B. (1986). The learning workplace: The conditions and resources of teaching. Ithaca, NY: Organizational Analysis and Practice of Ithaca, New York.

Bacharach, S. B., \& Conley, S. C. (1990, March). From school-site management to participatory school-site management. Phi Delta Kappan, 71, 539-544.

Badaracco, J. L., Jr., \& Ellsworth, R. R. (1989). Leadership and the quest for integrity. Boston: Harvard Business School Press.

Barth, R. S. (1988). School: A community of leaders. In A. Lieberman (Ed.), Building a professional culture in schools (pp. 129-147). New York: Teachers College Press.

Beach, D. M., \& Reinhartz, J. (1989). Supervision: Focus on instruction. New York: Harper and Row. 
Beare, H., Caldwell, B. J., \& Millikan, R. H. (1989). Creating an excellent school: Some new management techniques. London: Routledge.

Belenky, M. F., Clinchy, B. M., Goldberger, N. R., \& Tarule, J. M. (1986). Women's ways of knowing: The development of self, voice, and mind. New York: Basic Books, Inc.

Bennis, w. (1966). Changing organizations. New York: McGraw-Hill Book Company.

Berrier, G. G. (1974, March). The department chairman: What does he do? clearing House, 48, 432-436.

Bird, T., \& Little, J. พ. (1987). Instructional leadership "close to the classroom" in secondary schools. In W. D. Greenfield (Ed.), Instructional leadership: Concepts, issues and controversies (pp. 118-138). Boston: Allyn and Bacon, Inc.

Blum, R. E., \& McEady, B. J. (1984). Instructional leadership training. Portland, OR: Northwest Regional Educational Laboratory.

Blumberg, A. (1974). Supervisors and teachers: A private cold war. Berkeley, CA: Mccutchan Publishing corporation.

Brann, J., Emmet, T. A. (Eds.). (1972). The academic department or division chairman: A complex role. Detroit, MI: Balamp Publishing.

Budner, S. (1962). Intolerance of ambiguity as a personality variable. Journal of Personality, 30, 29-50.

Burlingame, M. (1987). Images of leadership in effective schools literature. In W. D. Greenfield (Ed.), Instructional leadership: Concepts, issues and controversies (pp. 3-16). Boston: Allyn and Bacon, Inc.

Calabrese, R. L., \& Anderson, R. E. (1986, April). The public school: A source of stress and alienation among female teachers. Urban Education, 21, 42-51.

Callahan, M. G. (1971). The effective school department head. West Nyack, NY: Parker Publishing Company, Inc. 
Capper, C. A. (Ed.). (1993). Educational administration in a pluralistic society. Albany: State University of New York Press.

Carnegie Forum on Education and the Economy. (1986). A nation prepared: Teachers for the twenty-first century. Washington, DC: Author.

Chenoweth, T. (1993). Why is the principal ignored in urban school restructuring? Unpublished manuscript, Portland State University, school of Education, Portland, OR.

Ciminillo, L. M. (1967). The department head's perception of the functions and characteristics of their position. Unpublished doctoral dissertation, Indiana University, Bloomington.

Clark, D. L., Lotto, L. S., \& Astuto, T. A. (1984, Summer). Effective schools and school improvement: A comparative analysis of two lines of inquiry. Educational Administration Quarterly, 20, 41-68.

Cognetta, R. A. (1967). The relationship of selected organization and personal variables to the behavior of high school department heads. Unpublished doctoral dissertation, Stanford University, Stanford, CA.

Conley, D. T. (1993). Roadmap to restructuring. Eugene, OR: ERIC Clearinghouse on Educational Management.

Conley, D. T., Goldman, P. (1994). Facilitative leadership: How principals lead without dominating. Eugene: Oregon School Study Council.

Conley, S. C. \& Cooper, B. S. (1991). The school as a work environment: Implications for reform. Boston: Allyn and Bacon.

Conway, J. A., \& Jacobson, S. I. (Eds.). (1991). Educational leadership in an age of reform. New York: Longman.

Costanza, J. F., Tracy, S. J., \& Holmes, R. (1987, November). Expanding instructional leadership through the department chair. NASSP Bulletin, 68, 77-82.

Cuban, L. (1988). The managerial imperative and the practice of leadership in schools. New York: State University of New York Press. 
Deal, T. E. (1987). The culture of schools. In L. T. Sheive \& M. B. Schoenheit (Eds.), Leadership: Examining the elusive (pp. 3-15). Alexandria, VA: Association for Supervision and Curriculum Development.

Deal, T. E., \& Peterson, K. D. (1994). The leadership paradox: Balancing logic and artistry in schools. San Francisco: Jossey-Bass Publishers.

DeRoche, E., Hunsaker, J., \& Kujawa, E. (1987, November/ December). Rules and responsibilities of the department chair. Thrust, 17, 40-42.

DeRoche, E., Hunsaker, J., \& Kujawa, E. (1988, February/ March). Department chairs: A school's untapped resource. The High School Journal, 71, 135-137).

Duke, D. I. (1982, October). Leadership functions and instructional effectiveness. NASSP Bulletin, 1-12.

Duke, D. L. (1987). School leadership and instructional improvement. New York: Random House.

Dunlap, D., \& Goldman, P. (1990, April 16-20). Power as a "system of authority" vs. power as a "system of facilitation." Paper presented at the annual meeting of the American Educational Research Association, Boston.

Durkee, F. M. (1947, April). Department heads in action. clearing House, 21, 47-59.

Easterday, K. (1965, October). The department chair: What are his duties and qualifications? NASSP Bulletin, 49, 77-85.

Edmonds, R. R. (1979, October). Effective schools for the urban poor. Educational Leadership, 15-24.

Edmonds, R. R. (1982, December). Programs of school improvement: An overview. Educational Leadership, 40, 4-11.

Fish, K. I. (1976, March). Department chairmen in urban high schools. NASSP Bulletin, 60, 106-110.

Foster, H. H. (1928). High school administration. New York: Century Company.

Fullan, M. G. (1991). The new meaning of educational change. New York: Teachers College Press. 
Getzels, J. W., \& Guba, E. G. (1957, Winter). School behavior and the administrative process. School Review, 55, 423-444.

Gilligan, C. (1982). In a different voice: Psychological theory and women's development. Cambridge, MA: Harvard University Press.

Gilligan, C., Ward, J. V., Taylor, J. M., \& Bardige, B. (1988). Mapping the moral domain. Cambridge, MA: Harvard university Press.

Glatthorn, A. A. (1990). Supervisory leadership: Introduction to instructional supervision. Glenview, IL: Scott, Foresman/Little, Brown Higher Education.

Glatthorn, A. A., Newberg, N. A. (1982). Instructional leadership: Four ethnographic studies on junior high principals. Philadelphia: University of Pennsylvania.

Glatthorn, A. A., \& Newberg, N. A. (1984, February). A team approach to instructional leadership. Educational Leadership, 42, 60-63.

Goldring, E. B., \& Rallis, S. F. (1993). Principals of dynamic schools: Taking charge of change. Newbury Park, CA: Corwin Press, Inc.

Goodson, I. F. (1992). Sponsoring the teacher's voice: Teachers' lives and teacher development. In $A$. Hargreaves \& M. G. Fullan (Eds.), Understanding teacher development (pp. 110-121). New York: Teachers College Press.

Gorton, R. A., \& Thierbach-Schneider, G. (1991) : Schoolbased leadership: Challenges and opportunities (3rd ed.). Dubuque, IA: William C. Brown Publishers.

Greenfield, W. D. (1985, winter). Value leadership: The department chair's role in instructional improvement. Illinois school Research and Development, 21, 22-27.

Greenfield, พ. D. (Ed.). (1987). Instructional leadership: Concepts. issues and controversies. Boston: Allyn and Bacon, Inc.

Gruman, A. J. (1955). Improving instruction through the use of department heads. California Journal of Secondary Education, 30, 167-169. 
Hall, G. E., \& Guzman, F. M. (1984). Sources of leadership for change. Austin: University of Texas, Research and Development Center for Teacher Education.

Hannay, L. M. (1994, April), Secondary school change: The role of department heads. Paper presented at the annual meeting of the American Educational Research Association, New Orleans, IA.

Hargreaves, A. (1992). Cultures of teaching: A focus for change. In $A$. Hargreaves \& M. G. Fullan (Eds.). Understanding teacher development (pp. 216-240). New York: Teachers College Press.

Hargreaves, A., \& Dawe, R. (1990). Paths of professional development: Contrived collegiality, collaborative culture, and the case of peer coaching. Teaching and Teacher Education, $\underline{6}(3), 227-241$.

Hatfield, R. C., Blackman, C., Claypool, C., \& Master, F. (1986). Exploring leadership roles performed by teaching faculty in $\mathrm{K}-12$ schools. Paper presented at the annual meeting of the American Association of Colleges for Teacher Education, Chicago, IL.

Helgesen, S. (1990). The female advantage: Women's ways of leadership. New York: Doubleday.

High, P. B. (1965, April). Supervisory role of the department head. clearing House, 39, 487-491.

Hipps, G. M. (1965, April). Supervision: A basic responsibility of the department head. Clearing House, 39, 492-497.

Hodgkinson, C. (1983). The philosophy of leadership. Oxford: Blackwell.

Hord, S. M., \& Murphy, S. C. (1985). The high school department head: Powerful or powerless in quiding change? Paper presented at the annual meeting of the American Educational Research Association, Chicago, II.

Hoy, W. K., \&orsyth, P. B. (1986). Effective supervision. New York: Random House.

Huston, H. M. (1988). Building collaboration and leadership roles. In A. Lieberman (Ed.), Building a professional culture in schools (pp. 109-128). New York: Teachers College Press. 
Irwin, R. I. (1995) A circle of empowerment: Women, education, and leadership. Albany: State University of New York Press.

Johnson, S. H. (1990). Redesigning teachers' work. In R. F. Elmore \& Associates (Eds.), Restructuring schools: The next generation of educational reform (pp. 125-151). San Francisco: Jossey-Bass Publishers.

Katz, D., \& Kahn, R. L. (1978). The social psychology of organizations (2nd ed.). New York: Wiley.

Kahn, R. L., Wolfe, D. M., Quinn, R. P., \& Snoek, J. D. (1964). Organizational stress: Studies in role conflict and ambiquity. New York: Wiley.

Kauffman, D. J. (1980). Systems one: An introduction to systems thinking. Cambridge, MA: Pegasus communications.

Keefe, J. W., \& Jenkins, J. M. (Eds.). (1984). Instructional leadership handbook. Reston, VA: National Association of Secondary School Principals.

Kidd, J. I. (1965, October). The department head and the supervisory role. Bulletin of the National Association of Secondary School Principals, 49, 7076 .

Kirby, P. C., \& Teddlie, C. (1989, Summer). Development of the reflective teaching instrument. Journal of Research and Development in Education, 22, 45-50.

Kirkland, G. G. (1978). The role of the department head in large, public senior high schools (Doctoral dissertation, University of Colorado, 1978). Dissertation Abstracts International, 39, 6436A.

Koch, H. C. (1930, April). Some aspects of the department headship in secondary schools. School Review, 38, 263-295.

Kohlberg, L. (1981). The philosophy of moral development. San Francisco: Harper and Row.

Korach, w. A. (1996). comparative study of perceptions of superintendents, high school principals, and high school department chairs on the role of the high school academic department chair: The voice of the administrator. Unpublished doctoral dissertation, Portland State University, Portland, OR. 
Kottkamp, R. B., \& Mansfield, J. R. (1985, April). Role conflict, role ambiguity, powerlessness and burnout among high school supervisors. Journal of Research and Development in Education, 28, 29-38.

Lashway, I. (1995). Facilitative leadership. Online ERIC Digest 96. Netscape: http://darkwing: uoregon.edu/ ericcem/digest96.html

Leithwood, K. A. (1992, February). Transformational leadership: Where does it stand? Educational Leadership, 49, 8-12.

Levine, s. (1989). Promoting adult growth in schools: The promise of professional development. Boston: Allyn and Bacon.

Lieberman, A., \&iller, L. (1984). Teachers, their world, and their work. Alexandria, VA: Association for Supervision and Curriculum Development.

Lieberman, A. (Ed.). (1990). Schools as collaborative cultures: Creating the future now. New York: The Falmer Press.

Lightfoot, S. G. (1983). The good high school. New York: Basic Books.

Lincoln, Y. S. (1989) . Critical requisites for transformational leadership: Needed research and discourse. Peabody Journal of Education, 66(3), 176-181.

Little, J. W. (1981). School success and staff development: The role of staff development in urban desegregated schools. Washington, DC: National Institute of Education.

Lyons, N. (1983). Two perspectives on self, relationships and morality. Harvard Educational Review, 53, 125-145.

Lucy, J. R. (1986, November). Curriculum revision: Who will provide the leadership? NASSP Bulletin, 70, 85-86.

Manlove, D. C., \& Buser, R. (1966, November). The department head: Myth and reality. NASSP Bulletin, 50, 99-107. 
McLaughlin, M., Talbert, J. E., \& Bascia, N. (Eds.). (1990). The contexts of teaching in secondary schools: Teachers' realities. New York: Teachers College Press.

Metty, M. P. (1969). The department chairman and public institutions or it's a bird, it's a plane, no it's a - In American Association for Higher Education. Chicago, IL. (ERIC Document Reproduction Service No. ED 028 715)

Mitchell, J. G. (1990). Re-visioning educational leadership: A phenomenological approach. New York: Garland Publishing Company.

Murphy, J. (1988, summer). Methodological, measurement, and conceptual problems in the study of instructional leadership. Educational Evaluation and Policy Analysis, 10, 117-139.

National Commission on Excellence in Education. (1983). At nation at risk: The imperative of educational reform. Washington, DC: U.S. Government Printing office.

Oja, S. N. (1991). Adult development: Insights on staff development. In A. Lieberman \& L. Miller (Eds.), Staff develorment for education in the 190s: new demands, new realities, new perspectives (pp. 37-60). New York: Teachers College Press.

Oliva, P. F. (1989). Supervision for today's schools (3rd ed.). New York: Longman.

Oregon Department of Education. (1990). Oregon school directory. Salem: ODE Publications and Media Center.

Orfinger, M. P. (1980). Perceptions of instructional improvement behaviors of English department chairpersons in large, urban, public high schools (Doctoral dissertation, Fordham University). Dissertation Abstracts International, 41(4), $1326 \mathrm{~A}$.

Owens, R. G. (1981). Organizational behavior in education (2nd ed.). Englewood cliffs, NJ: PrenticeHall, Inc.

Palmer, S. (1981). Role stress: How to handle everyday tension. Englewood Cliffs, NJ: Prentice-Hall, Inc.

Parsons, T. (1959). Essays in sociological theory. Glencoe, IL: Free Press. 
Pellicer, L. O., Anderson, I. W., Keefe, J. W., Kelley, E. A., \& Mccleary, L. E. (1990). High school leaders and their schools. Reston, VA: National Association of Secondary School Principals.

Peterson, K. D. (1989). Secondary principals and instructional leadership: Complexities in a diverse role. Madison, WI: National Center on Effective Secondary Schools.

Pitner, N. J. (1986, Spring). Substitutes for principal leader behavior: An exploratory study. Educational Administration Quarterly, 22, 23-42.

Polkinghorne, D. E. (1988). Narrative knowing and the human sciences. Albany: State University of New York Press.

Price, S. L. (1969). A study of the role of the department head in selected oregon secondary schools (Doctoral dissertation, University of Oregon, 1969). Dissertation Abstracts International, 30, 3200A.

Purkey, S. C., \& Smith, M. S. (1982, December), Too soon to cheer? Synthesis of research on effective schools. Educational Leadership, 40, 64-69.

Raun, T., \& Leithwood, K. (1993). Pragmatism, participation and duty: Value themes in superintendents' problem-solving. In P. Hallinger, K. Leithwood, \& J. Murphy (Eds.), Cognitive perspectives on educational leadership (pp. 54-70). New York: Teachers College Press.

Reber, A. S. (1985). The Penquin dictionary of psychology. Harmondsworth, Middlesex, England: Penguin Books Ltd.

Ritter, w. E. (1979) . Responsibilities of department chairpersons as perceived by exemplary high school principals (Doctoral dissertation, North Texas State University, 1979). Dissertation Abstracts International, 40, 6097A.

Roach, J. H. L. (1976, Winter). The academic department chairperson: Function and responsibilities. Educational Record, 57, 13-18.

Robertson, $\mathrm{H}-\mathrm{j}$. (1992). Teacher development and gender equity. In M. Fullan \& A. Hargreaves (Eds.), Understanding teacher development (pp. 43-61). New York: Teachers College Press. 
Rosenholtz, S. J. (1985, May). Political myths about education reform: Lessons from research on teaching. Phi Delta Kappan, 66, 349-355.

Rosenholtz, S .J (1989). Teachers' workplace: The social organization of schools. New York: Longman.

Sarason, S. B. (1971). The culture of the school and the problem of change. Boston: Allyn and Bacon.

Sarbin, T. R., \& Farberow, N. L. (1952). Contributions to role-taking theory: A clinical study of self and role. Journal of Abnormal and Social Psychology, 47, 117-125.

Schein, E. H. (1985). Organizational culture and leadership. San Francisco: Jossey-Bass Publishers.

Schmuck, R. A., \& Runckel, P. J. (1988). The handbook of organizational development in schools (3rd ed.). Prospect Heights, IL: Waveland Press, Inc.

Schrage, M. (1990). Shared minds: The new technologies of collaboration. New York: Random House.

Senge, P. M. (1990). The fifth discipline. New York: Doubleday.

Sergiovanni, T. J. (Ed.). (1982) Supervision of teaching. Alexandria, VA: Association for Supervision and Curriculum Development.

Sergiovanni, T. J (1984). Handbook for effective department leadership: Concepts and practices in today's secondary schools. Boston: Allyn and Bacon, Inc.

Sergiovanni, T. J. (1987). The theoretical basis for cultural leadership. In L. T. Sheive \& M. B. Schoenheit (Eds.), Leadership: Examining the elusive (pp. 116-129). Alexandria, VA: Association for supervision and Curriculum Development.

Sergiovanni, T. J. (1994). Building community in schools. San Francisco: Jossey-Bass Publishers.

Sergiovanni, T. J., \& Starratt, R. J. (1971). Emerging patterns of supervision: Human perspectives. New York: McGraw-Hill. 
Shakeshaft, C. (1993). Gender equity in schools. In C. A. Capper (Ed.), Educational administration in a pluralistic society (pp. 86-109). Albany: State University of New York Press.

Shakeshaft, C., \& Hanson, M. (1986, January). Androcentric bias in the Educational Administration Quarterly. Educational Administration Quarterly, 22, 68-92.

Shakeshaft, C., Nowell, I., \& Perry, A. (1991, Spring). Gender and supervision in school personnel. Theory into Practice, 30, 134-139.

Siskin, I. S. (1991, May). Departments as different worlds: Subject subcultures in secondary schools. Educational Administration Quarterly, 27, 134-160.

Smith, w. F., \& Andrews, R. L. (1987). Instructional leadership: How principals make a difference. Alexandria, VA: Association for Supervision and Curriculum Development.

Squire, J. R., \& Applebee, R. K. (1968). High school English instruction today. New York: AppletonCentury-crofts.

Turner, H. E. (1983, September). The department head-An untapped source of instructional leadership. NASSP Bulletin, 67, 25-28.

Vann, A. S. (1978). Relationships between selected variables and the amount of time devoted to curriculum development by elementary school principals (Doctoral dissertation, Columbia University Teachers College, 1978). Dissertation Abstracts International, 39, 3341A-3342A.

Vetter, E. W. (1976, November). Role pressure and the school principal. National Association of Secondary school Principals Bulletin, 60, 11-23.

Wasley, P. A. (1991). Teachers who lead: The rhetoric of reform and the realities of practice. New York: Teachers College Press.

Weaver, F., \& Gordon, J. (1979, May). Staff development needs of department heads. Educational Leadership, 36, 578-580.

Weber, J. R. (1987). Instructional leadership: Contexts and challenges. Eugene: Oregon school study Council. 
weick, K. E. (1989). Educational organizations as loosely coupled systems. Administrative Science Quarterly, 21, 1-19.

wilkinson, L., Hill, M., \& Vang, E. (1992). SYSTAT for the Macintosh, version 5.2 [Computer program]. Evanston, IL: SYSTAT, Inc.

williams, P. A. (1979, October). A comparative study of the perceptions of the role of the English departmental chairperson. CSSEDC ouarterly, 1, 2-3.

wimpelberg, R. K. (1987). The dilemma of instructional leadership and a central role for central office. In W. D. Greenfield (Ed.), Instructional leadership: Concepts, issues, and controversies (pp. 100-117). Boston: Allyn and Bacon, Inc.

Witherspoon, A. M. (Ed.). (1951). The college survey of English literature. New York: Harcourt, Brace and company.

Yukl, G. A. (1981). Leadership in organizations. Englewood Cliffs, NJ: Prentice-Hall, Inc. 
APPENDIX A

SURVEY INSTRUMENT 


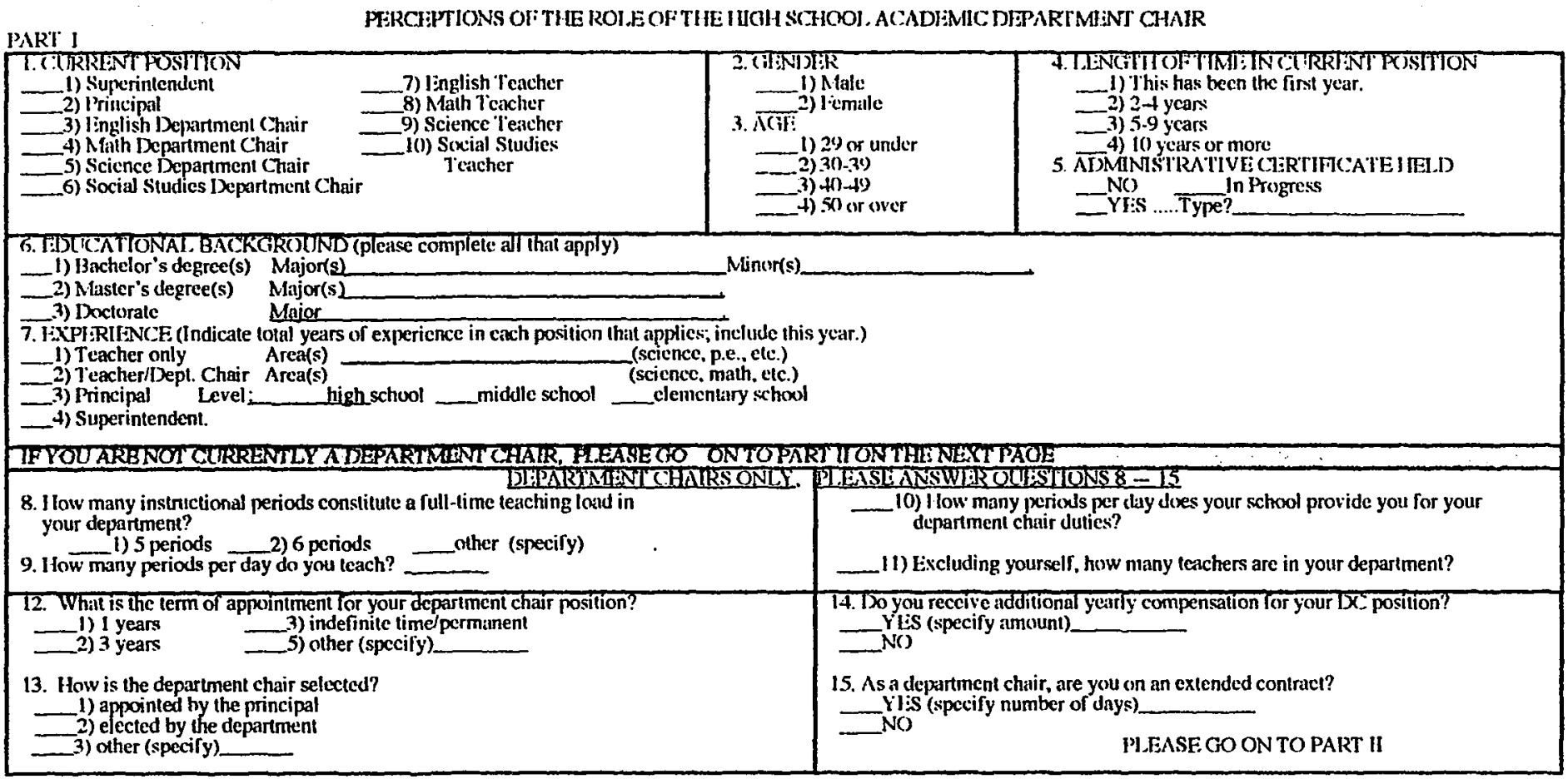


PART It. I'sing the scalcs hclow, please circle the number in citch column which best represenls your judgment regarding the role of the department chair. HOW ALTITIM: DOIS THI: CIAIR SIFND
ON THIS ACTIVITY? ONTHIS ACTIVITY?

(1) No time is spent

(2) I.ttle time is spent

(3) A moderate imount of time is spent
(4) A good deal of time is spent
(5) A great deal of time is spent

A.TIUTRAN A great doal of time is spent

T. TBuild and muintiain is suppentive depirtment lealm

2. Fincourage open communication among department members

3. Pacilitate effective comflict resslution

4. Foster coopcrative problem solving

5. Encourage trust, caring, and respect among depurtment members

6. Maintain regular, open conmunication with department members

7. Practice collaburative, participative decision-making proxesses

8. Promote an atmosphere that encourages continuous improvement

(1) It is of no importince

(2) Il is of litle importance (4) It is very important

(5) It is extrengly important

(2) Il is of timlly bortince

(3) It is of moderale importance

(4) It is very impxrtant

9. Encourage department members to share in leadership roles

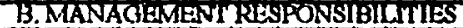

Develop department leaching schedule and assignments

X:Time spent

mpontance toLClisole

$12 x^{3}+5$

$12+3$

2. Participate in the sclection of department instructional personnel

$123+5$

$123+5$

$\begin{array}{lllll}1 & 2 & 3 & 4 & 5\end{array}$

$123+5$

$123+5$

1234

$123+5$

$123+5$

12345

12345

12345

1234

2345

$\begin{array}{lllll}1 & 2 & 3 & 4 & 5\end{array}$

$\begin{array}{lllll}1 & 2 & 3 & 4 & 5\end{array}$

12345

$\begin{array}{lllll}1 & 2 & 3 & 4 & 5\end{array}$

$\begin{array}{lllll}1 & 2 & 3 & 4 & 5\end{array}$

TeTimespen

mporance torcho

$1 \quad 2 \quad 3 \quad 4 \quad 5$

3. Deve!op and administer the department budget

12345

mportancetolmprov

4. Disseminate information to department staff

$1 \quad 2 \quad 3 \quad 45$

12345

$123+5$

1334

$\begin{array}{lllll}1 & 2 & 3 & 4 & 5\end{array}$

5. Allocate and maintain equipment, instructional materials, lacilities

345

6. Interpret and apply district policy and building standarts

$123+5$

$123+5$

123345

7. Plan and organize relevant department meetings

12345

$123+5$

$\begin{array}{llll}2 & 3 & 4 & 5\end{array}$

12345

12345

12345

8. Serve as liaison belween departmenl members and administration

12345

$123+5$

2345

12345 


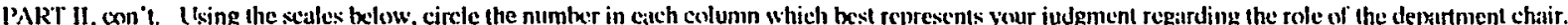

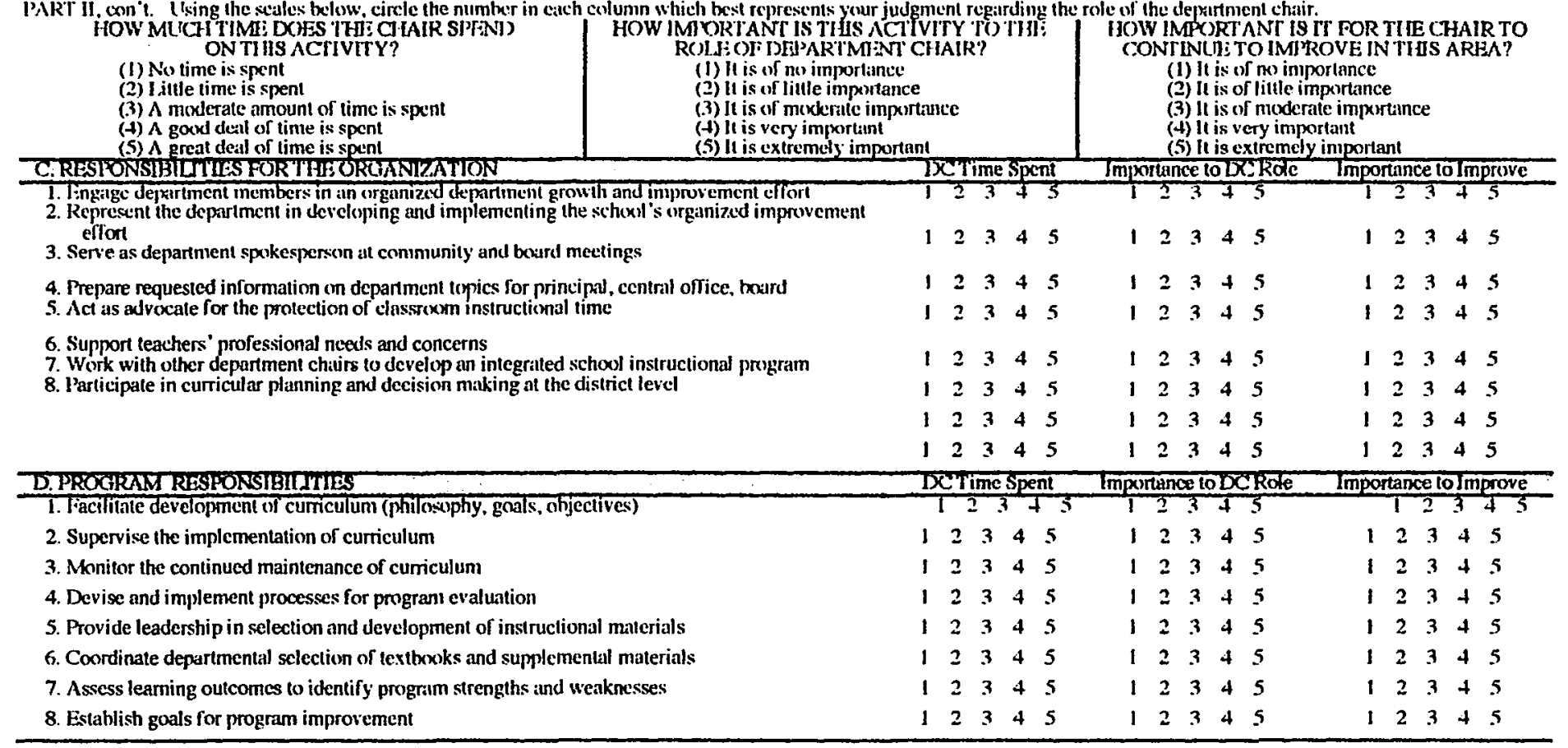


PART 11, con't. Using the seales below, circle the number in each column which best represents your judgment regarding the role of the department chair.

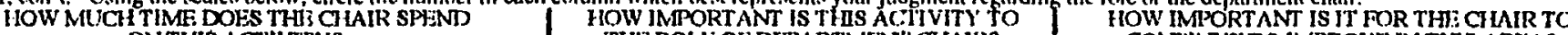
ONTHS ACTIVTYY?

(1) No time is spent

(3) A nwxlerate anount of time is spent

(4) A gond deal of time is spent

(5) A incel deal of time is spent

F. SUPERVISTONIRESTRNSILILITIES

2 Assist teachers in developing professionul gruuth pons

3. lincourage experimentation and innovation among te:kcturn.

4. Coordinate instruction among department members

5. Observe teachers in their classrooms and provide feedhack

6. Monitor teacher lesson plans

7. Practice clinical supervision (pre-conference, data coltection, post-conference)

8. Communicate high expectations for teacher performance

\begin{tabular}{|c|c|c|c|c|c|c|c|c|c|c|c|c|c|c|c|}
\hline \multicolumn{6}{|c|}{ 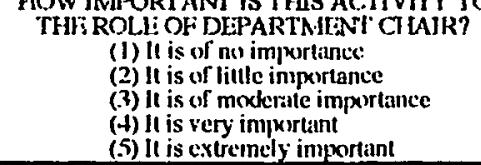 } & \multicolumn{10}{|c|}{$\begin{array}{l}\text { CONIIN IIE TO IMPROVVE IN THIS ARI:A? } \\
\text { (1) It is of no imprortance }\end{array}$} \\
\hline & & $\frac{T}{3}$ & $\frac{\mathrm{me}}{3}$ & $\frac{5 p c}{1}$ & & Impo & $\frac{\tan }{7}$ & $\frac{e 1}{3}$ & $\frac{D}{\pi}$ & Role & Impor & $\frac{\operatorname{ang}}{2}$ & $\frac{\mathrm{CTO}}{3}$ & & Frore \\
\hline & $T$ & 2 & 3 & 4 & & & 5 & 3 & 4 & 5 & & 2 & 3 & & \\
\hline & 1 & 2 & 3 & 4 & 5 & 1 & 2 & 3 & 4 & 5 & 1 & 2 & 3 & 4 & 5 \\
\hline & 1 & 2 & 3 & 4 & 5 & 1 & 2 & 3 & 4 & 5 & 1 & 2 & 3 & 4 & 5 \\
\hline & 1 & 2 & 3 & 4 & 5 & 1 & 2 & 3 & 4 & 5 & 1 & 2 & 3 & 4 & 5 \\
\hline & 1 & 2 & 3 & 4 & 5 & 1 & 2 & 3 & 4 & 5 & 1 & 2 & 3 & 4 & 5 \\
\hline & 1 & 2 & 3 & 4 & 5 & I & 2 & $\mathbf{3}$ & 4 & 5 & 1 & 2 & 3 & 4 & 5 \\
\hline (1-conference) & 1 & 2 & 3 & 4 & 5 & I & 2 & 3 & 4 & 5 & 1 & 2 & 3 & 4 & 5 \\
\hline & 1 & 2 & 3 & 4 & 5 & ! & 2 & 3 & 4 & 5 & 1 & 2 & 3 & 4 & 5 \\
\hline & 1 & 2 & 3 & 4 & 5 & 1 & 2 & 3 & 4 & 5 & 1 & 2 & 3 & 4 & 5 \\
\hline ed lessons, classromm & 1 & 2 & 3 & 4 & 5 & 1 & 2 & 3 & 4 & 5 & 1 & 2 & 3 & 4 & 5 \\
\hline & 1 & 2 & 3 & 4 & 5 & 1 & 2 & 3 & 4 & 5 & 1 & 2 & 3 & 4 & 5 \\
\hline
\end{tabular}

9. Assist teachers with the improvement of their instruction

10. Organize plan for teacher sharing, peer coaching (e.g., videotaped lessons, classrom

11. Evaluatc teacher performance

$$
12345
$$




\section{APPENDIX B}

\section{COVER LETTERS}


April 20, 1991

\section{Dear Educator:}

We are writing to request your participation in a study of the role of the secondary department chair we are conducting through the Portland State University School of Education. This dissertation study is a cooperative effort of Bill Korach, the superintendent of schools in the Lake Oswego School District, and Ricky Korach. the English department chair of Lake Oswego High School. Our study seeks to define the current role of the secondary department chair in the state of Oregon from the perspectives of superintendents and principals as well as those of department chairs and teachers in four areas: English, social studies, mathematics, and science.

We would appreciate your taking the time to respond to the enclosed questionnaire and retum it to us in the seli-addressed, stamped envelope before May 8.

In reporting the results of the study, only statistical summaries of the responses of the four groups (superintendents, principals, department chairs, and teachers) will be shared. Persons, schools, or school districts will not be individually identified. All information will be treated in strictest confidence.

Your response is important in helping us to develop a definitive profile of the role of the secondary departnent chair in Oregon schools. As w'e analyze and report the results of our study, we will be happy to share that information with you if you would care to request it.

Thank you for your cooperation in support of this project.

Sincerely,

William A. Korach, Superintendent

Lake Oswego School District

Rachel M. Korach

English Department Chais

Lake Oswego High School 
May 6, 1991

\section{Dear Colleague:}

For the past year we have been conducting a study of the role of the department chair in Oregon high schools through the Portland State University School of Education. This dissertation study is a cooperative effort of Bill Korach, the superintendent of schools in the Lake Oswego School District, and Ricky Korach, the English department chair of Lake Oswego High School. Our study seeks to define the current role of the secondary department chair in the state of Oregon from the perspectives of superintendents and principals as well as those of department chairs and teachers in four areas: English, social studies, mathematics, and science.

As the culminating activity of this study. we would appreciate your taking the time to respond to the enclosed questionnaire and return it to us in the self-addressed, stamped envelope before May 28.

In reporting the results of the study, only statistical summaries of the responses of the four groups (superintendents, principals, department chairs and teachers) will be shared. Persons, schools, or school districts will not be indiridually identified. All information will be treated in strictest confidence.

Your response is important in helping us to develop a definitive profile of the role of the secondary department chair in Oregon schools. As we analyze and report the results of our study, we will be happy to share that information with you if you would care to request it.

Thank you for your cooperation in support of this project.

Sincerely,

William A. Korach, Superintendent

Lake Osw'ego School District

Rachel M. Korach

English Department Chair

Lake Oswego High School 
May 29, 1991

\section{Dear Administrator.}

Recently we wrote to you requesting your participation in a study of the role of the secondary department chair in Oregon. For this study to be truly representative, a retum from each person to whom we sent the questionnaire is important. If you have already completed the questionnaire, thank you very much for your participation. If you have not done so, we would be appreciative if you could complete and retum it within the next week.

For your convenience in responding, we have enclosed an additional copy of the questionnaire and a stamped, return-addressed envelope.

Your participation in this study will help to define the current leadership role of the academic department chair in Oregon high schools. Thank you for your professional interest and cooperation.

\section{Sincerely;}

William A. Korach, Superintendent

Lake Oswego School District

Rachel M. Korach, English Department Chair Lake Oswego High School 
May 29, 1991

Dear Department Chair:

Recently we wrote to you requesting your participation in a study of the role of the secondary department chair in Oregon. For this study' to be trily representative, a return from each person to whom we sent the questionnaire is important. If you have already completed the questionnaire, thank you very much for your participation. If you have not done so, we would be appreciative if you could complete and return it within the next week.

For your convenience in responding, we have enclosed an additional copy of the questionnaire and a stamped, retum-addressed envelope. Since we cannot personally contact the members of your department to whom the teacher questionnaire w'as distributed, we would also appreciate your reminding them to return their completed questionnaires.

Your participation in this study will help to define the current leadership role of the academic depariment chair in Oregon high schools. Thank you for your professional interest and cooperation.

Sincerely,

William A. Korach, Superintendent

Lake Oswego School District

Rachel M. Korach, English Department Chair Lake Oswego High School 


\section{APPENDIX C}

FREQUENCY DISTRIBUTION CHARTS: DEPARTMENT CHAIRS/TEACHERS; MEAN AND STANDARD DEVIATION CHARTS: DEPARTMENT CHAIRS/TEACHERS 
Chart (:I

Department Chair Responsibility for lluman Relations: Ratings of Amount of "Time Spent.* Importanec to the Department Chair Role,** and Imporlance for the Chair to Continue to Junprove* as Perceived by Ifigh Scheol Department ( thairs and Teachers

[By Frequlencies of Responses: Given for tajeh of lour Ratings]

\begin{tabular}{|c|c|c|c|c|c|c|c|c|c|c|c|c|c|}
\hline \multirow[t]{2}{*}{ Activity } & \multirow[t]{2}{*}{ Group } & \multicolumn{4}{|c|}{7 ime } & \multicolumn{4}{|c|}{ Rolet } & \multicolumn{4}{|c|}{ Improte } \\
\hline & & 2 & 3 & 4 & 5 & 2 & 3 & 7 & 3 & 2 & 3 & 4 & 5 \\
\hline $\begin{array}{l}\text { HRI. Build and maintain a } \\
\text { supportive departmenl ieam }\end{array}$ & $\begin{array}{l}\text { Department Chair } \\
\text { Teacher }\end{array}$ & $\begin{array}{l}15 \\
3.3\end{array}$ & it & $\begin{array}{l}39 \\
29\end{array}$ & $\begin{array}{r}13 \\
8\end{array}$ & $\stackrel{9}{i}$ & 114 & $\begin{array}{l}61 \\
5.5\end{array}$ & 37 & $\begin{array}{l}7 \\
3\end{array}$ & $\begin{array}{l}17 \\
12\end{array}$ & $\begin{array}{l}47 \\
53\end{array}$ & $\begin{array}{l}47 \\
46\end{array}$ \\
\hline $\begin{array}{l}\text { HR2. Lincourage open communication } \\
\text { amnog department memhers }\end{array}$ & $\begin{array}{l}\text { Jepartment Chair } \\
\text { Teacher }\end{array}$ & $\begin{array}{r}9 \\
30\end{array}$ & $\begin{array}{l}45 \\
40\end{array}$ & $\begin{array}{l}38 \\
31\end{array}$ & $\begin{array}{l}26 \\
13\end{array}$ & $\begin{array}{l}4 \\
3\end{array}$ & $\begin{array}{l}6 \\
5\end{array}$ & $\begin{array}{l}57 \\
52\end{array}$ & $\begin{array}{l}51 \\
54\end{array}$ & $\begin{array}{l}3 \\
2\end{array}$ & $\begin{array}{l}13 \\
11\end{array}$ & $\begin{array}{l}50 \\
46\end{array}$ & $\begin{array}{l}52 \\
55\end{array}$ \\
\hline $\begin{array}{l}\text { HR3. Facilitate effective conflict } \\
\text { resolution }\end{array}$ & $\begin{array}{l}\text { Department Chair } \\
\text { Teacher }\end{array}$ & $\begin{array}{l}44 \\
46\end{array}$ & $\begin{array}{l}42 \\
37\end{array}$ & $\begin{array}{l}23 \\
27\end{array}$ & $\begin{array}{c}9 \\
4\end{array}$ & $\begin{array}{r}12 \\
4\end{array}$ & $\frac{25}{17}$ & $\begin{array}{l}53 \\
52\end{array}$ & $\begin{array}{l}28 \\
41\end{array}$ & $\begin{array}{r}11 \\
3\end{array}$ & $\begin{array}{l}31 \\
23\end{array}$ & $\begin{array}{l}49 \\
45\end{array}$ & 27 \\
\hline $\begin{array}{l}\text { HR4. Foster cooperative problem } \\
\text { solving }\end{array}$ & $\begin{array}{l}\text { Depirtment Chair } \\
\text { Teacher }\end{array}$ & 34 & $\begin{array}{l}48 \\
45\end{array}$ & $\begin{array}{l}35 \\
27\end{array}$ & $\begin{array}{r}11 \\
7\end{array}$ & $\begin{array}{l}7 \\
4\end{array}$ & 27 & $\begin{array}{l}49 \\
48\end{array}$ & $\begin{array}{l}35 \\
40\end{array}$ & $\begin{array}{l}8 \\
3\end{array}$ & $\begin{array}{l}26 \\
23\end{array}$ & $\begin{array}{l}48 \\
48\end{array}$ & $\begin{array}{l}36 \\
40\end{array}$ \\
\hline $\begin{array}{l}\text { HRS. Encourage trust, caring, and } \\
\text { respect among department members }\end{array}$ & $\begin{array}{l}\text { Depnitment Chair } \\
\text { Teacher }\end{array}$ & $\begin{array}{l}1.3 \\
39\end{array}$ & $\begin{array}{l}41 \\
34\end{array}$ & $\begin{array}{l}38 \\
31\end{array}$ & $\begin{array}{l}26 \\
10\end{array}$ & $\begin{array}{l}5 \\
4\end{array}$ & $\frac{12}{26}$ & $\begin{array}{l}43 \\
46\end{array}$ & $\begin{array}{l}58 \\
48\end{array}$ & $\begin{array}{l}4 \\
5\end{array}$ & $\begin{array}{l}21 \\
22\end{array}$ & 44 & $\begin{array}{l}49 \\
44\end{array}$ \\
\hline $\begin{array}{l}\text { HR6. Maintain regular, open } \\
\text { communication with department } \\
\text { members }\end{array}$ & $\begin{array}{l}\text { Department Chair } \\
\text { Teacher }\end{array}$ & 21 & 32 & $\begin{array}{l}+1 \\
+0\end{array}$ & $\frac{44}{20}$ & $\begin{array}{l}2 \\
0\end{array}$ & $\begin{array}{l}7 \\
9\end{array}$ & 31 & $\begin{array}{l}78 \\
63\end{array}$ & $i$ & $\begin{array}{l}18 \\
12\end{array}$ & $\begin{array}{l}33 \\
45\end{array}$ & $\begin{array}{l}65 \\
56\end{array}$ \\
\hline $\begin{array}{l}\text { HR7. Practice collaborative, participative } \\
\text { decision-making processes }\end{array}$ & $\begin{array}{l}\text { Department Chair } \\
\text { Teacher }\end{array}$ & $\begin{array}{l}17 \\
21\end{array}$ & $\begin{array}{l}41 \\
51\end{array}$ & $\begin{array}{l}34 \\
30\end{array}$ & $\begin{array}{l}26 \\
12\end{array}$ & $\begin{array}{l}2 \\
0\end{array}$ & $\begin{array}{l}21 \\
14\end{array}$ & 51 & $\begin{array}{l}52 \\
49\end{array}$ & 1 & $\begin{array}{l}28 \\
22\end{array}$ & $\begin{array}{l}45 \\
43\end{array}$ & $\begin{array}{l}44 \\
48\end{array}$ \\
\hline $\begin{array}{l}\text { HR8. Promote an atmosphere that } \\
\text { encourages continuous improvement }\end{array}$ & $\begin{array}{l}\text { Department Chuir } \\
\text { Teacher }\end{array}$ & $\begin{array}{l}12 \\
29\end{array}$ & $\begin{array}{l}39 \\
38\end{array}$ & $\begin{array}{l}48 \\
29\end{array}$ & $\begin{array}{l}19 \\
18\end{array}$ & $\begin{array}{l}1 \\
3\end{array}$ & 15 & $\begin{array}{l}45 \\
47\end{array}$ & $\begin{array}{l}57 \\
53\end{array}$ & $\begin{array}{l}2 \\
4\end{array}$ & $\begin{array}{l}17 \\
12\end{array}$ & $\begin{array}{l}40 \\
48\end{array}$ & $\begin{array}{l}59 \\
50\end{array}$ \\
\hline $\begin{array}{l}\text { HR9. Encourage departmen! members } \\
\text { 10 share in leadership roles }\end{array}$ & $\begin{array}{l}\text { Department Chair } \\
\text { Teacher }\end{array}$ & $\begin{array}{l}30 \\
39 \\
\end{array}$ & $\begin{array}{l}57 \\
45 \\
\end{array}$ & $\begin{array}{r}22 \\
18 \\
\end{array}$ & $\begin{array}{r}9 \\
12 \\
\end{array}$ & $\begin{array}{l}6 \\
4 \\
\end{array}$ & $\begin{array}{r}39 \\
37 \\
\end{array}$ & $\begin{array}{l}46 \\
45 \\
\end{array}$ & $\begin{array}{r}27 \\
28 \\
\end{array}$ & $\begin{array}{r}10 \\
6 \\
\end{array}$ & $\begin{array}{r}30 \\
36 \\
\end{array}$ & $\begin{array}{l}50 \\
43 \\
\end{array}$ & $\begin{array}{l}28 \\
29 \\
\end{array}$ \\
\hline
\end{tabular}

** Ratting scale 2-5: 2 (little or no importance); 3 (modcrate importance); 4 ( very important); and 5 (eviremely imporlant) 
Chars c:2

Department Chair Responsihility for Maulagement: Rittings or Amount of Time Spent,* Importince to the Department Chair Role,**

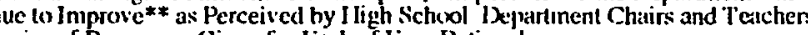

By l.requencies of Responses (iven for liach of Four Ratings

\begin{tabular}{|c|c|c|c|c|c|c|c|c|c|c|c|c|c|}
\hline \multirow{2}{*}{ Activity } & \multirow{2}{*}{ Grotip } & \multicolumn{4}{|c|}{ Time: } & \multicolumn{4}{|c|}{ Roletw } & \multicolumn{4}{|c|}{ Tmprove } \\
\hline & & 2 & 3 & 4 & 5 & 2 & 3 & 4 & 5 & 2 & & 4 & 5 \\
\hline $\begin{array}{l}\text { MGI. Develop department leaching } \\
\text { schedule and assignments }\end{array}$ & $\begin{array}{l}\text { Department Chair } \\
\text { Teacher }\end{array}$ & $\begin{array}{l}19 \\
14\end{array}$ & $\begin{array}{l}38 \\
36\end{array}$ & $\begin{array}{l}35 \\
37\end{array}$ & $\frac{26}{27}$ & $\frac{2}{6}$ & $\frac{24}{17}$ & 48 & $\begin{array}{l}44 \\
49\end{array}$ & $\frac{12}{8}$ & 29 & $\begin{array}{l}39 \\
38\end{array}$ & $\begin{array}{l}38 \\
48\end{array}$ \\
\hline $\begin{array}{l}\text { MC2. Participate in the selection of } \\
\text { department instructional personnel }\end{array}$ & $\begin{array}{l}\text { Department Chair } \\
\text { Teasher }\end{array}$ & $\begin{array}{l}42 \\
28\end{array}$ & $\begin{array}{l}32 \\
41\end{array}$ & $\begin{array}{l}28 \\
.32\end{array}$ & $\begin{array}{l}16 \\
13\end{array}$ & $\begin{array}{l}4 \\
5\end{array}$ & $\begin{array}{l}18 \\
13\end{array}$ & $\begin{array}{l}43 \\
47\end{array}$ & $\begin{array}{l}53 \\
49\end{array}$ & $\stackrel{8}{9}$ & $\begin{array}{l}19 \\
20\end{array}$ & 44 & $\begin{array}{l}47 \\
45\end{array}$ \\
\hline $\begin{array}{l}\text { MCi3. Develop and administer the } \\
\text { department budget }\end{array}$ & $\begin{array}{l}\text { Department Chair } \\
\text { Teacher }\end{array}$ & $\begin{array}{l}9 \\
7\end{array}$ & $\begin{array}{l}37 \\
27\end{array}$ & $\begin{array}{l}39 \\
49\end{array}$ & 33 & $\begin{array}{l}4 \\
1\end{array}$ & $\frac{22}{21}$ & $\begin{array}{l}4.3 \\
49\end{array}$ & $\begin{array}{l}49 \\
43\end{array}$ & $\begin{array}{l}7 \\
4\end{array}$ & $\begin{array}{l}30 \\
34\end{array}$ & $\begin{array}{l}42 \\
37\end{array}$ & $\begin{array}{l}39 \\
39\end{array}$ \\
\hline $\begin{array}{l}\text { MCit. Disseminate information to } \\
\text { department staff }\end{array}$ & $\begin{array}{l}\text { Department Chair } \\
\text { Tcacher }\end{array}$ & $\begin{array}{l}6 \\
8\end{array}$ & $\begin{array}{l}31 \\
41\end{array}$ & $\begin{array}{l}35 \\
35\end{array}$ & $\begin{array}{l}46 \\
30\end{array}$ & $\begin{array}{l}5 \\
4\end{array}$ & $\begin{array}{l}18 \\
21\end{array}$ & $\begin{array}{l}40 \\
38\end{array}$ & $\begin{array}{l}55 \\
51\end{array}$ & $\begin{array}{r}8 \\
10\end{array}$ & $\begin{array}{l}33 \\
27\end{array}$ & $\begin{array}{l}34 \\
34\end{array}$ & $\begin{array}{l}43 \\
43\end{array}$ \\
\hline $\begin{array}{l}\text { MG5. Allocate and maintain equipment. } \\
\text { instructional materials, and facilities }\end{array}$ & $\begin{array}{l}\text { Department Chair } \\
\text { Teacher }\end{array}$ & 40 & 53 & $\begin{array}{l}21 \\
15\end{array}$ & $\begin{array}{r}13 \\
5\end{array}$ & $\begin{array}{l}29 \\
19\end{array}$ & $\begin{array}{l}42 \\
42\end{array}$ & $\begin{array}{l}33 \\
32\end{array}$ & $\begin{array}{l}14 \\
21\end{array}$ & 29 & $\begin{array}{l}47 \\
42\end{array}$ & $\begin{array}{l}27 \\
27\end{array}$ & $\begin{array}{l}15 \\
24\end{array}$ \\
\hline $\begin{array}{l}\text { MGr. Interpret and apply district policy } \\
\text { and busilding standards }\end{array}$ & $\begin{array}{l}\text { Department Chair } \\
\text { Texcher }\end{array}$ & $\begin{array}{l}43 \\
42\end{array}$ & $\begin{array}{l}46 \\
49\end{array}$ & $\begin{array}{l}20 \\
20\end{array}$ & $\begin{array}{l}9 \\
3\end{array}$ & $\frac{25}{30}$ & $\begin{array}{l}41 \\
33\end{array}$ & $\begin{array}{l}33 \\
35\end{array}$ & $\begin{array}{l}19 \\
16\end{array}$ & $\begin{array}{l}26 \\
.31\end{array}$ & $\begin{array}{l}47 \\
34\end{array}$ & $\begin{array}{l}25 \\
31\end{array}$ & $\begin{array}{l}20 \\
18\end{array}$ \\
\hline $\begin{array}{l}\text { MGG7. Plan and organize relevant } \\
\text { department meetings }\end{array}$ & $\begin{array}{l}\text { Department Chair } \\
\text { Texcher }\end{array}$ & $\begin{array}{l}13 \\
20\end{array}$ & $\begin{array}{l}27 \\
36\end{array}$ & $\begin{array}{l}+2 \\
41\end{array}$ & $\begin{array}{l}26 \\
17\end{array}$ & $\begin{array}{l}4 \\
5\end{array}$ & $\begin{array}{l}17 \\
24\end{array}$ & $\begin{array}{l}51 \\
45\end{array}$ & $\begin{array}{l}46 \\
40\end{array}$ & $\begin{array}{l}8 \\
8\end{array}$ & $\begin{array}{l}22 \\
27\end{array}$ & $\begin{array}{l}41 \\
35\end{array}$ & $\begin{array}{l}47 \\
44\end{array}$ \\
\hline $\begin{array}{l}\text { MG8. Serve as liaison hetween department } \\
\text { members and the administration }\end{array}$ & $\begin{array}{l}\text { Department Chair } \\
\text { Teacher }\end{array}$ & $\begin{array}{r}5 \\
17 \\
\end{array}$ & $\begin{array}{l}31 \\
37 \\
\end{array}$ & $\begin{array}{l}33 \\
36 \\
\end{array}$ & $\begin{array}{l}49 \\
24\end{array}$ & $\begin{array}{l}3 \\
1 \\
\end{array}$ & $\begin{array}{l}10 \\
15\end{array}$ & $\begin{array}{l}50 \\
45\end{array}$ & $\begin{array}{l}55 \\
53\end{array}$ & $\begin{array}{l}7 \\
6 \\
\end{array}$ & $\begin{array}{l}22 \\
15\end{array}$ & $\begin{array}{l}41 \\
45\end{array}$ & $\begin{array}{l}48 \\
48\end{array}$ \\
\hline
\end{tabular}

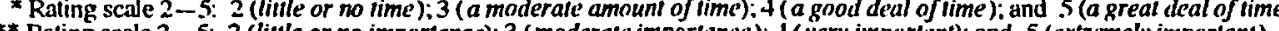


Chart $6: 3$

Department Chair Responsibility for the Organization: Ratings of Amount of Time Spent,* Importance to the Deparlment (.hair Role.**

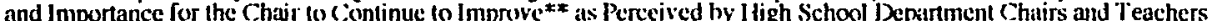

[13y Frequencies of Respunses (ijven for liach of l : our Ratings]
Subjects: Deparment Chairs $(N=118)$ Teachers $(N=114)$

\begin{tabular}{|c|c|c|c|c|c|c|c|c|c|c|c|c|c|}
\hline \multirow[t]{2}{*}{ Activity } & \multirow[t]{2}{*}{ Group } & \multicolumn{4}{|c|}{$T i m e^{*}$} & \multicolumn{4}{|c|}{ Role*: } & \multicolumn{4}{|c|}{ Improve ${ }^{x \times}$} \\
\hline & & 2 & 3 & 1 & 5 & 2 & 3 & 4 & 5 & 2 & 3 & 4 & 5 \\
\hline $\begin{array}{l}\text { OR1. Engage department members in an } \\
\text { organized department grosth and } \\
\text { improvement effort }\end{array}$ & $\begin{array}{l}\text { Department Chair } \\
\text { Teacher }\end{array}$ & $\begin{array}{l}36 \\
4.5\end{array}$ & $\begin{array}{l}43 \\
34\end{array}$ & $\begin{array}{l}26 \\
30\end{array}$ & $\begin{array}{r}13 \\
5\end{array}$ & $\begin{array}{l}8 \\
6\end{array}$ & $\begin{array}{l}32 \\
27\end{array}$ & 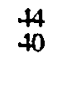 & $\begin{array}{l}34 \\
41\end{array}$ & $\frac{6}{8}$ & $\begin{array}{l}35 \\
27\end{array}$ & $\begin{array}{l}34 \\
35\end{array}$ & 43 \\
\hline $\begin{array}{l}\text { OR2. Represent the department in } \\
\text { developing and implementing school's } \\
\text { organized improvement effort }\end{array}$ & $\begin{array}{l}\text { Department Chair } \\
\text { Teacher }\end{array}$ & $\begin{array}{l}20 \\
28\end{array}$ & $\begin{array}{l}38 \\
48\end{array}$ & $\begin{array}{l}+1 \\
20\end{array}$ & $\begin{array}{r}19 \\
9\end{array}$ & $\begin{array}{l}9 \\
6\end{array}$ & $\begin{array}{l}35 \\
3.5\end{array}$ & $\begin{array}{l}45 \\
43\end{array}$ & $\begin{array}{r}29 \\
.30\end{array}$ & 11 & $\begin{array}{l}36 \\
35\end{array}$ & $\begin{array}{l}38 \\
45\end{array}$ & $\begin{array}{l}33 \\
28\end{array}$ \\
\hline $\begin{array}{l}\text { OR3. Serve as department spokesperson at } \\
\text { communily and board meetings }\end{array}$ & $\begin{array}{l}\text { Department Chair } \\
\text { Teacher }\end{array}$ & $\begin{array}{l}69 \\
54\end{array}$ & $\begin{array}{l}26 \\
.38\end{array}$ & $\begin{array}{l}12 \\
20\end{array}$ & 11 & $\begin{array}{l}31 \\
24\end{array}$ & $\begin{array}{l}31 \\
40\end{array}$ & $\begin{array}{l}41 \\
25\end{array}$ & $\begin{array}{l}15 \\
16\end{array}$ & $\begin{array}{l}28 \\
30\end{array}$ & $\begin{array}{l}41 \\
38\end{array}$ & $\begin{array}{l}34 \\
31\end{array}$ & $\begin{array}{l}15 \\
15\end{array}$ \\
\hline $\begin{array}{l}\text { OR4. Prepare requested information on } \\
\text { department topics for principal. central } \\
\text { office, school bxard }\end{array}$ & $\begin{array}{l}\text { Department Chair } \\
\text { Teacher }\end{array}$ & $\begin{array}{l}43 \\
29\end{array}$ & $\begin{array}{l}32 \\
48\end{array}$ & $\begin{array}{l}34 \\
31\end{array}$ & $\begin{array}{l}9 \\
6\end{array}$ & $\begin{array}{l}17 \\
17\end{array}$ & $\begin{array}{l}45 \\
39\end{array}$ & $\begin{array}{l}45 \\
40\end{array}$ & $\begin{array}{l}11 \\
18\end{array}$ & $\begin{array}{l}20 \\
21\end{array}$ & $\begin{array}{l}53 \\
36\end{array}$ & $\begin{array}{l}33 \\
39\end{array}$ & $\begin{array}{l}12 \\
18\end{array}$ \\
\hline $\begin{array}{l}\text { OR5. Acl as an advocate for the protection } \\
\text { of classroom instructional time }\end{array}$ & $\begin{array}{l}\text { Department Chair } \\
\text { Tcacher }\end{array}$ & $\begin{array}{l}35 \\
36\end{array}$ & $\begin{array}{l}44 \\
38\end{array}$ & 24 & $\begin{array}{l}15 \\
12\end{array}$ & $\begin{array}{r}13 \\
7\end{array}$ & $\begin{array}{l}29 \\
21\end{array}$ & $\begin{array}{l}38 \\
34\end{array}$ & $\begin{array}{l}38 \\
52\end{array}$ & $\begin{array}{r}1.5 \\
8\end{array}$ & $\begin{array}{l}40 \\
22\end{array}$ & $\begin{array}{l}28 \\
24\end{array}$ & $\begin{array}{l}35 \\
60\end{array}$ \\
\hline $\begin{array}{l}\text { ORG. Support teachers' professional necds } \\
\text { and concerns }\end{array}$ & $\begin{array}{l}\text { Department Chair } \\
\text { Teacher }\end{array}$ & $\begin{array}{l}31 \\
30\end{array}$ & $\begin{array}{l}38 \\
42\end{array}$ & $\frac{33}{21}$ & $\begin{array}{l}16 \\
21\end{array}$ & $\begin{array}{l}8 \\
6\end{array}$ & $\begin{array}{l}32 \\
21\end{array}$ & $\begin{array}{l}42 \\
39\end{array}$ & $\begin{array}{l}36 \\
48\end{array}$ & $\begin{array}{r}14 \\
6\end{array}$ & $\begin{array}{l}37 \\
20\end{array}$ & $\begin{array}{l}32 \\
39\end{array}$ & $\begin{array}{l}35 \\
49\end{array}$ \\
\hline $\begin{array}{l}\text { OR7. Work with other department chairs } \\
\text { to develop an integrated school } \\
\text { instructional program }\end{array}$ & $\begin{array}{l}\text { Jepartment Chair } \\
\text { Teacher }\end{array}$ & $\begin{array}{l}38 \\
41\end{array}$ & $\begin{array}{l}39 \\
34\end{array}$ & $\begin{array}{l}25 \\
30\end{array}$ & $\begin{array}{r}16 \\
9\end{array}$ & $\begin{array}{l}7 \\
8\end{array}$ & $\begin{array}{l}30 \\
29\end{array}$ & $\begin{array}{l}40 \\
53\end{array}$ & $\begin{array}{l}41 \\
24\end{array}$ & 5 & $\begin{array}{l}32 \\
29\end{array}$ & $\begin{array}{l}36 \\
45\end{array}$ & $\begin{array}{l}45 \\
30\end{array}$ \\
\hline $\begin{array}{l}\text { OR8. Participate in district-level planning } \\
\text { and decision making }\end{array}$ & $\begin{array}{l}\text { Department Chair } \\
\text { Teacher }\end{array}$ & $\begin{array}{r}32 \\
29 \\
\end{array}$ & $\begin{array}{r}32 \\
43 \\
\end{array}$ & $\begin{array}{r}33 \\
34 \\
\end{array}$ & $\begin{array}{r}21 \\
8 \\
\end{array}$ & $\begin{array}{l}8 \\
8\end{array}$ & $\begin{array}{r}29 \\
24 \\
\end{array}$ & $\begin{array}{l}4 \\
49 \\
\end{array}$ & $\begin{array}{l}37 \\
33 \\
\end{array}$ & $\begin{array}{r}9 \\
11 \\
\end{array}$ & $\begin{array}{l}30 \\
31 \\
\end{array}$ & $\begin{array}{l}41 \\
37 \\
\end{array}$ & $\begin{array}{l}38 \\
35 \\
\end{array}$ \\
\hline
\end{tabular}

* * Rating scale 2-5: 2 (linle or no importance); 3 (moderate importance): 4 (very important); and 5 (exrremely important) 
Chart cit

Department Chair Responsibility for Program: Ratings of Anounl of Time Spent. Impoxtance to the Department Chair Role.* and Importance for the Chair (o Continue to Improwe** as Perceived by lligh School IXeparment Chairs and Teachers

IBy Frequencies of Responses Given For liach of Four Ratings

\begin{tabular}{|c|c|c|c|c|c|c|c|c|c|c|c|c|c|}
\hline \multirow{2}{*}{ Activity } & \multirow{2}{*}{ Group } & \multicolumn{4}{|c|}{ Tinnex } & \multicolumn{4}{|c|}{ Rnelex: } & \multicolumn{4}{|c|}{ Improve } \\
\hline & & 2 & 3 & 4 & 5 & 2 & 3 & 4 & 5 & 2 & & 4 & 5 \\
\hline PG1. Facilitate development of curriculum & $\begin{array}{l}\text { Department Chair } \\
\text { Teacher }\end{array}$ & $\begin{array}{l}15 \\
18\end{array}$ & $\begin{array}{l}37 \\
51\end{array}$ & $\begin{array}{l}38 \\
30\end{array}$ & $\begin{array}{l}28 \\
16\end{array}$ & $\begin{array}{l}5 \\
2\end{array}$ & $\frac{20}{31}$ & $\begin{array}{l}56 \\
50\end{array}$ & 37 & $\begin{array}{l}6 \\
7\end{array}$ & $\begin{array}{l}25 \\
29\end{array}$ & $\begin{array}{l}53 \\
42\end{array}$ & 34 \\
\hline $\begin{array}{l}\text { PG2. Supervise the implementation of } \\
\text { curriculum }\end{array}$ & $\begin{array}{l}\text { Department Chair } \\
\text { Teacher }\end{array}$ & $\begin{array}{l}35 \\
38\end{array}$ & $\begin{array}{l}34 \\
48\end{array}$ & 32 & $\begin{array}{r}17 \\
8\end{array}$ & $\begin{array}{l}9 \\
5\end{array}$ & 22 & $\begin{array}{l}50 \\
44\end{array}$ & $\begin{array}{l}37 \\
26\end{array}$ & $\begin{array}{l}8 \\
5\end{array}$ & $\begin{array}{l}32 \\
39\end{array}$ & $\begin{array}{l}43 \\
40\end{array}$ & $\begin{array}{l}3.5 \\
30\end{array}$ \\
\hline $\begin{array}{l}\text { PG.3. Monitor the continued maintenance } \\
\text { of curriculum }\end{array}$ & $\begin{array}{l}\text { Department Chair } \\
\text { Teacher }\end{array}$ & $\begin{array}{l}37 \\
+7\end{array}$ & $\begin{array}{l}40 \\
42\end{array}$ & $\begin{array}{l}28 \\
16\end{array}$ & $\begin{array}{r}13 \\
5\end{array}$ & $\begin{array}{r}8 \\
10\end{array}$ & $\begin{array}{l}31 \\
40\end{array}$ & $\begin{array}{l}43 \\
+5\end{array}$ & $\begin{array}{l}36 \\
19\end{array}$ & $\underset{13}{8}$ & $\begin{array}{l}39 \\
36\end{array}$ & $\begin{array}{l}36 \\
41\end{array}$ & $\begin{array}{l}35 \\
24\end{array}$ \\
\hline $\begin{array}{l}\text { PG4. Devise and implement process for } \\
\text { program evaluation }\end{array}$ & $\begin{array}{l}\text { Department Chair } \\
\text { Teacher }\end{array}$ & $\begin{array}{l}55 \\
60\end{array}$ & $\begin{array}{l}41 \\
40\end{array}$ & $\begin{array}{l}20 \\
10\end{array}$ & $\begin{array}{l}2 \\
4\end{array}$ & $\begin{array}{r}14 \\
9\end{array}$ & $\begin{array}{l}38 \\
46\end{array}$ & $\begin{array}{l}50 \\
34\end{array}$ & $\begin{array}{l}16 \\
25\end{array}$ & $\begin{array}{l}13 \\
13\end{array}$ & $\begin{array}{l}37 \\
39\end{array}$ & $\begin{array}{l}46 \\
38\end{array}$ & $\frac{22}{24}$ \\
\hline $\begin{array}{l}\text { PGS. Provide leadership in the selection } \\
\text { and development of instructional } \\
\text { materials }\end{array}$ & $\begin{array}{l}\text { Department Chair } \\
\text { Teacher }\end{array}$ & $\begin{array}{l}19 \\
35\end{array}$ & $\begin{array}{l}47 \\
42\end{array}$ & $\frac{24}{28}$ & $\begin{array}{r}28 \\
9\end{array}$ & $\begin{array}{l}6 \\
7\end{array}$ & $\begin{array}{l}32 \\
33\end{array}$ & $\begin{array}{l}44 \\
45\end{array}$ & $\begin{array}{l}36 \\
29\end{array}$ & $\begin{array}{l}8 \\
9\end{array}$ & $\begin{array}{l}36 \\
33\end{array}$ & $\begin{array}{l}37 \\
40\end{array}$ & $\begin{array}{l}37 \\
32\end{array}$ \\
\hline $\begin{array}{l}\text { PG6. Coordinate departmental selection of } \\
\text { iextbooks and supplemental materials }\end{array}$ & $\begin{array}{l}\text { Department Chair } \\
\text { Teacher }\end{array}$ & $\begin{array}{l}17 \\
38\end{array}$ & $\begin{array}{l}35 \\
42\end{array}$ & $\begin{array}{l}31 \\
30\end{array}$ & $\begin{array}{l}35 \\
18\end{array}$ & $\begin{array}{l}4 \\
6\end{array}$ & $\begin{array}{l}24 \\
30\end{array}$ & $\begin{array}{l}47 \\
48\end{array}$ & $\begin{array}{l}43 \\
30\end{array}$ & $\begin{array}{l}7 \\
8\end{array}$ & $\begin{array}{l}30 \\
29\end{array}$ & $\begin{array}{l}38 \\
46\end{array}$ & $\begin{array}{l}43 \\
31\end{array}$ \\
\hline $\begin{array}{l}\text { PG7. Assess learning outcomes to identify } \\
\text { program strengths and weaknesses }\end{array}$ & $\begin{array}{l}\text { Department Chair } \\
\text { Teacher }\end{array}$ & $\begin{array}{l}49 \\
62\end{array}$ & $\begin{array}{l}38 \\
35\end{array}$ & $\begin{array}{r}26 \\
9\end{array}$ & $\begin{array}{l}5 \\
8\end{array}$ & $\begin{array}{r}11 \\
7\end{array}$ & $\begin{array}{l}31 \\
34\end{array}$ & $\begin{array}{l}55 \\
46\end{array}$ & $\begin{array}{l}21 \\
27\end{array}$ & $\begin{array}{r}12 \\
8\end{array}$ & $\begin{array}{l}28 \\
27\end{array}$ & $\begin{array}{l}54 \\
44\end{array}$ & $\begin{array}{l}24 \\
3.5\end{array}$ \\
\hline $\begin{array}{l}\text { PG8. Establish goals for program } \\
\text { improvement }\end{array}$ & $\begin{array}{l}\text { Department Chair } \\
\text { Teacher }\end{array}$ & $\begin{array}{l}36 \\
52 \\
\end{array}$ & $\begin{array}{l}41 \\
40\end{array}$ & $\begin{array}{l}31 \\
18 \\
\end{array}$ & $\begin{array}{r}10 \\
4\end{array}$ & $\begin{array}{l}7 \\
8\end{array}$ & $\begin{array}{l}24 \\
31\end{array}$ & $\begin{array}{l}58 \\
48 \\
48\end{array}$ & $\begin{array}{l}29 \\
27 \\
\end{array}$ & $\begin{array}{r}8 \\
10\end{array}$ & $\begin{array}{l}25 \\
27\end{array}$ & $\begin{array}{l}55 \\
42 \\
\end{array}$ & $\begin{array}{l}30 \\
3.5\end{array}$ \\
\hline
\end{tabular}


Chast 1.5

Depertment Chair Responsibility for Supervision: Ratings of Amount of Time Spent.* Importance to the Department Chair Role,** and Importance for the Chair to Continue to Inprove ${ }^{x *}$ as Perceired by lligh School Departsnent Chairs and 'Tenchers

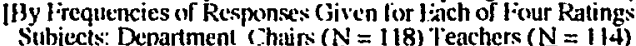

\begin{tabular}{|c|c|c|c|c|c|c|c|c|c|c|c|c|c|}
\hline \multirow[t]{2}{*}{ Activily } & \multirow{2}{*}{ Group } & \multirow{2}{*}{\multicolumn{4}{|c|}{$\frac{T i m c^{*}}{f}$}} & \multicolumn{4}{|c|}{ Rolex } & \multicolumn{4}{|c|}{ Improve } \\
\hline & & & & & & 2 & 3 & 4 & 5 & 2 & & 4 & 5 \\
\hline $\begin{array}{l}\text { SP1. Model a varicly of instructional } \\
\text { strategies }\end{array}$ & $\begin{array}{l}\text { Tepairment Chair } \\
\text { Teacher }\end{array}$ & 72 & $\begin{array}{l}36 \\
29\end{array}$ & $\begin{array}{l}14 \\
10\end{array}$ & 3 & 25 & $\begin{array}{l}38 \\
47\end{array}$ & $\begin{array}{l}31 \\
28\end{array}$ & 16 & 29 & $\begin{array}{l}35 \\
36\end{array}$ & $\begin{array}{l}31 \\
28\end{array}$ & $\begin{array}{l}25 \\
21\end{array}$ \\
\hline $\begin{array}{l}\text { SP2. Assist leachers in devcloping } \\
\text { professional growth plans }\end{array}$ & $\begin{array}{l}\text { Department Chair } \\
\text { Teacher }\end{array}$ & $\begin{array}{l}83 \\
81\end{array}$ & 24 & $\begin{array}{r}10 \\
8\end{array}$ & $i$ & $\begin{array}{l}+0 \\
28\end{array}$ & 42 & $\frac{27}{32}$ & $\stackrel{9}{11}$ & $\begin{array}{l}34 \\
29\end{array}$ & $\begin{array}{l}43 \\
38\end{array}$ & $\begin{array}{l}28 \\
29\end{array}$ & $\begin{array}{l}13 \\
18\end{array}$ \\
\hline $\begin{array}{l}\text { SP3. Encourage experimentation and } \\
\text { innovation among teachers }\end{array}$ & $\begin{array}{l}\text { Depintment Chair } \\
\text { Teacher }\end{array}$ & $\begin{array}{l}37 \\
46\end{array}$ & $\begin{array}{l}47 \\
+6\end{array}$ & $\begin{array}{l}25 \\
11\end{array}$ & $\stackrel{9}{11}$ & $\begin{array}{r}18 \\
9\end{array}$ & $\begin{array}{l}22 \\
32\end{array}$ & $\stackrel{48}{41}$ & $\begin{array}{l}30 \\
29\end{array}$ & $\begin{array}{l}16 \\
12\end{array}$ & $\begin{array}{l}21 \\
27\end{array}$ & $\begin{array}{l}48 \\
43\end{array}$ & $\begin{array}{l}33 \\
32\end{array}$ \\
\hline $\begin{array}{l}\text { SP4. Coordinate instruction among } \\
\text { depertment members }\end{array}$ & $\begin{array}{l}\text { Department Chair } \\
\text { Teacher }\end{array}$ & $\begin{array}{l}31 \\
53\end{array}$ & $\begin{array}{l}51 \\
40\end{array}$ & $\begin{array}{l}30 \\
17\end{array}$ & 4 & $\begin{array}{l}10 \\
14\end{array}$ & $\begin{array}{l}35 \\
40\end{array}$ & $\begin{array}{l}50 \\
35\end{array}$ & $\begin{array}{l}23 \\
25\end{array}$ & $\begin{array}{r}6 \\
16\end{array}$ & $\begin{array}{l}37 \\
38\end{array}$ & $\begin{array}{l}43 \\
36\end{array}$ & 32 \\
\hline $\begin{array}{l}\text { SP5. Ohserve teachers in their classrooms } \\
\text { and provide feedback }\end{array}$ & $\begin{array}{l}\text { Department Chair } \\
\text { Teacher }\end{array}$ & $\begin{array}{l}81 \\
72\end{array}$ & 32 & $\begin{array}{l}6 \\
9\end{array}$ & $\begin{array}{l}9 \\
1\end{array}$ & $\begin{array}{l}36 \\
25\end{array}$ & $\begin{array}{l}30 \\
40\end{array}$ & $\begin{array}{l}35 \\
29\end{array}$ & $\begin{array}{l}17 \\
20\end{array}$ & $\begin{array}{l}31 \\
25\end{array}$ & $\begin{array}{l}30 \\
31\end{array}$ & $\begin{array}{l}30 \\
33\end{array}$ & $\begin{array}{l}27 \\
25\end{array}$ \\
\hline SPG. Monitor teacher lesson plans & $\begin{array}{l}\text { Department Chair } \\
\text { Teacher }\end{array}$ & $\begin{array}{r}107 \\
98\end{array}$ & $\begin{array}{r}6 \\
14\end{array}$ & $\begin{array}{l}\mathbf{3} \\
\mathbf{2}\end{array}$ & $\frac{2}{0}$ & $\begin{array}{l}78 \\
68\end{array}$ & $\begin{array}{l}26 \\
35\end{array}$ & 11 & $\begin{array}{l}3 \\
6\end{array}$ & $\begin{array}{l}72 \\
66\end{array}$ & $\mathbf{2 7}$ & $\begin{array}{r}12 \\
5\end{array}$ & $\begin{array}{l}7 \\
9\end{array}$ \\
\hline SP7. Practice clinical supervision & $\begin{array}{l}\text { Department Chair } \\
\text { Teacher }\end{array}$ & $\begin{array}{l}97 \\
9.5\end{array}$ & 11 & $\begin{array}{l}8 \\
7\end{array}$ & $\frac{2}{0}$ & $\begin{array}{l}67 \\
60\end{array}$ & 37 & 17 & $\begin{array}{l}6 \\
6\end{array}$ & $\begin{array}{l}63 \\
58\end{array}$ & $\begin{array}{l}31 \\
35\end{array}$ & $\begin{array}{l}14 \\
11\end{array}$ & $\begin{array}{l}10 \\
10\end{array}$ \\
\hline $\begin{array}{l}\text { SP8. Communicate high expectations for } \\
\text { leacher performance }\end{array}$ & $\begin{array}{l}\text { Department Chair } \\
\text { Teacher }\end{array}$ & $\begin{array}{l}47 \\
59\end{array}$ & $\begin{array}{l}42 \\
33\end{array}$ & $\begin{array}{l}20 \\
1.5\end{array}$ & $\begin{array}{l}9 \\
7\end{array}$ & $\begin{array}{l}13 \\
15\end{array}$ & $\begin{array}{l}36 \\
34\end{array}$ & $\begin{array}{l}49 \\
38\end{array}$ & $\begin{array}{l}20 \\
27\end{array}$ & $\begin{array}{l}13 \\
18\end{array}$ & $\begin{array}{l}37 \\
29\end{array}$ & $\begin{array}{l}47 \\
37\end{array}$ & $\begin{array}{l}21 \\
30\end{array}$ \\
\hline $\begin{array}{l}\text { SP9. Assist teachers with improvement of } \\
\text { their instruction }\end{array}$ & $\begin{array}{l}\text { Department Chair } \\
\text { Teacher }\end{array}$ & $\begin{array}{l}60 \\
67\end{array}$ & $\begin{array}{l}+0 \\
30\end{array}$ & $\begin{array}{l}14 \\
13\end{array}$ & 4 & $\begin{array}{l}19 \\
16\end{array}$ & $\begin{array}{l}33 \\
36\end{array}$ & $\begin{array}{l}45 \\
42\end{array}$ & $\begin{array}{l}21 \\
20\end{array}$ & $\begin{array}{l}18 \\
17\end{array}$ & $\begin{array}{l}28 \\
32\end{array}$ & $\begin{array}{l}46 \\
35\end{array}$ & $\begin{array}{l}26 \\
30\end{array}$ \\
\hline $\begin{array}{l}\text { SPIO. Organize plan for teacher sharing. } \\
\text { peer coaching }\end{array}$ & $\begin{array}{l}\text { Department Chair } \\
\text { Teachet }\end{array}$ & $\begin{array}{l}92 \\
85\end{array}$ & $\begin{array}{l}18 \\
21\end{array}$ & $\begin{array}{l}5 \\
8\end{array}$ & $\begin{array}{l}3 \\
0\end{array}$ & $\begin{array}{l}39 \\
28\end{array}$ & $\begin{array}{l}38 \\
47\end{array}$ & $\begin{array}{l}26 \\
27\end{array}$ & $\begin{array}{l}15 \\
12\end{array}$ & $\begin{array}{l}36 \\
28\end{array}$ & $\begin{array}{l}36 \\
41\end{array}$ & $\begin{array}{l}27 \\
28\end{array}$ & $\begin{array}{l}19 \\
17\end{array}$ \\
\hline SPII. Jivaluate teacher performance & $\begin{array}{l}\text { Department Chair } \\
\text { Teacher }\end{array}$ & $\begin{array}{l}97 \\
83\end{array}$ & $\stackrel{11}{21}$ & $\begin{array}{l}7 \\
9\end{array}$ & 3 & $\begin{array}{l}67 \\
41\end{array}$ & $\begin{array}{l}23 \\
39\end{array}$ & $\begin{array}{l}19 \\
26\end{array}$ & $\begin{array}{l}9 \\
8\end{array}$ & $\begin{array}{l}64 \\
42\end{array}$ & $\begin{array}{l}21 \\
32\end{array}$ & $\begin{array}{l}19 \\
26\end{array}$ & $\begin{array}{l}14 \\
14\end{array}$ \\
\hline
\end{tabular}

** Rating scale $2-5: 2$ (liftle or no imporfance); 3 (moderale importunce); 4 (verv inportant); and 5 (extremely importamt) 
Chart C6

Department Chair Responsibility for Human Relations: Ratings of Amount of Time Spent,* Importance to the Department Chair Role, ${ }^{* *}$ and Importance for the Chair to Continue to Improv'e** as Perceived by Department Chairs and Teachers

Subjects $(\mathrm{N}=232)$

\begin{tabular}{|c|c|c|c|c|c|}
\hline \multirow[b]{2}{*}{ Activity } & \multirow[b]{2}{*}{ Issue } & \multicolumn{2}{|c|}{$\begin{array}{c}\text { Department Chairs } \\
(\mathrm{N}=118)\end{array}$} & \multicolumn{2}{|c|}{$\begin{array}{l}\text { Teachers } \\
(\mathrm{N}=114)\end{array}$} \\
\hline & & $\underline{M}$ & $\underline{S D}$ & $\mathrm{M}$ & $\underline{\mathrm{SD}}$ \\
\hline $\begin{array}{l}\text { HR1. Build and maintain a } \\
\text { supportive department team }\end{array}$ & $\begin{array}{l}\text { Time } \\
\text { Role } \\
\text { Improve }\end{array}$ & $\begin{array}{l}3.415 \\
4.059 \\
4.246\end{array}$ & $\begin{array}{l}0.870 \\
0.870 \\
0.747\end{array}$ & $\begin{array}{l}3.035 \\
4.246 \\
4.246\end{array}$ & $\begin{array}{l}1.021 \\
0.747 \\
0.698\end{array}$ \\
\hline $\begin{array}{l}\text { HR2. Encourage open } \\
\text { communication among } \\
\text { department members }\end{array}$ & $\begin{array}{l}\text { Time } \\
\text { Role } \\
\text { Improve }\end{array}$ & $\begin{array}{l}3.686 \\
4.305 \\
4.342\end{array}$ & $\begin{array}{l}0.903 \\
0.757 \\
0.762\end{array}$ & $\begin{array}{l}3.148 \\
4.377 \\
4.342\end{array}$ & $\begin{array}{l}1.102 \\
0.696 \\
0.762\end{array}$ \\
\hline $\begin{array}{l}\text { HR3. Facilitate effective } \\
\text { conflict resolution }\end{array}$ & $\begin{array}{l}\text { Time } \\
\text { Role } \\
\text { Improve }\end{array}$ & $\begin{array}{l}2.949 \\
3.805 \\
4.114\end{array}$ & $\begin{array}{l}0.977 \\
0.954 \\
0.849\end{array}$ & $\begin{array}{l}2.868 \\
4.140 \\
4.112\end{array}$ & $\begin{array}{l}0.936 \\
0.797 \\
0.849\end{array}$ \\
\hline $\begin{array}{l}\text { HR4. Foster cooperative } \\
\text { problem solving }\end{array}$ & $\begin{array}{l}\text { Time } \\
\text { Role } \\
\text { Improve }\end{array}$ & $\begin{array}{l}3.229 \\
3.932 \\
4.096\end{array}$ & $\begin{array}{l}0.991 \\
0.850 \\
0.809\end{array}$ & $\begin{array}{l}2.982 \\
4.088 \\
4.096\end{array}$ & $\begin{array}{l}1.004 \\
0.826 \\
0.809\end{array}$ \\
\hline $\begin{array}{l}\text { HR5. Encourage trust, caring, } \\
\text { and respect among department } \\
\text { members }\end{array}$ & $\begin{array}{l}\text { Time } \\
\text { Role } \\
\text { Improve }\end{array}$ & $\begin{array}{l}3.664 \\
4.297 \\
4.096\end{array}$ & $\begin{array}{l}0.965 \\
0.723 \\
0.892\end{array}$ & $\begin{array}{l}3.035 \\
4.211 \\
4.096\end{array}$ & $\begin{array}{l}1.088 \\
0.814 \\
0.892\end{array}$ \\
\hline $\begin{array}{l}\text { HR6. Maintain regular, open } \\
\text { communication with department } \\
\text { members }\end{array}$ & $\begin{array}{l}\text { Time } \\
\text { Role } \\
\text { Improve }\end{array}$ & $\begin{array}{l}4.085 \\
4.568 \\
4.368\end{array}$ & $\begin{array}{l}0.823 \\
0.685 \\
0.707\end{array}$ & $\begin{array}{l}3.491 \\
3.491 \\
4.368\end{array}$ & $\begin{array}{l}1.041 \\
1.041 \\
0.707\end{array}$ \\
\hline $\begin{array}{l}\text { HR7. Practice collaborative, } \\
\text { participative decision- } \\
\text { making processes }\end{array}$ & $\begin{array}{l}\text { Time } \\
\text { Role } \\
\text { Improve }\end{array}$ & $\begin{array}{l}3.551 \\
4.220 \\
4.211\end{array}$ & $\begin{array}{l}1.059 \\
0.828 \\
0.781\end{array}$ & $\begin{array}{l}3.327 \\
4.307 \\
4.211\end{array}$ & $\begin{array}{l}0.989 \\
0.680 \\
0.781\end{array}$ \\
\hline $\begin{array}{l}\text { HR8. Promote an atmosphere } \\
\text { that encourages continuous } \\
\text { improvement }\end{array}$ & $\begin{array}{l}\text { Time } \\
\text { Role } \\
\text { Improve }\end{array}$ & $\begin{array}{l}3.619 \\
4.339 \\
4.263\end{array}$ & $\begin{array}{l}0.896 \\
0.731 \\
0.788\end{array}$ & $\begin{array}{l}4.316 \\
3.289 \\
4.263\end{array}$ & $\begin{array}{l}0.756 \\
1.070 \\
0.788\end{array}$ \\
\hline $\begin{array}{l}\text { HR9. Encourage department } \\
\text { members to share in leadership } \\
\text { roles }\end{array}$ & $\begin{array}{l}\text { Time } \\
\text { Role } \\
\text { Improve }\end{array}$ & $\begin{array}{l}3.069 \\
3.780 \\
3.833\end{array}$ & $\begin{array}{l}0.894 \\
0.888 \\
0.872\end{array}$ & $\begin{array}{l}2.939 \\
3.842 \\
3.833\end{array}$ & $\begin{array}{l}1.091 \\
0.858 \\
0.782\end{array}$ \\
\hline
\end{tabular}

* Rating scale: $1-5$ (1) No time; (2) Little time (3) A moderate amoun of time ; (4) A good deal of time; (5) A great deal of time

** Rating scale: $1-5$ (1) No importance; (2) Linle importance; (3) Moderate importance; (4) Very important; (5) Extremely important 


\section{Chart C7}

Deparment Chair Responsibility for Management: Ratings of Amount of Time Spent,* Importance to the Department Chair Role,** and Importance for the Chair to Continue to Improve** as Perceived by Department Chairs and Teachers Subjects $(\mathrm{N}=232)$

\begin{tabular}{|c|c|c|c|c|c|}
\hline \multirow[b]{2}{*}{ Activity } & \multirow[b]{2}{*}{ Issue } & \multicolumn{2}{|c|}{$\begin{array}{l}\text { Department Chairs } \\
(\mathrm{N}=118)\end{array}$} & \multicolumn{2}{|c|}{$\begin{array}{l}\text { Teachers } \\
(\mathrm{N}=114)\end{array}$} \\
\hline & & $\underline{\mathrm{M}}$ & $\underline{\mathrm{SD}}$ & $\underline{\mathrm{M}}$ & $\underline{\mathrm{SD}}$ \\
\hline \multirow{3}{*}{$\begin{array}{l}\text { MG 1. Develop department } \\
\text { teaching schedule and } \\
\text { assignments }\end{array}$} & Time & 3.559 & 1.042 & 3.640 & 1.049 \\
\hline & Role & 4.136 & 0.794 & 4.167 & 0.901 \\
\hline & Improve & 3.864 & 1.004 & 4.096 & 0.959 \\
\hline \multirow{3}{*}{$\begin{array}{l}\text { MG2. Participate in the } \\
\text { selection of department } \\
\text { instructional personnel }\end{array}$} & Time & 3.017 & 1.247 & 3.202 & 1.066 \\
\hline & Role & 4.212 & 0.885 & 4.219 & 0.849 \\
\hline & Improve & 4.085 & 0.957 & 4.053 & 0.967 \\
\hline \multirow{3}{*}{$\begin{array}{l}\text { MG3. Develop and administer } \\
\text { the department budget }\end{array}$} & Time & 3.797 & 0.975 & 3.895 & 0.916 \\
\hline & Role & 4.153 & 0.888 & 4.167 & 0.786 \\
\hline & Improve & 3.941 & 0.954 & 3.965 & 0.911 \\
\hline \multirow{3}{*}{$\begin{array}{l}\text { MG4. Disseminate information } \\
\text { to department staff }\end{array}$} & Time & 4.008 & 0.974 & 3.746 & 0.967 \\
\hline & Role & 4.220 & 0.888 & 4.184 & 0.888 \\
\hline & Improve & 3.924 & 1.022 & 3.956 & 1.008 \\
\hline \multirow{3}{*}{$\begin{array}{l}\text { MG5. Allocate and maintain } \\
\text { equipment, instructional } \\
\text { matcrials, and facilities }\end{array}$} & Time & 2.924 & 1.163 & 2.763 & 0.962 \\
\hline & Role & 3.186 & 1.109 & 3.404 & 1.127 \\
\hline & Improve & 3.153 & 1.107 & 3.412 & 1.135 \\
\hline \multirow{3}{*}{$\begin{array}{l}\text { MG6. Interpret and apply } \\
\text { district policy and building } \\
\text { standards }\end{array}$} & Time & 2.856 & 1.064 & 2.772 & 0.932 \\
\hline & Role & 3.322 & 1.116 & 3.263 & 1.121 \\
\hline & Improve & 3.254 & 1.134 & 3.246 & 1.156 \\
\hline \multirow{3}{*}{$\begin{array}{l}\text { MG7. Plan and organize } \\
\text { reletant department } \\
\text { meetings }\end{array}$} & Time & 3.661 & 0.998 & 3.420 & 1.149 \\
\hline & Role & 4.161 & 0.857 & 3.974 & 1.043 \\
\hline & Improve & 4.059 & 0.972 & 3.974 & 1.043 \\
\hline \multirow{3}{*}{$\begin{array}{l}\text { MG8. Serie as liaison between } \\
\text { department members } \\
\text { and the administration }\end{array}$} & Time & 4.068 & 0.922 & 3.544 & 1.074 \\
\hline & Role & 4.322 & 0.772 & 4.307 & 0.766 \\
\hline & Improve & 4.085 & 0.957 & 4.158 & 0.937 \\
\hline
\end{tabular}

(4) Very important; (5) Extremely inportant 


\section{Chart C8}

Department Chair Responsibility for the Organization: Ratings of Amount of Time Spent,* Importance to the Department Chair Role,** and Importance for the Chair to Continue to Improve** as Perceived by Department Chairs and Teachers Subjects $(\mathrm{N}=\mathbf{2 3 2})$

\begin{tabular}{|c|c|c|c|c|c|}
\hline \multirow[b]{2}{*}{ Activity } & \multirow[b]{2}{*}{ Issue } & \multicolumn{2}{|c|}{$\begin{array}{c}\text { Department Chairs } \\
(\mathrm{N}=118)\end{array}$} & \multicolumn{2}{|c|}{$\begin{array}{l}\text { Teachers } \\
(\mathrm{N}=114) \\
\end{array}$} \\
\hline & & $\underline{\mathrm{M}}$ & $\underline{S D}$ & $\underline{\mathrm{M}}$ & $\underline{S D}$ \\
\hline $\begin{array}{l}\text { OR1. Engage department members in } \\
\text { an organized department growth and } \\
\text { improvement effort }\end{array}$ & $\begin{array}{l}\text { Time } \\
\text { Role } \\
\text { Improve }\end{array}$ & $\begin{array}{l}3.059 \\
3.864 \\
3.958\end{array}$ & $\begin{array}{l}1.096 \\
0.942 \\
0.955\end{array}$ & $\begin{array}{l}2.816 \\
4.009 \\
3.982\end{array}$ & $\begin{array}{l}1.110 \\
0.926 \\
1.022\end{array}$ \\
\hline $\begin{array}{l}\text { OR2. Represent the department in } \\
\text { developing implementing the school's } \\
\text { organized improvement effort }\end{array}$ & $\begin{array}{l}\text { Time } \\
\text { Role } \\
\text { Improve }\end{array}$ & $\begin{array}{l}3.466 \\
3.778 \\
3.780\end{array}$ & $\begin{array}{l}1.027 \\
0.923 \\
0.980\end{array}$ & $\begin{array}{l}3.088 \\
3.833 \\
3.816\end{array}$ & $\begin{array}{l}1.027 \\
0.921 \\
0.908\end{array}$ \\
\hline $\begin{array}{l}\text { OR3. Serve as department } \\
\text { spokesperson at community meetings, } \\
\text { board meetings }\end{array}$ & $\begin{array}{l}\text { Time } \\
\text { Role } \\
\text { Improve }\end{array}$ & $\begin{array}{l}2.483 \\
3.263 \\
3.327\end{array}$ & $\begin{array}{l}1.211 \\
1.136 \\
1.091\end{array}$ & $\begin{array}{l}2.588 \\
3.254 \\
3.219\end{array}$ & $\begin{array}{l}1.003 \\
1.020 \\
1.087\end{array}$ \\
\hline $\begin{array}{l}\text { OR4. Prepare requested information on } \\
\text { department topics for principal, central } \\
\text { office. school board }\end{array}$ & $\begin{array}{l}\text { Time } \\
\text { Role } \\
\text { Improve }\end{array}$ & $\begin{array}{l}2.975 \\
3.390 \\
3.280\end{array}$ & $\begin{array}{l}1.128 \\
0.925 \\
0.942\end{array}$ & $\begin{array}{l}3.044 \\
3.509 \\
3.447\end{array}$ & $\begin{array}{l}0.990 \\
0.952 \\
1.023\end{array}$ \\
\hline $\begin{array}{l}\text { OR5. Act as advocate for the } \\
\text { protection of classroom instructional } \\
\text { time }\end{array}$ & $\begin{array}{l}\text { Time } \\
\text { Role } \\
\text { Improve }\end{array}$ & $\begin{array}{l}3.093 \\
3.831 \\
3.653\end{array}$ & $\begin{array}{l}1.102 \\
1.057 \\
1.135\end{array}$ & $\begin{array}{l}3.053 \\
4.140 \\
4.184\end{array}$ & $\begin{array}{l}1.120 \\
0.958 \\
1.009\end{array}$ \\
\hline $\begin{array}{l}\text { OR6. Support teachers' } \\
\text { professional needs and concerns }\end{array}$ & $\begin{array}{l}\text { Time } \\
\text { Role } \\
\text { Improve }\end{array}$ & $\begin{array}{l}3.229 \\
3.881 \\
3.729\end{array}$ & $\begin{array}{l}1.105 \\
0.962 \\
1.051\end{array}$ & $\begin{array}{l}3.254 \\
4.132 \\
4.140\end{array}$ & $\begin{array}{l}1.112 \\
0.898 \\
0.921\end{array}$ \\
\hline $\begin{array}{l}\text { OR7. Work with other department } \\
\text { chairs to develop an integrated school } \\
\text { instructional program }\end{array}$ & $\begin{array}{l}\text { Time } \\
\text { Role } \\
\text { Improve }\end{array}$ & $\begin{array}{l}3.093 \\
3.975 \\
4.017\end{array}$ & $\begin{array}{l}1.132 \\
0.920 \\
0.934\end{array}$ & $\begin{array}{l}2.974 \\
3.807 \\
3.825\end{array}$ & $\begin{array}{l}1.101 \\
0.871 \\
0.943\end{array}$ \\
\hline $\begin{array}{l}\text { OR8. Participate in curricular } \\
\text { planning and decision making at the } \\
\text { district level }\end{array}$ & $\begin{array}{l}\text { Time } \\
\text { Role } \\
\text { Improve }\end{array}$ & $\begin{array}{l}3.280 \\
3.907 \\
3.907 \\
\end{array}$ & $\begin{array}{l}1.205 \\
0.978 \\
0.961 \\
\end{array}$ & $\begin{array}{l}3.140 \\
3.930 \\
3.833 \\
\end{array}$ & $\begin{array}{l}0.977 \\
0.909 \\
0.995 \\
\end{array}$ \\
\hline
\end{tabular}

* Rating scale: 1-5 (1) No time; (2) Linle time (3) A moderate amount of time ; (4) A good deal of time; (5) A great deal of time

** Rating scale: $1-5$ (1) No importance; (2) Little importance; (3) Moderate importance ;

(4) Very important; (5) Extremely important 
Chart $C 9$

Department Chair Responsibility for Program: Ratings of Amount of Time Spent,* Importance to the Department Chair Role,** and Importance for the Chair to Continue to Improve** as Perceived by Department Chairs and Teachers Subjects $(N=232)$

\begin{tabular}{|c|c|c|c|c|c|}
\hline \multirow{2}{*}{ Activity } & \multirow{2}{*}{ Issue } & \multicolumn{2}{|c|}{$\begin{array}{c}\text { Department Chairs } \\
(\mathrm{N}=118)\end{array}$} & \multicolumn{2}{|c|}{$\begin{array}{l}\text { Teachers } \\
(\mathrm{N}=114)\end{array}$} \\
\hline & & $\mathrm{M}$ & $\underline{S D}$ & $\underline{M}$ & $\underline{S D}$ \\
\hline $\begin{array}{l}\text { PG1. Facilitate development } \\
\text { of curriculum (philosophy; goals, } \\
\text { objectives) }\end{array}$ & $\begin{array}{l}\text { Time } \\
\text { Role } \\
\text { Improve }\end{array}$ & $\begin{array}{l}3.627 \\
4.051 \\
3.966\end{array}$ & $\begin{array}{l}1.069 \\
0.836 \\
0.867\end{array}$ & $\begin{array}{l}3.333 \\
3.965 \\
3.930\end{array}$ & $\begin{array}{l}1.001 \\
0.786 \\
0.929\end{array}$ \\
\hline $\begin{array}{l}\text { PG2. Supervise implementation } \\
\text { of curriculum }\end{array}$ & $\begin{array}{l}\text { Time } \\
\text { Role } \\
\text { Improve }\end{array}$ & $\begin{array}{l}3.186 \\
3.958 \\
3.873\end{array}$ & $\begin{array}{l}1.162 \\
0.946 \\
0.957\end{array}$ & $\begin{array}{l}2.895 \\
3.798 \\
3.816\end{array}$ & $\begin{array}{l}1.025 \\
0.843 \\
0.918\end{array}$ \\
\hline $\begin{array}{l}\text { PG3. Monitor the continued } \\
\text { maintenance of curriculum }\end{array}$ & $\begin{array}{l}\text { Time } \\
\text { Role } \\
\text { Improve }\end{array}$ & $\begin{array}{l}3.068 \\
3.890 \\
3.814\end{array}$ & $\begin{array}{l}1.107 \\
0.959 \\
0.978\end{array}$ & $\begin{array}{l}2.754 \\
3.632 \\
3.632\end{array}$ & $\begin{array}{l}0.927 \\
0.885 \\
0.885\end{array}$ \\
\hline $\begin{array}{l}\text { PG4. Devise and implement } \\
\text { process for program evaluation }\end{array}$ & $\begin{array}{l}\text { Time } \\
\text { Role } \\
\text { Improve }\end{array}$ & $\begin{array}{l}2.559 \\
3.534 \\
3.602\end{array}$ & $\begin{array}{l}1.026 \\
0.967 \\
1.022\end{array}$ & $\begin{array}{l}2.430 \\
3.640 \\
3.614\end{array}$ & $\begin{array}{l}1.022 \\
0.951 \\
1.000\end{array}$ \\
\hline $\begin{array}{l}\text { PG5. Provide leadership in the } \\
\text { selection and development of } \\
\text { insiructional materials }\end{array}$ & $\begin{array}{l}\text { Time } \\
\text { Role } \\
\text { Improve }\end{array}$ & $\begin{array}{l}3.500 \\
3.932 \\
3.873\end{array}$ & $\begin{array}{l}1.060 \\
0.884 \\
0.939\end{array}$ & $\begin{array}{l}3.009 \\
3.833 \\
3.816\end{array}$ & $\begin{array}{l}1.077 \\
0.901 \\
0.974\end{array}$ \\
\hline $\begin{array}{l}\text { PG6. Coordinate departmental } \\
\text { selection of textbooks and } \\
\text { supplemental materials }\end{array}$ & $\begin{array}{l}\text { Time } \\
\text { Role } \\
\text { Improve }\end{array}$ & $\begin{array}{l}3.678 \\
4.093 \\
3.992\end{array}$ & $\begin{array}{l}1.116 \\
0.837 \\
0.929\end{array}$ & $\begin{array}{l}3.333 \\
3.895 \\
3.868\end{array}$ & $\begin{array}{l}1.053 \\
0.856 \\
0.917\end{array}$ \\
\hline $\begin{array}{l}\text { PG7. Assess learning outcomes to } \\
\text { identify program strengths and } \\
\text { weaknesses }\end{array}$ & $\begin{array}{l}\text { Time } \\
\text { Role } \\
\text { Improve }\end{array}$ & $\begin{array}{l}2.780 \\
3.720 \\
3.754\end{array}$ & $\begin{array}{l}1.047 \\
0.886 \\
0.915\end{array}$ & $\begin{array}{l}2.482 \\
3.816 \\
3.921\end{array}$ & $\begin{array}{l}1.107 \\
0.868 \\
0.933\end{array}$ \\
\hline $\begin{array}{l}\text { PG8. Establish goals for program } \\
\text { improvement }\end{array}$ & $\begin{array}{l}\text { Time } \\
\text { Role } \\
\text { Improve }\end{array}$ & $\begin{array}{l}3.076 \\
3.915 \\
3.890 \\
\end{array}$ & $\begin{array}{l}1.031 \\
0.853 \\
0.904 \\
\end{array}$ & $\begin{array}{l}2.614 \\
3.825 \\
3.817 \\
\end{array}$ & $\begin{array}{l}1.043 \\
0.875 \\
0.988\end{array}$ \\
\hline
\end{tabular}

* Rating scale: 1-5 (1) No time; (2) Litle time (3) A moderate amount of time; (4) A good deal of time; (5) A great deal of time

** Rating scale: $1-5$ (1) No importance; (2) Little importance; (3) Moderate importance; (4) Very important; (5) Extremely important 


\section{Chart C10}

Department Chair Responsibility for Supervision: Ratings of Amount of Time Spent,* Importance to the Department Chair Role,** and Importance for the Chair to Continue to Improve** as Perceived by Department Chairs and Teachers Subjects $(\mathrm{N}=232)$

\begin{tabular}{|c|c|c|c|c|c|}
\hline \multirow[b]{2}{*}{ Activity } & \multirow[b]{2}{*}{ Issue } & \multicolumn{2}{|c|}{$\begin{array}{c}\text { Department Chairs } \\
(\mathrm{N}=118)\end{array}$} & \multicolumn{2}{|c|}{$\begin{array}{l}\text { Teachers } \\
(N=114) \\
\end{array}$} \\
\hline & & $\underline{\mathrm{M}}$ & SD & $\underline{M}$ & SD \\
\hline $\begin{array}{l}\text { SP1. Model a varicty of } \\
\text { insinctional strategies }\end{array}$ & $\begin{array}{l}\text { Time } \\
\text { Role } \\
\text { Improve }\end{array}$ & $\begin{array}{l}2.492 \\
3.169 \\
3.373\end{array}$ & $\begin{array}{l}1.100 \\
1.150 \\
1.211\end{array}$ & $\begin{array}{l}2.193 \\
3.158 \\
3.254\end{array}$ & $\begin{array}{l}1.063 \\
1.133 \\
1.247\end{array}$ \\
\hline $\begin{array}{l}\text { SP2. Assist leachers in } \\
\text { develuping professional growh plans }\end{array}$ & $\begin{array}{l}\text { Time } \\
\text { Role } \\
\text { Improve }\end{array}$ & $\begin{array}{l}2.059 \\
2.907 \\
3.051\end{array}$ & $\begin{array}{l}1.104 \\
1.132 \\
1.154\end{array}$ & $\begin{array}{l}2.035 \\
3.140 \\
3.228\end{array}$ & $\begin{array}{l}0.959 \\
1.080 \\
1.168\end{array}$ \\
\hline $\begin{array}{l}\text { SP3. Encourage experimentation } \\
\text { and innovation among teachers }\end{array}$ & $\begin{array}{l}\text { Time } \\
\text { Role } \\
\text { Improve }\end{array}$ & $\begin{array}{l}2.966 \\
3.703 \\
3.780\end{array}$ & $\begin{array}{l}1.045 \\
1.127 \\
1.103\end{array}$ & $\begin{array}{l}2.728 \\
3.781 \\
3.798\end{array}$ & $\begin{array}{l}1.139 \\
0.993 \\
1.041\end{array}$ \\
\hline $\begin{array}{l}\text { SP4. Coordinate instruction } \\
\text { among departmeni memhers }\end{array}$ & $\begin{array}{l}\text { Time } \\
\text { Role } \\
\text { Improve }\end{array}$ & $\begin{array}{l}3.051 \\
3.720 \\
3.927\end{array}$ & $\begin{array}{l}0.923 \\
0.895 \\
0.906\end{array}$ & $\begin{array}{l}2.605 \\
3.588 \\
3.553\end{array}$ & $\begin{array}{l}1.027 \\
1.037 \\
1.065\end{array}$ \\
\hline $\begin{array}{l}\text { SP5. Observe teachers in } \\
\text { their classrooms and provide leedback }\end{array}$ & $\begin{array}{l}\text { Time } \\
\text { Role } \\
\text { Improve }\end{array}$ & $\begin{array}{l}2.169 \\
3.136 \\
3.314\end{array}$ & $\begin{array}{l}1.186 \\
1.267 \\
1.325\end{array}$ & $\begin{array}{l}2.026 \\
3.395 \\
3.272\end{array}$ & $\begin{array}{l}1.060 \\
1.259 \\
1.207\end{array}$ \\
\hline $\begin{array}{l}\text { SP6. Monitor teacher lesson } \\
\text { plans. }\end{array}$ & $\begin{array}{l}\text { Time } \\
\text { Role } \\
\text { Improve }\end{array}$ & $\begin{array}{l}1.441 \\
2.017 \\
2.161\end{array}$ & $\begin{array}{l}0.843 \\
1.140 \\
1.267\end{array}$ & $\begin{array}{l}1.482 \\
2.211 \\
2.289\end{array}$ & $\begin{array}{l}0.778 \\
1.125 \\
1.203\end{array}$ \\
\hline $\begin{array}{l}\text { SP7. Practice clinical supervision } \\
\text { (pre-conlerence, data collection, post } \\
\text { conlerence) }\end{array}$ & $\begin{array}{l}\text { Time } \\
\text { Role } \\
\text { Improve }\end{array}$ & $\begin{array}{l}1.627 \\
2.237 \\
2.322\end{array}$ & $\begin{array}{l}1.019 \\
1.292 \\
1.358\end{array}$ & $\begin{array}{l}1.570 \\
2.377 \\
2.474\end{array}$ & $\begin{array}{l}0.912 \\
1.163 \\
1.249\end{array}$ \\
\hline $\begin{array}{l}\text { SP8. Communicate high } \\
\text { expectations for leacher performance }\end{array}$ & $\begin{array}{l}\text { Time } \\
\text { Role } \\
\text { lmprove }\end{array}$ & $\begin{array}{l}2.780 \\
3.576 \\
3.593\end{array}$ & $\begin{array}{l}1.126 \\
1.041 \\
1.105\end{array}$ & $\begin{array}{l}2.509 \\
3.605 \\
3.596\end{array}$ & $\begin{array}{l}1.162 \\
1.126 \\
1.217\end{array}$ \\
\hline $\begin{array}{l}\text { SP9. Assist teachers with the } \\
\text { improvement of their instruction }\end{array}$ & $\begin{array}{l}\text { Time } \\
\text { Role } \\
\text { Improve }\end{array}$ & $\begin{array}{l}2.525 \\
3.483 \\
3.585\end{array}$ & $\begin{array}{l}1.002 \\
1.145 \\
1.172\end{array}$ & $\begin{array}{l}2.342 \\
3.500 \\
3.596\end{array}$ & $\begin{array}{l}1.088 \\
1.099 \\
1.195\end{array}$ \\
\hline $\begin{array}{l}\text { SP10. Organize plan for teacher } \\
\text { sharing, peer coaching }\end{array}$ & $\begin{array}{l}\text { Time } \\
\text { Role } \\
\text { Improve }\end{array}$ & $\begin{array}{l}1.898 \\
3.000 \\
3.102\end{array}$ & $\begin{array}{l}0.982 \\
1.226 \\
1.270\end{array}$ & $\begin{array}{l}1.912 \\
3.140 \\
3.237\end{array}$ & $\begin{array}{l}0.937 \\
1.038 \\
1.108\end{array}$ \\
\hline $\begin{array}{l}\text { SP11. Evaluate teacher } \\
\text { periormance }\end{array}$ & $\begin{array}{l}\text { Time } \\
\text { Role } \\
\text { Improve }\end{array}$ & $\begin{array}{l}1.627 \\
2.297 \\
2.424 \\
\end{array}$ & $\begin{array}{l}1.044 \\
1.379 \\
1.470 \\
\end{array}$ & $\begin{array}{l}1.798 \\
2.746 \\
2.860 \\
\end{array}$ & $\begin{array}{l}1.057 \\
1.268 \\
1.349 \\
\end{array}$ \\
\hline
\end{tabular}




\section{APPENDIX D}

FREQUENCY DISTRIBUTION CHARTS: MALES/FEMALES;

MEAN AND STANDARD DEVIATION CHARTS:

MALES/FEMALES 
(hart D)

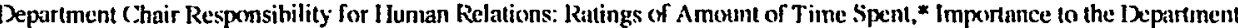

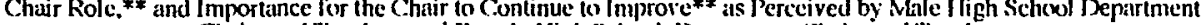
Chairs and Teachers and remale ligh Seheol bepartment Chairs and Texthers

(Byy Trequencies ar Responses (iven for lateh of four Ralings

\begin{tabular}{|c|c|c|c|c|c|c|c|c|c|c|c|c|c|}
\hline \multirow[t]{2}{*}{ Activity } & \multirow[t]{2}{*}{ Group } & \multicolumn{4}{|c|}{ Time } & \multicolumn{5}{|c|}{ TRole*3 } & \multicolumn{3}{|c|}{ Tmprovet* } \\
\hline & & 2 & 3 & 4 & 5 & 2 & 3 & 4 & 5 & 2 & & 4 & 5 \\
\hline $\begin{array}{l}\text { FR1. Build and maintain a supportive } \\
\text { department team }\end{array}$ & $\begin{array}{l}\text { Nales } \\
\text { Iremales }\end{array}$ & $\frac{27}{21}$ & $\begin{array}{l}71 \\
24\end{array}$ & $\begin{array}{l}51 \\
17\end{array}$ & 10 & $\begin{array}{l}8 \\
2\end{array}$ & $2 !$ & $\begin{array}{l}91 \\
35\end{array}$ & $\begin{array}{l}49 \\
32\end{array}$ & $\frac{7}{3}$ & $\begin{aligned} 26 \\
3\end{aligned}$ & $\begin{array}{l}68 \\
32\end{array}$ & $\begin{array}{l}58 \\
35\end{array}$ \\
\hline $\begin{array}{l}\text { HR2 Encourage open communication among } \\
\text { department memhers }\end{array}$ & $\begin{array}{l}\text { Nales } \\
\text { Fiemales }\end{array}$ & $\begin{array}{l}23 \\
16\end{array}$ & $\begin{array}{l}59 \\
26\end{array}$ & $\frac{52}{17}$ & 25 & $\begin{array}{l}7 \\
0\end{array}$ & $\begin{array}{l}9 \\
2\end{array}$ & $\begin{array}{l}77 \\
32\end{array}$ & $\begin{array}{l}66 \\
39\end{array}$ & .5 & 20 & $\begin{array}{l}68 \\
28\end{array}$ & $\begin{array}{l}66 \\
41\end{array}$ \\
\hline IRR3. Facilitate efrective conflict resolution & $\begin{array}{l}\text { Males } \\
\text { liemales }\end{array}$ & $\begin{array}{l}64 \\
26\end{array}$ & $\begin{array}{l}52 \\
27\end{array}$ & $\begin{array}{l}37 \\
13\end{array}$ & 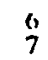 & $\begin{aligned} 14 \\
2\end{aligned}$ & $\begin{array}{l}31 \\
11\end{array}$ & $\begin{array}{l}71 \\
34\end{array}$ & $\begin{array}{l}+3 \\
26\end{array}$ & 12 & $\begin{array}{l}44 \\
10\end{array}$ & $\begin{array}{l}6,2 \\
32\end{array}$ & $\begin{array}{l}41 \\
29\end{array}$ \\
\hline HR4. Foster cooperative problem solving & $\begin{array}{l}\text { Males } \\
\text { lemales }\end{array}$ & $\begin{array}{l}39 \\
20\end{array}$ & $\begin{array}{l}66 \\
27\end{array}$ & $\begin{array}{l}39 \\
23\end{array}$ & $\begin{array}{r}15 \\
3\end{array}$ & $\begin{array}{r}10 \\
1\end{array}$ & $\begin{array}{l}\text { 39) } \\
\text { in }\end{array}$ & $\begin{array}{l}61 \\
36\end{array}$ & $\begin{array}{l}49 \\
26\end{array}$ & 11 & $\begin{array}{r}41 \\
8\end{array}$ & $\begin{array}{l}58 \\
38\end{array}$ & $\begin{array}{l}49 \\
27\end{array}$ \\
\hline $\begin{array}{l}\text { IRR5. Encourage trust, caring, and respect } \\
\text { among department members }\end{array}$ & $\begin{array}{l}\text { Males } \\
\text { Females }\end{array}$ & $\begin{array}{r}35 \\
17\end{array}$ & $\begin{array}{l}52 \\
23\end{array}$ & $\begin{array}{l}+7 \\
\mathbf{2 2}\end{array}$ & $\begin{array}{l}25 \\
11\end{array}$ & $\stackrel{9}{0}$ & 25 & 55 & $\begin{array}{l}70 \\
36\end{array}$ & $\begin{array}{l}8 \\
1\end{array}$ & $\begin{array}{r}39 \\
4\end{array}$ & $\begin{array}{l}55 \\
32\end{array}$ & $\begin{array}{l}57 \\
36\end{array}$ \\
\hline $\begin{array}{l}\text { HIR6. Maintain regular, open communication } \\
\text { with department members }\end{array}$ & $\begin{array}{l}\text { Males } \\
\text { Fem:les }\end{array}$ & 12 & $\begin{array}{l}47 \\
18\end{array}$ & $\begin{array}{l}59 \\
22\end{array}$ & $\begin{array}{l}41 \\
23\end{array}$ & 2 & $\begin{array}{r}1.3 \\
3\end{array}$ & $\begin{array}{l}50 \\
23\end{array}$ & $\begin{array}{l}94 \\
47\end{array}$ & 3 & $\begin{array}{r}28 \\
2\end{array}$ & $\begin{array}{l}51 \\
27\end{array}$ & $\begin{array}{l}77 \\
44\end{array}$ \\
\hline $\begin{array}{l}\text { IR7. Practice collaborative, participative } \\
\text { decision-making processes }\end{array}$ & $\begin{array}{l}\text { Males } \\
\text { Females }\end{array}$ & $\begin{array}{l}25 \\
1.3\end{array}$ & $\begin{array}{l}67 \\
25\end{array}$ & 24 & $\begin{array}{l}23 \\
15\end{array}$ & 2 & 31 & $\begin{array}{l}69 \\
25\end{array}$ & $\begin{array}{l}57 \\
44\end{array}$ & 2 & +4 & $\begin{array}{l}62 \\
26\end{array}$ & $\begin{array}{l}51 \\
41\end{array}$ \\
\hline $\begin{array}{l}\text { FIR8. Promote an almosphere that encourages } \\
\text { continuous improvement }\end{array}$ & $\begin{array}{l}\text { Males } \\
\text { Femules }\end{array}$ & $\begin{array}{l}28 \\
13\end{array}$ & $\begin{array}{l}57 \\
20\end{array}$ & $\begin{array}{l}54 \\
23\end{array}$ & $\begin{array}{l}20 \\
17\end{array}$ & $\begin{array}{l}4 \\
0\end{array}$ & 22 & $\begin{array}{l}71 \\
21\end{array}$ & $\begin{array}{l}62 \\
+8\end{array}$ & 6 & $\begin{array}{r}23 \\
6\end{array}$ & $\begin{array}{l}68 \\
20\end{array}$ & $\begin{array}{l}62 \\
47\end{array}$ \\
\hline $\begin{array}{l}\text { HR9. Encourage department members to share } \\
\text { in leadership roles }\end{array}$ & $\begin{array}{l}\text { Malcs } \\
\text { Iemales }\end{array}$ & $\begin{array}{l}51 \\
18\end{array}$ & $\begin{array}{l}70 \\
\mathbf{3 2}\end{array}$ & $\begin{array}{l}24 \\
16\end{array}$ & $\begin{array}{r}14 \\
7\end{array}$ & $\begin{array}{l}6 \\
4\end{array}$ & $\begin{array}{l}59 \\
17\end{array}$ & $\begin{array}{l}60 \\
31\end{array}$ & $\begin{array}{l}34 \\
21\end{array}$ & 11 & $\begin{array}{l}50 \\
16\end{array}$ & $\begin{array}{l}63 \\
30\end{array}$ & $\begin{array}{l}35 \\
22\end{array}$ \\
\hline
\end{tabular}


Chair 122

Department Chair Responsibility for Management: Rattings of Amount of Time Spent, ${ }^{*}$ Importance (o the Department C Chair Role, ** and Importine for the Chair to Conlinue to Iniprowe** as Perecived by Male Iligh School

[13y Frequencies of Responises (Giten for Ijach of Four Ritings]

\begin{tabular}{|c|c|c|c|c|c|c|c|c|c|c|c|c|c|}
\hline \multirow[t]{2}{*}{ Activity } & \multirow[t]{2}{*}{$\overline{\text { Group }}$} & \multicolumn{4}{|c|}{ Time } & \multicolumn{4}{|c|}{ Role } & \multicolumn{4}{|c|}{ Improre } \\
\hline & & 2 & 3 & 4 & 5 & 2 & 3 & $I$ & 3 & 2 & 3 & 4 & 5 \\
\hline $\begin{array}{l}\text { MCi1. Develop department teaching } \\
\text { schedule and assignments }\end{array}$ & $\begin{array}{l}\text { Males } \\
\text { Females }\end{array}$ & $\begin{array}{r}30 \\
3\end{array}$ & $\begin{array}{l}53 \\
21\end{array}$ & $\begin{array}{l}+4 \\
28\end{array}$ & 32 & $?$ & 31 & $\begin{array}{l}61 \\
29\end{array}$ & $\begin{array}{l}60 \\
33\end{array}$ & $\begin{array}{r}16 \\
4\end{array}$ & $\begin{array}{r}40 \\
9\end{array}$ & $\begin{array}{l}50 \\
27\end{array}$ & $\begin{array}{l}\mathbf{5 3} \\
\mathbf{3 3}\end{array}$ \\
\hline $\begin{array}{l}\text { MGS2. Participate in the selcction of } \\
\text { depentment instructional personnel }\end{array}$ & $\begin{array}{l}\text { Males } \\
\text { Females }\end{array}$ & 57 & $\begin{array}{l}51 \\
22\end{array}$ & $\begin{array}{l}36 \\
24\end{array}$ & 15 & 9 & 27 & $\begin{array}{l}57 \\
33\end{array}$ & $\begin{array}{l}66 \\
36\end{array}$ & $\stackrel{14}{3}$ & $\begin{array}{l}29 \\
10\end{array}$ & $\begin{array}{l}56 \\
28\end{array}$ & $\begin{array}{l}60 \\
32\end{array}$ \\
\hline $\begin{array}{l}\text { MCi3. Develop and administer the } \\
\text { Jepktrment budget }\end{array}$ & $\begin{array}{l}\text { Males } \\
\text { Fenales }\end{array}$ & 12 & $\begin{array}{l}48 \\
16\end{array}$ & $\begin{array}{l}57 \\
31\end{array}$ & $\begin{array}{l}42 \\
22\end{array}$ & $\stackrel{4}{1}$ & 28 & $\begin{array}{l}62 \\
30\end{array}$ & $\begin{array}{l}65 \\
27\end{array}$ & $\begin{array}{l}9 \\
2\end{array}$ & $\begin{array}{l}41 \\
20\end{array}$ & 54 & $\begin{array}{l}52 \\
26\end{array}$ \\
\hline $\begin{array}{l}\text { MG4. Disseminate information to } \\
\text { department staff }\end{array}$ & $\begin{array}{l}\text { Males } \\
\text { Fennules }\end{array}$ & 13 & $\begin{array}{l}50 \\
\mathbf{2 2}\end{array}$ & $\begin{array}{l}+7 \\
\mathbf{2 3}\end{array}$ & $\begin{array}{l}49 \\
27\end{array}$ & $\stackrel{9}{0}$ & 27 & $\begin{array}{l}54 \\
24\end{array}$ & $\begin{array}{l}69 \\
37\end{array}$ & $\begin{array}{r}15 \\
3\end{array}$ & +46 & $\begin{array}{l}44 \\
24\end{array}$ & $\begin{array}{l}54 \\
32\end{array}$ \\
\hline $\begin{array}{l}\text { MG.5. Alocite and maintain equipment, } \\
\text { instructional materials, and facilities }\end{array}$ & $\begin{array}{l}\text { Males } \\
\text { Fentules }\end{array}$ & $\begin{array}{l}56 \\
25\end{array}$ & $\begin{array}{l}64 \\
33\end{array}$ & $\begin{array}{l}24 \\
12\end{array}$ & $\begin{array}{r}15 \\
3\end{array}$ & $\begin{array}{l}35 \\
13\end{array}$ & $\begin{array}{l}58 \\
26\end{array}$ & $\begin{array}{l}40 \\
25\end{array}$ & $\begin{array}{r}26 \\
9\end{array}$ & $\begin{array}{l}37 \\
13\end{array}$ & $\begin{array}{l}61 \\
28\end{array}$ & $\begin{array}{l}21 \\
23\end{array}$ & $\begin{array}{r}30 \\
9\end{array}$ \\
\hline $\begin{array}{l}\text { MG.6. Interpret and apply district policy and } \\
\text { building standards }\end{array}$ & $\begin{array}{l}\text { Males } \\
\text { Femtes }\end{array}$ & $\begin{array}{l}61 \\
24\end{array}$ & $\begin{array}{l}63 \\
32\end{array}$ & 27 & 8 & 39 & 5 & $\begin{array}{l}43 \\
25\end{array}$ & $\begin{array}{l}23 \\
12\end{array}$ & $\begin{array}{l}40 \\
17\end{array}$ & $\begin{array}{l}61 \\
20\end{array}$ & 32 & $\begin{array}{l}26 \\
12\end{array}$ \\
\hline $\begin{array}{l}\text { MGi7. PYan and organize relevant } \\
\text { depxartment mectings }\end{array}$ & $\begin{array}{l}\text { Males } \\
\text { Femalcs }\end{array}$ & $\begin{array}{r}25 \\
8\end{array}$ & $\begin{array}{r}55 \\
18\end{array}$ & $\begin{array}{l}57 \\
26\end{array}$ & 22 & $\begin{array}{l}7 \\
2\end{array}$ & 30. & $\begin{array}{l}69 \\
27\end{array}$ & $\begin{array}{l}53 \\
33\end{array}$ & $\begin{array}{r}15 \\
1\end{array}$ & $\begin{array}{l}35 \\
14\end{array}$ & $\begin{array}{l}55 \\
21\end{array}$ & $\begin{array}{l}54 \\
37\end{array}$ \\
\hline $\begin{array}{l}\text { MG8. Serve as liaison between depirtment } \\
\text { members and the administration }\end{array}$ & $\begin{array}{l}\text { Malus } \\
\text { Females }\end{array}$ & $\begin{array}{r}16 \\
6\end{array}$ & $\begin{array}{l}47 \\
21\end{array}$ & 52 & $\stackrel{4}{49}$ & $\stackrel{4}{0}$ & $2 !$ & $\begin{array}{l}68 \\
27\end{array}$ & $\begin{array}{l}66 \\
42\end{array}$ & $\begin{array}{r}12 \\
1\end{array}$ & $\begin{array}{r}29 \\
8\end{array}$ & $\begin{array}{l}63 \\
23\end{array}$ & $\begin{array}{l}55 \\
41\end{array}$ \\
\hline
\end{tabular}

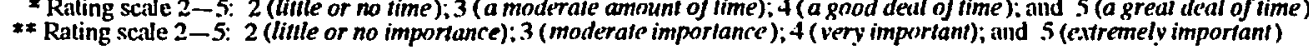


(hart 133

Department Chair Responsibility for the Organization: Ratings of Amount of Time Spent,* Importance to the Department Chair Role,* and Imperttince for the ( hair (1) Continite to Improve** as I'erceived by Malc High School thairs and Teachers and te cnale ligh School Departmenh hails and T eachers (By Trequencies of Responses Given for latch of rour Ratings

\begin{tabular}{|c|c|c|c|c|c|c|c|c|c|c|c|c|c|}
\hline \multirow[t]{2}{*}{ Activily } & \multirow{2}{*}{ Cinup } & \multicolumn{4}{|c|}{$\operatorname{Time}^{2}$} & \multicolumn{4}{|c|}{$\mathrm{Role}^{\mathrm{xx}}$} & & \multicolumn{3}{|c|}{ Improve } \\
\hline & & 2 & 3 & 4 & 5 & 2 & 3 & 4 & 5 & 2 & & 4 & 5 \\
\hline $\begin{array}{l}\text { ORI. Engage department members in an } \\
\text { orginized department growth and } \\
\text { improvement effort }\end{array}$ & $\begin{array}{l}\text { Males } \\
\text { Females }\end{array}$ & $\begin{array}{l}(x) \\
21\end{array}$ & $\begin{array}{l}51 \\
26\end{array}$ & $\begin{array}{l}38 \\
18\end{array}$ & $\begin{array}{r}10 \\
8\end{array}$ & $\begin{array}{r}13 \\
2\end{array}$ & $\begin{array}{l}45 \\
13\end{array}$ & $\begin{array}{l}59 \\
25\end{array}$ & 32 & 13 & $\begin{array}{l}48 \\
14\end{array}$ & $\begin{array}{l}47 \\
22\end{array}$ & $\begin{array}{l}51 \\
36\end{array}$ \\
\hline $\begin{array}{l}\text { OR2. Represent the department in develsping/ } \\
\text { implementing school's organizcd } \\
\text { improvement effort }\end{array}$ & $\begin{array}{l}\text { Males } \\
\text { Femalcs }\end{array}$ & $\begin{array}{l}36 \\
12\end{array}$ & $\begin{array}{l}.54 \\
32\end{array}$ & $\begin{array}{l}50 \\
20\end{array}$ & $\stackrel{19}{9}$ & $\begin{array}{r}13 \\
2\end{array}$ & $\begin{array}{l}51 \\
19\end{array}$ & $\begin{array}{l}62 \\
26\end{array}$ & $\begin{array}{l}33 \\
26\end{array}$ & $\begin{array}{r}15 \\
2\end{array}$ & $\begin{array}{l}55 \\
16\end{array}$ & $\begin{array}{l}.55 \\
28\end{array}$ & $\begin{array}{l}34 \\
27\end{array}$ \\
\hline $\begin{array}{l}\text { OR3. Serve as department spokesperson at } \\
\text { community and bourd meetings }\end{array}$ & $\begin{array}{l}\text { Malles } \\
\text { Females }\end{array}$ & $\begin{array}{l}81 \\
41\end{array}$ & $\begin{array}{ll}46 \\
18\end{array}$ & 22 & $\begin{array}{r}10 \\
3\end{array}$ & $\begin{array}{l}36 \\
19\end{array}$ & $\begin{array}{l}57 \\
23\end{array}$ & $\begin{array}{l}44 \\
22\end{array}$ & $\frac{22}{9}$ & $\begin{array}{l}35 \\
23\end{array}$ & $\begin{array}{l}60 \\
19\end{array}$ & $\begin{array}{l}42 \\
23\end{array}$ & 22 \\
\hline $\begin{array}{l}\text { OR4. Prepare requested information on } \\
\text { department topics for principal, central } \\
\text { office, schwol board }\end{array}$ & $\begin{array}{l}\text { A Gales } \\
\text { Fomales }\end{array}$ & $\begin{array}{l}50 \\
22\end{array}$ & $\begin{array}{l}55 \\
25\end{array}$ & $\begin{array}{ll}* 16 \\
19\end{array}$ & $\begin{array}{l}8 \\
7\end{array}$ & $\begin{array}{r}26 \\
8\end{array}$ & $\begin{array}{l}55 \\
29\end{array}$ & $\begin{array}{l}57 \\
28\end{array}$ & $\begin{array}{r}21 \\
8\end{array}$ & $\begin{array}{l}30 \\
11\end{array}$ & $\begin{array}{l}63 \\
26\end{array}$ & $\begin{array}{l}45 \\
27\end{array}$ & $\begin{array}{r}21 \\
9\end{array}$ \\
\hline $\begin{array}{l}\text { OR5. Act as an adrocate for the protection of } \\
\text { classroom instructional time }\end{array}$ & $\begin{array}{l}\text { Males } \\
\text { Females }\end{array}$ & $\begin{array}{l}47 \\
24\end{array}$ & $\begin{array}{l}61 \\
21\end{array}$ & $\begin{array}{l}36 \\
16\end{array}$ & $\begin{array}{l}15 \\
12\end{array}$ & $\begin{array}{r}16 \\
4\end{array}$ & $\begin{array}{l}38 \\
12\end{array}$ & $\begin{array}{l}52 \\
20\end{array}$ & $\begin{array}{l}53 \\
37\end{array}$ & $\begin{array}{r}19 \\
4\end{array}$ & $\begin{array}{l}47 \\
15\end{array}$ & $\begin{array}{l}36 \\
16\end{array}$ & $\begin{array}{l}57 \\
38\end{array}$ \\
\hline $\begin{array}{l}\text { ORG. Support teachers" professional needs and } \\
\text { concems }\end{array}$ & $\begin{array}{l}\text { Males } \\
\text { Females }\end{array}$ & $\begin{array}{l}44 \\
17\end{array}$ & $\begin{array}{l}50 \\
30\end{array}$ & 43 & 22 & $\begin{array}{ll}13 \\
1\end{array}$ & $\begin{array}{l}37 \\
16\end{array}$ & 37 & $\frac{52}{32}$ & $\begin{array}{r}20 \\
0\end{array}$ & $\frac{40}{17}$ & $\begin{array}{l}46 \\
25\end{array}$ & $\begin{array}{l}53 \\
31\end{array}$ \\
\hline $\begin{array}{l}\text { OR7. Work with other department chairs to } \\
\text { develop an integrated school instructional } \\
\text { program }\end{array}$ & $\begin{array}{l}\text { Males } \\
\text { Females }\end{array}$ & 25 & $\begin{array}{l}52 \\
21\end{array}$ & $\begin{array}{l}40 \\
15\end{array}$ & $\begin{array}{l}13 \\
12\end{array}$ & $\frac{12}{3}$ & $\begin{array}{l}48 \\
11\end{array}$ & $\begin{array}{l}59 \\
34\end{array}$ & $\begin{array}{l}40 \\
25\end{array}$ & $\begin{array}{r}14 \\
1\end{array}$ & $\begin{array}{l}48 \\
13\end{array}$ & $\begin{array}{l}50 \\
31\end{array}$ & $\begin{array}{l}47 \\
28\end{array}$ \\
\hline $\begin{array}{l}\text { OR8. Participate in district-level planning and } \\
\text { decision making }\end{array}$ & $\begin{array}{l}\text { Males } \\
\text { Females }\end{array}$ & $\begin{array}{l}45 \\
15 \\
\end{array}$ & $\begin{array}{l}49 \\
26 \\
\end{array}$ & $\begin{array}{l}48 \\
19 \\
\end{array}$ & $\begin{array}{l}16 \\
13 \\
\end{array}$ & $\begin{array}{r}15 \\
1 \\
\end{array}$ & $\begin{array}{l}.38 \\
15 \\
\end{array}$ & $\begin{array}{l}61 \\
32 \\
\end{array}$ & $\begin{array}{l}4.5 \\
25 \\
\end{array}$ & $\begin{array}{r}19 \\
1\end{array}$ & $\begin{array}{r}1 \\
20\end{array}$ & $\begin{array}{l}51 \\
27\end{array}$ & $\begin{array}{l}48 \\
25 \\
\end{array}$ \\
\hline
\end{tabular}

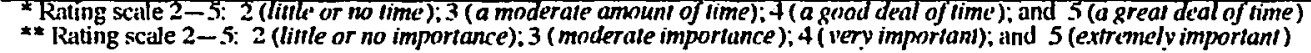


(Chart 1)4

Department Chair Responsibility for Program: Ratings of Amount of Time Spent, * Importince to the IXpartment

Chair Role, ** and Importance for the (:hair to continue to Improve** as Pereeived by Male High School

IBy Frequencies of Responses (iiren for fiach of Four Raling:

\begin{tabular}{|c|c|c|c|c|c|c|c|c|c|c|c|c|c|}
\hline Aetivity & Giroup & \multicolumn{4}{|c|}{ Time $e^{x}$} & \multicolumn{4}{|c|}{$\frac{R_{0} e^{x^{3 x}}}{4}$} & & \multicolumn{3}{|c|}{$\frac{T \text { mprovec }}{3} \frac{1 *}{4}$} \\
\hline PG1. Fiacilitate development of curriculum & $\begin{array}{l}\text { Malles } \\
\text { Fentales }\end{array}$ & ${ }_{11}^{22}$ & $\begin{array}{l}63 \\
25\end{array}$ & $\begin{array}{l}47 \\
20\end{array}$ & $\begin{array}{l}27 \\
17\end{array}$ & $\frac{5}{2}$ & $\begin{array}{l}41 \\
10\end{array}$ & $\begin{array}{l}70 \\
36\end{array}$ & $\begin{array}{l}43 \\
25\end{array}$ & $\begin{array}{r}11 \\
2\end{array}$ & $\begin{array}{l}40 \\
14\end{array}$ & $\begin{array}{l}65 \\
30\end{array}$ & $\begin{array}{l}43 \\
27\end{array}$ \\
\hline $\begin{array}{l}\text { PG2. Supervise the implementation of } \\
\text { curriculum }\end{array}$ & $\begin{array}{l}\text { Males } \\
\text { Females }\end{array}$ & $\begin{array}{l}54 \\
19\end{array}$ & $\begin{array}{l}55 \\
27\end{array}$ & $\begin{array}{l}36 \\
16\end{array}$ & 14 & $\stackrel{11}{3}$ & $\begin{array}{l}41 \\
20\end{array}$ & $\frac{6 x_{1}}{28}$ & ${ }_{22}^{41}$ & 11 & $\begin{array}{l}49 \\
22\end{array}$ & $\begin{array}{l}57 \\
26\end{array}$ & $\begin{array}{l}+2 \\
23\end{array}$ \\
\hline $\begin{array}{l}\text { PG3. Monitor the continued maintenance of } \\
\text { curriculum }\end{array}$ & $\begin{array}{l}\text { Males } \\
\text { Fenales }\end{array}$ & $\begin{array}{l}57 \\
27\end{array}$ & $\begin{array}{l}59 \\
27\end{array}$ & $\frac{32}{12}$ & $\frac{11}{7}$ & $\begin{array}{r}15 \\
3\end{array}$ & $\begin{array}{ll}46 \\
25\end{array}$ & $\begin{array}{l}60 \\
28\end{array}$ & 38 & $\begin{array}{r}18 \\
8\end{array}$ & $\begin{array}{l}48 \\
27\end{array}$ & $\begin{array}{l}52 \\
25\end{array}$ & $\begin{array}{l}41 \\
18\end{array}$ \\
\hline $\begin{array}{l}\text { PG4. Devise and implement process for program } \\
\text { evaluation }\end{array}$ & $\begin{array}{l}\text { Meles } \\
\text { Females }\end{array}$ & $\begin{array}{l}81 \\
34\end{array}$ & $\begin{array}{l}58 \\
23\end{array}$ & $\begin{array}{l}15 \\
15\end{array}$ & 5 & $\begin{aligned} 21 \\
2\end{aligned}$ & $\begin{array}{l}59 \\
25\end{array}$ & $\begin{array}{l}51 \\
33\end{array}$ & $\begin{array}{l}28 \\
1.3\end{array}$ & $\begin{array}{r}23 \\
3\end{array}$ & $\begin{array}{l}55 \\
21\end{array}$ & $\begin{array}{l}51 \\
33\end{array}$ & $\begin{array}{l}30 \\
16\end{array}$ \\
\hline $\begin{array}{l}\text { PGS. Provide leadership in the selection and } \\
\text { development of instructional materials }\end{array}$ & $\begin{array}{l}\text { Males } \\
\text { Females }\end{array}$ & $\begin{array}{l}36 \\
18\end{array}$ & $\begin{array}{l}60 \\
29\end{array}$ & $\begin{array}{l}39 \\
13\end{array}$ & $\frac{24}{13}$ & $\stackrel{10}{3}$ & 42 & ${ }_{21}^{68}$ & $\begin{array}{l}39 \\
26\end{array}$ & $\begin{array}{r}14 \\
3\end{array}$ & $\begin{array}{l}47 \\
22\end{array}$ & $\frac{56}{21}$ & $\begin{array}{l}42 \\
27\end{array}$ \\
\hline $\begin{array}{l}\text { PS6. Coordinate departmental selection of } \\
\text { lexibooks und supplemenlal malcrials }\end{array}$ & $\begin{array}{l}\text { Mates } \\
\text { Females }\end{array}$ & 11 & $\stackrel{+47}{30}$ & $\begin{array}{ll}45 \\
16\end{array}$ & $\begin{array}{l}37 \\
16\end{array}$ & $\begin{array}{l}6 \\
4\end{array}$ & $\begin{array}{r}35 \\
19\end{array}$ & $\begin{array}{l}68 \\
27\end{array}$ & $\begin{array}{l}50 \\
23\end{array}$ & $\stackrel{10}{s}$ & $\begin{array}{l}39 \\
20\end{array}$ & $\begin{array}{l}60 \\
24\end{array}$ & $\begin{array}{l}50 \\
24\end{array}$ \\
\hline $\begin{array}{l}\text { PG7. Assess learning outcomes to identify } \\
\text { program strenglhs and weaknesses }\end{array}$ & $\begin{array}{l}\text { Males } \\
\text { Females }\end{array}$ & $\begin{array}{l}75 \\
36\end{array}$ & $\begin{array}{l}47 \\
26\end{array}$ & 87 & ${ }_{3}^{10}$ & $\stackrel{15}{3}$ & $\begin{array}{l}45 \\
20\end{array}$ & 37 & $\frac{32}{16}$ & $\stackrel{17}{3}$ & $\begin{array}{l}40 \\
15\end{array}$ & $\begin{array}{l}64 \\
34\end{array}$ & $\frac{38}{21}$ \\
\hline PG8. Establish goals for program improvement & $\begin{array}{l}\text { Males } \\
\text { Females }\end{array}$ & ${ }_{25}^{63}$ & $\begin{array}{l}53 \\
28\end{array}$ & $\begin{array}{l}37 \\
12\end{array}$ & $\begin{array}{l}6 \\
8\end{array}$ & $\frac{12}{3}$ & $\begin{array}{l}45 \\
10\end{array}$ & $\begin{array}{l}70 \\
36\end{array}$ & 32 & $\begin{array}{r}14 \\
4\end{array}$ & ${ }_{11}^{41}$ & $\begin{array}{l}68 \\
29\end{array}$ & $\begin{array}{l}36 \\
39\end{array}$ \\
\hline
\end{tabular}

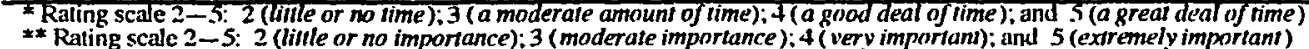


(.hart 125

Department Chair Responsibility for Supervision: Raltings of Amount of Time Spent, Intpertance to the Department Chair Rolc** and Inporance for the Chair to Conlinuc to Jmprowe** as Perceived by Mule High Schisol

Department Chairs and t'achers and Female 4 ligh School Depurtment Chairs and Teachers

(liby lirequencies of Responses ( Given for liach of lour Ratings]

Subjects: Malles $(\underline{N}=159)$ Females $(\underline{N}=73)$

\begin{tabular}{|c|c|c|c|c|c|c|c|c|c|c|c|c|c|}
\hline \multirow[t]{2}{*}{ Aclivily } & \multirow[t]{2}{*}{ Cirup } & \multicolumn{4}{|c|}{ Time* } & \multicolumn{4}{|c|}{ Role $e^{2 x}$} & \multicolumn{4}{|c|}{ Tmprove } \\
\hline & & 2 & 3 & + & 5 & 2 & 3 & 4 & $\mathbf{5}$ & 2 & & 4 & $\because$ \\
\hline SPT. Mindel a vanety of instructional strateg̨ies & $\begin{array}{l}\text { Males } \\
\text { Femules }\end{array}$ & $\begin{array}{l}94 \\
40\end{array}$ & $\stackrel{4}{21}$ & $\begin{array}{c}16 \\
8\end{array}$ & $\begin{array}{l}5 \\
4\end{array}$ & $\begin{array}{l}48 \\
10\end{array}$ & $\begin{array}{l}61 \\
24\end{array}$ & $\frac{32}{27}$ & $\begin{array}{l}18 \\
12\end{array}$ & म11 & $\begin{array}{l}48 \\
23\end{array}$ & $\begin{array}{l}38 \\
22\end{array}$ & $\frac{39}{17}$ \\
\hline $\begin{array}{l}\text { SP2. Assist leachers in developing professional } \\
\text { growth plans }\end{array}$ & $\begin{array}{l}\text { Males } \\
\text { Feinales }\end{array}$ & $\begin{array}{r}114 \\
50\end{array}$ & $\begin{array}{l}32 \\
1.3\end{array}$ & $\begin{array}{l}9 \\
9\end{array}$ & $\begin{array}{l}4 \\
1\end{array}$ & $\begin{array}{l}53 \\
1.5\end{array}$ & $\begin{array}{l}58 \\
27\end{array}$ & $\begin{array}{l}36 \\
23\end{array}$ & $\begin{array}{r}12 \\
8\end{array}$ & $\begin{array}{l}48 \\
15\end{array}$ & $\begin{array}{l}56 \\
25\end{array}$ & $\begin{array}{l}36 \\
21\end{array}$ & $\begin{array}{l}19 \\
12\end{array}$ \\
\hline $\begin{array}{l}\text { SP3. Encourage experimentation and innovation } \\
\text { among teachers }\end{array}$ & $\begin{array}{l}\text { Males } \\
\text { Females }\end{array}$ & $\begin{array}{l}63 \\
20\end{array}$ & $\begin{array}{l}62 \\
31\end{array}$ & $\begin{array}{l}21 \\
15\end{array}$ & $\begin{array}{r}13 \\
7\end{array}$ & $\begin{array}{r}22 \\
5\end{array}$ & il & $\begin{array}{l}58 \\
34\end{array}$ & $\begin{array}{l}36 \\
23\end{array}$ & $\begin{array}{r}23 \\
5\end{array}$ & $\begin{array}{l}35 \\
13\end{array}$ & $\begin{array}{l}59 \\
32\end{array}$ & $\begin{array}{l}42 \\
23\end{array}$ \\
\hline $\begin{array}{l}\text { SP4. Conrdinate instruction among department } \\
\text { members }\end{array}$ & $\begin{array}{l}\text { Males } \\
\text { Females }\end{array}$ & $\frac{56}{28}$ & $\begin{array}{l}66 \\
25\end{array}$ & $\begin{array}{l}301 \\
17\end{array}$ & $\begin{array}{l}7 \\
3\end{array}$ & $\begin{array}{r}19 \\
5\end{array}$ & $\begin{array}{l}58 \\
17\end{array}$ & $\mathbf{5 2}$ & $\begin{array}{l}30 \\
18\end{array}$ & $\begin{array}{r}17 \\
5\end{array}$ & $\begin{array}{l}58 \\
17\end{array}$ & $\begin{array}{l}+8 \\
31\end{array}$ & $\begin{array}{l}36 \\
20\end{array}$ \\
\hline $\begin{array}{l}\text { SPS. Observe teachers in their classrooms and } \\
\text { provide feedback }\end{array}$ & $\begin{array}{l}\text { Males } \\
\text { Females }\end{array}$ & $\begin{array}{r}111 \\
42\end{array}$ & $\begin{array}{l}28 \\
26\end{array}$ & $\begin{array}{r}13 \\
2\end{array}$ & $\begin{array}{l}7 \\
3\end{array}$ & $\begin{array}{l}47 \\
14\end{array}$ & $\begin{array}{l}47 \\
23\end{array}$ & $\begin{array}{l}41 \\
23\end{array}$ & 24 & 42 & $\begin{array}{l}40 \\
21\end{array}$ & $\begin{array}{l}41 \\
22\end{array}$ & $\begin{array}{l}36 \\
16\end{array}$ \\
\hline SPF. Monitor teacher lesson plans & $\begin{array}{l}\text { Males } \\
\text { Fernales }\end{array}$ & $\begin{array}{r}140 \\
65\end{array}$ & $\begin{array}{r}13 \\
7\end{array}$ & $\begin{array}{l}4 \\
1\end{array}$ & $\begin{array}{l}2 \\
0\end{array}$ & $\begin{array}{r}102 \\
44\end{array}$ & $\begin{array}{l}40 \\
21\end{array}$ & $\begin{array}{r}11 \\
5\end{array}$ & $\begin{array}{l}6 \\
3\end{array}$ & $\begin{array}{l}95 \\
43\end{array}$ & $\begin{array}{l}41 \\
20\end{array}$ & 11 & $\begin{array}{r}12 \\
4\end{array}$ \\
\hline SP7. Practice clinical supervision & $\begin{array}{l}\text { Males } \\
\text { Females }\end{array}$ & $\begin{array}{r}1.32 \\
60\end{array}$ & $\begin{array}{r}16 \\
7\end{array}$ & $\begin{array}{l}9 \\
6\end{array}$ & $\begin{array}{l}2 \\
0\end{array}$ & $\begin{array}{l}90 \\
37\end{array}$ & $\begin{array}{l}41 \\
24\end{array}$ & $\begin{array}{r}20 \\
6\end{array}$ & $\begin{array}{l}8 \\
0\end{array}$ & $\begin{array}{l}86, \\
35\end{array}$ & $\begin{array}{l}41 \\
25\end{array}$ & $\begin{array}{r}18 \\
7\end{array}$ & $\begin{array}{r}14 \\
6\end{array}$ \\
\hline $\begin{array}{l}\text { SPP. Communicate high expectations for teacher } \\
\text { perfermance }\end{array}$ & $\begin{array}{l}\text { Males } \\
\text { Females }\end{array}$ & $\begin{array}{l}79 \\
27\end{array}$ & $\begin{array}{l}50 \\
25\end{array}$ & $\begin{array}{l}21 \\
14\end{array}$ & $\begin{array}{l}9 \\
7\end{array}$ & $\begin{array}{r}23 \\
5\end{array}$ & $\begin{array}{l}52 \\
18\end{array}$ & $\begin{array}{l}57 \\
30\end{array}$ & $\begin{array}{l}27 \\
20\end{array}$ & $\begin{array}{r}25 \\
6\end{array}$ & $\begin{array}{l}47 \\
19\end{array}$ & $\begin{array}{l}56 \\
28\end{array}$ & $\begin{array}{l}31 \\
20\end{array}$ \\
\hline $\begin{array}{l}\text { SP9. Assist leachers with improvement of their } \\
\text { instruction }\end{array}$ & $\begin{array}{l}\text { Males } \\
\text { Females }\end{array}$ & $\begin{array}{l}90 \\
37\end{array}$ & $\begin{array}{l}47 \\
23\end{array}$ & $\begin{array}{r}18 \\
9\end{array}$ & $\begin{array}{l}4 \\
4\end{array}$ & $\begin{array}{r}26 \\
9\end{array}$ & $\begin{array}{l}48 \\
21\end{array}$ & $\begin{array}{l}58 \\
29\end{array}$ & $\begin{array}{l}27 \\
14\end{array}$ & $\begin{array}{r}27 \\
8\end{array}$ & $\begin{array}{l}41 \\
19\end{array}$ & $\begin{array}{l}56 \\
25\end{array}$ & $\begin{array}{l}35 \\
21\end{array}$ \\
\hline $\begin{array}{l}\text { SP10. Organize plan for teacher sharing. peer } \\
\text { coaching }\end{array}$ & $\begin{array}{l}\text { Males } \\
\text { Females }\end{array}$ & $\begin{array}{r}122 \\
55\end{array}$ & $\begin{array}{l}29 \\
10\end{array}$ & $\begin{array}{l}8 \\
5\end{array}$ & $\begin{array}{l}\mathbf{0} \\
\mathbf{3}\end{array}$ & $\begin{array}{l}51 \\
16\end{array}$ & $\begin{array}{l}61 \\
24\end{array}$ & $\begin{array}{l}31 \\
22\end{array}$ & $\begin{array}{l}16 \\
11\end{array}$ & $\begin{array}{l}49 \\
15\end{array}$ & $\begin{array}{l}53 \\
24\end{array}$ & $\begin{array}{l}35 \\
20\end{array}$ & $\begin{array}{l}22 \\
14\end{array}$ \\
\hline SPI1. IEvaluate teacher performance & $\begin{array}{l}\text { Males } \\
\text { Females }\end{array}$ & $\begin{array}{r}119 \\
61\end{array}$ & $\begin{array}{r}25 \\
7\end{array}$ & $\begin{array}{r}12 \\
4 \\
\end{array}$ & $\begin{array}{l}3 \\
1 \\
\end{array}$ & $\begin{array}{l}75 \\
33 \\
\end{array}$ & $\begin{array}{l}40 \\
22 \\
\end{array}$ & $\begin{array}{l}31 \\
14 \\
\end{array}$ & $\begin{array}{r}13 \\
4 \\
\end{array}$ & $\begin{array}{l}74 \\
32 \\
\end{array}$ & $\begin{array}{l}34 \\
19 \\
\end{array}$ & $\begin{array}{l}29 \\
16 \\
\end{array}$ & $\begin{array}{r}22 \\
6 \\
\end{array}$ \\
\hline
\end{tabular}

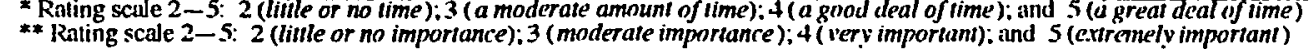




\section{Chart D6}

Department Chair Responsibility for Human Relations: Ratings of Amount of Time Spent, * Importance to the Department Chair Role,** and Importance for the Chair to Continue to Improve** as Perceived by Male and Female Department Chairs and Teachers Subjects $(\mathrm{N}=\mathbf{2 3 2})$

\begin{tabular}{|c|c|c|c|c|c|}
\hline \multirow[t]{2}{*}{ Activity } & \multirow[t]{2}{*}{ Issue } & \multicolumn{2}{|c|}{$\begin{array}{c}\text { Males } \\
(N=159)\end{array}$} & \multicolumn{2}{|c|}{$\begin{array}{l}\text { Females } \\
(\mathrm{N}=73)\end{array}$} \\
\hline & & $\underline{\underline{M}}$ & $\underline{\underline{S D}}$ & $\underline{\underline{M}}$ & $\underline{\mathrm{SD}}$ \\
\hline $\begin{array}{l}\text { HR1. Build and maintain a } \\
\text { supportive department team }\end{array}$ & $\begin{array}{l}\text { Time } \\
\text { Role } \\
\text { Improve }\end{array}$ & $\begin{array}{l}3.258 \\
4.069 \\
4.113\end{array}$ & $\begin{array}{l}0.858 \\
0.820 \\
0.834\end{array}$ & $\begin{array}{l}3.164 \\
4.329 \\
4.34 ?\end{array}$ & $\begin{array}{l}1.167 \\
0.708 \\
0.893\end{array}$ \\
\hline $\begin{array}{l}\text { HR 2. Encourage open } \\
\text { communication among department } \\
\text { members }\end{array}$ & $\begin{array}{l}\text { Time } \\
\text { Role } \\
\text { Improve }\end{array}$ & $\begin{array}{l}3.484 \\
4.264 \\
4.220\end{array}$ & $\begin{array}{l}0.954 \\
0.783 \\
0.809\end{array}$ & $\begin{array}{l}3.301 \\
4.507 \\
4.507\end{array}$ & $\begin{array}{l}1.198 \\
0.556 \\
0.604\end{array}$ \\
\hline $\begin{array}{l}\text { HR 3. Facilitate effective } \\
\text { conflict resolution }\end{array}$ & $\begin{array}{l}\text { Time } \\
\text { Role } \\
\text { Improve }\end{array}$ & $\begin{array}{l}2.874 \\
3.887 \\
3.818\end{array}$ & $\begin{array}{l}0.933 \\
0.934 \\
0.934\end{array}$ & $\begin{array}{l}2.986 \\
4.151 \\
4.205\end{array}$ & $\begin{array}{l}1.007 \\
0.776 \\
0.781\end{array}$ \\
\hline $\begin{array}{l}\text { HR 4. Foster cooperative } \\
\text { problem solving }\end{array}$ & $\begin{array}{l}\text { Time } \\
\text { Role } \\
\text { Improve }\end{array}$ & $\begin{array}{l}3.138 \\
3.925 \\
3.899\end{array}$ & $\begin{array}{l}1.003 \\
0.931 \\
0.949\end{array}$ & $\begin{array}{l}3.041 \\
4.192 \\
4.260\end{array}$ & $\begin{array}{l}1.006 \\
0.720 \\
0.646\end{array}$ \\
\hline $\begin{array}{l}\text { HR 5. Encourage trust, caring, } \\
\text { and respect among department } \\
\text { members }\end{array}$ & $\begin{array}{l}\text { Tine } \\
\text { Role } \\
\text { Improve }\end{array}$ & $\begin{array}{l}3.371 \\
4.164 \\
4.006\end{array}$ & $\begin{array}{l}1.035 \\
0.913 \\
0.917\end{array}$ & $\begin{array}{l}3.288 \\
4.452 \\
4.397\end{array}$ & $\begin{array}{l}1.148 \\
0.578 \\
0.721\end{array}$ \\
\hline $\begin{array}{l}\text { HR 6. Maintain regular, open } \\
\text { communication with department } \\
\text { members }\end{array}$ & $\begin{array}{l}\text { Time } \\
\text { Role } \\
\text { Improve }\end{array}$ & $\begin{array}{l}3.811 \\
4.484 \\
4.270\end{array}$ & $\begin{array}{l}0.908 \\
0.701 \\
0.817\end{array}$ & $\begin{array}{l}3.753 \\
4.603 \\
4.575\end{array}$ & $\begin{array}{l}1.128 \\
0.571 \\
0.551\end{array}$ \\
\hline $\begin{array}{l}\text { HR 7. Practice collaborative, } \\
\text { participative decision- making } \\
\text { processes }\end{array}$ & $\begin{array}{l}\text { Time } \\
\text { Role } \\
\text { Improve }\end{array}$ & $\begin{array}{l}3.371 \\
4.132 \\
4.019\end{array}$ & $\begin{array}{l}0.997 \\
0.788 \\
0.807\end{array}$ & $\begin{array}{l}3.452 \\
4.548 \\
4.479\end{array}$ & $\begin{array}{l}1.119 \\
0.602 \\
0.648\end{array}$ \\
\hline $\begin{array}{l}\text { HR 8. Promote an almosphere } \\
\text { that encourages continuous } \\
\text { improvement }\end{array}$ & $\begin{array}{l}\text { Time } \\
\text { Role } \\
\text { Improve }\end{array}$ & $\begin{array}{l}3.403 \\
4.201 \\
4.170\end{array}$ & $\begin{array}{l}0.949 \\
0.770 \\
0.813\end{array}$ & $\begin{array}{l}3.575 \\
4.603 \\
4.562\end{array}$ & $\begin{array}{l}1.092 \\
0.595 \\
0.645\end{array}$ \\
\hline $\begin{array}{l}\text { HR 9. Encourage department } \\
\text { members to share in leadership } \\
\text { roles }\end{array}$ & $\begin{array}{l}\text { Time } \\
\text { Role } \\
\text { Improve } \\
\end{array}$ & $\begin{array}{l}2.962 \\
3.755 \\
3.761 \\
\end{array}$ & $\begin{array}{l}0.980 \\
0.855 \\
0.889 \\
\end{array}$ & $\begin{array}{l}3.096 \\
3.932 \\
3.945 \\
\end{array}$ & $\begin{array}{l}1.030 \\
0.903 \\
0.896 \\
\end{array}$ \\
\hline
\end{tabular}




\section{Chart D7}

Department Chair Responsibility for Management: Ratings of Amount of Time Spent,* Importance to the Department Chair Role,** and Importance for the Chair to Continue to Improve** as Perceived by Male and Female Department Chairs and Teachers Subjects $(\mathrm{N}=\mathbf{2 3 2})$

\begin{tabular}{|c|c|c|c|c|c|}
\hline \multirow[t]{2}{*}{ Activity } & \multirow[t]{2}{*}{ Issue } & \multicolumn{2}{|c|}{$\begin{array}{c}\text { Males } \\
(N=159)\end{array}$} & \multicolumn{2}{|c|}{$\begin{array}{l}\text { Females } \\
(\mathrm{N}=73)\end{array}$} \\
\hline & & $\underline{\underline{M}}$ & $\underline{\mathrm{SD}}$ & $\underline{\mathbf{M}}$ & SD \\
\hline $\begin{array}{l}\text { MG1. Develop department } \\
\text { teaching schedule and assignments }\end{array}$ & $\begin{array}{l}\text { Time } \\
\text { Role } \\
\text { Improve }\end{array}$ & $\begin{array}{l}3.465 \\
4.088 \\
3.868\end{array}$ & $\begin{array}{l}1.066 \\
0.881 \\
1.020\end{array}$ & $\begin{array}{l}3.890 \\
4.288 \\
4.219\end{array}$ & $\begin{array}{l}0.936 \\
0.754 \\
0.870\end{array}$ \\
\hline $\begin{array}{l}\text { MG 2. Participate in the selectionof } \\
\text { department instructional personnel }\end{array}$ & $\begin{array}{l}\text { Time } \\
\text { Role } \\
\text { Improve }\end{array}$ & $\begin{array}{l}2.950 \\
4.113 \\
4.000\end{array}$ & $\begin{array}{l}1.135 \\
0.948 \\
1.006\end{array}$ & $\begin{array}{l}3.452 \\
4.219 \\
3.959\end{array}$ & $\begin{array}{l}1.155 \\
0.837 \\
0.904\end{array}$ \\
\hline $\begin{array}{l}\text { MG 3. Develop and administer } \\
\text { the department budget }\end{array}$ & $\begin{array}{l}\text { Time } \\
\text { Role } \\
\text { Improve }\end{array}$ & $\begin{array}{l}3.792 \\
4.170 \\
3.918\end{array}$ & $\begin{array}{l}0.962 \\
0.851 \\
0.961\end{array}$ & $\begin{array}{l}3.959 \\
4.137 \\
4.027\end{array}$ & $\begin{array}{l}0.904 \\
0.787 \\
0.866\end{array}$ \\
\hline $\begin{array}{l}\text { MG 4. Disseminate information to } \\
\text { department staff }\end{array}$ & $\begin{array}{l}\text { Time } \\
\text { Role } \\
\text { Improve }\end{array}$ & $\begin{array}{l}3.805 \\
4.138 \\
3.843\end{array}$ & $\begin{array}{l}1.022 \\
0.938 \\
1.041\end{array}$ & $\begin{array}{l}4.041 \\
4.342 \\
4.151\end{array}$ & $\begin{array}{l}0.857 \\
0.749 \\
0.923\end{array}$ \\
\hline $\begin{array}{l}\text { MG 5. Allocate and maintain } \\
\text { cquipment, instructional materials, } \\
\text { and facilities }\end{array}$ & $\begin{array}{l}\text { Time } \\
\text { Role } \\
\text { Improve }\end{array}$ & $\begin{array}{l}2.862 \\
3.270 \\
3.258\end{array}$ & $\begin{array}{l}1.116 \\
1.151 \\
1.170\end{array}$ & $\begin{array}{l}2.808 \\
3.342 \\
3.329\end{array}$ & $\begin{array}{l}0.967 \\
1.057 \\
1.028\end{array}$ \\
\hline $\begin{array}{l}\text { MG 6. Interpret and apply district } \\
\text { policy and building standards }\end{array}$ & $\begin{array}{l}\text { Time } \\
\text { Role } \\
\text { Improve }\end{array}$ & $\begin{array}{l}2.780 \\
3.245 \\
3.195\end{array}$ & $\begin{array}{l}1.017 \\
1.118 \\
1.150\end{array}$ & $\begin{array}{l}2.890 \\
3.397 \\
3.370\end{array}$ & $\begin{array}{l}0.966 \\
1.115 \\
1.124\end{array}$ \\
\hline $\begin{array}{l}\text { MG 7. Plan and organize } \\
\text { relevant department meetings }\end{array}$ & $\begin{array}{l}\text { Time } \\
\text { Role } \\
\text { Improve }\end{array}$ & $\begin{array}{l}3.428 \\
4.031 \\
3.893\end{array}$ & $\begin{array}{l}1.022 \\
0.910 \\
1.059\end{array}$ & $\begin{array}{l}3.795 \\
4.247 \\
4.288\end{array}$ & $\begin{array}{l}1.040 \\
0.813 \\
0.825\end{array}$ \\
\hline $\begin{array}{l}\text { MG 8. Serve as liaison } \\
\text { belween department } \\
\text { and the administration }\end{array}$ & $\begin{array}{l}\text { Time } \\
\text { Role } \\
\text { Improve }\end{array}$ & $\begin{array}{l}3.761 \\
4.220 \\
3.981 \\
\end{array}$ & $\begin{array}{l}1.009 \\
0.816 \\
0.997 \\
\end{array}$ & $\begin{array}{l}3.918 \\
4.521 \\
4.425 \\
\end{array}$ & $\begin{array}{l}1.077 \\
0.603 \\
0.744 \\
\end{array}$ \\
\hline
\end{tabular}




\section{Chart D8}

Department Chair Responsibility for the Organization: Ratings of Amount of Time Spent,* Importance to the Department Chair Role, ** and Importance for the Chair to Continue to Improie** as Perceived by Male and Female Department Chairs and Teachers Subjects $(\mathrm{N}=232)$

\begin{tabular}{|c|c|c|c|c|c|}
\hline \multirow[t]{2}{*}{ Activity } & \multirow[t]{2}{*}{ Issue } & \multicolumn{2}{|c|}{$\begin{array}{c}\text { Males } \\
(\mathrm{N}=159)\end{array}$} & \multicolumn{2}{|c|}{$\begin{array}{l}\text { Females } \\
(\mathrm{N}=73)\end{array}$} \\
\hline & & $\underline{M}$ & $\underline{\mathrm{SD}}$ & $\underline{M}$ & SD \\
\hline $\begin{array}{l}\text { OR1. Engage department members in an } \\
\text { organized department growth and } \\
\text { improvement effor }\end{array}$ & $\begin{array}{l}\text { Time } \\
\text { Role } \\
\text { Improve }\end{array}$ & $\begin{array}{l}2.881 \\
3.805 \\
3.830\end{array}$ & $\begin{array}{l}1.087 \\
0.951 \\
1.026\end{array}$ & $\begin{array}{l}3.068 \\
4.219 \\
4.274\end{array}$ & $\begin{array}{l}1.147 \\
0.837 \\
0.821\end{array}$ \\
\hline $\begin{array}{l}\text { OR2. Represent the department in } \\
\text { developing and implementing the } \\
\text { school's organized improvement effort }\end{array}$ & $\begin{array}{l}\text { Time } \\
\text { Role } \\
\text { Improve }\end{array}$ & $\begin{array}{l}3.270 \\
3.704 \\
3.660\end{array}$ & $\begin{array}{l}1.060 \\
0.932 \\
0.960\end{array}$ & $\begin{array}{l}3.301 \\
4.041 \\
4.096\end{array}$ & $\begin{array}{l}1.009 \\
0.857 \\
0.836\end{array}$ \\
\hline $\begin{array}{l}\text { OR3. Serve as department } \\
\text { spokesperson at community meetings, } \\
\text { board meetings }\end{array}$ & $\begin{array}{l}\text { Time } \\
\text { Role } \\
\text { Improve }\end{array}$ & $\begin{array}{l}2.572 \\
3.252 \\
3.239\end{array}$ & $\begin{array}{l}1.128 \\
1.108 \\
1.111\end{array}$ & $\begin{array}{l}2.452 \\
3.274 \\
3.205\end{array}$ & $\begin{array}{l}1.081 \\
1.017 \\
1.040\end{array}$ \\
\hline $\begin{array}{l}\text { OR4. Prepare requested information } \\
\text { on department lopics for principal, } \\
\text { central office, board }\end{array}$ & $\begin{array}{l}\text { Time } \\
\text { Role } \\
\text { Improve }\end{array}$ & $\begin{array}{l}2.981 \\
3.434 \\
3.321\end{array}$ & $\begin{array}{l}1.046 \\
0.971 \\
1.008\end{array}$ & $\begin{array}{l}3.068 \\
3.479 \\
3.452\end{array}$ & $\begin{array}{l}1.097 \\
0.868 \\
0.929\end{array}$ \\
\hline $\begin{array}{l}\text { OR5. Act as advocate for the } \\
\text { protection of classroom instructional } \\
\text { time }\end{array}$ & $\begin{array}{l}\text { Time } \\
\text { Role } \\
\text { Improve }\end{array}$ & $\begin{array}{l}3.050 \\
3.874 \\
3.786\end{array}$ & $\begin{array}{l}1.054 \\
1.030 \\
1.113\end{array}$ & $\begin{array}{l}3.123 \\
4.219 \\
4.192\end{array}$ & $\begin{array}{l}1.224 \\
0.961 \\
0.995\end{array}$ \\
\hline $\begin{array}{l}\text { OR6. Suppont teachers' professional } \\
\text { needs and concems }\end{array}$ & $\begin{array}{l}\text { Time } \\
\text { Role } \\
\text { Improve }\end{array}$ & $\begin{array}{l}3.208 \\
3.918 \\
3.811\end{array}$ & $\begin{array}{l}1.120 \\
0.974 \\
1.074\end{array}$ & $\begin{array}{l}3.315 \\
4.192 \\
4.192\end{array}$ & $\begin{array}{l}1.079 \\
0.828 \\
0.793\end{array}$ \\
\hline $\begin{array}{l}\text { OR7. Work with other department } \\
\text { chairs to develop an integrated school } \\
\text { instructional program }\end{array}$ & $\begin{array}{l}\text { Time } \\
\text { Role } \\
\text { Improve }\end{array}$ & $\begin{array}{l}3.006 \\
3.792 \\
3.805\end{array}$ & $\begin{array}{l}1.064 \\
0.921 \\
0.990\end{array}$ & $\begin{array}{l}3.096 \\
4.110 \\
4.178\end{array}$ & $\begin{array}{l}1.227 \\
0.809 \\
0.770\end{array}$ \\
\hline $\begin{array}{l}\text { OR8. Participate in curricular planning } \\
\text { and decision making at the district } \\
\text { level }\end{array}$ & $\begin{array}{l}\text { Time } \\
\text { Role } \\
\text { Improve }\end{array}$ & $\begin{array}{l}3.145 \\
3.836 \\
3.799 \\
\end{array}$ & $\begin{array}{l}1.090 \\
0.986 \\
1.017\end{array}$ & $\begin{array}{l}3.356 \\
4.096 \\
4.027 \\
\end{array}$ & $\begin{array}{l}1.110 \\
0.819 \\
0.866 \\
\end{array}$ \\
\hline
\end{tabular}

* Rating scale 1-5: 1 (no time); 2 (little time); 3 (a moderate amoum of time) ) 4 (a good deal of time); and 5 (a great deal of rime)

** Rating scale 1-5: 1 (no importance); 2 (little importance); 3 (moderate importance); 4 ( very importam); and 5 (extremely important) 


\section{Chart D9}

Department Chair Responsibility for Program: Ratings of Amount of Time Spent,* Importance to the Department Chair Role,** and Importance for the Chair to Continue to Improv'e** as Perceived by' Male and Female Department Chairs and Teachers Subjects $(\mathrm{N}=\mathbf{2 3 2})$

\begin{tabular}{|c|c|c|c|c|c|}
\hline \multirow[t]{2}{*}{ Activity } & \multirow[t]{2}{*}{ Issue } & \multicolumn{2}{|c|}{$\begin{array}{c}\text { Males } \\
(\mathrm{N}=159) \\
\end{array}$} & \multicolumn{2}{|c|}{$\begin{array}{l}\text { Females } \\
(\mathrm{N}=73)\end{array}$} \\
\hline & & $\underline{\underline{M}}$ & $\underline{S D}$ & $\underline{M}$ & $\underline{S D}$ \\
\hline $\begin{array}{l}\text { PG1. Facilitate development } \\
\text { of curriculum (philosophy, goals, } \\
\text { objectives) }\end{array}$ & $\begin{array}{l}\text { Time } \\
\text { Role } \\
\text { Improve }\end{array}$ & $\begin{array}{l}3.453 \\
3.943 \\
3.868\end{array}$ & $\begin{array}{l}1.023 \\
0.829 \\
0.922\end{array}$ & $\begin{array}{l}3.548 \\
4.151 \\
4.123\end{array}$ & $\begin{array}{l}1.093 \\
0.758 \\
0.816\end{array}$ \\
\hline $\begin{array}{l}\text { PG 2. Supervise } \\
\text { implementation of } \\
\text { curriculum }\end{array}$ & $\begin{array}{l}\text { Time } \\
\text { Role } \\
\text { Improve }\end{array}$ & $\begin{array}{l}2.987 \\
3.855 \\
3.799\end{array}$ & $\begin{array}{l}1.073 \\
0.899 \\
0.953\end{array}$ & $\begin{array}{l}3.164 \\
3.932 \\
3.945\end{array}$ & $\begin{array}{l}1.167 \\
0.903 \\
0.896\end{array}$ \\
\hline $\begin{array}{l}\text { PG 3. Monitor the continued } \\
\text { maintenance of curriculum }\end{array}$ & $\begin{array}{l}\text { Time } \\
\text { Role } \\
\text { Improve }\end{array}$ & $\begin{array}{l}2.906 \\
3.742 \\
3.692\end{array}$ & $\begin{array}{l}1.030 \\
0.969 \\
1.055\end{array}$ & $\begin{array}{l}2.932 \\
3.808 \\
3.795\end{array}$ & $\begin{array}{l}1.045 \\
0.844 \\
0.865\end{array}$ \\
\hline $\begin{array}{l}\text { PG 4. Devise and implement } \\
\text { process for program evaluation }\end{array}$ & $\begin{array}{l}\text { Time } \\
\text { Role } \\
\text { Improve }\end{array}$ & $\begin{array}{l}2.453 \\
3.503 \\
3.503\end{array}$ & $\begin{array}{l}1.011 \\
1.012 \\
1.061\end{array}$ & $\begin{array}{l}2.589 \\
3.767 \\
3.836\end{array}$ & $\begin{array}{l}1.052 \\
0.808 \\
0.850\end{array}$ \\
\hline $\begin{array}{l}\text { PG 5. Provide leadership in the } \\
\text { selection and development of } \\
\text { instructional materials }\end{array}$ & $\begin{array}{l}\text { Time } \\
\text { Role } \\
\text { Improve }\end{array}$ & $\begin{array}{l}3.277 \\
3.855 \\
3.786\end{array}$ & $\begin{array}{l}1.073 \\
0.863 \\
0.950\end{array}$ & $\begin{array}{l}3.219 \\
3.945 \\
3.973\end{array}$ & $\begin{array}{l}1.146 \\
0.956 \\
0.957\end{array}$ \\
\hline $\begin{array}{l}\text { PG 6. Coordinate departmental } \\
\text { selection of textbooks and } \\
\text { supplemental materials }\end{array}$ & $\begin{array}{l}\text { Time } \\
\text { Role } \\
\text { Improve }\end{array}$ & $\begin{array}{l}3.516 \\
4.019 \\
3.937\end{array}$ & $\begin{array}{l}1.130 \\
0.830 \\
0.919\end{array}$ & $\begin{array}{l}3.493 \\
3.945 \\
3.918\end{array}$ & $\begin{array}{l}1.029 \\
0.896 \\
0.939\end{array}$ \\
\hline $\begin{array}{l}\text { PG 7. Assess leaming } \\
\text { outcomes/identify program } \\
\text { strengths and weaknesses }\end{array}$ & $\begin{array}{l}\text { Time } \\
\text { Role } \\
\text { Improve }\end{array}$ & $\begin{array}{l}2.673 \\
3.730 \\
3.767\end{array}$ & $\begin{array}{l}1.117 \\
0.891 \\
0.949\end{array}$ & $\begin{array}{l}2.548 \\
3.849 \\
3.986\end{array}$ & $\begin{array}{l}1.014 \\
0.844 \\
0.858\end{array}$ \\
\hline $\begin{array}{l}\text { PG 8. Establish goals for } \\
\text { program improvement }\end{array}$ & $\begin{array}{l}\text { Time } \\
\text { Role } \\
\text { Improve }\end{array}$ & $\begin{array}{l}2.818 \\
3.761 \\
3.767 \\
\end{array}$ & $\begin{array}{l}1.018 \\
0.875 \\
0.956 \\
\end{array}$ & $\begin{array}{l}2.918 \\
4.110 \\
4.137 \\
\end{array}$ & $\begin{array}{l}1.152 \\
0.792 \\
0.871 \\
\end{array}$ \\
\hline
\end{tabular}

* Rating scale 1-5: 1 (no time); 2 (limle time); 3 (a moderate annoum of time ); 4 (a good deal of time); and 5 (a great deal of time)

** Rating scale 1-5: 1 (no importance); 2 (little importance); 3 (moderate importance); 4 (very important); and 5 (extremely important) 


\section{Chart D10}

Department Chair Responsibility for Supervision: Ratings of Amount of Time Spent,* Importance to the Department Chair Role** and Importance for the Chair to Continue to Improve** as Perceived by Male and Female Department Chairs and Teachers Subjects $(\mathrm{N}=232)$

\begin{tabular}{|c|c|c|c|c|c|}
\hline \multirow[t]{2}{*}{ Aclivity } & \multirow[t]{2}{*}{ Issue } & \multicolumn{2}{|c|}{$\begin{array}{c}\text { Nates } \\
N=159)\end{array}$} & \multicolumn{2}{|c|}{$\begin{array}{l}\text { Females } \\
(\mathrm{N}=73)\end{array}$} \\
\hline & & $\underline{M}$ & $\underline{\mathrm{SQ}}$ & $\underline{\underline{M}}$ & $\mathbf{S D}$ \\
\hline $\begin{array}{l}\text { SP1. Model a rariely of } \\
\text { instructional strategies }\end{array}$ & $\begin{array}{l}\text { Time } \\
\text { Role } \\
\text { Improve }\end{array}$ & $\begin{array}{l}3.296 \\
2.025 \\
3.214\end{array}$ & $\begin{array}{l}1.077 \\
1.012 \\
1.245\end{array}$ & $\begin{array}{l}3.453 \\
3.479 \\
3.534\end{array}$ & $\begin{array}{l}1.119 \\
1.094 \\
1.168\end{array}$ \\
\hline $\begin{array}{l}\text { SP 2. Assist teachers in developing } \\
\text { professional growth plans }\end{array}$ & $\begin{array}{l}\text { Time } \\
\text { Role } \\
\text { Improve }\end{array}$ & $\begin{array}{l}2.025 \\
2.906 \\
3.038\end{array}$ & $\begin{array}{l}1.012 \\
1.130 \\
1.179\end{array}$ & $\begin{array}{l}2.096 \\
3.274 \\
3.356\end{array}$ & $\begin{array}{l}1.082 \\
1.031 \\
1.098\end{array}$ \\
\hline $\begin{array}{l}\text { SP 3. Encourage experimentation } \\
\text { and innovation among teachers }\end{array}$ & $\begin{array}{l}\text { Time } \\
\text { Role } \\
\text { Improve }\end{array}$ & $\begin{array}{l}2.767 \\
3.616 \\
3.698\end{array}$ & $\begin{array}{l}1.098 \\
1.107 \\
1.124\end{array}$ & $\begin{array}{l}3.027 \\
4.014 \\
3.986\end{array}$ & $\begin{array}{l}1.080 \\
0.905 \\
0.920\end{array}$ \\
\hline $\begin{array}{l}\text { SP +. Coordinate instruction among } \\
\text { department members }\end{array}$ & $\begin{array}{l}\text { Tine } \\
\text { Role } \\
\text { Improve }\end{array}$ & $\begin{array}{l}2.843 \\
3.560 \\
3.811\end{array}$ & $\begin{array}{l}0.971 \\
0.985 \\
2.536\end{array}$ & $\begin{array}{l}2.808 \\
3.863 \\
3.877\end{array}$ & $\begin{array}{l}1.063 \\
0.902 \\
0.957\end{array}$ \\
\hline $\begin{array}{l}\text { SP 5. Ohsen e teachers in their } \\
\text { classr(x)ms and provide feedback }\end{array}$ & $\begin{array}{l}\text { Time } \\
\text { Role } \\
\text { Improve }\end{array}$ & $\begin{array}{l}2.057 \\
3.101 \\
3.289\end{array}$ & $\begin{array}{l}1.149 \\
1.284 \\
1.352\end{array}$ & $\begin{array}{l}2.192 \\
3.425 \\
3.493\end{array}$ & $\begin{array}{l}1.076 \\
1.105 \\
1.144\end{array}$ \\
\hline SP6. Mlonitor teacher lesson plans & $\begin{array}{l}\text { Time } \\
\text { Role } \\
\text { Improve }\end{array}$ & $\begin{array}{l}1.465 \\
2.057 \\
2.201\end{array}$ & $\begin{array}{l}0.848 \\
1.149 \\
1.267\end{array}$ & $\begin{array}{l}1.452 \\
2.233 \\
2.274\end{array}$ & $\begin{array}{l}0.727 \\
1.100 \\
1.170\end{array}$ \\
\hline $\begin{array}{l}\text { SP 7. Practice clinical supervision } \\
\text { (pre-ronference. data collection, post } \\
\text { conference) }\end{array}$ & $\begin{array}{l}\text { Time } \\
\text { Role } \\
\text { Improve }\end{array}$ & $\begin{array}{l}1.585 \\
2.226 \\
2.317\end{array}$ & $\begin{array}{l}0.970 \\
1.268 \\
1.352\end{array}$ & $\begin{array}{l}1.630 \\
2.479 \\
2.548\end{array}$ & $\begin{array}{l}0.965 \\
1.132 \\
1.19 !\end{array}$ \\
\hline $\begin{array}{l}\text { SP 8. Communicate high } \\
\text { expectations for teacher performance }\end{array}$ & $\begin{array}{l}\text { Time } \\
\text { Role } \\
\text { lmprove }\end{array}$ & $\begin{array}{l}2.560 \\
3.478 \\
3.503\end{array}$ & $\begin{array}{l}1.111 \\
1.090 \\
1.136\end{array}$ & $\begin{array}{l}2.836 \\
3.836 \\
3.795\end{array}$ & $\begin{array}{l}1.214 \\
1.028 \\
1.054\end{array}$ \\
\hline $\begin{array}{l}\text { SP 9. Assist teachers with the } \\
\text { improvement of their instruction }\end{array}$ & $\begin{array}{l}\text { Time } \\
\text { Role } \\
\text { Improve }\end{array}$ & $\begin{array}{l}2.396 \\
3.4+10 \\
3.516\end{array}$ & $\begin{array}{l}1.013 \\
1.151 \\
1.211\end{array}$ & $\begin{array}{l}2.521 \\
3.603 \\
3.753\end{array}$ & $\begin{array}{l}1.119 \\
1.051 \\
1.103\end{array}$ \\
\hline $\begin{array}{l}\text { SP 10. Organize plan for teacher } \\
\text { sharing, pecr coaching }\end{array}$ & $\begin{array}{l}\text { Time } \\
\text { Role } \\
\text { Improve }\end{array}$ & $\begin{array}{l}1.830 \\
2.950 \\
3.057\end{array}$ & $\begin{array}{l}0.902 \\
1.141 \\
1.218\end{array}$ & $\begin{array}{l}2.068 \\
3.329 \\
3.411\end{array}$ & $\begin{array}{l}1.058 \\
1.094 \\
1.103\end{array}$ \\
\hline SP 11. Evaluate teacher performance & $\begin{array}{l}\text { Time } \\
\text { Role } \\
\text { Improve }\end{array}$ & $\begin{array}{l}1.748 \\
2.509 \\
2.635\end{array}$ & $\begin{array}{l}1.091 \\
1.377 \\
1.469\end{array}$ & $\begin{array}{l}1.630 \\
2.534 \\
2.644\end{array}$ & $\begin{array}{l}0.965 \\
1.270 \\
1.337\end{array}$ \\
\hline
\end{tabular}

* Rating scale 1-5: 1 (no time); 2 (little time); 3 (a moderate amoum of time) ; 4 (a good deal of time); and 5 (a great deal of time)

** Rating scale 1-5: 1 (no importance); 2 (little importance); 3 (moderate importance); 4 (very important); and 5 (extremely important) 
APPENDIX E

DEMOGRAPHIC CHARTS: DEPARTMENT CHAIRS GROUPED BY DISCIPLINES 


\section{Chart El}

Personal Data: Department Chairs Grouped by Discipline

\begin{tabular}{|c|c|c|c|c|c|c|c|c|}
\hline \multirow{2}{*}{$\begin{array}{l}\text { Characteristic } \\
\text { Gender } \\
\end{array}$} & \multicolumn{2}{|c|}{$\begin{array}{l}\text { English } \\
\underline{N}=31\end{array}$} & \multicolumn{2}{|c|}{$\begin{array}{c}\text { Math } \\
N=29 \\
\end{array}$} & \multicolumn{2}{|c|}{$\begin{array}{r}\text { Science } \\
\mathrm{N}=27 \\
\end{array}$} & \multicolumn{2}{|c|}{$\begin{array}{c}\text { Social Studies } \\
N=31\end{array}$} \\
\hline & $\underline{\mathbf{n}}$ & Percentage & $\underline{\underline{n}}$ & Percentage & $\underline{\mathrm{n}}$ & Percentage & $\underline{\mathrm{n}}$ & Percentage \\
\hline $\begin{array}{l}\text { Male } \\
\text { Female } \\
\end{array}$ & $\begin{array}{l}12 \\
19 \\
\end{array}$ & $\begin{array}{l}38.71 \\
61.29 \\
\end{array}$ & $\begin{array}{r}27 \\
2 \\
\end{array}$ & $\begin{array}{r}93.10 \\
6.90 \\
\end{array}$ & $\begin{array}{r}25 \\
2 \\
\end{array}$ & $\begin{array}{r}92.59 \\
7.41 \\
\end{array}$ & $\begin{array}{r}27 \\
4 \\
\end{array}$ & $\begin{array}{l}87.10 \\
12.90 \\
\end{array}$ \\
\hline Age & $\underline{n}$ & Percentage & $\underline{\mathbf{n}}$ & Percentage & $\underline{n}$ & Percentage & $\underline{n}$ & Percentage \\
\hline $\begin{array}{l}\text { under } 30 \\
30-39 \\
40-49 \\
50 \text { or over } \\
\end{array}$ & $\begin{array}{r}1 \\
2 \\
16 \\
12 \\
\end{array}$ & $\begin{array}{r}3.2 \\
6.5 \\
51.61 \\
38.71 \\
\end{array}$ & $\begin{array}{r}0 \\
4 \\
18 \\
7 \\
\end{array}$ & $\begin{array}{c}0 \\
13.79 \\
62.07 \\
24.14 \\
\end{array}$ & $\begin{array}{r}0 \\
5 \\
16 \\
6 \\
\end{array}$ & $\begin{array}{r}0 \\
18.5 \\
59.3 \\
22.2 \\
\end{array}$ & $\begin{array}{r}0 \\
7 \\
15 \\
9 \\
\end{array}$ & $\begin{array}{r}0 \\
22.6 \\
48.4 \\
29.0 \\
\end{array}$ \\
\hline
\end{tabular}

\section{Chart E2}

Educational Background: Department Chairs Grouped by Discipline

\begin{tabular}{|c|c|c|c|c|c|c|c|c|}
\hline \multicolumn{2}{|c|}{ Characteristic } & \multicolumn{2}{|c|}{$\begin{array}{l}\text { English } \\
N=31\end{array}$} & \multicolumn{2}{|l|}{$\begin{array}{c}\text { Math } \\
\mathrm{N}=29\end{array}$} & \multirow{2}{*}{$\begin{array}{l}\begin{array}{l}\text { Science } \\
N=27\end{array} \\
\text { Percentage }\end{array}$} & \multicolumn{2}{|c|}{$\begin{array}{c}\text { Social Siudies } \\
N=31\end{array}$} \\
\hline Highest Degree & $\underline{\mathbf{n}}$ & Percentage & $\underline{\mathrm{n}}$ & Percentage & $\underline{n}$ & & $\underline{\mathrm{n}}$ & Percentage \\
\hline $\begin{array}{l}\text { Bachelor's } \\
\text { Master's } \\
\text { Doctoratc }\end{array}$ & $\begin{array}{r}10 \\
21 \\
0\end{array}$ & $\begin{array}{c}32.26 \\
67.74 \\
0\end{array}$ & $\begin{array}{r}4 \\
25 \\
0\end{array}$ & $\begin{array}{c}13.79 \\
86.21 \\
0\end{array}$ & $\begin{array}{r}2 \\
23 \\
2\end{array}$ & $\begin{array}{r}7.41 \\
85.19 \\
7.41 \\
\end{array}$ & $\begin{array}{r}3 \\
27 \\
1\end{array}$ & $\begin{array}{r}9.68 \\
87.10 \\
3.23\end{array}$ \\
\hline Academic Area & $\underline{\mathrm{n}}$ & Percentage & $\underline{\mathbf{n}}$ & Percentage & $\underline{n}$ & Percentage & $\underline{n}$ & Percentage \\
\hline $\begin{array}{l}\text { English } \\
\text { Math } \\
\text { Science } \\
\text { Social Studies }\end{array}$ & 31 & 100.00 & $\begin{array}{r}27 \\
2\end{array}$ & $\begin{array}{r}93.10 \\
6.90\end{array}$ & $\begin{array}{r}2 \\
24 \\
1\end{array}$ & $\begin{array}{r}7.41 \\
88.88 \\
3.71\end{array}$ & $\begin{array}{r}1 \\
29\end{array}$ & $\begin{array}{l}3.225 \\
93.55\end{array}$ \\
\hline
\end{tabular}


Chart E3

Educational Experience: Department Chairs Grouped by Discipline

\begin{tabular}{|c|c|c|c|c|c|c|c|c|}
\hline \multirow{2}{*}{$\begin{array}{c}\text { Characteristic } \\
\text { Total Teaching Experience }\end{array}$} & \multicolumn{2}{|c|}{$\begin{array}{l}\text { English } \\
N=31\end{array}$} & \multicolumn{2}{|c|}{$\begin{array}{c}\text { Math } \\
\mathrm{N}=\mathbf{2 9} \\
\end{array}$} & \multicolumn{2}{|c|}{$\begin{array}{l}\text { Science } \\
N=27\end{array}$} & \multicolumn{2}{|c|}{$\begin{array}{c}\text { Social Studies } \\
\mathbf{N}=31\end{array}$} \\
\hline & $\underline{\mathbf{n}}$ & $\%$ & $\underline{\mathrm{n}}$ & $\%$ & $\underline{\underline{n}}$ & $\%$ & $\underline{\underline{n}}$ & $\%$ \\
\hline $\begin{array}{l}\text { fewer than } 5 \text { years } \\
5-9 \text { years } \\
10-19 \text { years } \\
20-29 \text { years } \\
30 \text { or more years }\end{array}$ & $\begin{array}{r}2 \\
5 \\
15 \\
8 \\
1 \\
\end{array}$ & $\begin{array}{r}6.45 \\
16.13 \\
48.39 \\
25.81 \\
3.23 \\
\end{array}$ & $\begin{array}{r}3 \\
4 \\
16 \\
1 \\
5 \\
\end{array}$ & $\begin{array}{r}10.34 \\
13.79 \\
55.17 \\
3.45 \\
17.24 \\
\end{array}$ & $\begin{array}{r}1 \\
2 \\
17 \\
6 \\
1\end{array}$ & $\begin{array}{r}3.70 \\
7.41 \\
62.96 \\
22.22 \\
3.70 \\
\end{array}$ & $\begin{array}{r}2 \\
4 \\
15 \\
10 \\
0 \\
\end{array}$ & $\begin{array}{r}6.45 \\
12.90 \\
48.39 \\
32.26 \\
0 \\
\end{array}$ \\
\hline Total Years in Current Position & $\underline{n}$ & $\%$ & $\underline{\mathrm{n}}$ & $\%$ & $\underline{\mathrm{n}}$ & $\%$ & $\underline{\mathrm{n}}$ & $\%$ \\
\hline $\begin{array}{l}\text { first year } \\
\text { two - four years } \\
\text { five - nine years } \\
10 \text { or more years }\end{array}$ & $\begin{array}{l}5 \\
8 \\
9 \\
9 \\
\end{array}$ & $\begin{array}{l}16.13 \\
25.81 \\
29.03 \\
29.03 \\
\end{array}$ & $\begin{array}{r}6 \\
4 \\
7 \\
12 \\
\end{array}$ & $\begin{array}{l}20.69 \\
13.79 \\
24.14 \\
41.38 \\
\end{array}$ & $\begin{array}{r}4 \\
4 \\
6 \\
13 \\
\end{array}$ & $\begin{array}{l}14.81 \\
14.81 \\
22.22 \\
48.15 \\
\end{array}$ & $\begin{array}{r}7 \\
8 \\
11 \\
5 \\
\end{array}$ & $\begin{array}{l}22.58 \\
25.81 \\
35.48 \\
16.13 \\
\end{array}$ \\
\hline Total Years in Education & $\underline{\mathrm{n}}$ & $7 c$ & $\underline{\mathrm{n}}$ & $\%$ & $\underline{n}$ & $\%$ & $\underline{\mathbf{n}}$ & $\pi$ \\
\hline $\begin{array}{l}\text { fewer than } 10 \\
10-19 \\
20-29 \\
30 \text { or more }\end{array}$ & $\begin{array}{r}1 \\
8 \\
15 \\
7 \\
\end{array}$ & $\begin{array}{r}3.23 \\
25.81 \\
48.39 \\
22.58 \\
\end{array}$ & $\begin{array}{r}1 \\
11 \\
15 \\
2 \\
\end{array}$ & $\begin{array}{r}3.45 \\
37.93 \\
51.72 \\
6.90 \\
\end{array}$ & $\begin{array}{r}1 \\
7 \\
16 \\
3 \\
\end{array}$ & $\begin{array}{r}3.70 \\
25.93 \\
59.26 \\
11.11 \\
\end{array}$ & $\begin{array}{r}3 \\
8 \\
12 \\
8 \\
\end{array}$ & $\begin{array}{r}9.68 \\
25.81 \\
38.71 \\
25.81 \\
\end{array}$ \\
\hline
\end{tabular}




\begin{abstract}
APPENDIX F
FREQUENCY DISTRIBUTION CHARTS: DEPARTMENT CHAIRS BY DISCIPLINES
\end{abstract}


Chart til

Department Chair Responsibility for Human Relations: Ratings of Amount of Time Spent.* Importince

to the Departnient (hair Rolc.** and Importance for the Chair to Continue to Improve*

as Perceived by Iligh School Depar

|By Jirequencies of Responses for liach of liour Ratings:

\begin{tabular}{|c|c|c|c|c|c|c|c|c|c|c|c|c|c|}
\hline \multirow{2}{*}{ Activity } & \multirow{2}{*}{ Thairchoup } & \multicolumn{4}{|c|}{$\operatorname{Time}^{*}$} & \multicolumn{4}{|c|}{ Rolex: } & \multicolumn{4}{|c|}{ Improve } \\
\hline & & 2 & 3 & 4 & 5 & 2 & 3 & \pm & 5 & 2 & & 4 & 3 \\
\hline $\begin{array}{l}\text { 1. Build and maintain a } \\
\text { supportive department team }\end{array}$ & $\begin{array}{l}\text { linglish } \\
\text { Social Studies }\end{array}$ & $\begin{array}{l}0 \\
6\end{array}$ & 12 & $\begin{array}{l}11 \\
10\end{array}$ & $\begin{array}{l}8 \\
2\end{array}$ & $\stackrel{1}{3}$ & $\frac{2}{4}$ & $\begin{array}{l}15 \\
16\end{array}$ & $\begin{array}{r}13 \\
8\end{array}$ & $\mathbf{2}$ & $\begin{array}{l}3 \\
2\end{array}$ & 12 & 17 \\
\hline $\begin{array}{l}\text { 2. Fincourage open communication } \\
\text { among department members }\end{array}$ & $\begin{array}{l}\text { Tinglish } \\
\text { Social Studies }\end{array}$ & $\begin{array}{l}1 \\
3\end{array}$ & $\begin{array}{r}8 \\
10\end{array}$ & $\frac{12}{13}$ & $\begin{array}{r}10 \\
5\end{array}$ & i & $\begin{array}{l}0 \\
2\end{array}$ & $\frac{12}{18}$ & $\begin{array}{l}19 \\
10\end{array}$ & $\begin{array}{l}0 \\
2\end{array}$ & $\begin{array}{l}4 \\
2\end{array}$ & $\begin{array}{r}8 \\
13\end{array}$ & $\begin{array}{l}19 \\
14\end{array}$ \\
\hline $\begin{array}{l}\text { 3. Jacilitate effective conflict } \\
\text { resolution }\end{array}$ & $\begin{array}{l}\text { Fnglish } \\
\text { Sociul Studies }\end{array}$ & $\begin{array}{l}6 \\
11\end{array}$ & $\begin{array}{l}13 \\
13\end{array}$ & $\begin{array}{l}7 \\
6\end{array}$ & 5 & $\frac{2}{3}$ & $\frac{4}{7}$ & $\begin{array}{l}14 \\
18\end{array}$ & $\begin{array}{r}11 \\
3\end{array}$ & $\frac{2}{3}$ & $\begin{array}{l}5 \\
7\end{array}$ & $\begin{array}{l}10 \\
17\end{array}$ & $\begin{array}{r}14 \\
4\end{array}$ \\
\hline $\begin{array}{l}\text { 4. Foster cooperative problem } \\
\text { solving }\end{array}$ & $\begin{array}{l}\text { Finglish } \\
\text { Social Studics }\end{array}$ & $\begin{array}{l}\mathbf{3} \\
\mathbf{3}\end{array}$ & $\begin{array}{r}10 \\
5\end{array}$ & $\begin{array}{l}14 \\
10\end{array}$ & $\begin{array}{r}4 \\
12\end{array}$ & $\begin{array}{l}0 \\
3\end{array}$ & 4 & $\begin{array}{l}15 \\
16\end{array}$ & $\frac{12}{8}$ & $\begin{array}{l}\mathbf{0} \\
\mathbf{3}\end{array}$ & $\begin{array}{l}4 \\
2\end{array}$ & $\begin{array}{l}14 \\
18\end{array}$ & $\begin{array}{r}13 \\
8\end{array}$ \\
\hline $\begin{array}{l}\text { 5. Eincourage trust, caring, and } \\
\text { respect among departmenl members }\end{array}$ & $\begin{array}{l}\text { Einglish } \\
\text { Sociil Studies }\end{array}$ & $\begin{array}{l}0 \\
+\end{array}$ & 11 & $\begin{array}{r}5 \\
13\end{array}$ & $\begin{array}{r}15 \\
3\end{array}$ & $\stackrel{0}{1}$ & $\begin{array}{l}2 \\
4\end{array}$ & $\begin{array}{r}9 \\
12\end{array}$ & 20 & $\begin{array}{l}0 \\
2\end{array}$ & $\begin{array}{l}4 \\
3\end{array}$ & $\begin{array}{c}7 \\
13\end{array}$ & $\begin{array}{l}20 \\
13\end{array}$ \\
\hline $\begin{array}{l}\text { 6. Maintain regular, open oommuni- } \\
\text { cation with department members }\end{array}$ & $\begin{array}{l}\text { English } \\
\text { Social Studits }\end{array}$ & $\begin{array}{l}0 \\
0\end{array}$ & $\begin{array}{r}8 \\
10\end{array}$ & $\begin{array}{r}8 \\
12\end{array}$ & $\begin{array}{r}15 \\
9\end{array}$ & $\begin{array}{l}0 \\
0\end{array}$ & $\frac{2}{3}$ & $\stackrel{6}{11}$ & $\begin{array}{l}23 \\
17\end{array}$ & $\begin{array}{l}0 \\
0\end{array}$ & $\begin{array}{l}4 \\
5\end{array}$ & 11 & $\begin{array}{l}21 \\
15\end{array}$ \\
\hline $\begin{array}{l}\text { 7. Practice collaborative, participalive } \\
\text { decision-making processes }\end{array}$ & $\begin{array}{l}\text { English } \\
\text { Social Studies }\end{array}$ & $\begin{array}{l}\mathbf{3} \\
\mathbf{2}\end{array}$ & $\begin{array}{r}8 \\
13\end{array}$ & $\begin{array}{l}11 \\
10\end{array}$ & $\begin{array}{l}y \\
r\end{array}$ & $\begin{array}{l}0 \\
0\end{array}$ & $\frac{1}{6}$ & $\begin{array}{l}11 \\
13\end{array}$ & $\begin{array}{l}19 \\
12\end{array}$ & $\begin{array}{l}0 \\
0\end{array}$ & $\begin{array}{l}4 \\
7\end{array}$ & 10 & $\begin{array}{l}17 \\
13\end{array}$ \\
\hline $\begin{array}{l}\text { 8. Promote an atmosphere that } \mathrm{cn} \text { - } \\
\text { courages continuous improvement }\end{array}$ & $\begin{array}{l}\text { Finglish } \\
\text { Social Studies }\end{array}$ & $\frac{2}{3}$ & 11 & $\begin{array}{r}9 \\
17\end{array}$ & $\begin{array}{l}9 \\
2\end{array}$ & $\stackrel{0}{1}$ & 3 & $\begin{array}{r}8 \\
12\end{array}$ & $\begin{array}{l}20 \\
14\end{array}$ & i & 4 & 10 & $\frac{22}{16}$ \\
\hline $\begin{array}{l}\text { 9. Fincourage department members } \\
\text { to share in leadership roles }\end{array}$ & $\begin{array}{l}\text { Finglish } \\
\text { Social Studies }\end{array}$ & $\begin{array}{l}5 \\
8 \\
\end{array}$ & $\begin{array}{l}17 \\
14 \\
\end{array}$ & $\begin{array}{r}5 \\
8 \\
\end{array}$ & $\begin{array}{l}4 \\
1 \\
\end{array}$ & 1 & $\begin{array}{r}9 \\
12 \\
\end{array}$ & $\begin{array}{l}11 \\
14 \\
\end{array}$ & $\begin{array}{r}10 \\
4 \\
\end{array}$ & $\begin{array}{l}2 \\
2 \\
\end{array}$ & $\begin{array}{l}9 \\
8 \\
\end{array}$ & $\begin{array}{r}9 \\
15 \\
\end{array}$ & $\begin{array}{r}11 \\
6 \\
\end{array}$ \\
\hline
\end{tabular}

** Rating scale 2-5: 2 (little or no imporfance); 3 (moderale importance); 4 ( very important); and 5 (extremely importamt) 
C.hint I:

Department Chair Responsibility for Huntan Relations: Rattings of Amount of Time Spent,* Importance to the Department (Chair Role, *** and Impontanee for the Chair to (Continue to linprove

[By Frequencies of Responses for liach of Four Ratings]
Subjects: Mith $(N=29)$, Science $(N=27)$

\begin{tabular}{|c|c|c|c|c|c|c|c|c|c|c|c|c|c|}
\hline \multirow[t]{2}{*}{ Aclivity } & \multirow[t]{2}{*}{ Chair Group } & \multicolumn{4}{|c|}{ Time } & \multicolumn{4}{|c|}{ Role } & \multicolumn{4}{|c|}{ Improrex } \\
\hline & & 2 & 3 & 4 & 5 & 2 & 3 & $I$ & 5 & 2 & & 4 & 5 \\
\hline $\begin{array}{l}\text { 1. Build and maintain a } \\
\text { supportive department tcarn }\end{array}$ & $\begin{array}{l}\text { M Gath } \\
\text { Sciemte }\end{array}$ & 4 & $\begin{array}{l}13 \\
13\end{array}$ & $\begin{aligned} 11 \\
7\end{aligned}$ & $\begin{array}{l}\mathbf{0} \\
\mathbf{3}\end{array}$ & $\frac{2}{3}$ & $\begin{array}{l}3 \\
2\end{array}$ & $\begin{array}{l}17 \\
13\end{array}$ & $\begin{array}{l}7 \\
9\end{array}$ & $\begin{array}{l}1 \\
1\end{array}$ & $\begin{array}{l}6 \\
6\end{array}$ & $\begin{array}{r}17 \\
9\end{array}$ & $\stackrel{5}{11}$ \\
\hline $\begin{array}{l}\text { 2. lincourage open communicution } \\
\text { among department members }\end{array}$ & $\begin{array}{l}\text { Malth } \\
\text { Science }\end{array}$ & $\begin{array}{l}3 \\
\mathbf{2}\end{array}$ & $\begin{array}{l}15 \\
12\end{array}$ & 5 & $\begin{array}{l}6 \\
5\end{array}$ & 1 & $\frac{2}{2}$ & $\begin{array}{l}16 \\
11\end{array}$ & $\begin{array}{l}10 \\
12\end{array}$ & $\begin{array}{l}1 \\
0\end{array}$ & 3 & $\begin{array}{l}16 \\
13\end{array}$ & $\begin{array}{r}9 \\
10\end{array}$ \\
\hline $\begin{array}{l}\text { 3. Facilitate effective conflict } \\
\text { resolution }\end{array}$ & $\begin{array}{l}\text { Math } \\
\text { Science }\end{array}$ & $\begin{array}{l}16 \\
11\end{array}$ & 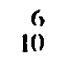 & $\begin{array}{l}6 \\
4\end{array}$ & $\frac{1}{2}$ & $\begin{array}{l}3 \\
3\end{array}$ & $\begin{array}{r}10 \\
4\end{array}$ & $\begin{array}{r}12 \\
9\end{array}$ & $\begin{array}{r}4 \\
10\end{array}$ & $\stackrel{4}{2}$ & $\begin{array}{r}10 \\
9\end{array}$ & $\begin{array}{r}13 \\
9\end{array}$ & $\frac{2}{7}$ \\
\hline $\begin{array}{l}\text { 4. Foster cooperative problem } \\
\text { solving }\end{array}$ & $\begin{array}{l}\text { Mhth } \\
\text { Science }\end{array}$ & $\begin{array}{l}8 \\
5\end{array}$ & 14 & $\stackrel{6}{3}$ & $\begin{array}{l}1 \\
5\end{array}$ & $\begin{array}{l}0 \\
3\end{array}$ & $\begin{array}{l}4 \\
8\end{array}$ & $\begin{array}{r}15 \\
7\end{array}$ & $\begin{array}{r}12 \\
9\end{array}$ & $\frac{2}{3}$ & $\begin{aligned} 11 \\
9\end{aligned}$ & $\begin{array}{r}10 \\
6\end{array}$ & $\begin{array}{l}6 \\
9\end{array}$ \\
\hline $\begin{array}{l}\text { 5. Incourage trust, caring, and } \\
\text { respect among department members }\end{array}$ & $\begin{array}{l}\text { Math } \\
\text { Science }\end{array}$ & $\begin{array}{l}3 \\
6\end{array}$ & $\begin{aligned} 11 \\
8\end{aligned}$ & $\begin{array}{r}11 \\
9\end{array}$ & $\begin{array}{l}4 \\
4\end{array}$ & 3 & $\begin{array}{l}3 \\
3\end{array}$ & $\begin{array}{r}13 \\
9\end{array}$ & $\begin{array}{l}12 \\
12\end{array}$ & $\begin{array}{l}0 \\
2\end{array}$ & $\begin{array}{l}8 \\
6\end{array}$ & $\begin{array}{l}13 \\
11\end{array}$ & $\begin{array}{l}8 \\
8\end{array}$ \\
\hline $\begin{array}{l}\text { 6. Maintain regular, open communi- } \\
\text { cation with department members }\end{array}$ & $\begin{array}{l}\text { Math } \\
\text { Science }\end{array}$ & 1 & $\begin{array}{l}7 \\
7\end{array}$ & $\begin{array}{l}11 \\
10\end{array}$ & $\begin{array}{l}10 \\
10\end{array}$ & $i$ & 1 & $\begin{array}{l}7 \\
7\end{array}$ & $\begin{array}{l}20 \\
18\end{array}$ & 1 & 5 & $\begin{array}{l}8 \\
8\end{array}$ & $\begin{array}{l}15 \\
14\end{array}$ \\
\hline $\begin{array}{l}\text { 7. Practice collaborative, participative } \\
\text { decision-making processes }\end{array}$ & $\begin{array}{l}\text { Math } \\
\text { Sciemce }\end{array}$ & $\begin{array}{l}6 \\
6\end{array}$ & $\begin{array}{l}10 \\
10\end{array}$ & $\begin{array}{l}8 \\
5\end{array}$ & $\begin{array}{l}5 \\
6\end{array}$ & i & 7 & $\frac{12}{7}$ & $\mathbf{9}$ & $\stackrel{1}{0}$ & $\begin{array}{l}9 \\
8\end{array}$ & $\begin{array}{l}13 \\
11\end{array}$ & $\begin{array}{l}6 \\
8\end{array}$ \\
\hline $\begin{array}{l}\text { 8. Promote an atmosphere that en- } \\
\text { courages continuous improvement }\end{array}$ & $\begin{array}{l}\text { Math } \\
\text { Science }\end{array}$ & $\begin{array}{l}5 \\
2\end{array}$ & $\stackrel{8}{11}$ & $\begin{array}{r}14 \\
8\end{array}$ & $\frac{2}{6}$ & $\begin{array}{l}0 \\
0\end{array}$ & $\begin{array}{l}4 \\
4\end{array}$ & $\begin{array}{r}17 \\
8\end{array}$ & $\begin{array}{r}8 \\
1.5\end{array}$ & $\begin{array}{l}\mathbf{0} \\
\mathbf{1}\end{array}$ & $\begin{array}{l}6 \\
3\end{array}$ & $\begin{array}{r}16 \\
9\end{array}$ & $\begin{array}{r}7 \\
14\end{array}$ \\
\hline $\begin{array}{l}\text { 9. Fncourage department members } \\
\text { to share in leadership roles }\end{array}$ & $\begin{array}{l}\text { Math } \\
\text { Science }\end{array}$ & $\begin{array}{l}9 \\
8 \\
\end{array}$ & $\begin{array}{l}12 \\
14 \\
\end{array}$ & $\begin{array}{l}8 \\
1 \\
\end{array}$ & $\begin{array}{l}0 \\
4 \\
\end{array}$ & 2 & $\begin{array}{l}9 \\
8 \\
\end{array}$ & $\begin{array}{l}11 \\
10 \\
\end{array}$ & $\begin{array}{l}7 \\
6 \\
\end{array}$ & $\begin{array}{l}2 \\
4 \\
\end{array}$ & $\begin{array}{l}8 \\
5 \\
\end{array}$ & $\begin{array}{l}14 \\
12 \\
\end{array}$ & $\begin{array}{l}5 \\
6 \\
\end{array}$ \\
\hline
\end{tabular}

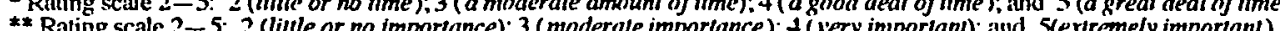


Chart 13

Department Chair Responsibility for Nanagement: Ratings of Amount of Time Spent,* Importance ot the Department Chair Role, ${ }^{* *}$ and Importance for the Chair to Continue to Improve*

and Srevial Studies

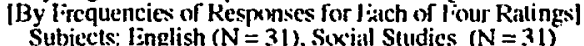

\begin{tabular}{|c|c|c|c|c|c|c|c|c|c|c|c|c|c|}
\hline \multirow{2}{*}{ Activity } & \multirow{2}{*}{ Groulp } & \multicolumn{4}{|c|}{$\lim e^{*}$} & \multicolumn{5}{|c|}{ Rolex } & \multirow{2}{*}{\multicolumn{3}{|c|}{$\frac{\text { Tmprove*f }}{4}$}} \\
\hline & & 7 & - & 7 & 5 & 2 & - & 4 & 5 & 2 & & & \\
\hline $\begin{array}{l}\text { 1. Develop department leaching schedule and } \\
\text { assignmenls }\end{array}$ & $\begin{array}{l}\text { English } \\
\text { Social Studies }\end{array}$ & 3 & 12 & $\begin{array}{l}7 \\
8\end{array}$ & 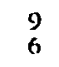 & $\frac{0}{2}$ & $\begin{array}{l}8 \\
6\end{array}$ & $\frac{12}{14}$ & $\stackrel{11}{9}$ & $\begin{array}{l}3 \\
5\end{array}$ & $\begin{array}{l}8 \\
8\end{array}$ & $\stackrel{10}{9}$ & $\stackrel{10}{9}$ \\
\hline $\begin{array}{l}\text { 2. Participate in the selection of deparment } \\
\text { instructional personnel }\end{array}$ & $\begin{array}{l}\text { Einglish } \\
\text { Social Studies }\end{array}$ & 17 & $\begin{array}{l}9 \\
6\end{array}$ & $\begin{array}{l}7 \\
6\end{array}$ & $\begin{array}{l}8 \\
2\end{array}$ & $\begin{array}{l}1 \\
0\end{array}$ & 4 & $\begin{array}{l}12 \\
16\end{array}$ & 115 & $\begin{array}{l}4 \\
0\end{array}$ & $\begin{array}{l}3 \\
2\end{array}$ & $\begin{array}{r}9 \\
14\end{array}$ & $\begin{array}{l}15 \\
15\end{array}$ \\
\hline $\begin{array}{l}\text { 3. Develop and administer the department } \\
\text { budgat }\end{array}$ & $\begin{array}{l}\text { English } \\
\text { Social Studies }\end{array}$ & $\stackrel{2}{i}$ & 11 & $\frac{12}{13}$ & $\stackrel{6}{9}$ & 1 & $\begin{array}{l}7 \\
5\end{array}$ & $\frac{12}{14}$ & 11 & 3 & $\begin{array}{r}10 \\
6\end{array}$ & $\begin{array}{r}8 \\
16\end{array}$ & $\stackrel{10}{9}$ \\
\hline $\begin{array}{l}\text { 4. Disseminate information to department } \\
\text { staff }\end{array}$ & $\begin{array}{l}\text { Fnglish } \\
\text { Social Stuxlies }\end{array}$ & $\frac{1}{3}$ & $\begin{array}{l}5 \\
9\end{array}$ & $\begin{array}{l}11 \\
10\end{array}$ & $\stackrel{14}{9}$ & $\frac{0}{2}$ & $\begin{array}{l}6 \\
6\end{array}$ & $\begin{array}{c}9 \\
10\end{array}$ & $\begin{array}{l}16 \\
13\end{array}$ & $\frac{2}{3}$ & $\begin{array}{l}9 \\
8\end{array}$ & $\begin{array}{l}9 \\
8\end{array}$ & $\begin{array}{l}11 \\
12\end{array}$ \\
\hline $\begin{array}{l}\text { 5. Allocalc and maintain equipment, } \\
\text { instructional materials, und facilitics }\end{array}$ & $\begin{array}{l}\text { English } \\
\text { Social Studies }\end{array}$ & $\begin{array}{l}13 \\
14\end{array}$ & $\underset{9}{12}$ & $\begin{array}{l}3 \\
5\end{array}$ & 3 & $\begin{array}{l}10 \\
10\end{array}$ & 12 & $\begin{array}{l}7 \\
7\end{array}$ & $\frac{2}{3}$ & $\begin{array}{l}10 \\
10\end{array}$ & 12 & $\begin{array}{l}6 \\
6\end{array}$ & $\frac{3}{4}$ \\
\hline $\begin{array}{l}\text { 6. Interpret and apply district policy and } \\
\text { building standards }\end{array}$ & $\begin{array}{l}\text { English } \\
\text { Social Studies }\end{array}$ & 13 & 15 & 6 & $\begin{array}{l}4 \\
0\end{array}$ & 5 & 12 & 11 & $\begin{array}{l}6 \\
4\end{array}$ & $\begin{array}{l}5 \\
6\end{array}$ & $\begin{array}{l}13 \\
10\end{array}$ & $\begin{array}{l}8 \\
6\end{array}$ & $\begin{array}{l}5 \\
5\end{array}$ \\
\hline $\begin{array}{l}\text { 7. Plan and organize relevani department } \\
\text { meetings }\end{array}$ & $\begin{array}{l}\text { English } \\
\text { Sxcial Studies }\end{array}$ & $\begin{array}{l}0 \\
5\end{array}$ & ${ }^{6}$ & II & $\begin{array}{r}14 \\
4\end{array}$ & $\stackrel{0}{3}$ & 4 & $\frac{11}{12}$ & $\begin{array}{l}19 \\
12\end{array}$ & $\stackrel{1}{3}$ & $\begin{array}{l}4 \\
6\end{array}$ & $\stackrel{6}{9}$ & $\begin{array}{l}20 \\
13\end{array}$ \\
\hline $\begin{array}{l}\text { 8. Serve as liaison between department } \\
\text { members and the administration }\end{array}$ & $\begin{array}{l}\text { English } \\
\text { Social Studies } \\
\end{array}$ & $\begin{array}{l}0 \\
1 \\
\end{array}$ & 15 & $\begin{array}{l}7 \\
9 \\
\end{array}$ & $\begin{array}{l}19 \\
10 \\
\end{array}$ & $\begin{array}{l}0 \\
1 \\
\end{array}$ & $\frac{1}{6}$ & 12 & $\begin{array}{l}18 \\
1.3 \\
\end{array}$ & $\begin{array}{l}1 \\
1 \\
\end{array}$ & $\begin{array}{l}6 \\
7 \\
\end{array}$ & $\begin{array}{r}8 \\
11 \\
\end{array}$ & $\begin{array}{l}16 \\
12 \\
\end{array}$ \\
\hline
\end{tabular}


Chart $1: 4$

Department Chair Responsibility for Management: Ratings of Amount of Time Spent.* IInjxortance to the Iscpartment Chair Role.** and limpertance for the Chair to Continue to Improve ${ }^{* *}$

requencies of Responscs for latch of Wur Ritings

\begin{tabular}{|c|c|c|c|c|c|c|c|c|c|c|c|c|c|}
\hline \multirow{2}{*}{ Kctivity } & \multirow[t]{2}{*}{ Group } & \multicolumn{4}{|c|}{ Timet } & \multicolumn{4}{|c|}{ Role** } & \multicolumn{4}{|c|}{ Imiprove ${ }^{* \pi}$} \\
\hline & & 2 & 3 & 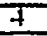 & 5 & 2 & 3 & 4 & 5 & 2 & 3 & 4 & 5 \\
\hline $\begin{array}{l}\text { 1. Develop department teaching schedule } \\
\text { and assignments }\end{array}$ & $\begin{array}{l}\text { Math } \\
\text { Science }\end{array}$ & 3 & 12 & $\begin{array}{l}8 \\
6\end{array}$ & $\frac{6}{7}$ & $\begin{array}{l}\mathbf{0} \\
\mathbf{0}\end{array}$ & $\begin{array}{l}6 \\
4\end{array}$ & $\begin{array}{l}10 \\
12\end{array}$ & 13 & $\frac{2}{2}$ & 9 & $\begin{array}{l}10 \\
10\end{array}$ & $\begin{array}{l}11 \\
8\end{array}$ \\
\hline $\begin{array}{l}\text { 2. Participate in the selection of department } \\
\text { instructional persemnel }\end{array}$ & $\begin{array}{l}\text { Math } \\
\text { Science }\end{array}$ & $\begin{array}{r}8 \\
10\end{array}$ & $\begin{array}{r}13 \\
4\end{array}$ & $\begin{array}{l}7 \\
8\end{array}$ & $\begin{array}{l}1 \\
5\end{array}$ & $\begin{array}{l}1 \\
2\end{array}$ & 4 & $\stackrel{10}{.5}$ & 11 & 1 & $\begin{array}{l}8 \\
6\end{array}$ & $\begin{array}{r}13 \\
8\end{array}$ & $\begin{array}{r}7 \\
10\end{array}$ \\
\hline $\begin{array}{l}\text { 3. Develop and administer the department } \\
\text { budget }\end{array}$ & $\begin{array}{l}\text { Malh } \\
\text { Science }\end{array}$ & $\frac{2}{4}$ & $\begin{array}{r}11 \\
7\end{array}$ & $\begin{array}{l}8 \\
6\end{array}$ & $\begin{array}{r}8 \\
10\end{array}$ & $\begin{array}{l}0 \\
3\end{array}$ & $\begin{array}{l}4 \\
6\end{array}$ & $\begin{array}{r}1.3 \\
4\end{array}$ & $\frac{12}{14}$ & $\stackrel{0}{4}$ & 8 & 12 & $\stackrel{9}{11}$ \\
\hline $\begin{array}{l}\text { 4. Disseminate information to department } \\
\text { staff }\end{array}$ & $\begin{array}{l}\text { Math } \\
\text { Science }\end{array}$ & 1 & $\begin{array}{l}8 \\
9\end{array}$ & $\begin{array}{l}6 \\
8\end{array}$ & $\begin{array}{r}14 \\
9\end{array}$ & $\frac{1}{2}$ & $\begin{array}{l}3 \\
3\end{array}$ & $\begin{array}{r}9 \\
12\end{array}$ & $\begin{array}{l}16 \\
10\end{array}$ & $\begin{array}{l}\mathbf{0} \\
\mathbf{3}\end{array}$ & $\begin{array}{l}8 \\
8\end{array}$ & $\stackrel{9}{8}$ & $\begin{array}{r}12 \\
8\end{array}$ \\
\hline $\begin{array}{l}\text { 5. Allocate and maintain equipment, } \\
\text { instructional materials, and facilities }\end{array}$ & $\begin{array}{l}\text { Math } \\
\text { Science }\end{array}$ & $\begin{array}{l}8 \\
6\end{array}$ & $\begin{array}{r}9 \\
13\end{array}$ & 4 & 3 & $\begin{array}{l}6 \\
3\end{array}$ & 8 & $\begin{array}{r}11 \\
8\end{array}$ & $\stackrel{4}{5}$ & 5 & $\begin{array}{l}13 \\
11\end{array}$ & $\begin{array}{l}8 \\
7\end{array}$ & $\begin{array}{l}3 \\
5\end{array}$ \\
\hline $\begin{array}{l}\text { 6. Interpret and apply district policy and } \\
\text { building standards }\end{array}$ & $\begin{array}{l}\text { Math } \\
\text { Science }\end{array}$ & $\stackrel{13}{11}$ & 13 & i & $\begin{array}{l}3 \\
2\end{array}$ & $\begin{array}{l}6 \\
5\end{array}$ & $\begin{array}{l}10 \\
12\end{array}$ & $\begin{array}{l}8 \\
6\end{array}$ & 5 & $\begin{array}{l}6 \\
6\end{array}$ & $\frac{12}{10}$ & 6 & $\begin{array}{l}5 \\
5\end{array}$ \\
\hline $\begin{array}{l}\text { 7. Plan and organize relevant department } \\
\text { meetings }\end{array}$ & $\begin{array}{l}\text { Math } \\
\text { Science }\end{array}$ & 4 & $\begin{array}{r}8 \\
12\end{array}$ & $\begin{array}{r}12 \\
8\end{array}$ & $\begin{array}{l}5 \\
3\end{array}$ & 1 & $\begin{array}{l}6 \\
6\end{array}$ & $\begin{array}{l}14 \\
14\end{array}$ & $\begin{array}{l}8 \\
7\end{array}$ & $\begin{array}{l}1 \\
3\end{array}$ & $\begin{array}{l}8 \\
4\end{array}$ & $\begin{array}{l}14 \\
12\end{array}$ & $\begin{array}{l}6 \\
8\end{array}$ \\
\hline $\begin{array}{l}\text { 8. Serve as liaison thetween department } \\
\text { members and the administration }\end{array}$ & $\begin{array}{l}\text { Math } \\
\text { Science }\end{array}$ & $\frac{2}{2}$ & $\begin{array}{r}10 \\
5 \\
\end{array}$ & $\begin{array}{r}5 \\
12 \\
\end{array}$ & $\begin{array}{r}12 \\
8\end{array}$ & 1 & j & $\begin{array}{l}14 \\
13\end{array}$ & 12 & $\frac{2}{3}$ & $\begin{array}{l}5 \\
4 \\
\end{array}$ & 11 & $\begin{array}{r}11 \\
9\end{array}$ \\
\hline
\end{tabular}

** Rating scale 2-5: 2 (himle or no lime); 3 (a moderale amount of time): 4 (a good deal of fime); and 5 (a greal deal of lime) 
C.hart is

Department Chair Responsibility for the Organizition: Latings of Amount of Time Spent, * Importance o the Departmon

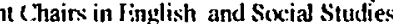

iby Irequencies of Responses for latch of liour Ratings:

\begin{tabular}{|c|c|c|c|c|c|c|c|c|c|c|c|c|c|}
\hline \multirow[t]{2}{*}{ Activity } & \multirow[t]{2}{*}{ Ciroup } & \multicolumn{4}{|c|}{ Timi: } & \multicolumn{4}{|c|}{ Role } & \multicolumn{4}{|c|}{ Improve } \\
\hline & & $\underline{z}$ & 3 & 4 & 5 & 2 & 3 & & 5 & 2 & & & 5 \\
\hline $\begin{array}{l}\text { 1. Ingage depertment members in an organized } \\
\text { department growth ind improvement effort }\end{array}$ & $\begin{array}{l}\text { English } \\
\text { Sccial Studies }\end{array}$ & 5 & $\begin{array}{ll}11 \\
13\end{array}$ & 9 & 3 & $\begin{array}{l}0 \\
3\end{array}$ & $\begin{array}{l}8 \\
6\end{array}$ & 11 & $\stackrel{14}{11}$ & $\begin{array}{l}0 \\
2\end{array}$ & $\begin{array}{l}8 \\
7\end{array}$ & $\begin{array}{r}10 \\
9\end{array}$ & $\begin{array}{l}13 \\
13\end{array}$ \\
\hline $\begin{array}{l}\text { 2. Represent the department in } \\
\text { developing/implementing school's organized } \\
\text { improvement effort }\end{array}$ & $\begin{array}{l}\text { English } \\
\text { S(xial Studie: }\end{array}$ & $\frac{4}{6}$ & $\frac{12}{10}$ & 10 & 6 & $\begin{array}{l}3 \\
3\end{array}$ & $\begin{array}{l}7 \\
6\end{array}$ & 12 & $\begin{array}{l}9 \\
9\end{array}$ & 3 & $\begin{array}{l}8 \\
6\end{array}$ & $\begin{array}{l}11 \\
12\end{array}$ & $\begin{array}{l}10 \\
10\end{array}$ \\
\hline $\begin{array}{l}\text { 3. Serve as department spokesperson at } \\
\text { community and board meetings }\end{array}$ & $\begin{array}{l}\text { English } \\
\text { Social Studies }\end{array}$ & $\frac{22}{19}$ & +4 & $\frac{2}{3}$ & 3 & $\begin{array}{l}10 \\
10\end{array}$ & 9 & $\begin{array}{r}10 \\
9\end{array}$ & $\begin{array}{l}2 \\
5\end{array}$ & $\begin{array}{l}7 \\
7\end{array}$ & $\begin{array}{r}13 \\
8\end{array}$ & $\begin{array}{l}9 \\
9\end{array}$ & $\frac{2}{5}$ \\
\hline $\begin{array}{l}\text { 4. Prepare requested information on department } \\
\text { topics for principal, central office, school } \\
\text { bxard }\end{array}$ & $\begin{array}{l}\text { English } \\
\text { Social Studies }\end{array}$ & $\begin{aligned} 8 \\
16\end{aligned}$ & $\frac{12}{6}$ & $\begin{array}{l}8 \\
8\end{array}$ & 3 & $\begin{array}{l}3 \\
8\end{array}$ & $\stackrel{13}{9}$ & 13 & $\frac{2}{3}$ & $\begin{array}{l}3 \\
7\end{array}$ & $\begin{array}{l}16 \\
11\end{array}$ & $\begin{array}{l}10 \\
10\end{array}$ & $\begin{array}{l}\mathbf{2} \\
\mathbf{3}\end{array}$ \\
\hline $\begin{array}{l}\text { 5. Act as an advocate for the protection of } \\
\text { classroom instructional time }\end{array}$ & $\begin{array}{l}\text { English } \\
\text { Sccial Studies }\end{array}$ & $\stackrel{8}{11}$ & $\begin{array}{r}8 \\
15\end{array}$ & 3 & ? & $\frac{2}{7}$ & 6 & $\begin{array}{l}6 \\
9\end{array}$ & $\begin{array}{r}17 \\
9\end{array}$ & 1 & 11 & $\begin{array}{l}4 \\
8\end{array}$ & $\begin{array}{l}15 \\
10\end{array}$ \\
\hline $\begin{array}{l}\text { 6. Support icachers' professional needs and } \\
\text { concerns }\end{array}$ & $\begin{array}{l}\text { English } \\
\text { Social Studics }\end{array}$ & 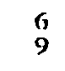 & $\stackrel{9}{11}$ & $\begin{array}{r}8 \\
10\end{array}$ & $\begin{array}{l}8 \\
1\end{array}$ & $\begin{array}{l}1 \\
4\end{array}$ & 5 & $\begin{array}{r}8 \\
13\end{array}$ & $\begin{array}{r}17 \\
8\end{array}$ & 2 & $\begin{array}{l}8 \\
7\end{array}$ & $\begin{array}{r}6 \\
13\end{array}$ & $\begin{array}{r}15 \\
8\end{array}$ \\
\hline $\begin{array}{l}\text { 7. Work with other department chairs to develop } \\
\text { an integrated school instructional program }\end{array}$ & $\begin{array}{l}\text { English } \\
\text { Sccial Studies }\end{array}$ & 11 & $\begin{array}{r}8 \\
12\end{array}$ & $\begin{array}{l}6 \\
8\end{array}$ & $\begin{array}{l}8 \\
0\end{array}$ & $\frac{1}{2}$ & $\begin{array}{l}5 \\
7\end{array}$ & $\begin{array}{l}11 \\
12\end{array}$ & $\begin{array}{l}14 \\
10\end{array}$ & $\begin{array}{l}0 \\
1\end{array}$ & $\begin{array}{l}6 \\
8\end{array}$ & $\begin{array}{l}11 \\
10\end{array}$ & $\begin{array}{l}14 \\
12\end{array}$ \\
\hline $\begin{array}{l}\text { 8. Participate in district-level planning and } \\
\text { decision making }\end{array}$ & $\begin{array}{l}\text { English } \\
\text { Social Studies }\end{array}$ & $\begin{array}{l}8 \\
9 \\
\end{array}$ & $\begin{array}{r}8 \\
10 \\
\end{array}$ & $\stackrel{9}{11}$ & $\begin{array}{l}6 \\
1 \\
\end{array}$ & $\begin{array}{l}1 \\
3 \\
\end{array}$ & $\begin{array}{l}7 \\
5 \\
\end{array}$ & $\begin{array}{l}14 \\
12 \\
\end{array}$ & 11 & $\begin{array}{l}1 \\
2 \\
\end{array}$ & $\begin{array}{l}9 \\
5 \\
\end{array}$ & $\begin{array}{l}13 \\
12 \\
\end{array}$ & $\begin{array}{r}8 \\
12 \\
\end{array}$ \\
\hline
\end{tabular}

** Rating scale 2-5: 2 (linle or no importance); 3 (moderate importance); 4 (very important); and 5 (extremely important) 
Chart Iis

Department Chair Responsibility for the Organization: Ratings of Amount of 7 ime Spent, ${ }^{*}$ Importance to the Department Chair Role,** and Impertance for the (hair to Continue to Improve ${ }^{* *}$

3y lireguencies of Responses for I:ach of I iour Ratings

\begin{tabular}{|c|c|c|c|c|c|c|c|c|c|c|c|c|c|}
\hline \multirow[t]{2}{*}{ Activity } & \multirow[t]{2}{*}{ (iroutup } & \multicolumn{4}{|c|}{ (immex } & \multicolumn{4}{|c|}{ Rolli** } & \multicolumn{4}{|c|}{ Improve } \\
\hline & & 2 & 3 & 4 & 5 & 2 & 3 & 4 & 5 & 2 & 3 & 4 & 5 \\
\hline $\begin{array}{l}\text { 1. Iingage department members in an organized } \\
\text { department growth and improvement effort }\end{array}$ & $\begin{array}{l}\text { Math } \\
\text { Science }\end{array}$ & 13 & $\begin{array}{r}9 \\
10\end{array}$ & $\frac{6}{4}$ & $\frac{1}{2}$ & 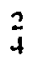 & $\begin{array}{r}10 \\
7\end{array}$ & $\begin{array}{l}14 \\
10\end{array}$ & $\stackrel{3}{6}$ & $\frac{1}{3}$ & 13 & $\begin{array}{l}9 \\
6\end{array}$ & $\stackrel{6}{11}$ \\
\hline $\begin{array}{l}\text { 2. Represent the department in developing and } \\
\text { implementing schnol's organized improvement } \\
\text { effort }\end{array}$ & $\begin{array}{l}\text { Math } \\
\text { Science }\end{array}$ & $\begin{array}{l}7 \\
3\end{array}$ & $\begin{array}{l}9 \\
8\end{array}$ & $\begin{array}{r}9 \\
13\end{array}$ & $\begin{array}{l}4 \\
3\end{array}$ & $\frac{2}{1}$ & $\begin{array}{l}12 \\
10\end{array}$ & $\stackrel{11}{9}$ & $\frac{4}{7}$ & $\begin{array}{l}3 \\
3\end{array}$ & $\begin{array}{r}13 \\
9\end{array}$ & $\begin{array}{l}8 \\
7\end{array}$ & $\frac{5}{8}$ \\
\hline $\begin{array}{l}\text { 3. Serve as department spokesperson at community } \\
\text { and hoard meetings }\end{array}$ & $\begin{array}{l}\text { Math } \\
\text { Science }\end{array}$ & 11 & $\begin{array}{r}12 \\
9\end{array}$ & $\begin{array}{l}8 \\
3\end{array}$ & 4 & $\begin{array}{l}6 \\
5\end{array}$ & $\begin{array}{r}11 \\
4\end{array}$ & $\begin{array}{l}10 \\
12\end{array}$ & $\frac{2}{6}$ & $\begin{array}{l}7 \\
5\end{array}$ & $\begin{array}{r}13 \\
7\end{array}$ & $\begin{array}{l}7 \\
9\end{array}$ & $\frac{2}{6}$ \\
\hline $\begin{array}{l}\text { 4. Prepare requested information on department } \\
\text { topics for principal, central office, school brard }\end{array}$ & $\begin{array}{l}\text { Math } \\
\text { Science }\end{array}$ & $\begin{array}{r}11 \\
8\end{array}$ & 7 & $\begin{array}{r}10 \\
8\end{array}$ & $\begin{array}{l}1 \\
4\end{array}$ & $\frac{4}{2}$ & 12 & $\stackrel{9}{12}$ & $\begin{array}{l}4 \\
2\end{array}$ & $\begin{array}{l}7 \\
3\end{array}$ & 15 & 4 & $\begin{array}{l}3 \\
4\end{array}$ \\
\hline $\begin{array}{l}\text { 5. Act as an advocate for the protection of classroom } \\
\text { instructional time }\end{array}$ & $\begin{array}{l}\text { Math } \\
\text { Science }\end{array}$ & $\begin{array}{l}8 \\
8\end{array}$ & $\begin{array}{l}10 \\
11\end{array}$ & $\begin{array}{l}9 \\
5\end{array}$ & $\frac{2}{3}$ & $\frac{2}{2}$ & $\begin{array}{r}12 \\
5\end{array}$ & $\begin{array}{l}10 \\
1.3\end{array}$ & $\begin{array}{l}5 \\
7\end{array}$ & 4 & $\begin{array}{r}15 \\
8\end{array}$ & $\begin{array}{r}6 \\
10\end{array}$ & $\begin{array}{l}4 \\
6\end{array}$ \\
\hline 6. Support teachers" professional needs and concerns & $\begin{array}{l}\text { Math } \\
\text { Science }\end{array}$ & $\begin{array}{l}8 \\
8\end{array}$ & $\begin{array}{r}8 \\
10\end{array}$ & $\begin{array}{r}10 \\
5\end{array}$ & $\begin{array}{l}3 \\
4\end{array}$ & $\begin{array}{l}1 \\
2\end{array}$ & $\begin{array}{r}9 \\
12\end{array}$ & $\begin{array}{r}12 \\
9\end{array}$ & $\begin{array}{l}7 \\
4\end{array}$ & $\begin{array}{l}3 \\
6\end{array}$ & $\begin{array}{r}13 \\
9\end{array}$ & $\begin{array}{l}8 \\
5\end{array}$ & $\begin{array}{l}5 \\
7\end{array}$ \\
\hline $\begin{array}{l}\text { 7. Work with other department chairs to develop an } \\
\text { integrated schoof instructional program }\end{array}$ & $\begin{array}{l}\text { Mituth } \\
\text { Science }\end{array}$ & 11 & $\begin{array}{r}12 \\
7\end{array}$ & 5 & 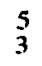 & $\stackrel{1}{3}$ & 11 & $\begin{array}{r}7 \\
10\end{array}$ & $\begin{array}{r}10 \\
7\end{array}$ & $\frac{1}{3}$ & 11 & $\begin{array}{l}7 \\
8\end{array}$ & $\begin{array}{r}10 \\
9\end{array}$ \\
\hline $\begin{array}{l}\text { 8. Purticipate in district-Jevel planning and decision } \\
\text { making }\end{array}$ & $\begin{array}{l}\text { Math } \\
\text { Science }\end{array}$ & $\begin{array}{l}8 \\
7\end{array}$ & $\begin{array}{l}6 \\
8\end{array}$ & $\frac{6}{7}$ & $\begin{array}{l}9 \\
5\end{array}$ & $\frac{2}{2}$ & $\begin{array}{l}9 \\
8\end{array}$ & $\stackrel{7}{11}$ & 11 & $\begin{array}{l}2 \\
4\end{array}$ & $\begin{array}{r}10 \\
6\end{array}$ & 9 & $\begin{array}{r}8 \\
10\end{array}$ \\
\hline
\end{tabular}

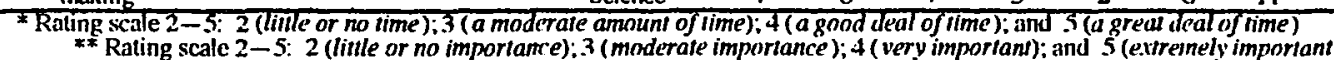


Chart 1.7

Department Chair Responsibility for 1'rogrant: Ratings or Amount of Time Spent, * Importance

to the Department Chair Role, ** and Inportance for the Chair of Continuc of Improve"

I13y lirequencies of Responlses for liach of lour Ratings
Subjeets: English $(N=31)$, Social Studits: $(N=31)$

\begin{tabular}{|c|c|c|c|c|c|c|c|c|c|c|c|c|c|}
\hline \multirow{2}{*}{ Activity } & \multirow[t]{2}{*}{ (iroup } & \multicolumn{4}{|c|}{ Time } & \multicolumn{4}{|c|}{ Rule* } & \multicolumn{4}{|c|}{ Improve** } \\
\hline & & 2 & 3 & 4 & 5 & 2 & 3 & $I$ & 5 & 2 & & & 5 \\
\hline 1. Facilitate development of curriculum & $\begin{array}{l}\text { English } \\
\text { Social Studies }\end{array}$ & $\frac{2}{5}$ & $\begin{aligned} 8 \\
12\end{aligned}$ & $\begin{array}{r}9 \\
10\end{array}$ & 12 & $\begin{array}{l}0 \\
3\end{array}$ & $\frac{2}{4}$ & $\begin{array}{l}13 \\
17\end{array}$ & $\begin{array}{r}16 \\
7\end{array}$ & $\frac{1}{3}$ & 5 & $\frac{12}{17}$ & 1.3 \\
\hline 2. Supervise the implementation of curriculum & $\begin{array}{l}\text { Finglish } \\
\text { Socied Sterdies }\end{array}$ & $\begin{array}{r}9 \\
10\end{array}$ & $\stackrel{5}{11}$ & $\begin{aligned} 11 \\
7\end{aligned}$ & $\begin{array}{l}6 \\
3\end{array}$ & $\begin{array}{l}3 \\
3\end{array}$ & $\begin{array}{l}3 \\
6\end{array}$ & 11 & $\begin{array}{r}14 \\
8\end{array}$ & $\frac{1}{2}$ & $\begin{array}{r}11 \\
9\end{array}$ & 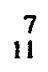 & 12 \\
\hline $\begin{array}{l}\text { 3. Monitor the continued maintenance of } \\
\text { curriculum }\end{array}$ & $\begin{array}{l}\text { Einglish } \\
\text { Sociiul Studies }\end{array}$ & $\begin{array}{r}6 \\
1.3\end{array}$ & 11 & $\begin{array}{l}8 \\
6\end{array}$ & $\frac{6}{2}$ & $\begin{array}{l}1 \\
2\end{array}$ & $\begin{array}{l}7 \\
8\end{array}$ & $\begin{array}{r}9 \\
1.3\end{array}$ & $\begin{array}{r}14 \\
8\end{array}$ & $\frac{1}{2}$ & $1 !$ & ${ }_{11}^{7}$ & $\begin{array}{r}12 \\
9\end{array}$ \\
\hline $\begin{array}{l}\text { 4. Devise and implement process for program } \\
\text { evaluation }\end{array}$ & $\begin{array}{l}\text { Finglish } \\
\text { Social Studics }\end{array}$ & $\frac{2}{17}$ & $\begin{array}{r}8 \\
10\end{array}$ & $\begin{array}{r}15 \\
3\end{array}$ & $i$ & $\begin{array}{l}1 \\
6\end{array}$ & $\begin{array}{l}9 \\
6\end{array}$ & $\begin{array}{l}17 \\
12\end{array}$ & $\begin{array}{l}4 \\
7\end{array}$ & $\frac{2}{6}$ & $\begin{array}{l}7 \\
5\end{array}$ & 17 & $\begin{array}{l}5 \\
7\end{array}$ \\
\hline $\begin{array}{l}\text { 5. Irovide leadership in the selection and } \\
\text { devclopment of instructional malerials }\end{array}$ & $\begin{array}{l}\text { English } \\
\text { Social Studics }\end{array}$ & 3 & $\begin{array}{l}15 \\
16\end{array}$ & 3 & $\begin{array}{r}10 \\
5\end{array}$ & $\begin{array}{l}0 \\
0\end{array}$ & 9 & $\begin{array}{r}9 \\
12\end{array}$ & 13 & 2 & $\begin{array}{r}10 \\
9\end{array}$ & 15 & $\begin{array}{r}14 \\
9\end{array}$ \\
\hline $\begin{array}{l}\text { 6. Coordinnte departmental selection of } \\
\text { textbooks and supplemental materials }\end{array}$ & $\begin{array}{l}\text { English } \\
\text { Social Studies }\end{array}$ & $\begin{array}{l}5 \\
5\end{array}$ & $\stackrel{14}{9}$ & 10 & 8 & $\begin{array}{l}1 \\
0\end{array}$ & $\begin{array}{l}8 \\
4\end{array}$ & $\begin{array}{l}10 \\
12\end{array}$ & 12 & $\begin{array}{l}2 \\
0\end{array}$ & $\begin{array}{r}11 \\
4\end{array}$ & $\begin{array}{r}6 \\
1.3\end{array}$ & $\begin{array}{l}12 \\
14\end{array}$ \\
\hline $\begin{array}{l}\text { 7. Assess icarning outcomes to identify program } \\
\text { strengths and weaknesses }\end{array}$ & $\begin{array}{l}\text { English } \\
\text { Social Studies }\end{array}$ & $\begin{array}{r}1 \\
17\end{array}$ & 9 & 12 & $\frac{12}{2}$ & $\frac{1}{3}$ & 11 & $\begin{array}{r}20 \\
8\end{array}$ & $\begin{array}{l}6 \\
9\end{array}$ & $\frac{2}{3}$ & $1^{3}$ & $\begin{array}{r}20 \\
9\end{array}$ & $\begin{array}{l}6 \\
8\end{array}$ \\
\hline 8. Fstablish goals for program improvement & $\begin{array}{l}\text { Finglish } \\
\text { Social Studies }\end{array}$ & 15 & 11 & $\begin{array}{r}12 \\
8\end{array}$ & 5 & $\begin{array}{l}2 \\
4\end{array}$ & 5 & $\begin{array}{l}17 \\
12\end{array}$ & $\begin{array}{l}11 \\
10\end{array}$ & $\begin{array}{l}2 \\
3\end{array}$ & $\begin{array}{l}1 \\
6\end{array}$ & $\begin{array}{l}18 \\
11\end{array}$ & $\begin{array}{l}10 \\
11\end{array}$ \\
\hline
\end{tabular}

** Rating scale $2-5$ : 2 (iille or no importance): 3 (maderate importance): 4 (very important); and 5 (extremely important) 


\section{Chart Ix}

Department Chair Responsibility for Program: Ratings of Amount of "Time Spent, * Importance

to the Department Chair Role.** and Importunce for the Chair to Continte ki improve**

as Perceived by High $S$ ch(x)] Depurtment (Chairs in Math and Science

[By lirequencies of Responses for Liach of Four Ratings]

\begin{tabular}{|c|c|c|c|c|c|c|c|c|c|c|c|c|c|}
\hline \multirow[t]{2}{*}{ Tctivity } & \multirow[t]{2}{*}{ Giroup } & \multicolumn{4}{|c|}{$\operatorname{Timx^{*}}$} & \multicolumn{4}{|c|}{ Role } & \multicolumn{4}{|c|}{ Tmprove } \\
\hline & & 2 & 3 & 4 & 3 & 2 & 3 & $I$ & 5 & 2 & & & 5 \\
\hline 1. Facilitale development of curriculum & $\begin{array}{l}\text { Math } \\
\text { Science }\end{array}$ & $\begin{array}{l}5 \\
3\end{array}$ & $\begin{array}{l}8 \\
9\end{array}$ & $\begin{array}{r}9 \\
10\end{array}$ & $\begin{array}{l}7 \\
5\end{array}$ & $\dot{1}$ & $\begin{array}{l}9 \\
5\end{array}$ & $\begin{array}{ll}11 \\
15\end{array}$ & $\begin{array}{l}8 \\
6\end{array}$ & $\begin{array}{l}0 \\
2\end{array}$ & $\underset{5}{11}$ & $\begin{array}{l}12 \\
12\end{array}$ & $\stackrel{6}{8}$ \\
\hline 2. Supervise the implementation of curriculum & $\begin{array}{l}\text { Math } \\
\text { Scicnce }\end{array}$ & $\begin{array}{l}7 \\
9\end{array}$ & 7 & $\begin{array}{r}10 \\
4\end{array}$ & $\begin{array}{l}5 \\
3\end{array}$ & $\frac{1}{2}$ & 5 & 1.3 & $\begin{array}{r}10 \\
5\end{array}$ & 2 & $\begin{array}{l}8 \\
9\end{array}$ & $\begin{array}{l}10 \\
11\end{array}$ & 7 \\
\hline $\begin{array}{l}\text { 3. Monitor the continued maintenance of } \\
\text { curriculum }\end{array}$ & $\begin{array}{l}\text { Math } \\
\text { Science }\end{array}$ & $\begin{array}{r}6 \\
12\end{array}$ & $\begin{array}{r}10 \\
9\end{array}$ & $\begin{array}{r}10 \\
4\end{array}$ & $\begin{array}{l}3 \\
2\end{array}$ & $\stackrel{2}{3}$ & $\frac{9}{7}$ & $\begin{array}{r}9 \\
12\end{array}$ & $\begin{array}{l}9 \\
5\end{array}$ & 2 & $\begin{array}{r}12 \\
7\end{array}$ & $\begin{array}{r}8 \\
10\end{array}$ & $\begin{array}{l}7 \\
7\end{array}$ \\
\hline $\begin{array}{l}\text { 4. Devise and implement process for program } \\
\text { evaluation }\end{array}$ & $\begin{array}{l}\text { Math } \\
\text { Science }\end{array}$ & $\begin{array}{r}4 \\
14\end{array}$ & $\begin{array}{r}10 \\
7\end{array}$ & $\begin{array}{l}9 \\
5\end{array}$ & $\begin{array}{l}6 \\
i\end{array}$ & $\begin{array}{l}3 \\
4\end{array}$ & $\begin{array}{r}15 \\
8\end{array}$ & $\begin{array}{r}9 \\
12\end{array}$ & $\frac{2}{3}$ & $\frac{2}{3}$ & $\begin{array}{r}15 \\
9\end{array}$ & $\begin{array}{l}9 \\
7\end{array}$ & $\begin{array}{l}2 \\
8\end{array}$ \\
\hline $\begin{array}{l}\text { 5. Provide leadership in the selection and } \\
\text { development of instructional materials }\end{array}$ & $\begin{array}{l}\text { Math } \\
\text { Science }\end{array}$ & 5 & $\begin{array}{l}9 \\
7\end{array}$ & 10 & $\begin{array}{r}10 \\
3\end{array}$ & $\stackrel{4}{2}$ & $\begin{array}{l}7 \\
8\end{array}$ & $\begin{array}{l}10 \\
1.3\end{array}$ & $\begin{array}{l}8 \\
4\end{array}$ & $\begin{array}{l}3 \\
3\end{array}$ & $\begin{array}{r}11 \\
6\end{array}$ & $\begin{array}{r}7 \\
12\end{array}$ & 8 \\
\hline $\begin{array}{l}\text { 6. Coordinate departmental selection of } \\
\text { textbooks and supplemental materials }\end{array}$ & $\begin{array}{l}\text { Math } \\
\text { Science }\end{array}$ & 4 & $\begin{array}{l}5 \\
7\end{array}$ & $\begin{array}{l}8 \\
9\end{array}$ & $\begin{array}{l}13 \\
7\end{array}$ & $i$ & 5 & $\begin{array}{l}12 \\
13\end{array}$ & $\begin{array}{r}10 \\
6\end{array}$ & $\begin{array}{l}3 \\
2\end{array}$ & $\begin{array}{l}6 \\
9\end{array}$ & $\begin{array}{r}10 \\
9\end{array}$ & $\begin{array}{r}10 \\
7\end{array}$ \\
\hline $\begin{array}{l}\text { 7. Assess learning outcomes to identify } \\
\text { program strengths and weaknesses }\end{array}$ & $\begin{array}{l}\text { Math } \\
\text { Science }\end{array}$ & $\begin{array}{l}11 \\
14\end{array}$ & 11 & 5 & $\frac{2}{1}$ & $\begin{array}{l}1 \\
6\end{array}$ & $\begin{array}{r}10 \\
6\end{array}$ & $\begin{array}{l}14 \\
13\end{array}$ & $\begin{array}{l}4 \\
2\end{array}$ & $\begin{array}{l}2 \\
5\end{array}$ & $\begin{array}{r}10 \\
4\end{array}$ & $\begin{array}{l}13 \\
12\end{array}$ & $\begin{array}{l}4 \\
6\end{array}$ \\
\hline 8. listablish goals for program improvement & $\begin{array}{l}\text { Math } \\
\text { Science }\end{array}$ & $\begin{array}{r}11 \\
9\end{array}$ & $\begin{array}{r}12 \\
9\end{array}$ & $\begin{array}{l}4 \\
7\end{array}$ & 2 & i & $\begin{array}{r}10 \\
8\end{array}$ & $\begin{array}{l}16 \\
13\end{array}$ & $\begin{array}{l}3 \\
5\end{array}$ & $\begin{array}{l}0 \\
3\end{array}$ & $\begin{array}{r}12 \\
6\end{array}$ & $\begin{array}{l}13 \\
13\end{array}$ & $\begin{array}{l}4 \\
5\end{array}$ \\
\hline
\end{tabular}

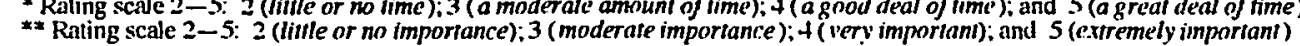


(.hart I.

Department (hair Responsibility for Supervision: Ratings of Amount of Time Sixenl.* Importance to the 1)epartment (Chair Role.** and

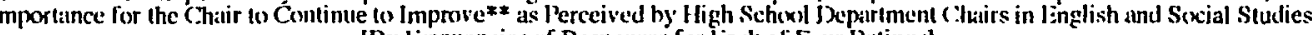
[By lirequencies of Responses for liach ol Four Rulings:
Subjects: Iinglish $(N=31)$. Sociall Studies $(N=31)$

\begin{tabular}{|c|c|c|c|c|c|c|c|c|c|c|c|c|c|}
\hline \multirow{2}{*}{ Activily } & \multirow[t]{2}{*}{ Group } & \multicolumn{4}{|c|}{ Time* } & \multicolumn{4}{|c|}{ 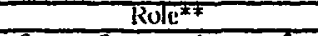 } & \multicolumn{4}{|c|}{ Improve ${ }^{2 \pi}$} \\
\hline & & 2 & $\overline{3}$ & I & 5 & 2 & 3 & + & 5 & 2 & & & 5 \\
\hline T. . Iosec a vatrely of insiructional siralegies & $\begin{array}{l}\text { Tinglish } \\
\text { Scritil Studies }\end{array}$ & $\begin{array}{l}14 \\
13\end{array}$ & $\begin{array}{l}10 \\
1.3\end{array}$ & 4 & $i^{3}$ & $\frac{7}{8}$ & 9 & $\begin{array}{l}73 \\
10\end{array}$ & 5 & $\begin{array}{l}5 \\
5\end{array}$ & $\begin{array}{l}7 \\
7\end{array}$ & 10 & $\frac{9}{7}$ \\
\hline $\begin{array}{l}\text { 2. Assist teachers in developing professional } \\
\text { grouth plans }\end{array}$ & $\begin{array}{l}\text { linglish } \\
\text { Scciol Studies }\end{array}$ & $\begin{array}{l}15 \\
26\end{array}$ & +9 & $i$ & 1 & 7 & 14 & 12 & $i$ & $\begin{array}{l}6 \\
7\end{array}$ & $\stackrel{9}{15}$ & $\frac{12}{7}$ & $\begin{array}{l}4 \\
2\end{array}$ \\
\hline $\begin{array}{l}\text { 3. Incourage experimentation and innovation } \\
\text { among leachers }\end{array}$ & $\begin{array}{l}\text { Finglish } \\
\text { Social Studies }\end{array}$ & $\stackrel{4}{9}$ & $\begin{array}{r}8 \\
17\end{array}$ & $\begin{array}{r}13 \\
5\end{array}$ & $\hat{0}$ & $\begin{array}{l}3 \\
5\end{array}$ & $\begin{array}{l}0 \\
6\end{array}$ & $\begin{array}{l}14 \\
10\end{array}$ & $\begin{array}{l}14 \\
10\end{array}$ & $\frac{2}{4}$ & $\begin{array}{l}1 \\
4\end{array}$ & $\begin{array}{l}15 \\
13\end{array}$ & $\begin{array}{l}13 \\
10\end{array}$ \\
\hline $\begin{array}{l}\text { 4. Coordinate instruction among department } \\
\text { menbers }\end{array}$ & $\begin{array}{l}\text { Finglish } \\
\text { Social studies }\end{array}$ & $\begin{array}{l}6 \\
9\end{array}$ & $\begin{array}{l}11 \\
14\end{array}$ & $\begin{aligned} 11 \\
7\end{aligned}$ & $i$ & i & $\begin{array}{l}5 \\
9\end{array}$ & $\begin{array}{l}16 \\
1.5\end{array}$ & $\begin{array}{l}9 \\
6\end{array}$ & $\begin{array}{l}1 \\
0\end{array}$ & $\begin{array}{r}5 \\
11\end{array}$ & $\begin{array}{l}14 \\
11\end{array}$ & $\begin{array}{r}11 \\
9\end{array}$ \\
\hline $\begin{array}{l}\text { 5. Otserve teachers in their classnoms and } \\
\text { provide feedback }\end{array}$ & $\begin{array}{l}\text { Finglish } \\
\text { Social Studies }\end{array}$ & $\begin{array}{l}18 \\
22\end{array}$ & $\begin{array}{l}8 \\
8\end{array}$ & $\frac{2}{1}$ & $\begin{array}{l}3 \\
0\end{array}$ & $\begin{array}{l}9 \\
9\end{array}$ & 10 & $\begin{array}{l}13 \\
10\end{array}$ & $\begin{array}{l}5 \\
2\end{array}$ & $\begin{array}{l}7 \\
8\end{array}$ & $\stackrel{6}{11}$ & $\stackrel{10}{5}$ & $\begin{array}{l}8 \\
7\end{array}$ \\
\hline 6. Monitor teacher lesson plans & $\begin{array}{l}\text { Jinglish } \\
\text { Social Studies }\end{array}$ & $\begin{array}{l}27 \\
28\end{array}$ & 2 & $\frac{2}{0}$ & $\hat{i}$ & $\begin{array}{l}15 \\
22\end{array}$ & $\begin{array}{r}12 \\
5\end{array}$ & 4 & $\begin{array}{l}1 \\
0\end{array}$ & $\begin{array}{l}15 \\
20\end{array}$ & $\begin{array}{r}11 \\
6\end{array}$ & $\begin{array}{l}4 \\
3\end{array}$ & $\begin{array}{l}1 \\
2\end{array}$ \\
\hline 7. P'ictice clinical supervision & $\begin{array}{l}\text { Finglish } \\
\text { Social Studies }\end{array}$ & $\begin{array}{l}23 \\
27\end{array}$ & $\frac{5}{2}$ & 3 & $\stackrel{0}{1}$ & 17 & $\begin{array}{r}10 \\
9\end{array}$ & 5 & $\begin{array}{l}2 \\
0\end{array}$ & $\begin{array}{l}14 \\
16\end{array}$ & $\begin{array}{r}10 \\
9\end{array}$ & $\begin{array}{l}4 \\
3\end{array}$ & $\begin{array}{l}3 \\
3\end{array}$ \\
\hline $\begin{array}{l}\text { 8. Communicate high expectations for teacher } \\
\text { performance }\end{array}$ & $\begin{array}{l}\text { English } \\
\text { Social Studies }\end{array}$ & $\begin{array}{l}10 \\
15\end{array}$ & $\begin{array}{r}8 \\
1.3\end{array}$ & $\begin{array}{l}8 \\
2\end{array}$ & i & 3 & 5 & $\begin{array}{l}14 \\
14\end{array}$ & $\begin{array}{l}9 \\
+\end{array}$ & $\begin{array}{l}3 \\
5\end{array}$ & $\begin{array}{l}8 \\
6\end{array}$ & $\begin{array}{ll}11 \\
16\end{array}$ & $\begin{array}{l}9 \\
4\end{array}$ \\
\hline $\begin{array}{l}\text { 9. Assist teachers with improvement of their } \\
\text { instruction }\end{array}$ & $\begin{array}{l}\text { English } \\
\text { Social Studies }\end{array}$ & $\begin{array}{l}12 \\
17\end{array}$ & 12 & 5 & $\stackrel{2}{0}$ & 3 & $\begin{array}{l}8 \\
9\end{array}$ & $\begin{array}{l}13 \\
13\end{array}$ & $\begin{array}{l}7 \\
5\end{array}$ & 4 & $\begin{array}{l}8 \\
7\end{array}$ & $\begin{array}{l}11 \\
12\end{array}$ & $\begin{array}{l}8 \\
8\end{array}$ \\
\hline $\begin{array}{l}\text { 10. Organize plan for teacher sharing, peer } \\
\text { coseching }\end{array}$ & $\begin{array}{l}\text { English } \\
\text { Social Studies }\end{array}$ & $\begin{array}{l}20 \\
27\end{array}$ & 4 & $\begin{array}{l}3 \\
0\end{array}$ & $\frac{2}{0}$ & 11 & $\begin{array}{r}10 \\
8\end{array}$ & $\stackrel{10}{9}$ & $\stackrel{6}{3}$ & 11 & 11 & $\begin{array}{r}9 \\
10\end{array}$ & $\begin{array}{l}7 \\
3\end{array}$ \\
\hline 11. IEvaluate teacher performance & $\begin{array}{l}\text { Finglish } \\
\text { Social Studies }\end{array}$ & $\begin{array}{l}25 \\
25\end{array}$ & $\begin{array}{l}3 \\
5\end{array}$ & $\begin{array}{l}3 \\
1\end{array}$ & $\begin{array}{l}0 \\
0\end{array}$ & $\begin{array}{l}15 \\
18 \\
\end{array}$ & 7 & $\begin{array}{r}8 \\
4 \\
\end{array}$ & $\begin{array}{l}1 \\
2\end{array}$ & $\begin{array}{l}15 \\
18\end{array}$ & $\begin{array}{l}5 \\
6 \\
\end{array}$ & $\begin{array}{l}9 \\
3 \\
\end{array}$ & $\frac{2}{4}$ \\
\hline
\end{tabular}

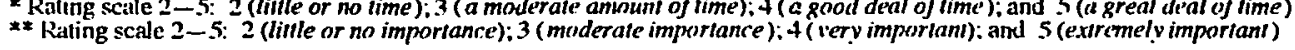




\section{(hart filo}

Department Chair Responsibility for Supervision: Ratings of Amount of Time Spent.* Importance to the lxepartment Chair Role,**and Impxortance for the Chair to (ontinute in Improve* ats Perceived by I ligh Schoul Deparment Chairs in Math and Science

[13y [requencies of Regponses for liach of ] iour Rating:

\begin{tabular}{|c|c|c|c|c|c|c|c|c|c|c|c|c|c|}
\hline \multirow{2}{*}{ Activity } & \multirow{2}{*}{ (Broup } & \multicolumn{4}{|c|}{ Time* } & \multicolumn{4}{|c|}{ Rolex } & \multicolumn{4}{|c|}{ Tmprove } \\
\hline & & 2 & 3 & 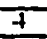 & 5 & 2 & 3 & 4 & 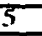 & 2 & & & 5 \\
\hline 1. Model a variety of instructional strategies & $\begin{array}{l}\text { Mard } \\
\text { Science }\end{array}$ & $\begin{array}{l}20 \\
1.5\end{array}$ & $\frac{6}{7}$ & 5 & $\frac{2}{0}$ & $\frac{12}{9}$ & $\begin{array}{l}10 \\
10\end{array}$ & $\begin{array}{l}3 \\
5\end{array}$ & $\begin{array}{l}4 \\
3\end{array}$ & $\begin{array}{l}8 \\
7\end{array}$ & $\begin{array}{r}13 \\
8\end{array}$ & $\begin{array}{l}4 \\
7\end{array}$ & $\begin{array}{l}4 \\
5\end{array}$ \\
\hline $\begin{array}{l}\text { 2. Assist teachers in developing professional } \\
\text { growth plans }\end{array}$ & $\begin{array}{l}\text { Math } \\
\text { Scicnce }\end{array}$ & $\frac{22}{20}$ & 4 & $\frac{1}{2}$ & $i$ & $\begin{array}{l}13 \\
11\end{array}$ & $\begin{array}{r}10 \\
9\end{array}$ & 3 & $\frac{3}{2}$ & $\begin{array}{l}11 \\
10\end{array}$ & $\begin{array}{c}11 \\
8\end{array}$ & $\begin{array}{l}4 \\
5\end{array}$ & $\begin{array}{l}3 \\
4\end{array}$ \\
\hline $\begin{array}{l}\text { 3. Encourage experimentation and } \\
\text { innovation amung teachers }\end{array}$ & $\begin{array}{l}\text { Math } \\
\text { Science }\end{array}$ & $\begin{array}{l}13 \\
11\end{array}$ & 12 & 3 & $\frac{1}{2}$ & $\begin{array}{l}6 \\
4\end{array}$ & $\begin{array}{l}9 \\
7\end{array}$ & $\frac{12}{12}$ & 2 & $\ddot{4}$ & 9 & $\begin{array}{l}10 \\
10\end{array}$ & $\begin{array}{l}4 \\
6\end{array}$ \\
\hline $\begin{array}{l}\text { 4. Coordinate instruction among department } \\
\text { nembers }\end{array}$ & $\begin{array}{l}\text { Math } \\
\text { Scicnce }\end{array}$ & 5 & 15 & $\begin{array}{l}8 \\
4\end{array}$ & i & $\begin{array}{l}2 \\
6\end{array}$ & $\begin{array}{r}14 \\
7\end{array}$ & $\begin{array}{r}8 \\
11\end{array}$ & $\begin{array}{l}5 \\
3\end{array}$ & 4 & $\begin{array}{r}16 \\
5\end{array}$ & $\begin{array}{r}6 \\
12\end{array}$ & 6 \\
\hline $\begin{array}{l}\text { 5. Otserve teachers in their classrooms and } \\
\text { provide fecdback }\end{array}$ & $\begin{array}{l}\text { Math } \\
\text { Science }\end{array}$ & $\begin{array}{l}22 \\
19\end{array}$ & $\begin{array}{l}3 \\
3\end{array}$ & $\frac{1}{2}$ & 3 & $\begin{array}{r}8 \\
10\end{array}$ & $\begin{array}{l}9 \\
7\end{array}$ & $\begin{array}{l}7 \\
5\end{array}$ & 5 & $\begin{array}{l}8 \\
8\end{array}$ & $\begin{array}{l}10 \\
3\end{array}$ & $\begin{array}{l}7 \\
8\end{array}$ & $\begin{array}{l}4 \\
8\end{array}$ \\
\hline 6. Monitor leacher lesson plans & $\begin{array}{l}\text { Math } \\
\text { Science }\end{array}$ & $\begin{array}{l}27 \\
25\end{array}$ & 1 & $\begin{array}{l}0 \\
1\end{array}$ & $\begin{array}{l}1 \\
0\end{array}$ & $\frac{24}{17}$ & $\begin{array}{l}1 \\
8\end{array}$ & 3 & 1 & $\begin{array}{l}23 \\
14\end{array}$ & $\frac{2}{8}$ & $\frac{2}{3}$ & 2 \\
\hline 7. Practice clinical supervision & $\begin{array}{l}\text { Math } \\
\text { Sciunce }\end{array}$ & $\frac{25}{27}$ & $\frac{2}{2}$ & 1 & 1 & $\begin{array}{l}19 \\
17\end{array}$ & 5 & $\begin{array}{l}3 \\
4\end{array}$ & $\begin{array}{l}3 \\
1\end{array}$ & $\begin{array}{l}19 \\
14\end{array}$ & 6 & $\begin{array}{l}1 \\
6\end{array}$ & $\begin{array}{l}3 \\
1\end{array}$ \\
\hline $\begin{array}{l}\text { 8. Communicate high expectations for } \\
\text { leacher performance }\end{array}$ & $\begin{array}{l}\text { Math } \\
\text { Science }\end{array}$ & $\dddot{11}$ & $\frac{12}{9}$ & $\begin{array}{l}5 \\
5\end{array}$ & $\begin{array}{l}1 \\
2\end{array}$ & $\begin{array}{l}\mathbf{3} \\
\mathbf{3}\end{array}$ & $\begin{array}{r}1.3 \\
9\end{array}$ & $\stackrel{10}{11}$ & 3 & $\frac{3}{2}$ & $\begin{array}{r}15 \\
8\end{array}$ & $\stackrel{9}{11}$ & $\frac{2}{6}$ \\
\hline $\begin{array}{l}\text { 9. Assist leachers with improvement of their } \\
\text { instruction }\end{array}$ & $\begin{array}{l}\text { Math } \\
\text { Science }\end{array}$ & $\begin{array}{l}16 \\
15\end{array}$ & 11 & $\frac{2}{6}$ & $\stackrel{0}{2}$ & $\begin{array}{l}6 \\
6\end{array}$ & $\begin{array}{r}10 \\
6\end{array}$ & $\begin{array}{r}10 \\
9\end{array}$ & $\begin{array}{l}3 \\
6\end{array}$ & $\begin{array}{l}5 \\
5\end{array}$ & $\begin{array}{l}8 \\
5\end{array}$ & $\begin{array}{l}13 \\
10\end{array}$ & $\begin{array}{l}3 \\
7\end{array}$ \\
\hline $\begin{array}{l}\text { 10. Organize plan for teacher sharing, peer } \\
\text { conching }\end{array}$ & $\begin{array}{l}\text { Malh } \\
\text { Science }\end{array}$ & $\frac{25}{20}$ & $\begin{array}{l}2 \\
6\end{array}$ & 1 & $\begin{array}{l}1 \\
0\end{array}$ & $\begin{array}{l}13 \\
10\end{array}$ & 11 & $\begin{array}{l}4 \\
3\end{array}$ & 3 & $\begin{array}{r}12 \\
9\end{array}$ & $\begin{array}{l}9 \\
9\end{array}$ & $\begin{array}{l}4 \\
4\end{array}$ & $\begin{array}{l}4 \\
5\end{array}$ \\
\hline 11. Evaluatc teacher performance & $\begin{array}{l}\text { Math } \\
\text { Science }\end{array}$ & $\begin{array}{l}26 \\
21 \\
\end{array}$ & $\begin{array}{l}0 \\
3 \\
\end{array}$ & $\frac{1}{2}$ & $\frac{2}{1}$ & $\begin{array}{l}19 \\
15\end{array}$ & $\begin{array}{r}5 \\
4 \\
\end{array}$ & $\begin{array}{l}2 \\
5\end{array}$ & $\begin{array}{l}3 \\
3\end{array}$ & $\begin{array}{l}19 \\
12\end{array}$ & $\begin{array}{l}6 \\
4 \\
\end{array}$ & $\begin{array}{l}1 \\
6\end{array}$ & $\begin{array}{r}3 \\
5 \\
\end{array}$ \\
\hline
\end{tabular}

** Rating scale 2-5: 2 (limle or no imponance); 3 (moderate importance); 4 ( very importamt); ind 5 (extremely inporfumt) 
APPENDIX $G$

MEAN AND STANDARD DEVIATION CHARTS: DEPARTMENT

CHAIRS GROUPED BY DISCIPLINES 


\section{Chart G1}

Department Chair Responsibility for Human Relations: Ratings of Amount of Time Spent,* Importance to the Department Chair Role, ${ }^{* *}$ and Importance for the Chair to Continue to Improve** as Perceived by High School Academic Department Chairs Subjects $(N=118)$

\begin{tabular}{|c|c|c|c|c|c|c|c|c|c|}
\hline \multirow[t]{2}{*}{ Activity } & \multirow[t]{2}{*}{ Issue } & \multicolumn{2}{|c|}{$\begin{array}{c}\text { English } \\
(\mathrm{N}=31) \\
\end{array}$} & \multicolumn{2}{|c|}{$\begin{array}{c}\text { Math } \\
(\mathrm{N}=29)\end{array}$} & \multicolumn{2}{|c|}{$\begin{array}{l}\text { Science } \\
(\mathrm{N}=27) \\
\end{array}$} & \multicolumn{2}{|c|}{$\begin{array}{c}\text { Social Studics } \\
(N=31)\end{array}$} \\
\hline & & $\underline{\underline{M}}$ & $\underline{S D}$ & $\underline{\mathrm{M}}$ & $S D$ & $\underline{\mathrm{M}}$ & $\underline{S D}$ & $\underline{M}$ & SD \\
\hline HR-1 & $\begin{array}{l}\text { Time } \\
\text { Role } \\
\text { Improve }\end{array}$ & $\begin{array}{l}3.871 \\
4.290 \\
4.290\end{array}$ & $\begin{array}{l}0.806 \\
0.739 \\
1.006\end{array}$ & $\begin{array}{l}3.207 \\
3.966 \\
3.897\end{array}$ & $\begin{array}{l}0.726 \\
0.906 \\
0.724\end{array}$ & $\begin{array}{l}3.296 \\
4.037 \\
4.111\end{array}$ & $\begin{array}{l}0.953 \\
0.940 \\
0.892\end{array}$ & $\begin{array}{l}3.258 \\
3.935 \\
4.194\end{array}$ & $\begin{array}{l}0.855 \\
0.892 \\
0.946\end{array}$ \\
\hline HR-2 & $\begin{array}{l}\text { Time } \\
\text { Role } \\
\text { Improve }\end{array}$ & $\begin{array}{l}4.000 \\
4.613 \\
4.484\end{array}$ & $\begin{array}{l}0.856 \\
0.495 \\
0.724\end{array}$ & $\begin{array}{l}3.483 \\
4.172 \\
4.138\end{array}$ & $\begin{array}{l}0.949 \\
0.848 \\
0.743\end{array}$ & $\begin{array}{l}3.593 \\
4.222 \\
4.222\end{array}$ & $\begin{array}{l}0.888 \\
0.892 \\
0.698\end{array}$ & $\begin{array}{l}3.645 \\
4.194 \\
4.258\end{array}$ & $\begin{array}{l}0.877 \\
0.703 \\
0.855\end{array}$ \\
\hline HR-3 & $\begin{array}{l}\text { Time } \\
\text { Rolc } \\
\text { Improve }\end{array}$ & $\begin{array}{l}3.355 \\
4.097 \\
4.161\end{array}$ & $\begin{array}{l}0.985 \\
0.870 \\
0.934\end{array}$ & $\begin{array}{l}2.690 \\
3.552 \\
3.448\end{array}$ & $\begin{array}{l}0.923 \\
0.948 \\
0.827\end{array}$ & $\begin{array}{l}2.815 \\
3.889 \\
3.741\end{array}$ & $\begin{array}{l}1.039 \\
1.155 \\
1.033\end{array}$ & $\begin{array}{l}2.903 \\
3.677 \\
3.710\end{array}$ & $\begin{array}{l}0.801 \\
0.791 \\
0.824\end{array}$ \\
\hline $\mathrm{HR}-4$ & $\begin{array}{l}\text { Time } \\
\text { Role } \\
\text { Improve }\end{array}$ & $\begin{array}{l}3.613 \\
4.258 \\
4.290\end{array}$ & $\begin{array}{l}0.844 \\
0.680 \\
0.693\end{array}$ & $\begin{array}{l}2.931 \\
3.759 \\
3.690\end{array}$ & $\begin{array}{l}0.923 \\
0.830 \\
0.891\end{array}$ & $\begin{array}{l}3.259 \\
3.778 \\
3.741\end{array}$ & $\begin{array}{l}1.059 \\
1.121 \\
1.130\end{array}$ & $\begin{array}{l}3.097 \\
3.903 \\
3.968\end{array}$ & $\begin{array}{l}1.044 \\
0.978 \\
0.948\end{array}$ \\
\hline HR-5 & $\begin{array}{l}\text { Time } \\
\text { Role } \\
\text { Improve }\end{array}$ & $\begin{array}{l}4.129 \\
4.581 \\
4.516\end{array}$ & $\begin{array}{l}0.922 \\
0.620 \\
0.724\end{array}$ & $\begin{array}{l}3.552 \\
4.241 \\
4.000\end{array}$ & $\begin{array}{l}0.870 \\
0.786 \\
0.756\end{array}$ & $\begin{array}{l}3.370 \\
4.074 \\
3.889\end{array}$ & $\begin{array}{l}1.079 \\
1.107 \\
1.103\end{array}$ & $\begin{array}{l}3.484 \\
4.258 \\
4.194\end{array}$ & $\begin{array}{l}0.851 \\
0.815 \\
0.873\end{array}$ \\
\hline HR-6 & $\begin{array}{l}\text { Time } \\
\text { Role } \\
\text { Improve }\end{array}$ & $\begin{array}{l}4.226 \\
4.677 \\
4.548\end{array}$ & $\begin{array}{l}0.845 \\
0.599 \\
0.723\end{array}$ & $\begin{array}{l}4.034 \\
4.586 \\
4.276\end{array}$ & $\begin{array}{l}0.865 \\
0.733 \\
0.882\end{array}$ & $\begin{array}{l}4.111 \\
4.556 \\
4.296\end{array}$ & $\begin{array}{l}0.801 \\
0.751 \\
0.869\end{array}$ & $\begin{array}{l}3.968 \\
4.452 \\
4.323\end{array}$ & $\begin{array}{l}0.795 \\
0.675 \\
0.748\end{array}$ \\
\hline $\mathrm{HR}-7$ & $\begin{array}{l}\text { Time } \\
\text { Role } \\
\text { Improve }\end{array}$ & $\begin{array}{l}3.839 \\
4.581 \\
4.419\end{array}$ & $\begin{array}{l}0.969 \\
0.564 \\
0.720\end{array}$ & $\begin{array}{l}3.379 \\
3.966 \\
3.828\end{array}$ & $\begin{array}{l}1.083 \\
0.944 \\
0.805\end{array}$ & $\begin{array}{l}3.333 \\
4.111 \\
4.000\end{array}$ & $\begin{array}{l}1.209 \\
0.934 \\
0.784\end{array}$ & $\begin{array}{l}3.613 \\
4.194 \\
4.194\end{array}$ & $\begin{array}{l}0.955 \\
0.749 \\
0.792\end{array}$ \\
\hline HR-8 & $\begin{array}{l}\text { Time } \\
\text { Roie } \\
\text { Improve }\end{array}$ & $\begin{array}{l}3.806 \\
4.548 \\
4.581\end{array}$ & $\begin{array}{l}0.946 \\
0.675 \\
0.720\end{array}$ & $\begin{array}{l}3.448 \\
4.138 \\
4.034\end{array}$ & $\begin{array}{l}0.870 \\
0.639 \\
0.680\end{array}$ & $\begin{array}{l}3.630 \\
4.407 \\
4.333\end{array}$ & $\begin{array}{l}1.006 \\
0.747 \\
0.832\end{array}$ & $\begin{array}{l}3.581 \\
4.258 \\
4.323\end{array}$ & $\begin{array}{c}0.765 \\
0.810 \\
.832\end{array}$ \\
\hline HR-9 & $\begin{array}{l}\text { Time } \\
\text { Role } \\
\text { Improve }\end{array}$ & $\begin{array}{l}3.258 \\
3.968 \\
3.935\end{array}$ & $\begin{array}{l}0.893 \\
0.875 \\
0.964\end{array}$ & $\begin{array}{l}2.966 \\
3.759 \\
3.724\end{array}$ & $\begin{array}{l}0.788 \\
0.988 \\
0.922 \\
\end{array}$ & $\begin{array}{l}2.963 \\
3.704 \\
3.741 \\
\end{array}$ & $\begin{array}{l}1.091 \\
0.953 \\
0.984\end{array}$ & $\begin{array}{l}3.065 \\
3.677 \\
3.806\end{array}$ & $\begin{array}{l}0.814 \\
0.748 \\
0.833\end{array}$ \\
\hline
\end{tabular}

* Rating scale: $1-5$ (1) No time; (2) Linle time ; (3) A moderate amoum of time; (4) A good deal of time; (5) A greal deal of rime

** Rating scale: i-5 (1) No importance; (2) Little importance; (3) Moderate imporiance; (4)Very important; (5) Extremely important 
Chart G2

Department Chair Responsibility for Management: Ratings of Amount of Time Spent,* Importance 10 the Department Chair Role, ${ }^{* *}$ and Importance for the Chair to Continue to Improve** as Perceived by High School Academic Department Chairs

Subjects $(N=118)$

\begin{tabular}{|c|c|c|c|c|c|c|c|c|c|}
\hline \multirow[t]{2}{*}{ Activity } & \multirow[t]{2}{*}{ Issue } & \multicolumn{2}{|c|}{$\begin{array}{c}\text { English } \\
(\mathrm{N}=31)\end{array}$} & \multicolumn{2}{|c|}{$\begin{array}{c}\text { Math } \\
(\mathrm{N}=29)\end{array}$} & \multicolumn{2}{|c|}{$\begin{array}{l}\text { Science } \\
(\mathrm{N}=27)\end{array}$} & \multicolumn{2}{|c|}{$\begin{array}{l}\text { Social Studies } \\
(\mathrm{N}=31)\end{array}$} \\
\hline & & $\underline{M}$ & $S D$ & $\underline{\mathrm{M}}$ & SD & $\underline{\mathrm{M}}$ & $\underline{\underline{S D}}$ & $\underline{\mathrm{M}}$ & $\underline{\mathrm{SD}}$ \\
\hline MG-1 & $\begin{array}{l}\text { Time } \\
\text { Role } \\
\text { Improve }\end{array}$ & $\begin{array}{l}3.710 \\
4.097 \\
3.839\end{array}$ & $\begin{array}{l}1.006 \\
0.790 \\
1.008\end{array}$ & $\begin{array}{l}3.552 \\
4.241 \\
4.034\end{array}$ & $\begin{array}{l}1.021 \\
0.786 \\
0.944\end{array}$ & $\begin{array}{l}3.444 \\
4.259 \\
3.889\end{array}$ & $\begin{array}{l}1.219 \\
0.712 \\
0.934\end{array}$ & $\begin{array}{l}3.516 \\
3.968 \\
3.710\end{array}$ & $\begin{array}{l}0.956 \\
0.875 \\
1.071\end{array}$ \\
\hline MG-2 & $\begin{array}{l}\text { Time } \\
\text { Role } \\
\text { Improve }\end{array}$ & $\begin{array}{l}3.387 \\
4.290 \\
4.097\end{array}$ & $\begin{array}{l}1.334 \\
0.902 \\
1.136\end{array}$ & $\begin{array}{l}2.966 \\
4.009 \\
3.897\end{array}$ & $\begin{array}{l}0.944 \\
0.884 \\
0.817\end{array}$ & $\begin{array}{l}3.222 \\
4.259 \\
3.889\end{array}$ & $\begin{array}{l}1.281 \\
1.095 \\
1.121\end{array}$ & $\begin{array}{l}2.516 \\
4.226 \\
4.419\end{array}$ & $\begin{array}{l}1.262 \\
0.669 \\
0.620\end{array}$ \\
\hline MG-3 & $\begin{array}{l}\text { Time } \\
\text { Role } \\
\text { Improve }\end{array}$ & $\begin{array}{l}3.710 \\
4.065 \\
3.806\end{array}$ & $\begin{array}{l}0.864 \\
0.854 \\
1.014\end{array}$ & $\begin{array}{l}3.724 \\
4.276 \\
4.034\end{array}$ & $\begin{array}{l}1.032 \\
0.702 \\
0.778\end{array}$ & $\begin{array}{l}3.778 \\
4.037 \\
3.815\end{array}$ & $\begin{array}{l}1.188 \\
1.192 \\
1.272\end{array}$ & $\begin{array}{l}3.968 \\
4.226 \\
4.097\end{array}$ & $\begin{array}{l}0.836 \\
0.717 \\
0.700\end{array}$ \\
\hline$M G-4$ & $\begin{array}{l}\text { Time } \\
\text { Role } \\
\text { Improve }\end{array}$ & $\begin{array}{l}4.226 \\
4.323 \\
3.903\end{array}$ & $\begin{array}{l}0.845 \\
0.791 \\
1.044\end{array}$ & $\begin{array}{l}4.138 \\
4.379 \\
4.138\end{array}$ & $\begin{array}{l}0.953 \\
0.820 \\
0.833\end{array}$ & $\begin{array}{l}3.889 \\
4.111 \\
3.778\end{array}$ & $\begin{array}{l}1.013 \\
0.892 \\
1.013\end{array}$ & $\begin{array}{l}3.774 \\
4.065 \\
3.871\end{array}$ & $\begin{array}{l}1.055 \\
1.031 \\
1.176\end{array}$ \\
\hline MG-5 & $\begin{array}{l}\text { Time } \\
\text { Role } \\
\text { Improve }\end{array}$ & $\begin{array}{l}2.774 \\
2.968 \\
3.000\end{array}$ & $\begin{array}{l}1.087 \\
1.016 \\
1.065\end{array}$ & $\begin{array}{l}3.103 \\
3.345 \\
3.207\end{array}$ & $\begin{array}{l}1.205 \\
1.173 \\
1.082\end{array}$ & $\begin{array}{l}3.148 \\
3.519 \\
3.444\end{array}$ & $\begin{array}{l}1.099 \\
1.014 \\
1.050\end{array}$ & $\begin{array}{l}2.710 \\
2.968 \\
3.000\end{array}$ & $\begin{array}{l}1.243 \\
1.169 \\
1.211\end{array}$ \\
\hline MG-6 & $\begin{array}{l}\text { Time } \\
\text { Role } \\
\text { Improve }\end{array}$ & $\begin{array}{l}3.258 \\
3.581 \\
3.387\end{array}$ & $\begin{array}{l}0.930 \\
0.992 \\
1.022\end{array}$ & $\begin{array}{l}2.897 \\
3.379 \\
3.310\end{array}$ & $\begin{array}{l}1.205 \\
1.083 \\
1.072\end{array}$ & $\begin{array}{l}2.630 \\
3.259 \\
3.222\end{array}$ & $\begin{array}{l}1.043 \\
1.095 \\
1.281\end{array}$ & $\begin{array}{l}2.613 \\
3.065 \\
3.097\end{array}$ & $\begin{array}{l}0.989 \\
1.203 \\
1.193\end{array}$ \\
\hline MG-7 & $\begin{array}{l}\text { Time } \\
\text { Role } \\
\text { Improve }\end{array}$ & $\begin{array}{l}4.258 \\
4.581 \\
4.452\end{array}$ & $\begin{array}{l}0.773 \\
0.564 \\
0.850\end{array}$ & $\begin{array}{l}3.621 \\
4.000 \\
3.862\end{array}$ & $\begin{array}{l}0.942 \\
0.802 \\
0.789\end{array}$ & $\begin{array}{l}3.333 \\
4.037 \\
3.926\end{array}$ & $\begin{array}{l}0.961 \\
0.706 \\
0.958\end{array}$ & $\begin{array}{l}3.387 \\
4.000 \\
3.968\end{array}$ & $\begin{array}{l}1.054 \\
1.125 \\
1.169\end{array}$ \\
\hline MG-8 & $\begin{array}{l}\text { Time } \\
\text { Role } \\
\text { Improve }\end{array}$ & $\begin{array}{l}4.452 \\
4.548 \\
4.258\end{array}$ & $\begin{array}{l}0.768 \\
0.568 \\
0.893\end{array}$ & $\begin{array}{l}3.931 \\
4.241 \\
4.000\end{array}$ & $\begin{array}{l}1.033 \\
0.872 \\
1.102\end{array}$ & $\begin{array}{l}3.963 \\
4.333 \\
3.963 \\
\end{array}$ & $\begin{array}{l}0.898 \\
0.734 \\
0.980\end{array}$ & $\begin{array}{l}3.903 \\
4.161 \\
4.097\end{array}$ & $\begin{array}{l}0.908 \\
0.860 \\
0.870 \\
\end{array}$ \\
\hline
\end{tabular}

* Rating scale: $1-5$ (1) No time; (2) Little time ; (3) A moderate amount of time;

(4) A good deal of time; (5) A great deal of time

** Rating scale: $1-5$ (1) No importance ; (2) Little importance; (3) Moderate importance ; (4)

Very important; (5) Extremely important 


\section{Chart G3}

Department Chair Responsibility for The Organization: Ratings of Amount of Time Spent,* Importance to the Department Chair Role,** and Importance for the Chair to Continuc to Improve** as Perceived by High School Academic Department Chairs

Subjects $(\mathrm{N}=118)$

\begin{tabular}{|c|c|c|c|c|c|c|c|c|c|}
\hline \multirow[t]{2}{*}{ Activity } & \multirow[t]{2}{*}{ Issue } & \multicolumn{2}{|c|}{$\begin{array}{l}\text { English } \\
(\mathrm{N}=31) \\
\end{array}$} & \multicolumn{2}{|c|}{$\begin{array}{c}\text { Math } \\
(N=29)\end{array}$} & \multicolumn{2}{|c|}{$\begin{array}{l}\text { Science } \\
(\mathrm{N}=27) \\
\end{array}$} & \multicolumn{2}{|c|}{$\begin{array}{l}\text { Social Studies } \\
(\mathrm{N}=31)\end{array}$} \\
\hline & & $\underline{M}$ & $\underline{\mathrm{SD}}$ & $\underline{M}$ & $\underline{S D}$ & $\underline{M}$ & $\underline{\mathrm{SD}}$ & $\underline{M}$ & $\underline{\mathrm{SD}}$ \\
\hline OR-1 & $\begin{array}{l}\text { Time } \\
\text { Role } \\
\text { Improve }\end{array}$ & $\begin{array}{l}3.516 \\
4.194 \\
4.161\end{array}$ & $\begin{array}{l}0.996 \\
0.833 \\
0.820\end{array}$ & $\begin{array}{l}2.724 \\
3.621 \\
3.690\end{array}$ & $\begin{array}{l}1.032 \\
0.775 \\
0.850\end{array}$ & $\begin{array}{l}2.815 \\
3.667 \\
3.926\end{array}$ & $\begin{array}{l}1.039 \\
1.000 \\
1.072\end{array}$ & $\begin{array}{l}3.129 \\
3.935 \\
4.032\end{array}$ & $\begin{array}{l}1.176 \\
1.063 \\
1.048\end{array}$ \\
\hline OR-2 & $\begin{array}{l}\text { Time } \\
\text { Role } \\
\text { Improve }\end{array}$ & $\begin{array}{l}3.516 \\
3.871 \\
3.935\end{array}$ & $\begin{array}{l}1.029 \\
0.957 \\
0.929\end{array}$ & $\begin{array}{l}3.310 \\
3.586 \\
3.517\end{array}$ & $\begin{array}{l}1.072 \\
0.825 \\
0.911\end{array}$ & $\begin{array}{l}3.556 \\
3.815 \\
3.741\end{array}$ & $\begin{array}{l}0.934 \\
0.879 \\
1.023\end{array}$ & $\begin{array}{l}3.484 \\
3.871 \\
3.903\end{array}$ & $\begin{array}{l}1.092 \\
1.024 \\
1.044\end{array}$ \\
\hline OR-3 & $\begin{array}{l}\text { Time } \\
\text { Role } \\
\text { Improve }\end{array}$ & $\begin{array}{l}2.323 \\
3.097 \\
3.194\end{array}$ & $\begin{array}{l}1.194 \\
1.012 \\
0.873\end{array}$ & $\begin{array}{l}2.379 \\
3.241 \\
3.138\end{array}$ & $\begin{array}{l}0.942 \\
0.951 \\
0.875\end{array}$ & $\begin{array}{l}2.815 \\
3.667 \\
3.519\end{array}$ & $\begin{array}{l}1.302 \\
1.109 \\
1.189\end{array}$ & $\begin{array}{l}2.452 \\
3.097 \\
3.129\end{array}$ & $\begin{array}{l}1.362 \\
1.375 \\
1.360\end{array}$ \\
\hline OR-4 & $\begin{array}{l}\text { Time } \\
\text { Role } \\
\text { Improve }\end{array}$ & $\begin{array}{l}3.161 \\
3.452 \\
3.355\end{array}$ & $\begin{array}{l}1.003 \\
0.768 \\
0.755\end{array}$ & $\begin{array}{l}2.931 \\
3.448 \\
3.103\end{array}$ & $\begin{array}{l}1.100 \\
0.910 \\
0.900\end{array}$ & $\begin{array}{l}3.185 \\
3.481 \\
3.519\end{array}$ & $\begin{array}{l}1.241 \\
0.849 \\
0.893\end{array}$ & $\begin{array}{l}2.645 \\
3.194 \\
3.161\end{array}$ & $\begin{array}{l}1.142 \\
1.138 \\
1.157\end{array}$ \\
\hline OR-5 & $\begin{array}{l}\text { Time } \\
\text { Role } \\
\text { Improve }\end{array}$ & $\begin{array}{l}3.484 \\
4.226 \\
4.065\end{array}$ & $\begin{array}{l}1.235 \\
0.990 \\
0.998\end{array}$ & $\begin{array}{l}3.138 \\
3.621 \\
3.345\end{array}$ & $\begin{array}{l}0.990 \\
0.862 \\
0.897\end{array}$ & $\begin{array}{l}3.074 \\
3.926 \\
3.630\end{array}$ & $\begin{array}{l}1.035 \\
0.874 \\
1.115\end{array}$ & $\begin{array}{l}2.677 \\
3.548 \\
3.548\end{array}$ & $\begin{array}{l}1.103 \\
1.312 \\
1.387\end{array}$ \\
\hline OR-6 & $\begin{array}{l}\text { Time } \\
\text { Role } \\
\text { Improve }\end{array}$ & $\begin{array}{l}3.581 \\
4.323 \\
4.097\end{array}$ & $\begin{array}{l}1.089 \\
0.871 \\
1.012\end{array}$ & $\begin{array}{l}3.207 \\
3.828 \\
3.483\end{array}$ & $\begin{array}{l}1.114 \\
0.928 \\
0.986\end{array}$ & $\begin{array}{l}3.111 \\
3.556 \\
3.481\end{array}$ & $\begin{array}{l}1.155 \\
0.847 \\
1.122\end{array}$ & $\begin{array}{l}3.000 \\
3.774 \\
3.806\end{array}$ & $\begin{array}{l}1.033 \\
1.055 \\
1.014\end{array}$ \\
\hline OR-7 & $\begin{array}{l}\text { Time } \\
\text { Role } \\
\text { Improve }\end{array}$ & $\begin{array}{l}3.387 \\
4.226 \\
4.258\end{array}$ & $\begin{array}{l}1.230 \\
0.845 \\
0.773\end{array}$ & $\begin{array}{l}3.276 \\
3.897 \\
3.897\end{array}$ & $\begin{array}{l}1.032 \\
0.939 \\
0.939\end{array}$ & $\begin{array}{l}2.926 \\
3.778 \\
3.815\end{array}$ & $\begin{array}{l}1.207 \\
0.974 \\
1.111\end{array}$ & $\begin{array}{l}2.774 \\
3.968 \\
4.065\end{array}$ & $\begin{array}{l}0.990 \\
0.912 \\
0.892\end{array}$ \\
\hline OR-8 & $\begin{array}{l}\text { Time } \\
\text { Role } \\
\text { Improve }\end{array}$ & $\begin{array}{l}3.387 \\
4.000 \\
3.903 \\
\end{array}$ & $\begin{array}{l}1.145 \\
0.816 \\
0.831\end{array}$ & $\begin{array}{l}3.448 \\
3.897 \\
3.759 \\
\end{array}$ & $\begin{array}{l}1.378 \\
1.081 \\
1.023\end{array}$ & $\begin{array}{l}3.296 \\
3.741 \\
3.852\end{array}$ & $\begin{array}{l}1.203 \\
0.984 \\
1.099 \\
\end{array}$ & $\begin{array}{l}3.000 \\
3.968 \\
4.097 \\
\end{array}$ & $\begin{array}{l}1.095 \\
1.048 \\
0.908 \\
\end{array}$ \\
\hline
\end{tabular}

* Rating scale: $1-5$ (1) No time; (2) Little time ; (3) A moderate amouml of time; (4) A good deal of time; (5) A great deal of time

** Rating scale: 1-5 (1) No importance; (2) Litlle imporlance; (3) Moderate importance ; (4) Ven imporlant; (5) Extremely important 
Chart G4

Department Chair Responsibility for the Program: Ratings of Amount of Time Spent,* Importance to the Department Chair Role,** and Importance for the Chair to Continue to Improve** as Perceived by High School Academic Department Chairs Subjects $(N=118)$

\begin{tabular}{|c|c|c|c|c|c|c|c|c|c|}
\hline \multirow[t]{2}{*}{ Activity } & \multirow[t]{2}{*}{ Issue } & \multicolumn{2}{|c|}{$\begin{array}{c}\text { English } \\
(\mathrm{N}=31)\end{array}$} & \multicolumn{2}{|c|}{$\begin{array}{c}\text { Math } \\
(\mathrm{N}=29)\end{array}$} & \multicolumn{2}{|c|}{$\begin{array}{c}\text { Science } \\
(\mathrm{N}=27)\end{array}$} & \multicolumn{2}{|c|}{$\begin{array}{c}\text { Social Studies } \\
(\mathrm{N}=31)\end{array}$} \\
\hline & & $\underline{\mathrm{M}}$ & SD & $\underline{\mathrm{M}}$ & SD & $\underline{M}$ & SD & $\underline{M}$ & $\mathrm{SD}$ \\
\hline PG-1 & $\begin{array}{l}\text { Time } \\
\text { Role } \\
\text { Improve }\end{array}$ & $\begin{array}{l}4.000 \\
4.452 \\
4.194\end{array}$ & $\begin{array}{l}0.966 \\
0.624 \\
0.833\end{array}$ & $\begin{array}{l}3.586 \\
3.897 \\
3.828\end{array}$ & $\begin{array}{l}1.119 \\
0.860 \\
0.759\end{array}$ & $\begin{array}{l}3.593 \\
3.963 \\
3.963\end{array}$ & $\begin{array}{l}1.010 \\
0.759 \\
0.898\end{array}$ & $\begin{array}{l}3.323 \\
3.871 \\
3.871\end{array}$ & $\begin{array}{l}1.107 \\
0.957 \\
0.957\end{array}$ \\
\hline PG-2 & $\begin{array}{l}\text { Time } \\
\text { Role } \\
\text { Improve }\end{array}$ & $\begin{array}{l}3.419 \\
4.161 \\
4.000\end{array}$ & $\begin{array}{l}1.177 \\
0.969 \\
0.966\end{array}$ & $\begin{array}{l}3.379 \\
4.069 \\
3.862\end{array}$ & $\begin{array}{l}1.178 \\
0.923 \\
1.026\end{array}$ & $\begin{array}{l}2.963 \\
3.741 \\
3.815\end{array}$ & $\begin{array}{l}1.091 \\
0.859 \\
0.834\end{array}$ & $\begin{array}{l}2.968 \\
3.839 \\
3.806\end{array}$ & $\begin{array}{l}1.169 \\
1.003 \\
1.014\end{array}$ \\
\hline PG-3 & $\begin{array}{l}\text { Time } \\
\text { Role } \\
\text { Improve }\end{array}$ & $\begin{array}{l}3.452 \\
4.161 \\
3.968\end{array}$ & $\begin{array}{l}1.028 \\
0.898 \\
0.948\end{array}$ & $\begin{array}{l}3.276 \\
3.828 \\
3.655\end{array}$ & $\begin{array}{l}1.066 \\
1.037 \\
1.010\end{array}$ & $\begin{array}{l}2.741 \\
3.704 \\
3.778\end{array}$ & $\begin{array}{l}1.095 \\
0.912 \\
0.974\end{array}$ & $\begin{array}{l}2.774 \\
3.839 \\
3.839\end{array}$ & $\begin{array}{l}1.117 \\
0.969 \\
1.003\end{array}$ \\
\hline$P G-4$ & $\begin{array}{l}\text { Time } \\
\text { Role } \\
\text { Improve }\end{array}$ & $\begin{array}{l}2.806 \\
3.774 \\
3.806\end{array}$ & $\begin{array}{l}0.833 \\
0.717 \\
0.792\end{array}$ & $\begin{array}{l}2.586 \\
3.310 \\
3.345\end{array}$ & $\begin{array}{l}0.983 \\
0.850 \\
0.814\end{array}$ & $\begin{array}{l}2.481 \\
3.481 \\
3.667\end{array}$ & $\begin{array}{l}1.189 \\
0.975 \\
1.177\end{array}$ & $\begin{array}{l}2.355 \\
3.548 \\
3.581\end{array}$ & $\begin{array}{l}1.082 \\
1.234 \\
1.232\end{array}$ \\
\hline PG-5 & $\begin{array}{l}\text { Time } \\
\text { Role } \\
\text { Improve }\end{array}$ & $\begin{array}{l}3.645 \\
4.129 \\
4.000\end{array}$ & $\begin{array}{l}1.050 \\
0.846 \\
1.033\end{array}$ & $\begin{array}{l}3.655 \\
3.759 \\
3.690\end{array}$ & $\begin{array}{l}1.203 \\
1.023 \\
1.004\end{array}$ & $\begin{array}{l}3.296 \\
3.704 \\
3.778\end{array}$ & $\begin{array}{l}1.068 \\
0.823 \\
0.934\end{array}$ & $\begin{array}{l}3.387 \\
4.097 \\
4.000\end{array}$ & $\begin{array}{l}0.919 \\
0.790 \\
0.775\end{array}$ \\
\hline PG-6 & $\begin{array}{l}\text { Time } \\
\text { Role } \\
\text { Improve }\end{array}$ & $\begin{array}{l}3.484 \\
4.065 \\
3.903\end{array}$ & $\begin{array}{l}1.061 \\
0.892 \\
1.012\end{array}$ & $\begin{array}{l}4.034 \\
4.034 \\
3.931\end{array}$ & $\begin{array}{l}1.117 \\
0.906 \\
0.998\end{array}$ & $\begin{array}{l}3.667 \\
3.889 \\
3.778\end{array}$ & $\begin{array}{l}1.109 \\
0.801 \\
0.934\end{array}$ & $\begin{array}{l}3.548 \\
4.355 \\
4.323\end{array}$ & $\begin{array}{l}1.150 \\
0.709 \\
0.702\end{array}$ \\
\hline PG.7 & $\begin{array}{l}\text { Time } \\
\text { Role } \\
\text { Improve }\end{array}$ & $\begin{array}{l}3.129 \\
4.000 \\
3.968\end{array}$ & $\begin{array}{l}0.846 \\
0.683 \\
0.752\end{array}$ & $\begin{array}{l}2.828 \\
3.724 \\
3.655\end{array}$ & $\begin{array}{l}1.071 \\
0.751 \\
0.814\end{array}$ & $\begin{array}{l}2.667 \\
3.407 \\
3.704\end{array}$ & $\begin{array}{l}1.074 \\
0.931 \\
1.031\end{array}$ & $\begin{array}{l}2.484 \\
3.710 \\
3.677\end{array}$ & $\begin{array}{l}1.122 \\
1.071 \\
1.045\end{array}$ \\
\hline PG-8 & $\begin{array}{l}\text { Time } \\
\text { Role } \\
\text { Improve }\end{array}$ & $\begin{array}{l}3.516 \\
4.194 \\
4.161 \\
\end{array}$ & $\begin{array}{l}1.029 \\
0.792 \\
0.779\end{array}$ & $\begin{array}{l}2.862 \\
3.759 \\
3.724 \\
\end{array}$ & $\begin{array}{l}0.953 \\
0.636 \\
0.702 \\
\end{array}$ & $\begin{array}{l}3.000 \\
3.778 \\
3.657 \\
\end{array}$ & $\begin{array}{l}1.074 \\
0.892 \\
1.074\end{array}$ & $\begin{array}{l}2.903 \\
3.903 \\
3.968\end{array}$ & $\begin{array}{l}0.978 \\
1.012 \\
0.983 \\
\end{array}$ \\
\hline
\end{tabular}

* Rating scale: $1-5$ (1) No time; (2) Limle time ; (3) A moderate amount of time;

(4) A good deal of time; (5) A great deal of time

** Rating scale: $1-5$ (1) No importance; (2) Little importance; (3) Moderate importance ;

(4)Very importamt; (5) Extremely important 


\section{Chart G5}

Department Chair Responsibility for Supervision: Ratings of Amount of Time Spent,* Importance to the Department Chair Role,** and Importance for the Chair to Continue to Improve** as Perceived by High School Academic Department Chairs Subjects $(N=118)$

\begin{tabular}{|c|c|c|c|c|c|c|c|c|c|}
\hline \multirow[t]{2}{*}{ Activity } & \multirow[t]{2}{*}{ Issue } & \multicolumn{2}{|c|}{$\begin{array}{c}\text { English } \\
(\mathrm{N}=31) \\
\end{array}$} & \multicolumn{2}{|c|}{$\begin{array}{c}\text { Math } \\
(\mathrm{N}=29)\end{array}$} & \multicolumn{2}{|c|}{$\begin{array}{l}\text { Science } \\
(\mathrm{N}=27) \\
\end{array}$} & \multicolumn{2}{|c|}{$\begin{array}{c}\text { Social Studies } \\
(\mathrm{N}=31)\end{array}$} \\
\hline & & $\underline{\underline{M}}$ & $\underline{S D}$ & $\underline{\underline{M}}$ & $\underline{\text { SD }}$ & $\underline{\mathrm{M}}$ & $\underline{S D}$ & $\underline{\mathrm{M}}$ & $\underline{\mathrm{SD}}$ \\
\hline SP-1 & $\begin{array}{l}\text { Time } \\
\text { Role } \\
\text { Improve }\end{array}$ & $\begin{array}{l}2.710 \\
3.613 \\
3.677\end{array}$ & $\begin{array}{l}1.189 \\
0.919 \\
1.194\end{array}$ & $\begin{array}{l}2.379 \\
2.931 \\
3.103\end{array}$ & $\begin{array}{l}0.979 \\
1.100 \\
1.407\end{array}$ & $\begin{array}{l}2.333 \\
2.963 \\
3.259\end{array}$ & $\begin{array}{l}1.109 \\
1.160 \\
1.259\end{array}$ & $\begin{array}{l}2.516 \\
3.129 \\
3.419\end{array}$ & $\begin{array}{l}1.122 \\
1.310 \\
1.311\end{array}$ \\
\hline SP-2 & $\begin{array}{l}\text { Time } \\
\text { Role } \\
\text { Improve }\end{array}$ & $\begin{array}{l}2.516 \\
3.258 \\
3.387\end{array}$ & $\begin{array}{l}1.391 \\
1.125 \\
1.086\end{array}$ & $\begin{array}{l}1.966 \\
2.724 \\
2.828\end{array}$ & $\begin{array}{l}1.180 \\
1.162 \\
1.167\end{array}$ & $\begin{array}{l}1.963 \\
2.704 \\
2.926\end{array}$ & $\begin{array}{l}1.126 \\
1.235 \\
1.328\end{array}$ & $\begin{array}{l}1.774 \\
2.903 \\
3.032\end{array}$ & $\begin{array}{l}0.805 \\
0.978 \\
1.016\end{array}$ \\
\hline SP-3 & $\begin{array}{l}\text { Time } \\
\text { Role } \\
\text { Improve }\end{array}$ & $\begin{array}{l}3.645 \\
4.226 \\
4.226\end{array}$ & $\begin{array}{l}1.018 \\
0.99 \\
0.920\end{array}$ & $\begin{array}{l}2.621 \\
3.276 \\
3.345\end{array}$ & $\begin{array}{l}0.942 \\
1.032 \\
1.111\end{array}$ & $\begin{array}{l}2.778 \\
3.519 \\
3.630\end{array}$ & $\begin{array}{l}1.086 \\
1.087 \\
1.079\end{array}$ & $\begin{array}{l}2.774 \\
3.742 \\
3.871\end{array}$ & $\begin{array}{l}0.845 \\
1.210 \\
1.147\end{array}$ \\
\hline SP-4 & $\begin{array}{l}\text { Time } \\
\text { Role } \\
\text { Improve }\end{array}$ & $\begin{array}{l}3.323 \\
4.065 \\
4.129\end{array}$ & $\begin{array}{l}0.979 \\
0.772 \\
0.806\end{array}$ & $\begin{array}{l}3.172 \\
3.552 \\
3.586\end{array}$ & $\begin{array}{l}0.759 \\
0.756 \\
0.867\end{array}$ & $\begin{array}{l}2.741 \\
3.370 \\
3.704\end{array}$ & $\begin{array}{l}0.944 \\
1.043 \\
1.068\end{array}$ & $\begin{array}{l}2.935 \\
3.839 \\
3.935\end{array}$ & $\begin{array}{l}0.929 \\
0.779 \\
0.814\end{array}$ \\
\hline SP-5 & $\begin{array}{l}\text { Time } \\
\text { Role } \\
\text { Improve }\end{array}$ & $\begin{array}{l}2.419 \\
3.323 \\
3.484\end{array}$ & $\begin{array}{l}1.232 \\
1.301 \\
1.338\end{array}$ & $\begin{array}{l}2.138 \\
3.138 \\
3.069\end{array}$ & $\begin{array}{l}1.246 \\
1.329 \\
1.280\end{array}$ & $\begin{array}{l}2.185 \\
3.000 \\
3.444\end{array}$ & $\begin{array}{l}1.360 \\
1.387 \\
1.450\end{array}$ & $\begin{array}{l}1.935 \\
3.065 \\
3.258\end{array}$ & $\begin{array}{l}0.892 \\
1.093 \\
1.264\end{array}$ \\
\hline SP-6 & $\begin{array}{l}\text { Time } \\
\text { Role } \\
\text { Improve }\end{array}$ & $\begin{array}{l}1.548 \\
2.387 \\
2.387\end{array}$ & $\begin{array}{l}0.888 \\
1.116 \\
1.174\end{array}$ & $\begin{array}{l}1.379 \\
1.759 \\
1.828\end{array}$ & $\begin{array}{l}0.862 \\
1.154 \\
1.256\end{array}$ & $\begin{array}{l}1.444 \\
1.963 \\
2.333\end{array}$ & $\begin{array}{l}0.751 \\
1.160 \\
1.330\end{array}$ & $\begin{array}{l}1.387 \\
1.935 \\
2.097\end{array}$ & $\begin{array}{l}0.882 \\
1.093 \\
1.300\end{array}$ \\
\hline SP-7 & $\begin{array}{l}\text { Time } \\
\text { Role } \\
\text { Improve }\end{array}$ & $\begin{array}{l}1.774 \\
2.516 \\
2.516\end{array}$ & $\begin{array}{l}1.055 \\
1.228 \\
1.363\end{array}$ & $\begin{array}{l}1.143 \\
2.069 \\
2.000\end{array}$ & $\begin{array}{l}1.022 \\
1.462 \\
1.389\end{array}$ & $\begin{array}{l}1.704 \\
2.074 \\
2.333\end{array}$ & $\begin{array}{l}1.031 \\
1.299 \\
1.359\end{array}$ & $\begin{array}{l}1.548 \\
2.258 \\
2.419\end{array}$ & $\begin{array}{l}0.995 \\
1.125 \\
1.336\end{array}$ \\
\hline SP-8 & $\begin{array}{l}\text { Time } \\
\text { Role } \\
\text { Improve }\end{array}$ & $\begin{array}{l}3.161 \\
3.935 \\
3.839\end{array}$ & $\begin{array}{l}1.241 \\
0.929 \\
0.969\end{array}$ & $\begin{array}{l}2.759 \\
3.345 \\
3.241\end{array}$ & $\begin{array}{l}0.988 \\
1.045 \\
0.988\end{array}$ & $\begin{array}{l}2.778 \\
3.481 \\
3.741\end{array}$ & $\begin{array}{l}1.155 \\
1.122 \\
0.984\end{array}$ & $\begin{array}{l}2.419 \\
3.516 \\
3.548\end{array}$ & $\begin{array}{l}1.025 \\
1.029 \\
1.064\end{array}$ \\
\hline SP-9 & $\begin{array}{l}\text { Time } \\
\text { Role } \\
\text { Improve }\end{array}$ & $\begin{array}{l}2.806 \\
3.710 \\
3.645\end{array}$ & $\begin{array}{l}1.046 \\
1.071 \\
1.119\end{array}$ & $\begin{array}{l}2.345 \\
3.207 \\
3.345\end{array}$ & $\begin{array}{l}0.857 \\
1.177 \\
1.173\end{array}$ & $\begin{array}{l}2.630 \\
3.407 \\
3.593\end{array}$ & $\begin{array}{l}1.245 \\
1.338 \\
1.279\end{array}$ & $\begin{array}{l}2.323 \\
3.581 \\
3.742\end{array}$ & $\begin{array}{l}0.791 \\
0.992 \\
1.064\end{array}$ \\
\hline SP-10 & $\begin{array}{l}\text { Time } \\
\text { Role } \\
\text { Improve }\end{array}$ & $\begin{array}{l}2.355 \\
3.452 \\
3.516\end{array}$ & $\begin{array}{l}1.142 \\
1.179 \\
1.180\end{array}$ & $\begin{array}{l}1.724 \\
2.690 \\
2.793\end{array}$ & $\begin{array}{l}0.996 \\
1.257 \\
1.320\end{array}$ & $\begin{array}{l}2.630 \\
2.815 \\
3.037\end{array}$ & $\begin{array}{l}1.245 \\
1.178 \\
1.315\end{array}$ & $\begin{array}{l}1.613 \\
3.000 \\
3.032\end{array}$ & $\begin{array}{l}0.715 \\
1.211 \\
1.224\end{array}$ \\
\hline SP-11 & $\begin{array}{l}\text { Time } \\
\text { Role } \\
\text { Improve }\end{array}$ & $\begin{array}{l}1.645 \\
2.452 \\
2.548 \\
\end{array}$ & $\begin{array}{l}1.018 \\
1.338 \\
1.434 \\
\end{array}$ & $\begin{array}{l}1.586 \\
2.138 \\
2.103 \\
\end{array}$ & $\begin{array}{l}1.150 \\
1.382 \\
1.345 \\
\end{array}$ & $\begin{array}{l}1.889 \\
2.319 \\
2.741 \\
\end{array}$ & $\begin{array}{l}0.892 \\
1.523 \\
1.631 \\
\end{array}$ & $\begin{array}{l}1.581 \\
2.226 \\
2.323 \\
\end{array}$ & $\begin{array}{l}0.886 \\
1.334 \\
1.469 \\
\end{array}$ \\
\hline
\end{tabular}


APPENDIX H

SUMMARY OF CHI-SQUARE VALUES: DEPARTMENT CHAIRS GROUPED BY DISCIPLINE 


\section{Chart $\mathrm{H} 1$}

Summary of Chi-Square Values Indicating Significant Differences $(p<.05)$ in Perceptions of Five Categories of Department Chair Responsibilities

Subjects: High School English Department Chairs $(\underline{N}=31)$ and High School Social Studies Department Chairs $(\underline{\underline{N}}=31)$

\begin{tabular}{lllll}
\hline Activity & $\underline{N}$ & $\left(\chi^{2}\right)$ & $($ df & $(\mathrm{p})$ \\
\hline HRIT* & 62 & 9.688 & 3 & 0.021 \\
HR5T* & 62 & 15.556 & 3 & 0.001 \\
\hline *More than one-filth of fitted cells were sparse (frequency $<5$ ).
\end{tabular}

*More than one-fitth of fitted cells were sparse (frequency $<5$ ).

\section{Chart H2}

Summary of Chi-Square Values Indicating Significant Differences $(\mathrm{p}<.05)$

in Perceptions of Five Categories of Department Chair Responsibilities Subjects: High School Science Department Chairs $(\underline{N}=27)$ and High School Math Department Chairs $(\underline{N}=29)$

\begin{tabular}{ccccc}
\hline Activity & $\underline{N}$ & $\left(\chi^{2}\right)$ & $(\mathrm{df})$ & $(\mathrm{p})$ \\
\hline HRQT* $^{*}$ & 56 & 9.958 & 3 & 0.022 \\
SP4M $^{*}$ & 56 & 9.503 & 3 & 0.019 \\
\hline *More than one-fifth of fitted cells were sparse (frequency $<5$ ). &
\end{tabular}

*More than one-fifth of fitted cells were sparse (frequency $<5$ ).

\section{Chart $\mathrm{H} 3$}

Summary of Chi-Square Values Indicating Significant Differences $(p<.05)$ in Perceptions of Five Categories of Department Chair Responsibilities Subjects: High School Social Studies Department Chairs $(\underline{N}=31)$ and High School Science Department Chairs $(\underline{N}=27)$

\begin{tabular}{llrll}
\hline Activity & $\underline{N}$ & $\left(\chi^{2}\right)$ & (df) & (D) \\
\hline HR4T $^{*}$ & 58 & 9.194 & 3 & 0.027 \\
HR4M & 58 & 10.286 & 3 & 0.016 \\
PG7P* & 58 & 7.887 & 3 & 0.049 \\
SP9T* & 58 & 10.234 & 3 & 0.017 \\
\hline
\end{tabular}

${ }^{*}$ More than one-fifth of fitted cells were sparse (frequency $<5$ ). 


\section{Chart H4}

Summary of Chi-Square Values Indicating Significant Differences $(p<.05)$

in Perceptions of Five Categories of Department Chair Responsibilities

Subjects: High School Social Studies Department Chairs $(\underline{N}=31)$ and High School Math Department Chairs $(\underline{N}=29)$

\begin{tabular}{llrll}
\hline Activity & $\underline{N}$ & $\left(\chi^{2}\right)$ & $(\mathrm{d})$ & $(\mathrm{p})$ \\
\hline HR1M* $^{*}$ & 60 & 8.068 & 3 & 0.045 \\
HR4M* & 60 & 9.746 & 4 & 0.045 \\
PG4M* & 60 & 11.213 & 4 & 0.024 \\
PG8P* & 60 & 9.952 & 3 & 0.019 \\
PG8M* & 60 & 8.376 & 3 & 0.039 \\
\hline
\end{tabular}

* More than one-fifth of fitted cells were sparse (frequency $<5$ ).

\section{Chart H5}

Summary of Chi-Square Values Indicating Significant Differences $(p<.05)$ in Perceptions of Five Categories of Department Chair Responsibilities Subjects: High School English Department Chairs $(\underline{N}=31)$ and High School Science Department Chairs $(\underline{N}=27)$

\begin{tabular}{llrll}
\hline Activity & $\underline{N}$ & $\left(\chi^{2}\right)$ & $(\mathrm{df})$ & $(\mathrm{p})$ \\
\hline HR4T** & 58 & 8.158 & 3 & 0.043 \\
HR4M* & 58 & 8.615 & 3 & 0.035 \\
HR5T* & 58 & 13.775 & 3 & 0.003 \\
HR5M* & 58 & 8.195 & 3 & 0.042 \\
MGT** & 58 & 13.379 & 3 & 0.010 \\
MG7P* & 58 & 9.238 & 2 & 0.010 \\
MG7M* & 58 & 7.905 & 3 & 0.048 \\
OR6P* & 58 & 1.1 .099 & 3 & 0.011 \\
PG8P* & 58 & 8.325 & 3 & 0.040 \\
SP3T* & 58 & 10.025 & 3 & 0.018 \\
\hline
\end{tabular}

*More than one-fifth of fitted cells were sparse (frequency $<5$ ). 